\title{
"Increasing Heavy Oil Reserves in The Wilmington Oil Field Through Advanced Reservoir Characterization And Thermal Production Technologies" Contract \#DE-FC22-95BC14939
}

\author{
Annual Report \\ for the Period \\ April 1, 1997 to March 31, 2000
}

\author{
Prepared for \\ U.S. Department of Energy \\ Assistant Secretary for Fossil Energy
}

Gary Walker, DOE Project Manager

National Petroleum Technology Laboratory

1 West $3^{\text {rd }}$ Street

William Center Tower 1 - Suite 1400

Tulsa, OK 74103

P.O. Box 3628

Tulsa, OK 74101

Prepared by

City of Long Beach

Tidelands Oil Production Company

University of Southern California

GeoSystems, formerly David K. Davies and Associates

August 8, 2001 


\section{Disclaimer}

This report was prepared as an account of work sponsored by an agency of the United States Government. Neither the United States Government nor any agency thereof, nor any of their employees, makes any warranty, expressed or implied, or assumes any legal liability or responsibility for the accuracy, completeness, or usefulness of any information, apparatus, product, or process disclosed, or represents that its use would not infringe privately owned rights. Reference herein to any specific commercial product, process, or service by trade name, trademark, manufacturer, or otherwise does not necessarily constitute or imply its endorsement, recommendation, or favoring by the United States Government or any agency thereof. The views and opinions of authors expressed herein do not necessarily state or reflect those of the United States Government. 


\section{CONTENTS}

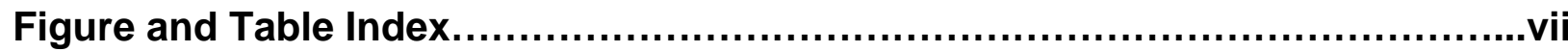

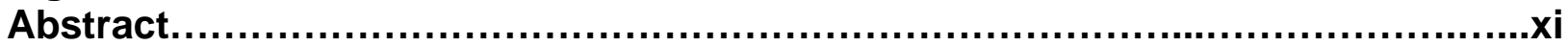

Executive Summary ...............................................................................

Acknowledgments.........................................................................

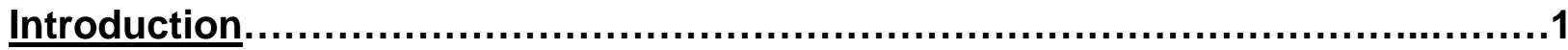

Report Overview

Project Overview

Development and Production History

Geologic Setting

Activity 1 - Compilation and Analysis of Existing Data...............................10

1.1 Data Compilation - N/A

1.1.1 Well Production/Injection

1.1.2 Pressure Volume Temperature / Water Composition Test

1.2 Log Digitization and Normalization - N/A

1.2.1 Build Log Data Base

1.2.2 Digitize Well Logs / Directional Data

1.2.3 Normalize Well Logs / Markers

Activity 2 - Advanced Reservoir Characterization.

2.1 Basic Reservoir Engineering - N/A

2.1.1 Material Balance

2.1.2 Flood Response

2.1.3 Steamflood Response

2.1.4 Productivity Problem Analysis

2.1.5 Analysis of Injection Profile

\subsection{Obtaining New Characterization Data}

2.2.1 Measurement While Drilling Data - N/A

2.2.2 Tracer Surveys

2.2.3 Water Composition Tests - N/A

2.2.4 Oil Finger Printing - N/A

2.2.5 Drill 3 Observation and 2 Core Hole / Observation Wells - N/A

2.3 Deterministic 3-D Geologic Model

2.3.1 Three Dimensional Earth Vision Structure - N/A

2.3.2 Core Based Log Model

2.3.2.1 Work Performed by USC

2.3.2.2 Work Performed by David K. Davies, Inc.

2.3.3 Porosity-Permeability Model

2.3.4 Rock-Log Model

2.3.5 V-Shale Model

2.3.6 Qualitative Conditioning 
2.3.7 Basin Modeling - N/A

2.3.8 Updating - N/A

2.4 Stochastic 3-D Geologic Modeling

2.4.1 Vertical and Horizontal Geostatistical Spatial Correlation Studies

2.4.2 Kriging $-\mathrm{N} / \mathrm{A}$

2.4.3 Conditional Stimulation - N/A

2.4.4 Interface with Deterministic 3-D Geologic Model - N/A

2.4.5 Integrate Tracer Survey

2.4.6 Updating $-\mathrm{N} / \mathrm{A}$

Activity 3 - Activity Reservoir Simulation .65

3.1 Deterministic 3-D thermal Reservoir Modeling

3.1.1 Reservoir and Geologic Description

3.1.2 Production and Operational History

3.1.3 Description of the Model

3.1.4 Development of the Compaction/Rebound Algorithm

3.1.5 Mathematical Derivation of Compaction/Rebound Algorithm

3.1.6 Model Validation

3.1.7 History Match of Primary Depletion

3.1.8 History Match of Waterflood

3.1.9 History Match of Steamflood Pilot

3.1.10 Development of Revised Operating Scenario

3.1.11 Objectives for Operating Strategy

3.1.12 Choosing the Optimal Operating Scenario

3.1.13 Conclusions

3.2 Stochastic 3-D Reservoir Modeling - N/A

3.2.1 Model Building / Calibration

3.2.2 Integrate Pilot Project Data

3.2.3 Sensitivity Studies / Predictions

3.2.4 Well and Recovery Process Planning

Activity 4 - Reservoir Management.

4.1 Horizontal Wells and Surface Locations - N/A

4.2 Horizontal Well Cyclic Steam Stimulation Pilot - N/A

4.3 Horizontal Well Steam Drive - See Section 4.7

4.4 Hot Water Alternating Steam (WAS) Drive Pilot - See Section 4.7

4.5 Geochemistry of Rock / Fluid / Interactions - See Section 5.1 and 5.5

4.6 Steam Drive Mechanisms - See Section 3.1.4 and 4.7

4.7 Reservoir Surveillance

4.7.1 Reservoir Pressures

4.7.2 Reservoir Pressure Monitoring

Activity 5 - Operational Management..

5.1 Alkaline Water/ Steam Injection Sand Control 


\subsubsection{Geology}

5.1.2 Alkaline Hot Water/Steam Sand Consolidation Procedure - A Brief Description

5.1.3 Application of Sand Consolidation Technique on UP-955

5.1.4 Analyses of Sand Consolidation on UP-955 tubing Tail

5.1.5 Geochemistry of the Process

5.1.6 Results and Conclusions

5.2 Horizontal Well Completion Techniques - See Chapter 5.1

5.3 Profile Control in Horizontal Injectors

5.4 Minimize Carbonate Scale Problems - N/A

5.5 Determine Temperature Limits to Minimize Operating Problems

5.5.1 Cased-hole Log Tests

5.5.2 Analysis of High Temperature Laboratory Tests on Shales and PostSteamflood Cores

Activity 6 - Expansion Program

Activity 7 - Technology Transfer

\subsection{DOE Reports}

7.2 Publications

7.2.1 Professional Societies

7.2.2 Industry Trade Journals and Newspapers

7.2.3 DOE Symposium Proceedings

7.2.4 Professional Society Newsletters / Mailing List

7.2.5 Database Files

7.2.6 Academic Studies

7.2.7 Web Sites and CD-ROM Projects

\subsection{Presentations}

7.3.1 Professional Societies

7.3.2 Industry Organizations

7.3.3 Non-Oil Industry Organizations

7.4 Technology Awards

7.5 Web Site and CD-ROM Projects

7.6 Field Tours

Activity 8 - Project Management. 121

Executive Committee and Steering Committees

References.

122

A. Papers, Articles, Reports, CD-ROMS, Web Sites, and Other Original Technical Work Generated by DOE Project Team.

B. Publications Related to Original DOE Project Technical Work and Articles of Interest.

C. Presentations, Poster Sessions, Tours, and Other Activities from which No New Reference Materials Were Generated. 

D. Outside References Cited in Report.
E. Required Reports Generated for the Department of Energy.
F. References for Section 2.2.2
G. References for Sections 2.3.2 and 2.4.1
H. References for Sections 3.1 


\section{Introduction}

Figure 1: Geographical location of the Wilmington Field in Southern California.....5

Figure 2: Plan view of Tidelands' facilities and Tar II-A and Tar V projects in the Wilmington Field. 6

Figure 3: Aerial view of the Wilmington Field showing Tar II-A and Tar V projects..6

Figure 4: Geologic representation of the Wilmington Field detailing Fault Line Layout..................................................................

Figure 5: Cross section of a representative NW-SE slice of the Wilmington field detailing producing zones........................................................

Figure 6: Fault Block II-A, Wilmington Field.....................................

Figure 7: Type Log, Fault Block II-A Tar Zone, illustrating "T" and "D1" Sands....9

\section{Activity 1}

None

\section{Activity 2}

Figure 2.2.2-1: Two Seven-Spot Patterns for Salinity Tracer....................13

Figure 2.2.2-2: Homogeneous Isotropic and Anisotropic Patterns................14

Table 2-1: $\quad$ Concentration of Produced Water and Steam Water............. 15

Figure 2.2.2-3: Salinity Concentrations for UP-927 production................. 15

Figure 2.2.2-4: Average Salinity of each of the Wells for the Three-Month

Period............................................................. 16

Figure 2.2.2-5: Typical Salinity Distribution Map Showing a Northeast to Southwest Trend................................................ 17

Figure 2.2.2-6: X-Plot of Simulated Ideal Waterflood Data....................... 18

Figure 2.2.2-7: X-Plot of Simulated Steamflood Data............................ 19

Figure 2.2.2-8: X-Plot for UP-912 ......................................... 20

Table 2-2: $\quad$ Water Invaded Calculation from X-Plot..........................21

Figure 2.2.2-9: The percentage of cumulative oil, gross fluid, and water invaded for each well from the total of all the wells sorted by increasing salinity.........................................................

Figure 2.3.2-1: Turbidite Sequence Structure................................24

Figure 2.3.2-2: Present-day Repettian-Stage submarine-fan facies map........25

Figure 2.3.2-3: Explanation for Repettian-Stage submarine-fan facies map....25

Figure 2.3.2-4: Fault Block II-A, Wilmington Field............................26

Figure 2.3.2-5: Stylized diagram showing subdivisions of Tar Zone.............26

Figure 2.3.2-6: Tar II-A core photo of typical $4 \mathrm{ft}$ turbidite sand sequence.......27

Figure 2.3.2-7: Typical $4 \mathrm{ft}$ sand sequence showing grain size ( $y$-axis) vs. depth ( $x$ -

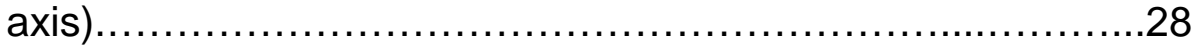

Figure 2.3.2-8: Typical $4 \mathrm{ft}$ sand sequence showing porosity (y-axis) vs. depth ( $\mathrm{x}$ -

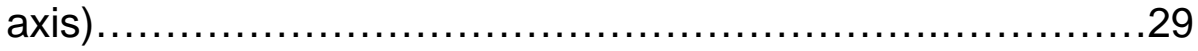


Figure 2.3.2-9: Typical $4 \mathrm{ft}$ sand sequence showing Klinkenburg-corrected permeability (y-axis) vs. depth (x-axis) .........................29

Figure 2.3.2-10: Use of special core data analysis data to convert routine porosity to in situ stress condition.... 31

Figure 2.3.2-11: Use of special core analysis data to convert routine permeability to in situ stress condition. 31

Figure 2.3.2-12: Correlation of core porosity (x-axis) vs. density log porosity (y-axis) in the D1 sub-zone sands. 32

Figure 2.3.2-13: Revised correlation of core porosity and logging density porosity for D1 sand section. 33

Figure 2.3.2-14: Correlation of core porosity (x-axis) vs. density log porosity (y-axis) in the D1 sub-zone sands. 34

Figure 2.3.2-15: Permeability versus shaliness indicator Ion plot....................35

Figure 2.3.2-16: Correlating permeability with shaliness indicator I $\phi n$ (D1 sand), with some low permeability data points deleted. 35

Figure 2.3.2-17: Correlating permeability with shaliness indicator $I \delta \phi$ (D1 sand), with some low permeability data points deleted.........................36

Figure 2.3.6-1: An example of a formation with clean intervals...................42

Figure 2.3.6-2: An example of a formation with small and dirty intervals...........42

Figure 2.3.6-3: Location Map of Wilmington Field..................................42

Figure 2.3.6-4: 3-D Geological Model from Wilmington Field......................43

Figure 2.3.6-5: Examples of consistent and inconsistent markers..................44

Figure 2.3.6-6: Typical well log responses in the Tar zone of the Wilmington Field, California..........................................................44

Figure 2.3.6-7: Original (left signal), smoothed (star sign), and shale-sand indicator (rectangular shape) signals, representing Model "A"

in interval T5 for well UP-908.....................................45

Figure 2.3.6-8: Original (left signal), smoothed (star sign), and shale-sand indicator (rectangular shape) signals, representing Model "A" in interval T5 for well 2AT-37...................................45

Figure 2.3.6-9: Areal distribution of lithological models for marker T5.............45

Figure 2.3.6-10: A cross section for marker T5, showing micro lamination distribution.................................................... 46

Figure 2.4.1-1: Turbidite sequence structure..................................48

Figure 2.4.1-2: Present-day Repettian-Stage submarine-fan facies map...........48

Figure 2.4.1-3: Explanation for Repettian-Stage submarine-fan facies map.......49

Figure 2.4.1-4: Fault Block II-A, Wilmington Field.................................49

Figure 2.4.1-5: Stylized diagram showing subdivisions of Tar Zone ...............50

Figure 2.4.1-6: Schematic modeling area of Fault Block II-A......................52

Figure 2.4.1-7: Stochastic modeling stratigraphic grid system....................52

Figure 2.4.1-8: Areal variogram analyses plot for porosity area....................53

Figure 2.4.1-9: Vertical variogram analyses plot for porosity area.................53

Figure 2.4.1-10: Porosity (SGS) image: realization one, slice at 10' $\mathrm{ft}$ below D1 top............................................................53

Figure 2.4.1-11: Porosity (SGS) image: realization one, slice at middle of D1.....54 
Figure 2.4.1-12: Porosity (SGS) image: realization one, slice at 10' $\mathrm{ft}$ below D1 bottom......................................................54

Figure 2.4.1-13: Porosity (SGS) image: realization one, cross-section view.........54

Figure 2.4.1-14: Areal variogram analyses plot for original logging porosity ...data............................................................55

Figure 2.4.1-15: Vertical variogram analyses plot for original logging porosity

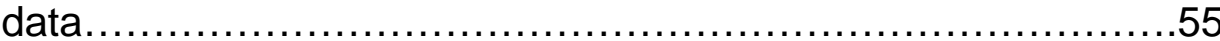

Figure 2.4.1-16: Porosity (SGS) image on using the original logging porosity realization one, slice at middle of D1 ......................................55

Figure 2.4.1-17: Areal variogram analysis plot for shaliness indicator data.........56

Figure 2.4.1-18: Vertical variogram analysis plot for shaliness indicator data.......56

Figure 2.4.1-19: Stochastic modeling of shale indicator and permeability fields.....56

Figure 2.4.1-20: Permeability (SGS) image: realization one, slice at -10' $\mathrm{ft}$ below D1 top............................................................ 57

Figure 2.4.1-21: Permeability (SGS) image: realization one, slice at middle D1...........................................................57

Figure 2.4.1-22: Permeability (SGS) image: realization one, slice at -10' ft below D1 bottom........................................................57

Figure 2.4.1-23: Permeability (SGS) image: realization one, cross-section view.......................................................... 57

Figure 2.4.1-24: A schematic correlation of shale strikes versus logging curve responses.....................................................59

Figure 2.4.1-25: Shale thickness accumulative distribution functions for D1 and T2 intervals.......................................................... 60

Figure 2.4.1-26: Shale geometry divided into rectangular grids...................61

Figure 2.4.1-27: The accumulative distribution function of the equivalent square-shaped shale sizes, for D1 interval.......................................61

\section{Activity 3}

Figure 3.1.1-1

Figure 3.1.1-2:

Figure 3.1.5-1:

Figure 3.1.5-2:

Figure 3.1.7-1:

Figure 3.1.7-2:

Figure 3.1.7-3:

Figure 3.1.7-4: Figure 3.1.7-5:

Figure 3.1.7-6: Figure 3.1.7-7:

Figure 3.1.7-8: Table 3-1:
Fault Block II-A, Wilmington Field .65

Typical Tar Zone Electrical Log Pattern............................66

Stress-strain relationship for porous media.........................71

Demonstration of the compaction / rebound formulation............73

Effect of Formation Compressibility................................74

Effect of Aquifer Size..............................................74

Structural contour map and location of WOC in the Tar of Fault Block II-A................................................................75

Field production history for the Tar Zone in Fault Block II...........75 Dynamic aquifer invasion required for history matching the primary

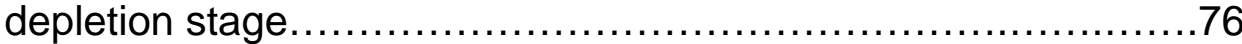

History matching results for the Fault Block II-A...................76 WOR match for different regions in the Tar Zone of Fault Block II-

A...................................................................76

Formation compaction in the Tar Zone of Fault Block II-A..........77

Reservoir Description............................................. 77 
Figure 3.1.8-1: Estimation of formation compressibility for rebound process......77

Figure 3.1.8-2: History matching results for the waterflooding stage ...............78

Figure 3.1.9-1: Comparison of and field results for steamflooding pilot in the Tar Zone of Fault Block II-A........................................78

Figure 3.1.9-2: Prediction of individual pilot well responses, oil rate..................79

Figure 3.1.9-3: Prediction of individual well responses, WOR ....................79

Figure 3.1.12-1: Predicted steam chest volume - scenario I......................80

Figure 3.1.12-2: Prediction of reservoir pressure, temperature, steam chest volume under scenario II.

Figure 3.1.12-3: Prediction reservoir pressure, temperature, and steam chest volume scenario III. 82

Figure 3.1.12-4: Prediction of reservoir pressure, temperature, steam chest volume and the impact of subsequent rate adjustments for scenario IV.........83

Figure 3.1.12-5: Visualizations of the steam-chest collapsing. $.84-85$

\section{Activity 4}

None

\section{Activity 5}

Figure 5.1.1-1: Typical Mineralogy of Tar Zone Sands..........................93

Table 5-1: $\quad$ Sand Consolidation Jobs - New Vertical Wells....................94

Table 5-2: $\quad$ Sand Consolidation Jobs - New Horizontal Wells................ 95

Table 5-3: $\quad$ Sand Consolidation Jobs - Vertical Well Recompletes / Liner Repairs......................................................96

Figure 5.1.2-1: Schematic representation of an ideal perforation showing distribution of synthetic cements and dissolution wormholes...

Figure 5.1.3-1: Wellbore Schematic for UP-955 showing sand inflow encrusted onto tubing tail.... .98

Figure 5.1.4-1: UP-955 tubing tail sample showing the three cement layers and the pictures of the three cement types bonding the sand grains 100

Figure 5.1.5-1: Typical Water Analyses of Steam Feedwater and Formation Waters 102

Figure 5.1.5-2: Thin section photomicrographs of pore structure. Sand grains are white and black; pores are gray areas between sand grains.

\section{Activity 6}

None

Activity 7

None

\section{Activity 8}

None 


\section{ABSTRACT}

The objective of this project is to increase the recoverable heavy oil reserves within sections of the Wilmington Oil Field, near Long Beach, California, through the testing and application of advanced reservoir characterization and thermal production technologies. The hope is that successful application of these technologies will result in their implementation throughout the Wilmington Field and, through technology transfer, will be extended to increase the recoverable oil reserves in other slope and basin clastic (SBC) reservoirs.

The existing steamflood in the Tar zone of Fault Block II-A (Tar II-A) has been relatively inefficient because of several producibility problems which are common in SBC reservoirs: inadequate characterization of the heterogeneous turbidite sands, high permeability thief zones, low gravity oil and non-uniform distribution of the remaining oil. This has resulted in poor sweep efficiency, high steam-oil ratios, and early steam breakthrough. Operational problems related to steam breakthrough, high reservoir pressure, and unconsolidated sands have caused premature well and downhole equipment failures. In aggregate, these reservoir and operational constraints have resulted in increased operating costs and decreased recoverable reserves.

A suite of advanced reservoir characterization and thermal production technologies are being applied during the project to improve oil recovery and reduce operating costs, including:

1. Development of three-dimensional (3-D) deterministic and stochastic reservoir simulation models - thermal or otherwise - to aid in reservoir management of the steamflood and post-steamflood phases and subsequent development work.

2. Development of computerized 3-D visualizations of the geologic and reservoir simulation models to aid reservoir surveillance and operations.

3. Perform detailed studies of the geochemical interactions between the steam and the formation rock and fluids.

4. Testing and proposed application of a novel alkaline-steam well completion technique for the containment of the unconsolidated formation sands and control of fluid entry and injection profiles.

5. Installation of a $2100 \mathrm{ft}, 14$ " insulated, steam line beneath a harbor channel to supply steam to an island location.

6. Testing and proposed application of thermal recovery technologies to increase oil production and reserves:

a. Performing pilot tests of cyclic steam injection and production on new horizontal wells. 
b. Performing pilot tests of hot water-alternating-steam (WAS) drive in the existing steam drive area to improve thermal efficiency.

7. Perform a pilot steamflood with the four horizontal injectors and producers using a pseudo steam-assisted gravity-drainage (SAGD) process.

8. Advanced reservoir management, through computer-aided access to production and geologic data to integrate reservoir characterization, engineering, monitoring and evaluation.

\section{The Project Team Partners include the following organizations:}

1. The City of Long Beach - the operator of the field as a trustee of the State of California-granted tidelands;

2. Tidelands Oil Production Company - the contract operator of the field for the City of Long Beach, and the party in-charge of implementing the project;

3. The University of Southern California, Petroleum Engineering Program consultants to the project, playing a key role in reservoir characterization and simulation; and

4. David K. Davies and Associates - consultants to the project regarding petrography, rock- based log modeling, and geochemistry of rock and fluid interactions.

Key Accomplishments for the Reporting Period, April 1, 1997 - March 31, 2000 , include:

1. Completion of a 3-D deterministic thermal reservoir simulation model for the Tar IIA steamflood sands.

2. Development of a post-steamflood operational plan for Tar II-A based on the 3-D reservoir simulation model to address the loss of steam injection and apparent steamflood-related surface subsidence.

3. Post-steamflood reservoir fill-up of steam chest using flank cold-water injection accomplished on schedule.

4. Reservoir pressure monitoring system developed for post-steamflood operations.

5. Completed initial studies evaluating shale sensitivity to steam and heat.

6. Continued interest among other operators within industry, both domestic and international, in two technologies developed as a result of the project, namely:

a. 3-D geologic modeling work; and

b. A novel low-cost well completion technique using steam for formations with unconsolidated sands. 
7. Developed a new, cost-effective procedure to analyze new core data and correlations to revise old core analysis data.

8. Developed a neural network system and tested a procedure for correlating geologic markers in turbidite sequences.

9. Tracer studies to track water salinity and non-radioactive chemicals provided mixed, but valuable results for future tracer work.

10. Expanded the steamflood project to include the five well horizontal steamflood pilot in the Fault Block V Tar zone. 


\section{EXECUTIVE SUMMARY}

\section{Introduction}

The objective of this project is to increase the recoverable heavy oil reserves within sections of the Wilmington Oil Field, near Long Beach, California. This is realized through the testing and application of advanced reservoir characterization and thermal production technologies. It is hoped that the successful application of these technologies will result in their implementation throughout the Wilmington Field and, through technology transfer, will be extended to increase the recoverable oil reserves in other slope and basin clastic $(\mathrm{SBC})$ reservoirs.

The project involves the implementation of thermal recovery in the Tar zone of Fault Blocks II-A (Tar II-A) and V (Tar V). The more mature Tar II-A steamflood has been relatively inefficient due to several producibility problems commonly associated with SBC reservoirs. Inadequate characterization of the heterogeneous turbidite sands, high permeability thief zones, low gravity oil, and non-uniform distribution of the remaining oil have all contributed to poor sweep efficiency, high steam-oil ratios and early steam breakthrough. Operational problems related to steam breakthrough, high reservoir pressure, and unconsolidated formation sands have caused premature well and downhole equipment failures. In aggregate, these reservoir and operational constraints have resulted in increased operating costs and decreased recoverable reserves.

The first two years of the project, from March 30, 1995 to March 31, 1997, began with the application of advanced reservoir characterization methods to enable improved design and application of thermal recovery methods, including the drilling of four horizontal steamflood wells and five observation wells. Historical data was compiled and new data was acquired to perform basic reservoir engineering and to develop advanced geologic and rock-log models. A state-of-the-art $2100 \mathrm{ft}$ steam line was installed under a harbor channel to provide steam to the horizontal wells on Terminal Island. The horizontal wells underwent a new completion technique that controls sand production by injecting steam through limited-entry perforations. The injected steam also resulted in high peak oil production rates of 200-300 BOPD per well. Other completed work included a neural network analyzer that can recognize key log traits for correlating sand sequences and a study on the comparative thermal recovery efficiencies of vertical and horizontal wells.

This report is a compilation of studies completed from April 1, 1997 to March 31, 2000. Members from all four project partners performed the studies and the topics encompass the entire range of upstream petroleum technology including reservoir characterization, reservoir simulation, rock mechanics, reservoir surveillance, sub-surface and facility engineering, and operations. The objective of this report is to show the relationship between the various studies and how the synergy of technical transfer between team members with diverse backgrounds can significantly improve the performance of a project. 


\section{Work Completed Prior to Reporting Period}

A computer database of production and injection data, historical reservoir engineering data, detailed core studies, and digitized and normalized log data was completed to start work on the basic reservoir engineering study and 3-D deterministic and stochastic geologic models. Logs from 171 wells were digitized and normalized for use in the rock-log and geologic models. The digitized logs included the electric or induction and the spontaneous potential (SP) and/or gamma ray (GR) for all of the wells and the formation density and compensated neutron logs for the nine cored wells used for the rock-log model. The 171 wells (of over 600 wells penetrating the Tar zone in the area) are distributed throughout the fault block. New data acquired included Measurement While Drilling (MWD) and Logging While Drilling (LWD) data from the installation of four new horizontal wells, open hole logs and conventional cores from five new observation wells and a tracer study.

A basic reservoir engineering study was conducted and a report generated that evaluated the role of aquifer water influx, determined the original oil in place from gas production data to support the material balance work, and calculated the cumulative oil, gas and water recovery from the Tar zone. Allocating oil, gas, and water production to each well and to each zone completed in the wells was a problem because multiple sands were commingled in most of the wells. This was evident from using this data in the analysis of primary and waterflood recoveries and material balance. For this reason, multiple approaches were used to calculate original oil in place (OOIP) and cumulative oil, gas and water recoveries from the Tar sands. The study included permeability estimates from performance data, compared water injection profile surveys to the allocated injection volumes for each sub-zone, determined vertical communication between sands, evaluated the aquifer for water influx and determined original oil in place from gas saturations to support the material balance work. The quality of the new and old well logs was evaluated for determining log-derived OOIP, oil saturations over time, and the validity of geologic marker picks. The calculated OOIP using the different methods ranged from 98-100 million stock tank barrels of oil, a surprisingly tight range that provided more confidence of the methodologies used and OOIP estimates.

Geostatistical computer software routines were developed for correlating sand bodies and the conditional simulation of reservoir images. This work was incorporated into a neural network code to analyze the characteristics of geological markers observed on lithology logs for fieldwide correlation purposes.

A three-dimensional (3-D) deterministic geologic model was completed using the EarthVision ${ }^{\mathrm{TM}}$ 3-D imaging software by Dynamic Graphics, Inc. The geologic model was initially completed in June 1995 with ten defined sand tops in the Tar zone. The geologic model was used to drill four horizontal steamflood wells and five observation wells, two of which were conventionally cored throughout the two steamflood formations in 
the "T" and "D" sands. The geologic model was also used to develop the framework of the 3-D deterministic reservoir simulation model to optimize reservoir management and thermal recovery methods. Since then, the fault picks were re-evaluated and the defined sand tops were increased from ten to eighteen. The model and newly acquired data have identified the existence of a northeast-southwest gradient of sand quality, the presence of a major channel sand cutting through the upper "T" sands, and the existence of previously unmapped faults.

Following development of the 3-D deterministic geologic model, work began on a 3$D$ stochastic geologic model to describe the heterogeneous turbidite geology of the Fault Block II-A Tar zone. Determining sand continuity is of particular importance for turbidite sands, because sand sequences in adjacent wells may look similar but in fact may not be connected because of the lobated nature of the sand sequences. The detailed core analyses work on eleven cored wells located throughout the Tar II-A zone provided the backbone of the stochastic model. The core analysis work on the two wells cored in 1995, OB2-3 and OB2-5, were performed under both in situ overburden pressure of $1800 \mathrm{psi}$ and "routine" minimum pressure of about 300 psi. Most core analysis work performed on unconsolidated sands, including the nine Tar II-A wells cored from 1981-88, use the routine minimum pressure to hold the core sample together. The higher in situ overburden pressure give lower porosity and permeability measurements. By analyzing the differences in formation characteristics between the core samples measured under the two pressures, the older core data could be normalized for the stochastic geologic model. The stochastic geologic modeling work was in the variogram development stage at the end of 1998 when stochastic modeling work was discontinued in favor of more detailed deterministic modeling work to operate the Tar II-A post-steamflood operation.

A petrophysical rock-log model was completed that identified five rock types to describe the sands and shales within the "T" and "D" formations. Building the model required the development of empirical relationships between the core and log data and the porosity and permeability data. The study was performed on the seven wells drilled from 1988-89 that had modern log suites (gamma ray [GR], resistivity, formation density and compensated neutron) and conventional cores through the Tar sands. Defining the five rock types with similar log and reservoir characteristics is critical for the stochastic geologic modeling as it provides an objective means of predicting petrophysical rock types and permeability profiles for "T" and "D" sands in locations where only minimum log data and no core data are available. The model was applied to uncored wells within the area to aid in reservoir description and permeability modeling for the stochastic and reservoir simulation models. Another important outcome of this study is that traditional log analysis techniques can significantly overestimate shale content and consequently underestimate oil saturation and net oil sand picks in thin-bedded sands. This modeling technique corrects for that problem.

For reservoir simulation work, benchmark tests were conducted on several advanced thermal reservoir simulation packages and computer workstations. The project team selected the STARS ${ }^{\text {TM }}$ thermal reservoir simulation software by the Computer 
Modelling Group (CMG) of Calgary. The software was installed on a R10,000 Onyx RE2 work station by Silicon Graphics Incorporated (SGI) for modeling purposes. History matches covering the primary depletion and waterflood periods were completed. During the preliminary runs, the single component oil (dead oil) feature of STARS was applied in simulations to speed up the modeling work. The project team identified two dynamic reservoir processes that significantly affected the history matches: compaction-related deformation of the rock and gas liberation. The project team developed a rock compaction algorithm that is able to mimic the local and dynamic features of rock compaction and rebound as a function of reservoir pressure. CMG tested this algorithm in an alpha version of STARS 97.00, entitled STARS 97.20, and incorporated it into their full working version of the model starting with STARS 98.00 in January 1998.

Three observation wells and two core hole/observation wells were drilled to monitor steam drive operations and to obtain critical log, core and reservoir pressure data for the stochastic geologic and reservoir simulation models.

Four horizontal wells (two producers and two steam injectors) were drilled in late 1995 utilizing a new and lower cost drilling program. The four wells were drilled with measured depths of $4380-4820 \mathrm{ft}$ and $1700-2075 \mathrm{ft}$ of section in the target "D2" sands at a true vertical subsea depth ranging from $2410-2660 \mathrm{ft}$. The two steam injectors were completed with eleven 0.25 " limited-entry perforations over an interval range of 330-465 $\mathrm{ft}$ at the end of the wells. Both wells underwent cyclic steam injection to consolidate the sand grains in the perforation tunnels to control sand movement into the wellbore and to thermally stimulate oil production. The two producers were completed across the same correlatable interval as the injectors but with 36-48 quarter inch perforations to increase productivity. Both producers were cyclically steamed after the injectors.

Two pilot projects were envisioned for the horizontal wells, one for cyclic steam stimulation and the other for steamflooding. Cyclic steam stimulation was initiated in injection wells 2AT-61 and 2AT-63 (146,000 and 186,000 bbls steam, respectively) during the first half of 1996 and production commenced in early summer. Gross production ranged from 1200-1500 BPD/well compared to projected production rates of $1500 \mathrm{BPD} /$ well. Peak oil production rates ranged from 41-60 BPD/well compared to projected rates of $300 \mathrm{BPD} /$ well. Production wells UP-955 and UP-956 underwent cyclic steam stimulation (114,000 and 183,000 bbls steam, respectively) during the second half of 1996. UP-955 achieved cyclic peak production rates of 1450 BPD gross and 80 BPD oil, while UP-956 achieved cyclic peak production rates of 1570 BPD gross and 103 BPD oil. The four wells initially would accept only low rates of about 300-500 barrels of cold water equivalent steam per day (BCWESPD) at 1300 psi injection pressure and $900 \mathrm{psi}$ reservoir pressure. This would increase to the desired rate of 1500 BCWESPD per well gradually over two months (process accelerated in two wells by breaking down the perforations with high pressure water). Each well was given a one-month steam soak period prior to initiating production. These rates were lower than the projected rates of 2100 BPD gross and 300 BPD oil. At the close of the previous work period in March 1997, UP-956 reported a gradual increase in gross and oil production rates, however, 
UP-955 oil production experienced a decrease in oil production and an increase in gross production. It was hoped that UP-955 would exhibit a favorable response to steam drive injection from the two offset horizontal injectors. Of note is that all four horizontal wells had no sand fill during well pulling operations, indicating successful sand consolidation jobs.

Injection wells 2AT-61 and 2AT-63 were converted to permanent steam injection in November 1996 and January 1997, respectively, at rates ranging from 1700-2000 BCWESPD. The horizontal steam drive wells have been operated based on a pseudo "steam assisted gravity drainage (SAGD)" technique. The SAGD technique was designed by Butler ${ }^{\mathrm{D} 2} \mathrm{D} 4$ and has been tested extensively in the heavy oil fields in Canada. Several articles have been written on the SAGD technique in the Canadian Journal of Petroleum Technology. A good article summarizing the heavy oil recovery techniques used in Canada was written by Polikar and Redford ${ }^{\mathrm{D}}$. The pseudo SAGD method involved completing the last $400-500 \mathrm{ft}$ of the horizontal wells in the most updip section of the reservoir. The horizontal segments of the wells average $1300 \mathrm{ft}$ and were drilled going west to east at a $96-99^{\circ}$ angle (going uphill) to compensate for the reservoir dip. The concept is to concentrate the steam updip in a smaller area to take advantage of gravity segregation of the steam in order to promote earlier development of a steam chest. As the steam chest grows to envelop the producer completion intervals, more perforations will be opened downdip and the updip perforations will be plugged off, if necessary. The pseudo SAGD technique is preferred over a conventional SAGD technique because the Tar zone has more mobile oil ( $13^{\circ} \mathrm{API}$ gravity) than the bitumen in Canada and has very mobile free water located primarily downdip and along the bottom of the sands caused by prior waterflooding.

A hot water-alternating-steam (WAS) drive pilot project was initiated in 1995 in four mature vertical well steamflood patterns. Four steam injection wells (wells 2AT-32, 2AT-33, 2AT-40, and 2AT-41) were converted to hot water injection from March 1995 to February 1996. Injection rates ranged from 500-3000 barrels of water per day (BWPD). Steam injection was resumed from February to November 1996 and hot water injection resumed in November at 4400 BWPD. No significant beneficial or adverse production response was observed that could be attributed to the hot waterflood injection. One major difficulty in observing response is scale buildup in the producers that reduces productivity until the wells are acidized. Four additional steam injectors (wells 2AT-36, 2AT-37, 2AT-44, and 2AT-45) were converted to hot waterflood injection in February 1997. Reservoir tracers were injected into wells 2AT-32 ("T" sand) and 2AT-33 ("D" sand) on February 14, 1997 as described in the Reservoir Characterization section.

A $2100 \mathrm{ft}$ steam line was installed under the Cerritos Channel and placed in service in December 1995 to provide steam to Terminal Island for the four horizontal steamflood wells. The steam line operated without problems until it was idled in January 1999 with the loss of the Harbor Cogeneration Plant steam source. 
An improved $\mathrm{H}_{2} \mathrm{~S}$ caustic scrubber was designed and implemented by a joint team of engineers from T.J. Cross Engineers and Tidelands Oil Production Company, adapting the $\mathrm{H}_{2} \mathrm{~S}$ caustic scrubber principle proposed by Dow Chemical (Patent No. 2,747, 962). The scrubber would be utilized for stripping $\mathrm{H}_{2} \mathrm{~S}$ from steamflood related produced gas streams at less than half the previous cost. The new scrubber process (entitled Lo CoST ${ }^{\mathrm{SM}}$ ) improves the caustic mixing system by gas contact by way of an ejectorventuri contactor, followed by gas separation. The added efficiency allows for a lower caustic concentration. A more effective caustic substitute called SulfaTreat ${ }^{\mathrm{TM}}$ removes lower $\mathrm{H}_{2} \mathrm{~S}$ concentrations to $<4 \mathrm{ppm}$ in the latter of a two-stage process. The net cost of removal of a pound of sulfur is $\$ 0.43$, which translates into a yearly operating cost of $\$ 226,000$. This is significantly lower than the original four-stage process, which cost $\$ 0.74$ per pound of sulfur and a yearly operating cost of $\$ 393,000$.

A 7ppm NO$\times 50 \mathrm{MMBtu} / \mathrm{hr}$ oil field steam generator utilizing the non-commercial low Btu produced gas from Tidelands Operations was installed in the Fault Block $V$ area. The lowest quality gas is produced from the Fault Block II-A, Tar zone. A pilot steamflood was initiated in the Fault Block V Tar zone in 1996 based on drilling and operating lessons learned in this project and by turning a negative situation (waste gas) into a growth opportunity. The unit was the first $50 \mathrm{MMbtu} / \mathrm{hr}$-steam generator permitted in the Los Angeles Basin since the 1980s. The steam generator, by Struthers, was delivered in February 1996 and system checkout started in June 1996. The burner was designed and built by North American Manufacturing Company and guaranteed to emit under $9 \mathrm{ppm} \mathrm{NO}_{\mathrm{x}}$ without selective catalytic reduction (SCR). $\mathrm{NO}_{x}$ control was dictated by maintaining the air-fuel mix at lean condition. The SCAQMD (South Coast Air Quality Management District) requires that stack emissions data be sent to the SCAQMD via a modem using a Continuous Emissions Monitoring System (CEMS). Stack emissions were in compliance with the SCAQMD guidelines, with stack emissions tested at 5.44ppm without FGR (Flue Gas Recirculation) and a burner not equipped with SCR. A third party stack-testing laboratory, World Environmental, verified this.

A novel well completion technique tailored towards stabilizing unconsolidated, porous and permeable sands has been successfully applied in the Tar Zone of the Wilmington Field. This well completion technique, which involves the application of steam, has been applied in 12 horizontal wells and 22 vertical wells with over $90 \%$ of the wells capable of production or injection after two years. This completion has been used in place of the more expensive opened-hole, gravel-packed and slotted liner completions. Sand control was achieved without any adverse effects on well productivity. The successful application of this technique has resulted in significantly lower drilling and completion costs, better control of fluid profiles into the well-bore, interchangeability of production and injection wells as they now share common drilling and completion methods, and more workover flexibility.

A geochemical study of the scale minerals created in the steamflood producing wells was completed that determines the mineralogy and source of the scales and how to minimize their occurrence. Wellbore fill samples (sand, scale, gravel pack) from the 
existing steamflood wells were analyzed and found to contain several types of scale, including calcites, dolomites, barites, anhydrites, and magnesium-silicates. Although only the carbonate scales are soluble in hydrochloric acid $(\mathrm{HCl})$, performing $\mathrm{HCl}$ jobs appear to eliminate most of the wellbore scale damage and increase production to typical Tar zone rates. The problem occurs mostly in wells that produce very hot fluids. To minimize the problem, most of the hot wells are produced with more backpressure on the formation. This initial geochemical study points to the importance of performing more thorough high temperature lab work on the cores and formation fluids before initiating a steamflood.

\section{Work Completed This Reporting Period}

\section{Advanced Reservoir Characterization}

A very important purpose of the DOE Class III project was the compilation of existing as well as new reservoir data to characterize the turbidite sequences in the Fault Block II-A area. This data was used to develop a new 3-D deterministic geologic model and a rock-log model. The emphasis on a synergistic approach to use the above source of data was to address the stress sensitivity of the formation in the reservoir simulation models.

\section{Converting Core Data from Standard Conditions to In-situ Conditions}

Past core analysis data had indicated inflated values for porosity and permeability because sample testing was conducted under too low a confining pressure. This study provides a more cost-effective procedure for analyzing conventional core data compared to the "routine" porosity, permeability, and saturation techniques used by commercial core analysis companies. The most important change is to place the core samples under original overburden-type stresses for a recommended 15 minutes, but no less than two minutes, before measuring reservoir characteristics. This report also provides correlations to normalize core analysis data measured using the previous "routine" core analysis method.

\section{Neural Network Modeling}

For the stochastic geologic model, a neural network analyzer was developed to analyze the similarities of various zones and sub-zones in terms of sequence stratigraphy using GR logs. Sample stochastic grid block models were test run on the 3-D Earth-Vision ${ }^{T M}$ visualization software to ensure compatibility. A neural network analyzer can identify the unique well log characteristics of geologic markers in turbidite sequences and quickly correlate hundreds of digitized well logs. The required changes in the character of lithology logs / sand-shale, makes the visual correlation often a very difficult task. With over 600 penetrating well logs through the Tar II-A sands, the need 
for developing a neural network analyzer to expedite the stochastic geologic modeling was evident.

\section{Characterization of Discontinuous Shale Bodies}

Systematic reservoir characterization and the first phase of stochastic modeling of the Tar Zone Fault Block II-A in the Wilmington Field has been completed through Sub-task 2.4.1 on "Vertical and Horizontal Geostatistical Spatial Correlation Studies".

The Tar Zone is a turbidite reservoir consisting of unconsolidated sands with interbedded shale streaks. The reservoir characterization work was first partitioned into sand modeling and shale description projects. For sand modeling, conventional core data were first calibrated to reservoir conditions. The calibrated core data were then used to check and correct the density log porosity. Shaliness indicators were identified from density and neutron logs and correlated with the corrected core permeability.

The stochastic model was created by the sequential gaussian simulator. For input, the simulator used the variogram models of the porosity and permeability fields, density log porosity data, permeability cloud transforms, and permeability-normalized neutron log porosity data. Stochastic simulations were conducted on porosity and shaliness indicators. Permeability fields were generated from shaliness indicator results through cloud-transforms. Detailed shale mapping was partially created based on resistivity and density log responses to define the shale streaks accurately. The shale streaks control the effective vertical permeability. A method for upscaling the model is discussed for porosity, sand permeability and the combination of the shale spatial continuity information and the sand permeability.

The original intent of the 3-D stochastic geologic modeling work was to address the lateral variations in rock geology using geostatistical correlation methods. Upon completion of the geostatistical work, the plan was to convert the 3-D deterministic geologic model and examine various stochastic realizations of reservoir conceptual models for simulation purposes. With the extended time to complete the core analysis work and the unexpected shutdown in January 1999 of the steam injection process in the Tar II-A zone, the project priorities were modified by the City of Long Beach to address their concerns about steamflood-related surface subsidence and how to safely operate the Tar II-A wells during the post-steamflood phase. In mid-1998, stochastic geologic modeling work was discontinued so the project team could concentrate on developing a post-steamflood operating plan using the 3-D deterministic thermal reservoir simulation model.

\section{Using Water Salinities to Define Reservoir Heterogeneity}

A field pilot study was successfully conducted that demonstrated a low cost and operationally simple reservoir tracer alternative to obtain information about reservoir rock anisotropy from produced water chemistry data. Normally, reservoir tracer work is expensive and generally performed in one batch treatment that can lead to inconclusive 
results. This study periodically acquired inexpensive water chemistry data from producers to measure naturally existing cations and anions (salinity) in the produced formation water as affected by dilution from the condensed fresh water in the steam. The study was performed in a mature steamflood in the Tar II-A sands that had been previously waterflooded for 29 years. It was conducted over a three-month period on two 7.5-acre inverted seven-spot well patterns with two steamflood injectors per pattern and ten producers.

The methodology cross-correlated the salinity concentration data of produced water with water-influx results from X-Plot Analysis. ${ }^{\text {D6, D7 }}$ The water influx data included water cut data and produced fluid temperatures to confirm steam drive response between steam injectors and their offset producers. The correlation study showed that the reservoir sand connectivity or preferential permeability path of the steam condensate front trended in a northeast to southwest direction, which is consistent with the geological description of interpreted sand deposition. Down-hole pumping conditions affected by well operational changes, i.e., acid jobs to clean scaled-up wellbores, tubing and pump changes and completion intervals in the producers and injectors, must be taken into consideration when analyzing the salinity data.

Salinity monitoring can serve as a cost effective anisotropic mapping tool in steamflood operations. Cross-correlating salinity data with water influx from X-Plots is recommended. Salinity monitoring is ideal for non-commingled production intervals. Regular salinity testing is recommended to define the preferential movement of injected fluids through the reservoir over time and to aid in optimizing steamflood performance and expansions.

\section{$\underline{\text { Reservoir Tracer Program }}$}

The tracer work included the issues related to tracer selection, concentrations, and volumes and to field sampling, laboratory analyses, and interpretation of the produced water results for tracer hits. In spite of its mixed results, the technology transfer value of the findings is substantial for other similar thermal operations.

The reservoir tracers, ammonium thiocyanate (AT) and lithium chloride (LC), were bulk injected on February 14, 1997 into two hot water-alternating-steam pilot injectors. Sampling of produced fluids from first and second rows of producers were collected for analysis of the ammonium and lithium tracers. Very few tracer hits above background levels were recorded. The mixed signals were partly because the tracers break down in the very high temperature environment and in part because of operational changes dictated by the rapid conversion of steam injectors to water injectors.

\section{Productivity Response in a Steamflood between Horizontal Injectors and Producers}

A study was also completed on the projected steam drive recoveries from vertical and horizontal wells and the diagnostic methods for evaluation of steam displacement 
between horizontal injectors and producers. The study utilized the TETRAD ${ }^{\mathrm{TM}}$ thermal reservoir simulator program, a product of Dyad 88 Software Inc. The aim of the study is to compare recovery from vertical and horizontal well completions as a function of reservoir properties, crude oil characteristics, and injection strategies.

\section{$\underline{\text { Reservoir Simulation }}$}

This report includes a summary of the 3-D deterministic reservoir simulation work that successfully history-matched primary production in the Tar II-A sands starting in 1938, waterflood operations starting in 1960, and the steamflood pilot and expansion operations starting in 1981. The report explains how the model was built, the key reservoir and modeling assumptions used, the testing of the model to predict waterflood and steamflood performance versus actual rates, and the development of a rock compaction subroutine that was incorporated into the CMG STARS ${ }^{\mathrm{TM}}$ thermal reservoir simulation software. A separate report discusses the use of the model to develop an operational post-steamflood plan. The post-steamflood reservoir simulation modeling study was the basis for a technical paper presented at the SPE Western Regional Meeting in June 2000. Another separate study was performed to quantify the formation over and underburden heating over a ten-year period using the CMG thermal reservoir simulation program, STARS. The purpose was to determine the potential for thermalrelated shale compaction over time.

\section{3-D Deterministic Reservoir Simulation Model}

The 3-D deterministic reservoir simulation model incorporated the 3-D deterministic geologic model for the Fault Block II-A Tar Zone created for this project. The reservoir simulation study started in January 1997. The model consisted of 26,660 grid blocks ( $43 \times 155 \times 4$ grids), with aquifers on the north and south flanks. The model was calibrated by history matching 23 years of primary production and 22 years of waterflood production. The major reservoir parameters were determined as a function of the history match for the primary depletion and waterflooding processes. The formation compaction / rebound irreversibility was quantitatively determined and the contribution of the Tar Zone to the total surface subsidence was also estimated.

The model's four layers were expanded to 13 layers to account for steam gravity override to simulate the 20-acre steamflood pilot and 150 acres of steamflood expansions. This increased the number of grid blocks to 86,645 . The model was validated when a seven-year projection of oil and water production for the 20-acre steamflood pilot compared favorably with actual total project production data. The model subsequently was able to closely match ten years of production from the 150 acres of steamflood expansions. 


\section{3-D Stochastic Reservoir Simulation Model}

The original intent of the 3-D advanced reservoir modeling work was to address the lateral variations in rock geology using geostatistical correlation methods. Upon completion of the geostatistical work, the plan was to rebuild the 3-D geologic model and examine various stochastic realizations of reservoir conceptual models for simulation purposes. With the extended time to complete the core analysis work and the unexpected shutdown in January 1999 of the steam injection process in the Tar II-A zone, the project priorities were modified by the City of Long Beach to address their concerns about steamflood-related surface subsidence and how to safely operate the Tar II-A wells during the post-steamflood phase. In mid-1998, stochastic geologic modeling work was discontinued so the project team could concentrate on developing a post-steamflood operating plan.

\section{Applying Deterministic Model for Post-Steamflood Plan}

The USC and Tidelands project members used the 3-D deterministic thermal reservoir simulation model to develop the post-steamflood plan. The objective was to use the model as a reservoir management tool to convert a high pressure - high temperature steamflood to a cold waterflood in a stress sensitive formation without any surface subsidence. The model was used to create multiple sensitivity cases to optimize oil production while accelerating steam chest fill-up within the reservoir by measuring the mass fluid and heat balance effects as they pertained to reservoir pressure. Reservoir pressures in the target area are affected by the following occurrences: mixing of the hot and cold fluids at the water injection sites; continuous heat loss in the mature steamflood area to the overburden and underburden formations; steam chest collapse and expansion in the structurally updip areas; and the movement and production of hot fluids throughout the steamflood project area. Taken together, these parameters make the prediction of reservoir pressures too difficult without a viable reservoir model. The model results demonstrated the importance of carefully monitoring and managing the reservoir pressure. A new, comprehensive reservoir pressure monitoring program was developed and has been in continual use throughout the poststeamflood phase as discussed in the Reservoir Management section.

Model sensitivity cases were developed assuming the conversion of various wells to water injection at various rates. The model confirmed the project team's plan to convert structurally downdip wells to create a flank water injection strategy. Whereas the City's initial plan was to idle all producing wells until steam chest fillup occurred from flank water injection, the simulation model successfully provided for limited oil production while filling the steam chest before it could collapse from heat loss to the overburden formation. Oil production in August 1998 averaged 2253 BOPD. Following termination of steamflooding in January 1999, oil production in February was reduced to 781 BOPD, bad but much better than no oil production. The model accurately predicted steam chest fillup in October 1999 due in part to operations successfully meeting the model's water injection rate projections. 
Heating and Cooling Effects on the Over and Underburden Shales and Sands After a Steamflood

A study was performed to quantify the heating of over and underburden shales and sands in a typical Tar II steamflood pattern over a ten-year period subsequent to steamflooding. The purpose was to determine the potential for thermal-related shale compaction over time. The CMG STARS thermal reservoir simulator was used to develop a $1 / 12$ of a seven-spot, 2025 grid block ( $5 \times 5 \times 81$ grids) model to determine how much, how far vertically, and for what length of time the reservoir heat is thermally conducted from the Fault Block II-A Tar Zone steamflood to the overburden and underburden sands and shales. The model mimicked an area in the middle of the steamflood project and had two injectors (one for the T Sand \& one for the D Sand), one producer, and an observation well halfway between the injectors and the producer. Two basic scenarios were run, one with continual $500^{\circ} \mathrm{F}$ hot water injection and one with $135^{\circ} \mathrm{F}$ cold water injection.

The first scenario injected steam and produced reservoir fluids for ten years. The producer was then shut-in and injectors injected only enough $500^{\circ} \mathrm{F}$ hot water to maintain a $90 \%$ hydrostatic reservoir pressure. The model continued to run an additional ten years to determine the heating and cooling effects while steaming and after steaming. The heating and cooling data of the layers above and below the steam zone were recorded and analyzed. The model showed that ten years after steam injection the steam zone only cooled off by $53-67^{\circ} \mathrm{F}$ while the shale layers above and below continued to heat up.

The second scenario injected steam and produced reservoir fluids for ten years. The producer was then shut-in while the injector injected only enough $135^{\circ} \mathrm{F}$ cold water to maintain a $90 \%$ hydrostatic reservoir pressure in the T and D Sands until steam chest fill-up occurred. The model continued to run an additional ten years to determine the heating and cooling effects of the layers above and below the steam zone. The model predicted that reservoir fill-up would occur in October 1999, the same as the full 3-D deterministic reservoir simulation model. The model predicted that the steam zone would cool to $135^{\circ} \mathrm{F}$ within five years after the steam was shut-in. Generally speaking, ten years after steamflooding the layers above and below the steam zone continued to heat up proportionally to how the steam zone was cooling off. The model's predicted temperature profile of the steam zone and non-steam layers above and below the observation well for January 1, 1999 was compared and had a very good match to an actual temperature profile in observation well OB2-5 for the same time period.

\section{Reservoir Management}

Reservoir management focused on the end of the steamflood phase for the Tar II-A project and developing and implementing a post-steamflood plan. The availability of a history-matched simulator for the Tar II-A was quite timely and it became the basis for a reservoir management study of the conversion process. 
Thermal-related formation compaction is a concern of the project team due to observed surface subsidence in the local area above the steamflood project. On January 12, 1999, the steamflood project lost its inexpensive steam source from the Harbor Cogeneration Plant as a result of the recent deregulation of electrical power rates in California. An operational plan was developed and implemented to mitigate the effects of the two situations by injecting cold water into the flanks of the steamflood. The purpose of flank injection is to increase and subsequently maintain reservoir pressures at a level which would fill-up the steam chests in the "T" and "D" sands before they can collapse and cause formation compaction and prevent the steam chests from reoccurring. Intensive reservoir engineering and geomechanics studies have been performed to determine the possible causes of formation compaction and the best ways to operate the Tar II-A zone in post-steamflood mode while minimizing any future surface subsidence.

The new 3-D deterministic thermal reservoir simulation model was used to provide sensitivity cases to optimize production, steam injection, flank cold water injection and reservoir temperature and pressure. The model provided operations with the necessary injection rates and allowable production rates by well in order to operate the reservoir safely. The model accurately projected reservoir steam chest fill-up by October 1999. Fill-up occurred in the "D" sands in August 1999 and in the "T" sands in October. Steam chest fill-up was accompanied by steeply rising reservoir pressures, as would be expected in a fully liquid, relatively incompressible fluid situation.

It was believed that once steam chest fill-up occurred, the reservoir would act more like a waterflood and production and cold water injection could be operated at lower I/P ratios and net injection rates. In mid-September 1999, net water injection was reduced substantially in the "D" sands. This caused reservoir pressures to plummet about 100 psi within six weeks. Starting in late-October 1999, net "D" sand injection was increased and reservoir pressures have slowly increased back to steam chest fillup pressures as of the end of March 2000. When the "T" sands reached fill-up, net "T" sand injection was lowered only slightly and reservoir pressures stabilized.

A reservoir pressure monitoring program was developed as part of the poststeamflood reservoir management plan. This bi-monthly sonic fluid level program measures the static fluid levels in all idle wells an average of once a month. The fluid levels have been calibrated for liquid and gas density gradients by comparing a number of them with Amerada bomb pressures taken within a few days. The data allows engineering to respond quickly to rises or declines in reservoir pressure by either increasing injection or production or idling production.

Expanding thermal recovery operations to other sections of the Wilmington Oil Field is a critical part of the City of Long Beach and Tidelands Oil Production Company's development strategy for the field. The current thermal operations in the Wilmington Field are economical with today's oil prices due to the availability of inexpensive steam from an 
existing a $50 \mathrm{MMBTU} / \mathrm{hr}$ steam generator that can utilize non-commercial low Btu produced gas. Such favorable terms for obtaining steam are not expected to be available in the future. Future expansion of thermal recovery to other parts of the Wilmington Field and other SBC reservoirs will depend on improving the efficiency and economics of heavy oil recovery, as is the intent of the project.

\section{Operational Management}

Operational management focused on the apparent steamflood-related surface subsidence for the Tar II-A project due to shale compaction above the "D" sands. A study has been performed to confirm steamflood-related shale compaction, to determine where this phenomenon is occurring, to measure the extent of shale failure and identify the critical temperatures and reactions that occur during shale failure. This section also updates the study on the sand consolidation well completion technique using steam.

Expanding the project to the Tar V steamflood has allowed the project team to continue ongoing thermal operations in a pilot horizontal well steamflood that was based on the Tar II-A horizontal well pilot. Two of the three Tar V horizontal producers have experienced sand inflow problems and required the wells to be re-treated with steam to reconsolidate the formation sands. Both jobs were recently completed and the wells have been on production with no further sand problems. As of this report, a flank well is being converted to water injection to supplement the injection to production ratio for surface subsidence control and to provide more reservoir pressure support from outside the pilot area to improve well productivity as is currently being experienced with the flank water injection in the Tar II-A project.

\section{Project Expansion}

The Thermal project will expand the S sand steamflood in the Fault Block V Tar Zone in Budget Period 2 of this project. The current Tar V steamflood pilot is based on the knowledge gained from the horizontal well drilling and completion technology and reservoir characterization, pilot testing, and reservoir management techniques learned from the Tar II-A steamflood project performed in Budget Period 1. The plan is to add four horizontal producers, four horizontal injectors, and three observation wells to the existing pilot project. The original Budget Period 2 plan to expand the Tar II-A steamflood project has been withdrawn because of the loss of the Tar II-A steam source from the Harbor Cogeneration Plant.

The expansion project has a drainage area of approximately 88 acres and a net oil sand thickness of $50 \mathrm{ft}$. The remaining oil saturation after waterflooding is estimated to be $50 \%$. The remaining oil in place is estimated to be $4,850,000$ barrels of oil. Projected recovery from the expansion project is estimated to be $1,940,000$ barrels of oil.

\section{Technical Transfer}


The project team was extremely active this reporting period in publishing and presenting the new technologies detailed in the preceding pages to the petroleum engineering community. Twenty-two original technical papers and six articles related to original project technical work were published for industry professional societies and prestigious industry magazines and journals. At USC, one student did her doctoral thesis on the project, a multi-media CD-Rom of the project was developed, and the project web page was updated. The project team was heavily involved in the 1997 Western Regional Meeting of the Society of Petroleum Engineers in Long Beach and in the activities of the West Coast Petroleum Technology Transfer Council. Project team members gave 24 technical presentations at professional society and industry meetings given throughout California, in Texas, and even internationally in China, Spain and Finland.

\section{Acknowledgments}

This research is performed under the Class III Oil Program of the U.S. Department of Energy (DOE), Pittsburgh Energy Technology Center, and contract number DE-FC2295BC14939. The Contracting Officer's Representative is Gary Walker, with the DOE National Petroleum Technology Laboratory in Tulsa, OK.

The following individuals and companies provided valuable assistance to this project through participation on the project team or as consultants to the team:

The City of Long Beach 562-570-3900
Bailey, Scott

Clarke, Don

Colazas, Xenophon

Costa, Alex

Koerner, Roy

Schoij, Suzanne

Sullivan, Dennis

Cassinis, Rick

Tidelands Oil Production Company 562-436-9918
Farabaugh, Kenneth

Fickes, Robert

Hara, Scott

Jongbloed Peter

Kapelke, Mark

Mondragon, Julius*

Phillips, Chris

Quay, Jim

Siegwein, Steve

Walker,Scott

Whitaker, Walt 
University of Southern California 213-740-2311

GeoSystems,

formerly David K. Davies \& Associates

281-358-2662

Dynamic Graphics Inc.

510-522-0700

T. J. Cross Engineers 661-831-8782
Akkutlu, Yucel

Al-Qahtani, M.

Amili, Pouya

An, Linji

Arias, Jose

Bronson, Jon

Du, Changan

Ershaghi, Iraj

Gallant, Geoff

Ghaffari, Bayesti

Handy, Lyman.

Hassibi, Mahnaz

Hosn, Nadim

Yang, Zhengming

Yew, Kelvin

Aumon, John

Davies, David K.

Vessell, Richard K.

Penny, John

Schwalm, Jeffrey

Heisler, Stuart 


\section{INTRODUCTION}

\section{Report Overview}

This is the third "annual" technical progress report for the project covering the period from April 1, 1997 to March 31, 2000. Although the contract was awarded on March 30, 1995 and Pre-Award Approval was given on January 26, 1995, work was initiated on October 1, 1994. The first two annual reports submitted cover the period from project initiation to March 31, 1997.

The remainder of the chapter provides an overview of the project and the Wilmington Oil Field, in which the project is being implemented. Subsequent chapters summarize the objectives, status and conclusions to date of the major activities of the project. The report concludes by describing technology transfer activities stemming from the project and providing a list of related references.

\section{Project Overview}

The objective of this project is to increase the recoverable heavy oil reserves within sections of the Wilmington Oil Field, near Long Beach, California, through the testing and application of advanced reservoir characterization and thermal production technologies. The hope is that successful application of these technologies will result in their implementation throughout the Wilmington Field and, through technology transfer, will be extended to increase the recoverable oil reserves in other slope and basin clastic (SBC) reservoirs.

The project has primarily involved the implementation of thermal recovery in the Tar zone of Fault Block II-A (Tar II-A) and in 1999 the project was expanded to include the Tar zone of Fault Block V (Tar V). The existing steamflood has been relatively inefficient due to several producibility problems commonly associated with SBC reservoirs. Inadequate characterization of the heterogeneous turbidite sands, high permeability thief zones, low gravity oil, and non-uniform distribution of the remaining oil have all contributed to poor sweep efficiency, high steam-oil ratios and early steam breakthrough. Operational problems related to steam breakthrough, high reservoir pressure, and unconsolidated formation sands have caused premature well and downhole equipment failures. In aggregate, these reservoir and operational constraints have resulted in increased operating costs and decreased recoverable reserves.

A suite of advanced reservoir characterization and thermal production technologies were planned, applied and completed during the project to improve oil recovery and reduce operating costs, including:

1. Development of a basic reservoir engineering study to evaluate the role of aquifer water influx, determine the original oil in place from gas production data to support the material balance work, and calculate the cumulative oil, gas and water recovery from the Tar zone. 
2. Development of a three-dimensional (3-D) deterministic reservoir simulation model - thermal or otherwise - to aid in reservoir management and subsequent development work. The development of a 3-D stochastic thermal reservoir simulation model was begun but discontinued to focus on post-steamflood modeling work.

3. Development of computerized three-dimensional (3-D) visualizations of the geologic and reservoir simulation models to aid analysis.

4. Perform a detailed study on the geochemical interactions between the steam, formation rocks and associated fluids.

5. Testing and proposed application of a novel alkaline-steam well completion technique for containment of formation sand and control of fluid entry profiles.

6. Installation of a $2100-\mathrm{ft}, 14$ " insulated steam line underneath a harbor channel to Terminal Island to service the four new horizontal wells.

7. Testing and proposed application of thermal recovery technologies to increase oil production and reserves:

a. Performing pilot tests of cyclic steam injection and production on new horizontal wells.

b. Performing pilot tests of hot water-alternating-steam (WAS) injection in the existing steam drive area to improve thermal efficiency.

8. Perform a pilot steamflood with the four horizontal injectors and producers using a pseudo steam-assisted gravity-drainage process.

9. Advanced reservoir management through computer-aided access to production and geologic data to integrate reservoir characterization, engineering, monitoring and evaluation.

The report emphasizes the activities that have been the most significant throughout the past three years in terms of effort, monetary expenditure and interest within the petroleum community with regard to Technology Transfer activities:

Key accomplishments for the reporting period, April 1, 1997 - March 31, 2000, include:

1. Completion of a 3-D deterministic thermal reservoir simulation model for the Tar IIA steamflood sands.

2. A post-steamflood operational plan was developed for Tar II-A based on the 3-D reservoir simulation model to address the loss of steam injection and apparent steamflood-related surface subsidence. 
3. Post-steamflood reservoir fill-up of steam chest using flank cold water injection accomplished on schedule.

4. Reservoir pressure monitoring system developed for post-steamflood operations.

5. Initial studies evaluating shale sensitivity to steam and heat completed.

6. Continued interest among other operators within industry, both domestic and international, in two technologies developed as a result of the project, namely:

a. 3-D geologic modeling and visualization work; and

b. A novel low-cost well completion technique using steam for formations with unconsolidated sands.

7. Developed a new, cost-effective procedure to analyze new core data and correlations to revise old core analysis data.

8. Developed a neural network system and tested a procedure for correlating geologic markers in turbidite sequences.

9. Tracer studies to track water salinity and non-radioactive chemicals provided mixed, but valuable results for future tracer work.

10. The steamflood project was expanded to include the five well horizontal steamflood pilot in the Fault Block V Tar zone.

The project is being conducted in two budget periods. The first budget period begins with applying advanced reservoir characterization methods and testing thermal production methods as described above to reduce the capital and operating costs of the Tar II-A and Tar V steamfloods and to justify future steamfloods in other SBC reservoirs with similar reservoir characteristics. All of the technologies applied in this project have been transferred to the petroleum industry through papers and presentations as listed in Chapter 7 on Technology Transfer and in the References section.

The Thermal project will expand the "S" sand steamflood in the Fault Block V Tar Zone in Budget Period 2 of this project. The current Tar $\mathrm{V}$ steamflood pilot is based on the knowledge gained from the horizontal well drilling and completion technology and reservoir characterization, pilot testing, and reservoir management techniques learned from the Tar II-A steamflood project performed in Budget Period 1. The plan is to add four horizontal producers, four horizontal injectors, and three observation wells to the existing pilot project. The original Budget Period 2 plan to expand the Tar II-A steamflood project has been withdrawn because of the loss of the Tar II-A steam source from the Harbor Cogeneration Plant. 
The expansion project has a drainage area of approximately 88 acres and a net oil sand thickness of $50 \mathrm{ft}$. The remaining oil saturation after waterflooding is estimated to be $50 \%$. The remaining oil in place is estimated to be $4,850,000$ barrels of oil. Projected recovery from the expansion project is estimated to be $1,940,000$ barrels of oil.

The project is being implemented by a team including:

1. The City of Long Beach - the operator of the field as a trustee of the State of California-granted tidelands;

2. Tidelands Oil Production Company - the contract operator of the field for the City of Long Beach, and the party in-charge of implementing the project;

3. The University of Southern California, Petroleum Engineering Program consultants to the project, playing a key role in reservoir characterization and simulation; and

4. GeoSystems, formerly David K. Davies and Associates - consultants to the project regarding petrography, rock- based log modeling, and geochemistry of rock and fluid interactions. 


\section{Development and Production History}

The Wilmington Oil Field is the third largest oil field in the United States, based on the total oil recovered. Over 2.5 billion barrels of oil have been produced to date, from an original oil in place of 8.8 billion barrels.

The field is located in and around the City of Long Beach, in Southern California. Location maps of the field are in Figures 1 and 2. Figure 3 shows an aerial view of Fault Block II-A. Divided into ten fault blocks, the field has seven major producing zones as illustrated in Figures 4 and 5. Heavy oil occurs in the Tar, Ranger and Upper Terminal zones. This project is being conducted in the Tar zone of Fault Block II-A as shown in Figure 6.

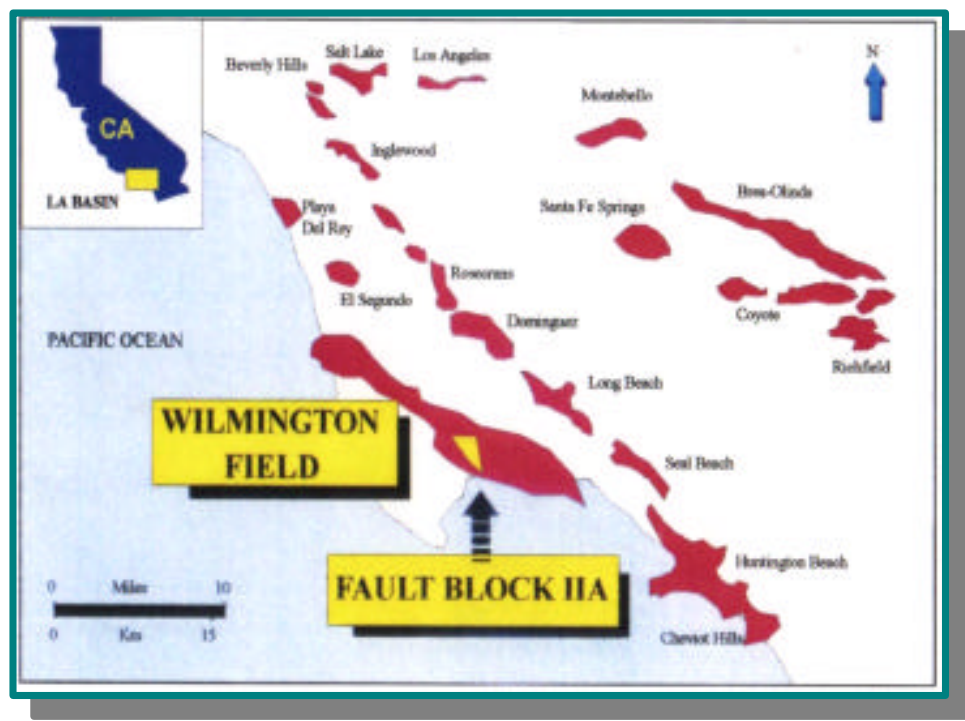

Figure 1: Map showing the geographical location of the Wilmington Field in Southern California.

Primary production from the field began in 1936. Waterflooding was introduced on a large scale during the 1950-60s to increase oil recovery and control surface subsidence. Various tertiary recovery projects have been tried since 1960, but with limited success. For most of the producing zones, waterflooding remains the dominant form of economic oil recovery. The current water cut is approximately $96 \%$. Recoveries in the waterflood and tertiary recovery projects have been hindered by poor sweep efficiency, as is typical of SBC reservoirs with heterogeneous turbidite geology.

The Tar zone in Fault Block II-A began producing in 1937. Unitization for reservoir pressure maintenance and secondary recovery (waterflood) operations took place in 1960 and water injection began in that year. Cumulative oil production through 1979, after 19 years of waterflooding, was 20 million barrels; equivalent to a recovery factor of only $20 \%$ OOIP. This low recovery factor was due to adverse mobility ratio and sand heterogeneity, which have resulted in low areal and vertical sweep efficiencies. Because of the poor performance of waterflooding, it was decided to evaluate the 
economics of applying steam injection to improve recovery of this heavy ( $\left.13^{\circ} \mathrm{API}\right)$ oil ${ }^{\mathrm{A} 1}$, D3

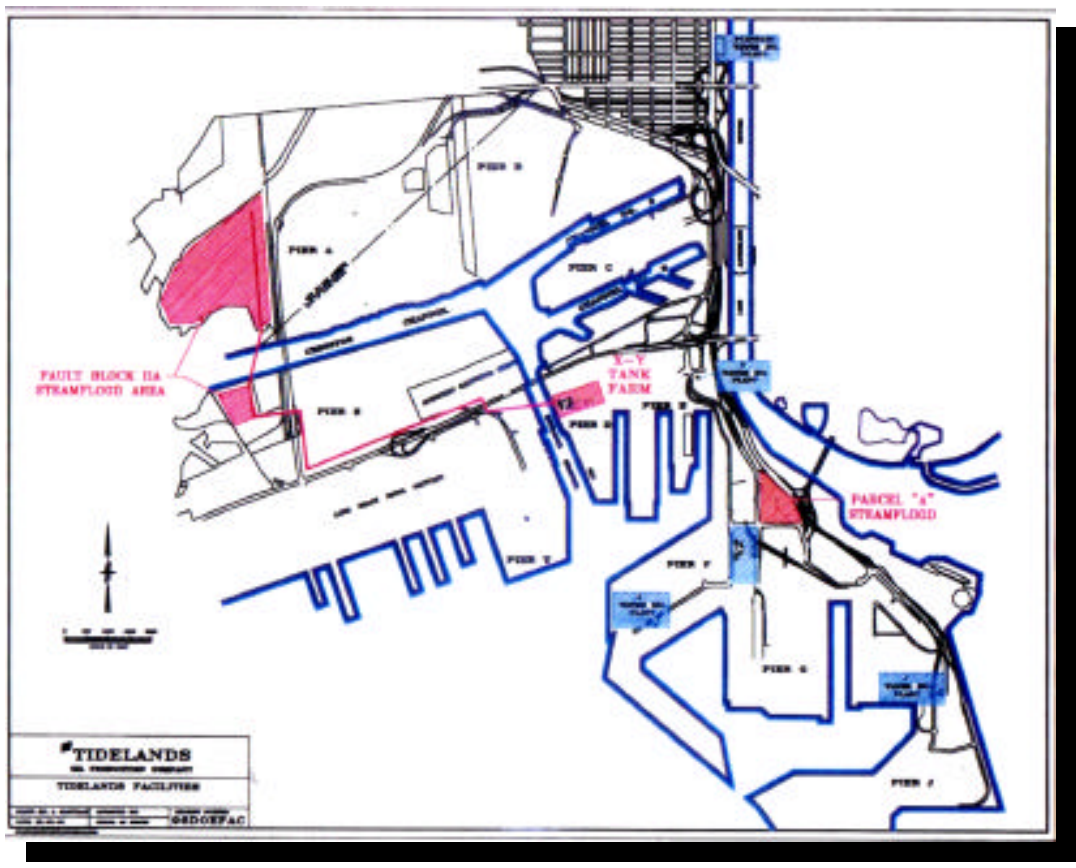

Figure 2: Plan view of Tidelands' facilities and the Tar II-A and Tar V projects, Wilmington Field.

Figure 3: Aerial view of the Wilmington Field shows the location of the Tar II-A and Tar V projects.

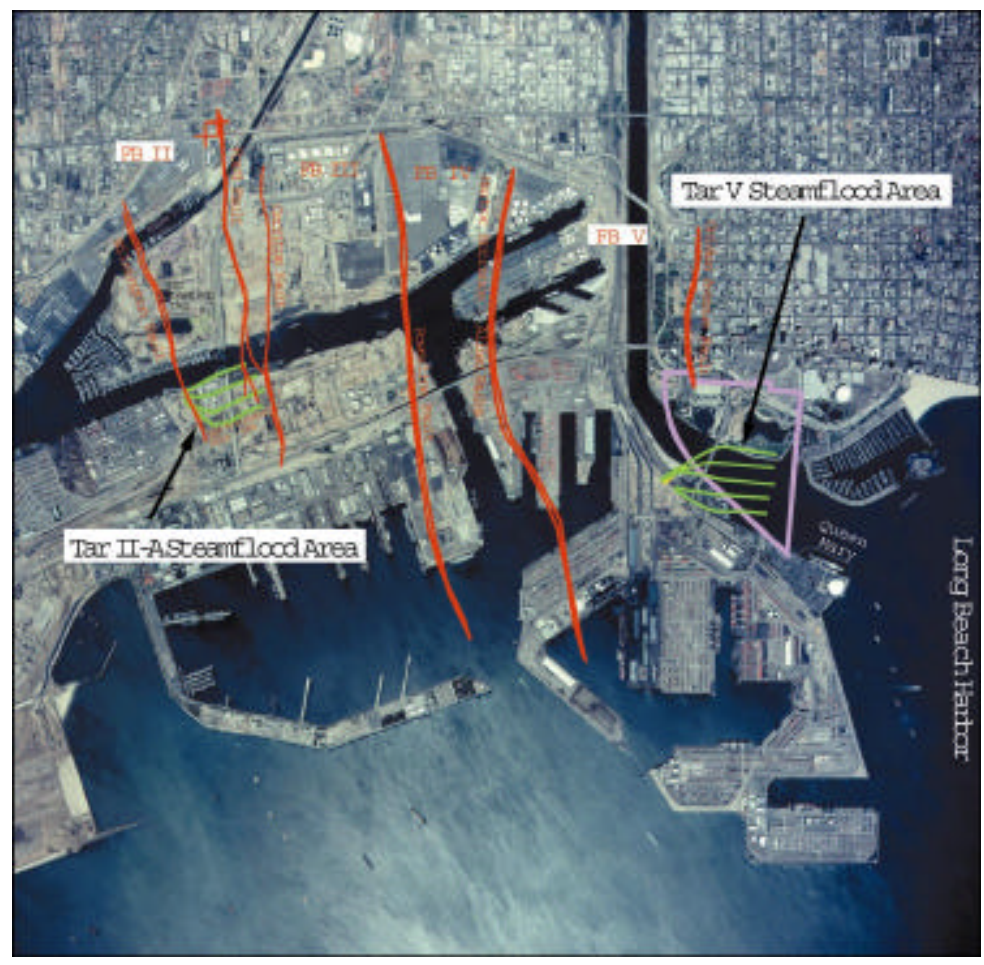


A successful steam injection pilot test, comprised of four inverted 5-acre five-spot patterns, was carried out in the Tar zone of Fault Block II-A from 1982-1989 ${ }^{\mathrm{D} 3}$. The pilot recovered 1.1 million barrels of oil, for a recovery factor of $75 \%$ of the oil-in-place in a previously waterflooded area.

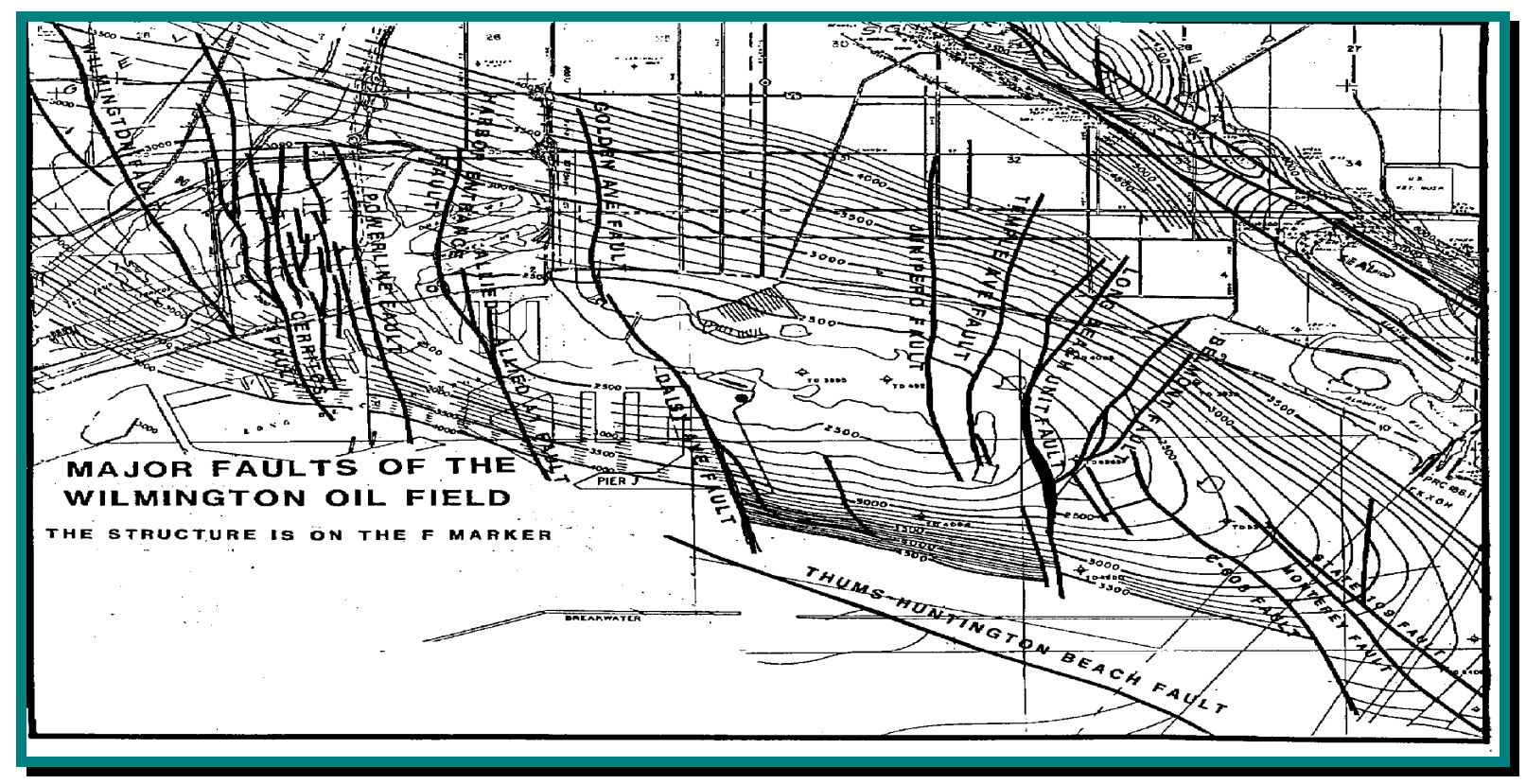

Figure 4: Geologic representation of the Wilmington Oil Field detailing fault line layout.

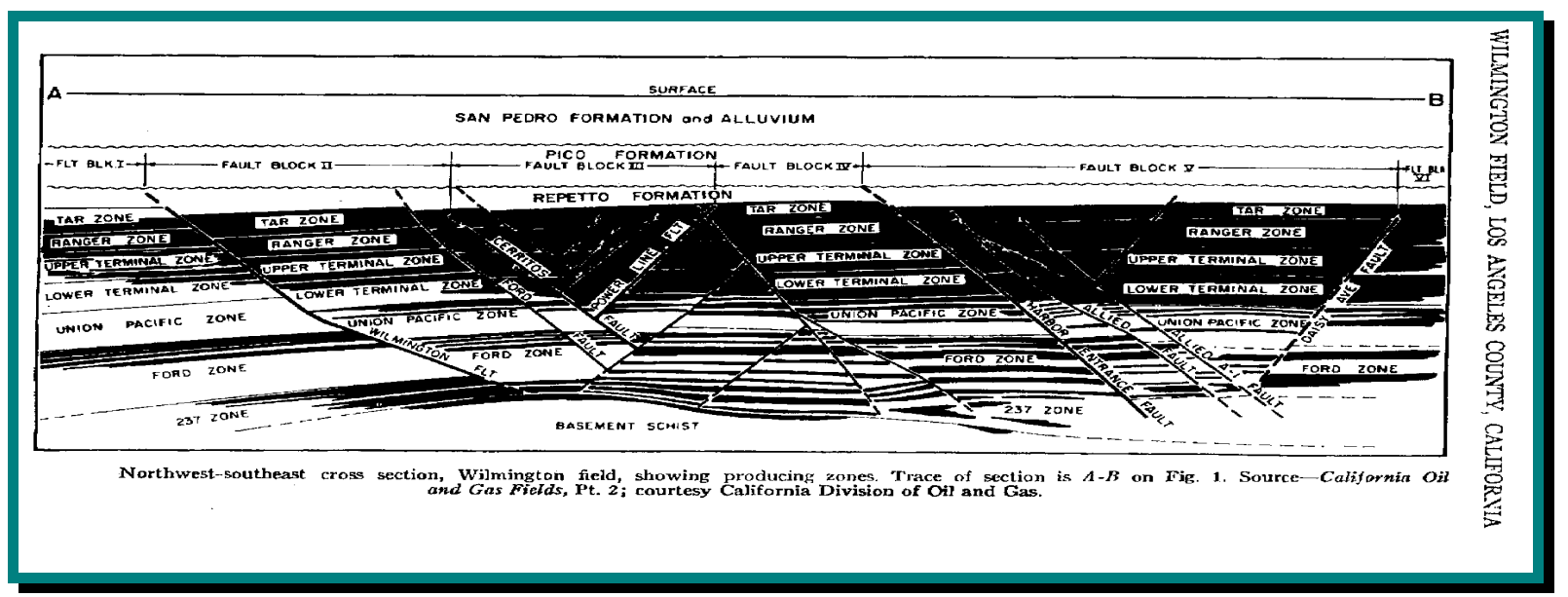

Figure 5: Cross section of a representative NW-SE slice of the Wilmington field detailing producing zones.

The pilot was expanded to 150 acres using an inverted 7-spot pattern throughout the northern half of the fault block in 1989, but the expansion has not met with the same degree of success as the pilot. As of March 1997, the steamflood was producing 2618 $\mathrm{b} / \mathrm{d}$ oil, $35,323 \mathrm{~b} / \mathrm{d}$ of water, and $500 \mathrm{mscf} / \mathrm{d}$ of low BTU gas from the 49 wells. Steam injection was $31,000 \mathrm{~b} / \mathrm{d}$ cold water equivalent into 39 injection wells. The cumulative 
steam/oil ratio is a high 8.5. Recovery efficiency has been relatively low due to poor sweep, with high water cut and early steam breakthrough. Operational problems have included scaling and premature equipment failure due to the high produced fluid temperatures accompanying steam breakthrough. Costly and inflexible completion practices were utilized to control sanding problems that have occurred elsewhere in the field. These are problems frequently encountered in the complex turbidite geology of $\mathrm{SBC}$ reservoirs in the Tar zone.

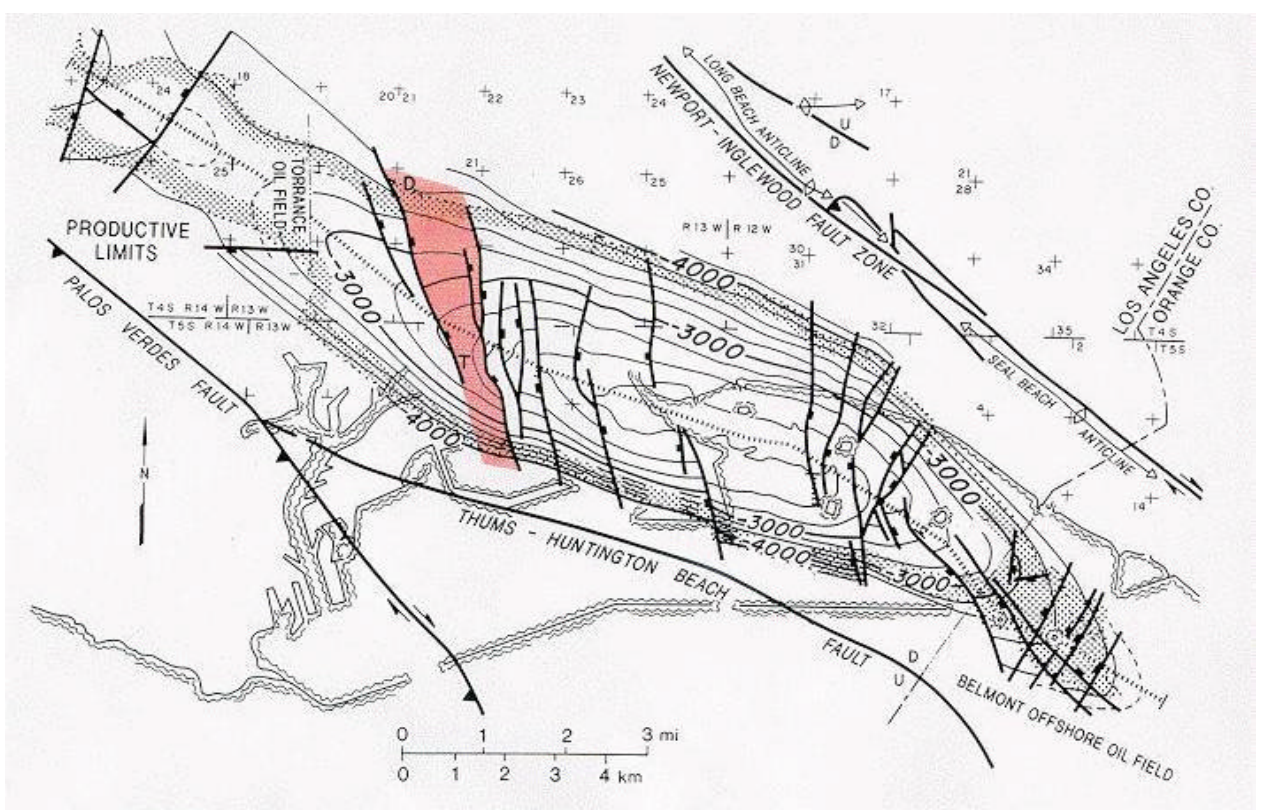

Figure 6: Fault Block II-A, Wilmington Field.

\section{Geologic Setting}

The Wilmington Oil Field is an asymmetrical, highly faulted, doubly plunging anticline, eleven miles long and three miles wide. The productive area consists of approximately 13,500 acres. Fault Block II-A is located near the western edge of the field and is bounded on the east by the Cerritos Fault and on the west by the Wilmington Fault. The north and south limits of the fault block are governed by water-oil contacts within the individual sand members of the various zones. The seven zones within each fault block listed in order of increasing depth are: Tar, Ranger, Upper Terminal, Lower Terminal, Union Pacific, Ford and "237".

Oil from the Wilmington Field and from throughout the Los Angeles Basin is produced mainly from Lower Pliocene and Upper Miocene age deposits. The Tar zone has the shallowest oil producing sands of the thick Miocene-Pliocene sequence. The Tar zone sands are lower Pliocene, middle Repetto formation lobe deposits. 
The upper Miocene Puente and lower Pliocene Repetto formations within Fault Block II-A consist of interbedded sand/shale sequences belonging to submarine fan facies. These are considered to be bathayal, slope and base-of-slope deposits. The upper Miocene sands are intercalated with shales and siltstones in the form of widespread thin turbidites. Large lobate fans dominate the Pliocene section.

The Tar zone in Fault Block II-A consists of four major producing intervals. Each exhibits typical California-type alternation of sand and shale layers as illustrated by the type log in Figure 7.

The Tar zone sands tend to be unconsolidated, friable, fine to medium-grained and contain varying amounts of silt. The thickness of the sand layers varies from a few inches to several tens of feet. Shales and siltstones are generally massive, with abundant foraminifera, mica, and some carbonaceous material. The shales are generally soft and poorly indurated, although there are thin beds of fairly firm to hard shale. The oil is of low gravity, ranging from $12-15^{\circ} \mathrm{API}$ with a viscosity of $360 \mathrm{cp}$ and an initial formation volume factor of $1.057 \mathrm{RB} / \mathrm{STB}$. Based on available information, the Tar zone sands have an average porosity ranging from $30-35 \%$ and permeabilities ranging from 500-8,000 millidarcies with a weighted average of 1,000 millidarcies. Approximate zone thickness ranges from 250-300 ft. The top of the structure appears at a depth of 2,330 ft below sea level in Fault Block II.

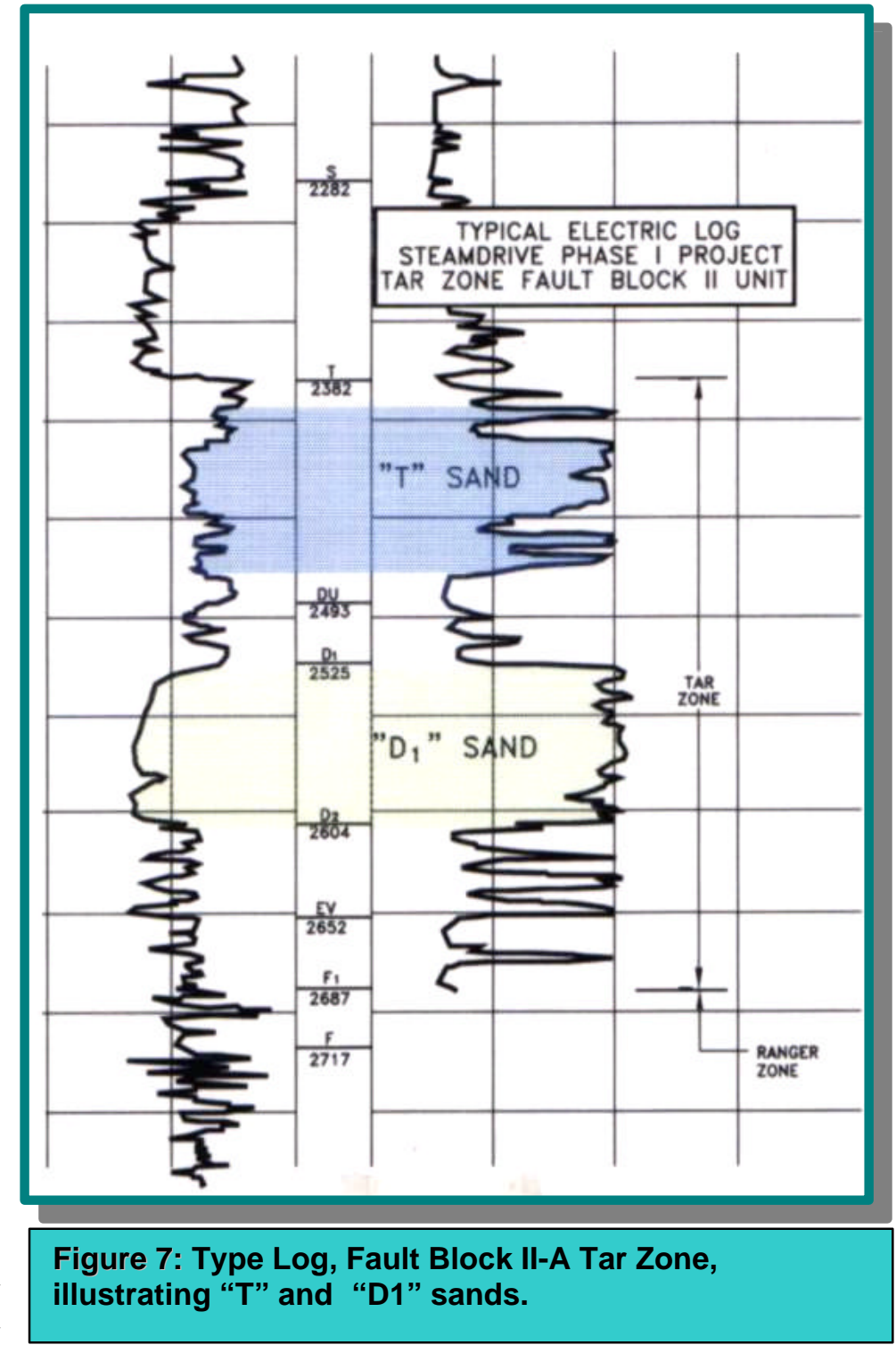




\section{ACTIVITY 1 - COMPILATION AND ANALYSIS OF EXISTING DATA}

\section{Introduction}

Previous to this reporting period, existing field production and injection data were compiled, evaluated for reliability, and analyzed in terms of production response and constraints to provide a foundation for creating geologic and reservoir simulation models. The data were incorporated into Production Analyst ${ }^{T M}$ (PA), a computer-aided data retrieval system by Geoquest, to facilitate simulation-based reservoir management.

Historical reservoir engineering data such as pressure, volume, and temperature (PVT) test results on crude, annual isobaric data, water injection profile surveys, and past reservoir engineering studies were retrieved and analyzed to perform material balance calculations.

A database of available well logs was compiled. Digitization and normalization of log data from 178 wells distributed throughout Fault Block II-A Tar Zone were completed for use in the 3-D deterministic and stochastic geologic models and rock-log model.

No data compilation work was performed this reporting period. During the next year, the project team may complete the production and injection data compilation work for the Tar $\mathrm{V}$ wells for use in the PA system.

\subsection{Data Compilation}

No activity reported this period.

\subsection{Log Digitization and Normalization}

No activity reported this period. 


\section{ACTIVITY 2 - ADVANCED RESERVOIR CHARACTERIZATION}

\subsection{Basic Reservoir Engineering}

No activity reported this period.

\subsection{Obtaining New Characterization Data}

\subsubsection{Measurement While Drilling Data}

No activity reported this period.

\subsubsection{Tracer Surveys}

\section{Introduction}

The reservoir tracers, ammonium thiocyanate (AT) and lithium chloride (LC), were bulk injected on February 14, 1997 into two hot water-alternating-steam pilot injectors. Sampling of produced fluids from first and second rows of producers were collected for analysis of the ammonium and lithium tracers. Very few tracer hits above background levels were recorded. The mixed signals were partly because the tracers break down in the very high temperature environment and in part because of operational changes dictated by the rapid conversion of steam injectors to water injectors. A report by Akkutlu, Yew, Ershaghi, Mondragon and Cavallero is still in progress and should be completed by the next annual report.

A field pilot study successfully demonstrated a low cost and operationally simple reservoir tracer alternative to obtain information about reservoir rock anisotropy from produced water chemistry data. Normally, reservoir tracer work is expensive and generally performed in one batch treatment that can lead to inconclusive results. This study periodically acquired inexpensive water chemistry data from producers to measure the salinity of the produced formation water. Wells responding to steam injection would have lower salinity produced water. This surveillance method can show permeability trends in the reservoir and how steamflood response in wells can change over time with corresponding operational changes. The study was performed in a mature steamflood in the Tar II-A sands that had been previously waterflooded for 29 years. It was conducted over a three-month period on two 7.5-acre inverted seven-spot well patterns with two steamflood injectors per pattern and ten producers. The study was the subject of a SPE paper by Bronson, Ershaghi, Mondragon, and Hara entitled "Reservoir Characterization in a Steamflood Using Produced Water Chemistry Data, Wilmington Field, California" (SPE 54118) ${ }^{\text {A28 }}$.

The methodology cross-correlated the salinity concentration data of produced water with water-influx results from X-Plot Analysis F2, F3, and F4. The water influx data included water cut data and produced fluid temperatures to confirm steam drive response between steam injectors and their offset producers. The correlation study 
showed that the reservoir sand connectivity or preferential permeability path of the steam condensate front trended in a northeast to southwest direction, which is consistent with the geological description of interpreted sand deposition. Down-hole pumping conditions affected by well operational changes, i.e., acid jobs to clean scaledup wellbores, tubing and pump changes and completion interval changes in the producers and injectors, must be taken into consideration when analyzing the salinity data.

Salinity monitoring can serve as a cost effective anisotropic mapping tool in steamflood operations. Cross-correlating salinity data with water influx from X-Plots is recommended. Salinity monitoring is ideal for non-commingled production intervals. Regular salinity testing is recommended to define the preferential movement of injected fluids through the reservoir over time and to aid in optimizing steamflood performance and expansions.

\section{Study Area and Well Description}

The Tar II-A steamflood produces from the T and D sands. The Tar Zone had primary production from 1937 to 1960 producing 15.2 MMBO (15.5\% of OOIP). Because of production-related formation compaction, waterflooding was initiated in 1960 as a pressure maintenance tool to control surface subsidence. The waterflood performance was poor, recovering only 8.3 MMBO (8.5\% of OOIP) from 1960 to 1982 because of adverse oil-water mobility. A successful steamflood pilot was initiated in 1982 with expansions to the rest of the reservoir beginning in 1989. Incremental recovery by steamflooding from 1982 to present has recovered an additional 10.8 MMBO (11.0\% of OOIP) from the steamflood area for a total cumulative oil production of $34.3 \mathrm{MMBO}(35.0 \%$ of OOIP). Steamflood efficiency, as in waterflood operations, is dependent upon achieving good vertical and areal injection sweep efficiency. Vertical sweep efficiency can be achieved mechanically in the wellbores by maintaining good vertical injection profiles. Good areal sweep requires optimizing producer and injector well placement, which requires understanding the characteristics of the producing formation sands such as high permeability and porosity trends and the depositional history and petrography of the formation sands.

The Tar II-A sand environment of deposition is deep water, marine turbidites. The strata are primarily intercalated and amalgamated conglomerates, sands and sandstones, silts and siltstones, clays, and shales ${ }^{\mathrm{F} 1}$ derived from the local peninsular mountain range, currently east to southeast of the field but theorized to be north to northeast of the field during Tar sand deposition. The formation sand porosity ranges between $28-33 \%$ and the permeability ranges from $400-8,000$ md with a weighted average of $1,000 \mathrm{md}$. Original oil saturation was $75 \%$ of the pore volume. The oil has a gravity of $14^{\circ} \mathrm{API}$ and a viscosity of $280 \mathrm{cp}$ at pre-steam reservoir temperature of $123^{\circ} \mathrm{F}$. The pre-steam reservoir pressure was $640 \mathrm{psi}$.

The study was conducted over a three-month period from November 22, 1995 to February 2, 1996 on two 7.5-acre inverted seven-spot patterns as shown in Figure 
2.2.2-1. The study area had been under steam injection in both the T and D sands since 1989. The area has ten production wells UP-912, UP913, UP-917, UP-918, UP-922, UP-923, UP-927, UP-928, UP-932, and UP-933. UP-912, UP-913, and UP-923 are T sand producers and the rest are $T$ and $D$ sand producers. The area has four injection wells (2-wells/pattern), 2AT-032 and 2AT-040 for the T sand and 2AT-033 and 2AT041 for the $D$ sand. Both producers and injectors were completed with wire-wrapped slotted-liners and gravel packs. Each injector had insulated-tubing, a thermal expansion joint and a thermal packer set above the liner top to reduce heat loss when injecting steam.

\section{Methodology}

The salinity concentration of the produced formation water and the water injected during waterflooding ranged between 27,000 - 30,000 ppm of total dissolved solids. The steam

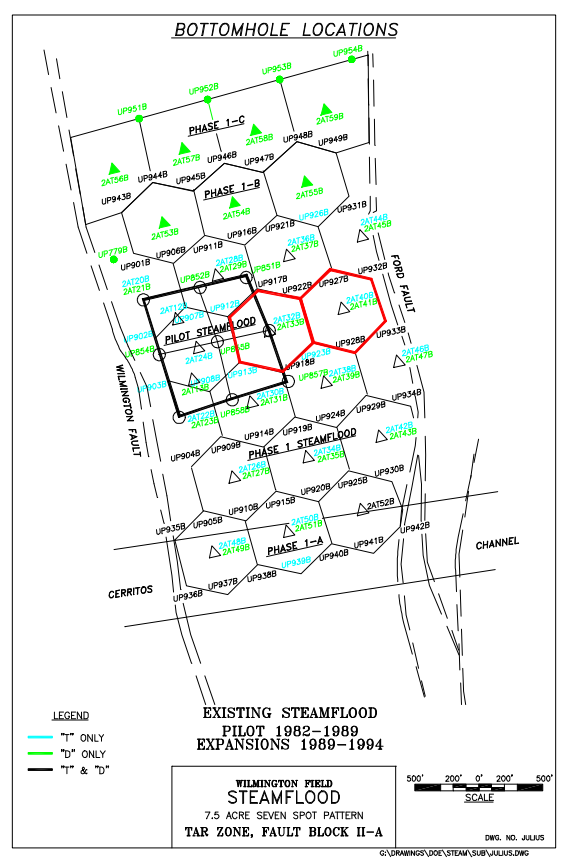

Figure 2.2.2 -1: Two Seven-Spot Patterns for Salinity Tracer generator feedwater used deaerated and softened fresh water purchased from the City of Los Angeles with a salinity concentration of $429 \mathrm{ppm}$. The steam generator produced $600^{\circ} \mathrm{F} 80 \%$ quality steam for injection into the Tar Zone. A steam condensate front forms as the injected steam front moves through the $123^{\circ} \mathrm{F}$ reservoir and begins to cool off and mixes with the formation water, lowering the salinity concentration of the produced water. The changes in the salinity concentration can be monitored and mapped to determine the path of the steam front and the connectivity between injectors and producers.

When flooding a homogeneous, isotropic permeability pattern, all of the producing wells will respond equally to the advancing injected fluid front. The presence of anisotropy in a pattern will tend to cause preferential movement of the injected fluid front and the producing wells will have unequal production responses. Figure 2.2.2-2 shows two schematics, one of a typical injection pattern with homogeneous isotropy and one with homogeneous anisotropy. There are a number of methods to detect preferential direction of fluid movement, i.e., produced fluid temperature and water cut data, chemical tracer surveys, and indigenous tracer surveys. This study uses produced water salinity, an indigenous tracer, as the basis for monitoring preferential movement of the fluid front. The salinity data is cross-correlated with water-influx results from X-Plot Analysis F2, F3, F4 using water cut data and wellhead temperatures of the produced fluids to show steam drive response between the steam injectors and their offset producers. Producer wellhead temperatures and work history supplement this type of reservoir characterization. 


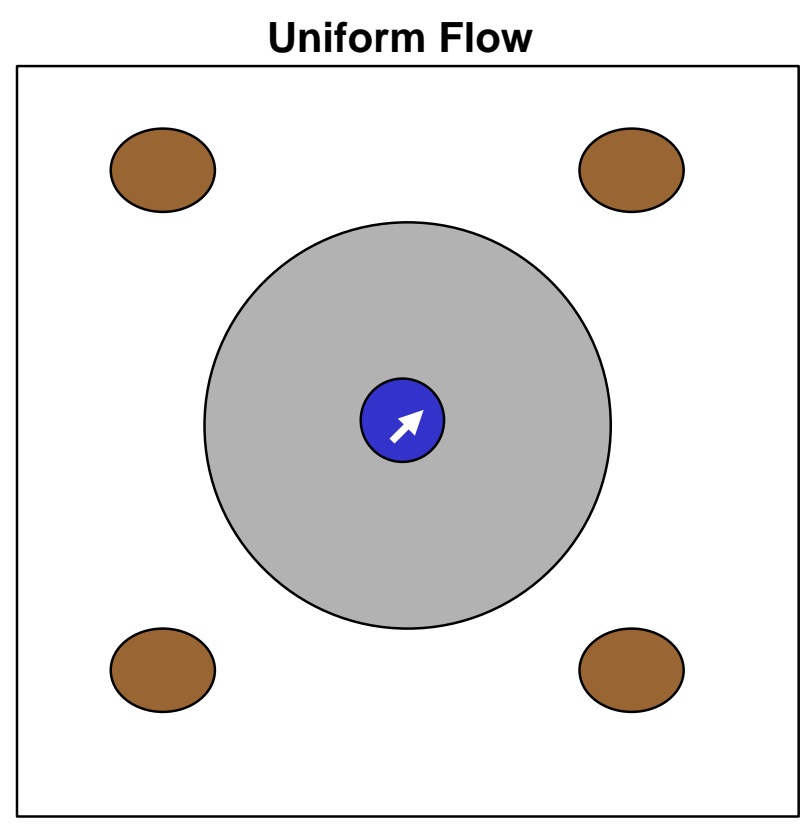

Homogeneous Isotropic

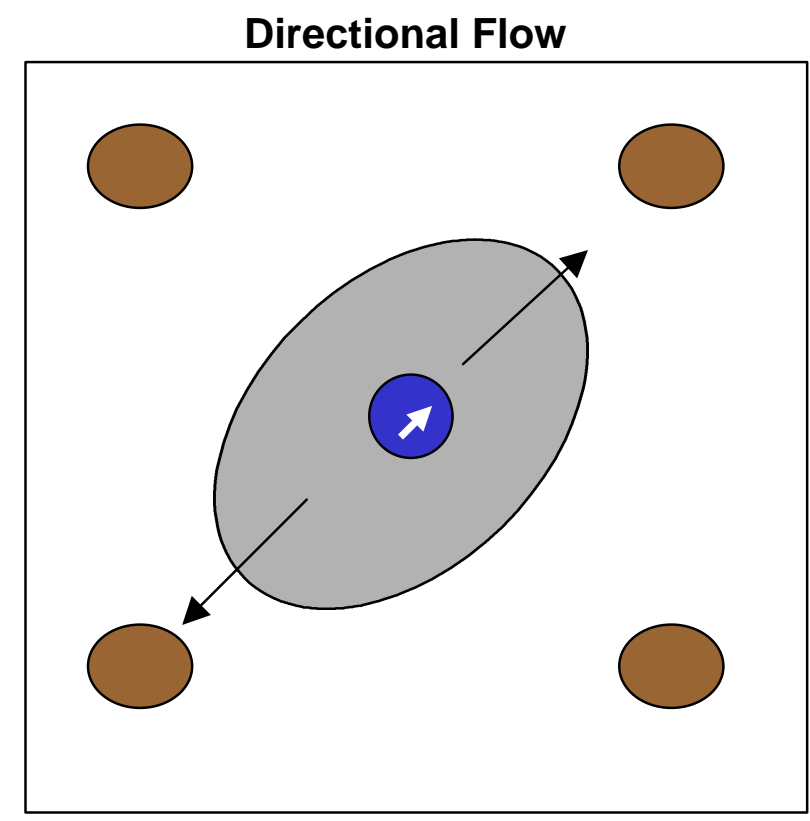

Homogeneous Anisotropic

Figure 2.2.2-2: Homogeneous Isotropic and Homogeneous Anisotropic Permeability Patterns.

Table 1 shows that the historical salinity concentration levels of produced water before steamflooding ranges between 27,000 and 30,000 ppm. The steam injection feed water salinity concentration averages $400 \mathrm{ppm}$. The produced water salinity concentration in a mature steamflood area is $7,000 \mathrm{ppm}$ or less. In this study, the produced fluids from each well were sampled and tested on a regular basis for salinity concentrations. The data were then mapped and analyzed for each time frame to determine if there was any type of preferential fluid flow.

Information related to the preferential movement of fluids and other reservoir data, i.e. porosity, permeability, fluid saturations and geologic data, could be used in building or revising a 3-D geologic model and a 3-D reservoir simulation model to describe the reservoir characterization of the Tar Zone.

\section{Study Results}

Nine samples of produced fluids per well were gathered and tested for salinity concentration between November 22, 1995 and February 2, 1996. The salinity concentration between all the wells ranged between 4,500 and 11,000 ppm.

Figure 2.2.2-3 shows a plot of the produced water salinity data for production well UP-927 from March 1995 to May 1997. The salinity ranges from 11,500 ppm to 2,000 ppm. UP-927 is in the preferential path of the steam condensate front in a northeast to southwest direction. UP-927 had been shut-in during February and March of 1995 to comply with the injection/production ratio constraint of 1.05 in the Tar Zone. The well was 
Table 1: Concentration of Produced Water and Steam Water ( $\mathrm{mg} / \mathrm{l})$

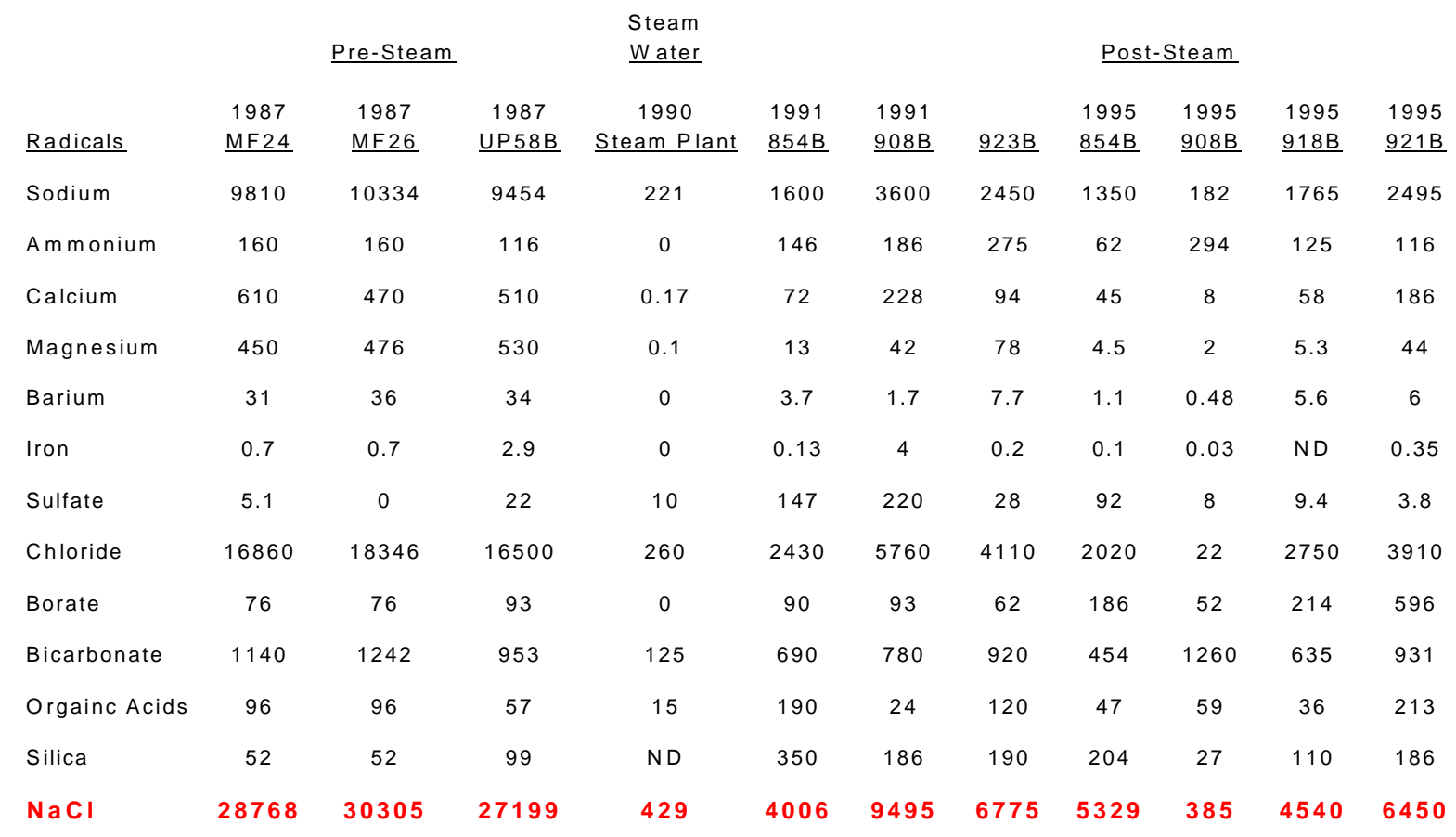

UP-927

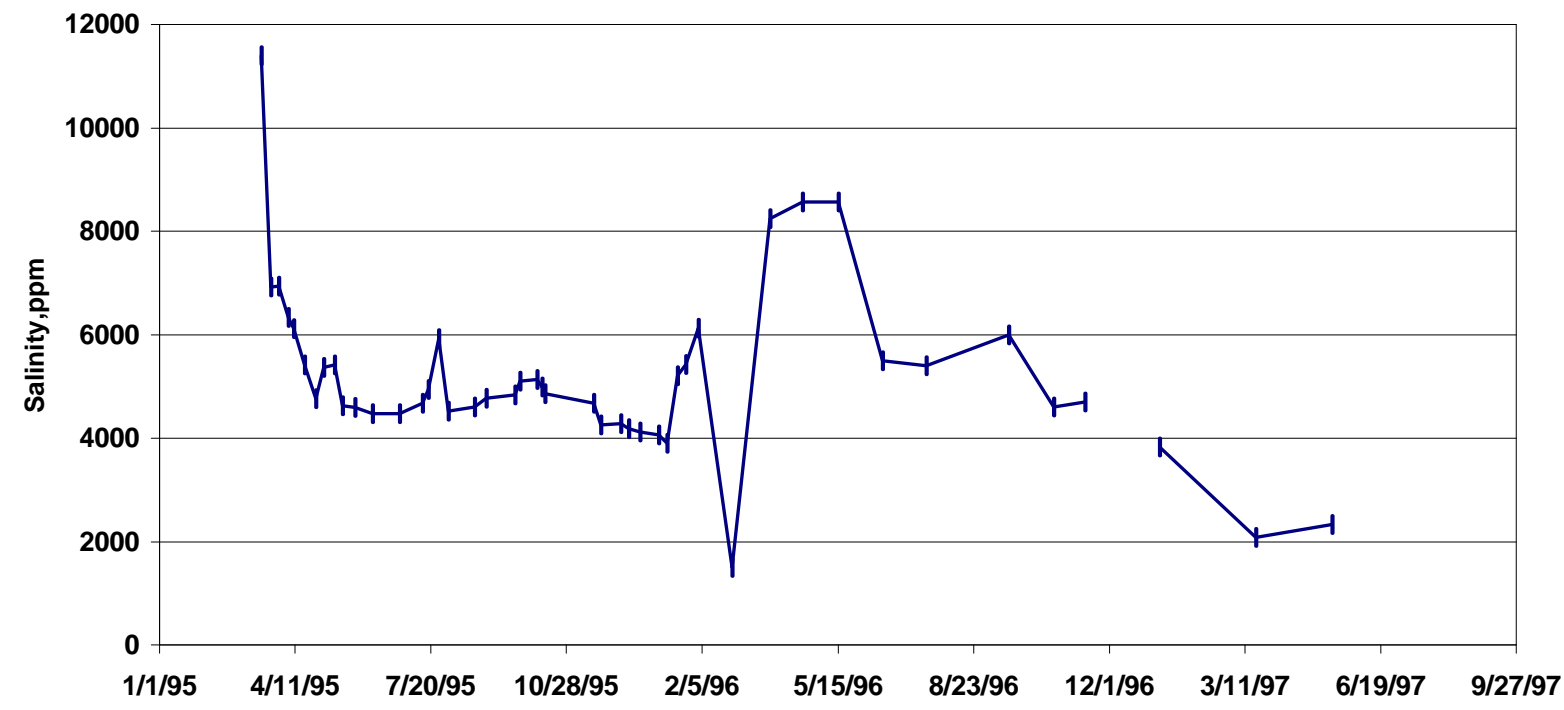

Figure 2.2.2-3: Salinity concentrations for UP-927 production.

returned to production in mid-March 1995. During the time the well was shut-in, the natural reservoir fluids mixed with the steam condensate as the mini steam chest around the wellbore collapsed causing the salinity to increase to $11,400 \mathrm{ppm}$ when the 
well was returned to production. Whenever the well was shut-in because of rig work, the salinity would change temporarily because the well was killed with fresh water. When the well was shut-in because of surface problems the salinity increased proportionally to the time the well was shut-in.

Figure 2.2.2-4 shows the average salinities of the individual wells in the study area over the three-month study period. They range between 4,000 ppm and 8,000 ppm. Wells UP-917 and UP-928 have the highest salinity concentrations, 8,000 ppm and $7,000 \mathrm{ppm}$ respectively, and are located on the edges of the preferential steam condensate front path. The remaining eight wells are located within the preferential steam condensate path and their average salinity is $4,760 \mathrm{ppm}$.

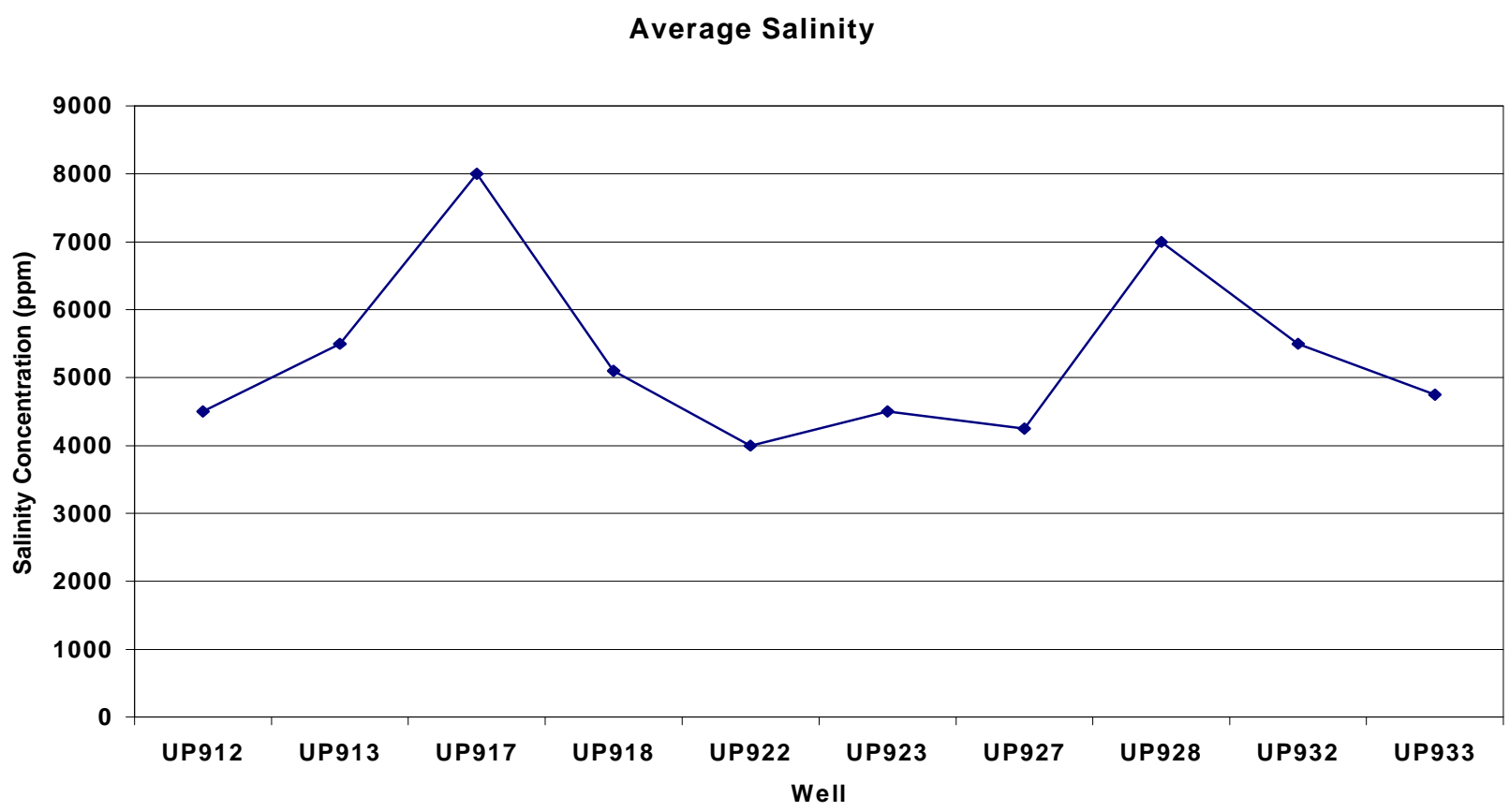

Figure 2.2.2-4: Average Salinity of each of the Wells for the Three-Month Period.

\section{Salinity Distribution Contour Maps}

The ideal situation would show a radial flow pattern such that wells equidistant from a steam injector have the same salinity concentration and wells closer to an injector have lower salinities. In actuality, however, the flow was confirmed to be preferential in the direction of sand deposition.

Figure 2.2.2-5 is a contour map showing the well locations and their produced fluid salinity concentrations for the first samples taken on November 22, 1995 . The lower salinity contours show the wells responding to steam injection. The trend of responding wells is clearly in a northeast to southwest direction and the responding wells indicate the probable channel width. To give a better representation of the actual 
reservoir effect and to help determine where the injection was going, an arbitrary value of 3,000 ppm was given to each injector for the contour map.

\section{Salinity Distribution}

\section{1/22/95}

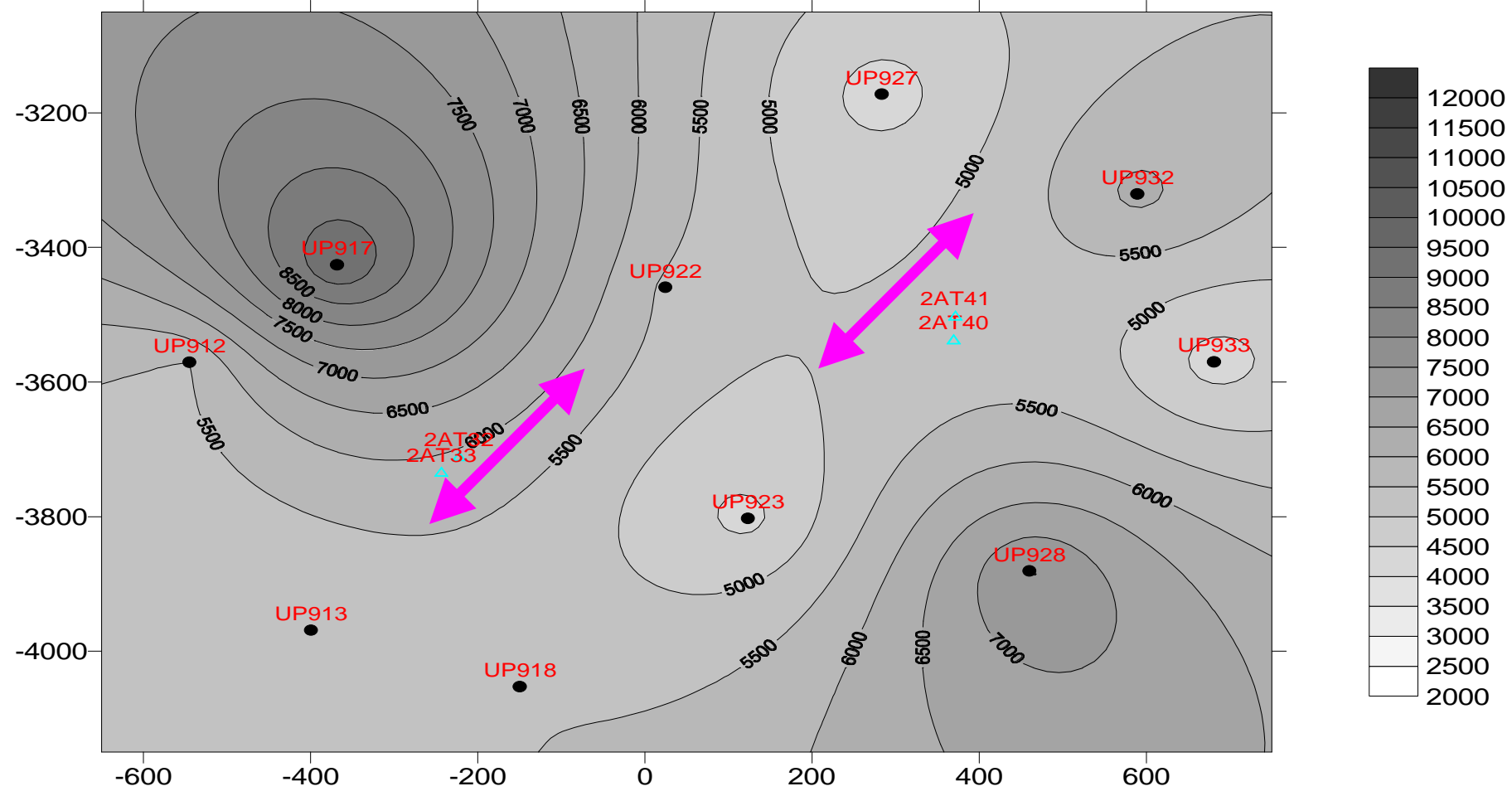

Figure 2.2.2-5: Typical Salinity Distribution Map Showing a Northeast to Southwest Trend.

Similar contour maps were generated for each of the nine water salinity samples taken from the wells. All of the contour maps show a general preferential steamcondensate flow path in a northeast to southwest direction. The injectors are located adjacent to the arrows. The direction of the arrows relates to the wells with the lower salinities, indicating more influence of dilution by the steam condensate front. Wells UP-922, UP-923, UP-927, and UP-933 had the lowest salinity concentrations ranging from 3,900 to $6,130 \mathrm{ppm}$ and are located in the northeast to southwest preferential steam-condensate flow path. Wells UP-912, UP-913, UP-918, and UP-932 had the middle of the road salinity concentrations ranging from 4,280 to $6,720 \mathrm{ppm}$ and are located at the northeast and southwest ends of the steam-condensate flow path. Wells UP-917 and UP-928 have the highest salinity concentrations ranging from 5,855 to $9,540 \mathrm{ppm}$ and are located on the edges of the steam-condensate flow path in a northwest to southeast direction, which is almost perpendicular to the preferential flow path. 


\section{Salinity and Temperature Correlation}

At the beginning of a steamflood, the produced fluid temperatures should increase and the produced fluid salinities should decrease with time as wells respond to steam injection. The produced fluid temperatures for the wells measured at the wellhead ranged from 250 to $365^{\circ} \mathrm{F}$. Low temperature spikes in the data occurred when a well was shut-in for surface or downhole problems. Because of the maturity of the steamflood, a correlation between the salinity concentration and the temperature of the produced fluids could not be made.

\section{X-Plot Analysis and Water Influx Calculation}

The X-Plot analysis and its application introduced by Ershaghi and Omoregie F2, Ershaghi and Abdassah ${ }^{\mathrm{F} 3}$, and Ershaghi, Handy, and Hamdi ${ }^{\mathrm{F} 4}$ is a convenient method for representing oilfield performance history under water injection or natural water drive. Figure 2.2.2-6 shows the linear correlation between the calculated X-value and the cumulative oil recovery for an ideal waterflood case (reservoir simulated data) indicating that the performance is controlled by the relative-permeability-ratio characteristics of the reservoir. The linear plot allows a quick estimate of the volume of water invaded into the drainage area of the well at specified water cut.

Waterflood Simulation X-Plot

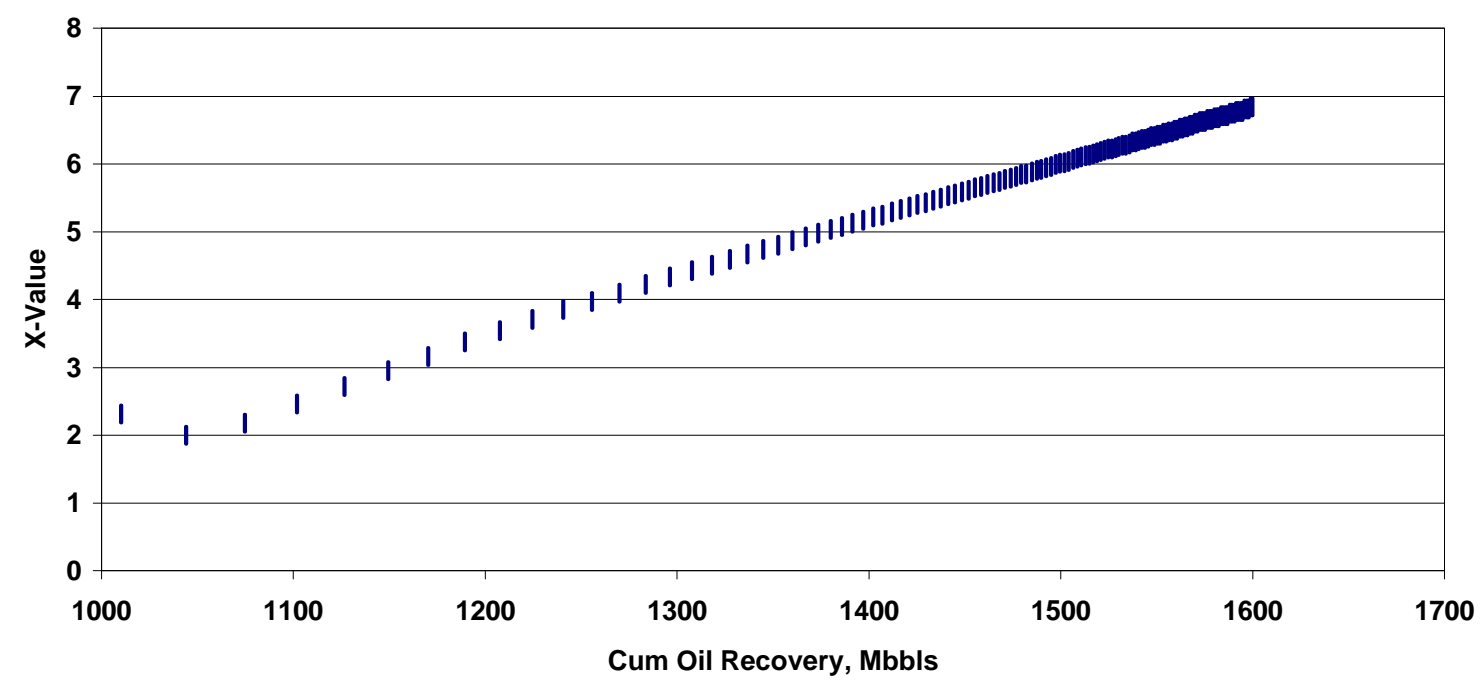

Figure 2.2.2-6: X-Plot of Simulated Ideal Waterflood Data.

This study applied the X-Plot analysis to a steamflood operation. To verify its applicability, a simulation was conducted for a steamflood operation. After calculating the volume of cold water equivalent (CWE) steam invaded for the simulation test, it was found that the calculated volume was fairly close to the amount of CWE steam injected. 
Figure 2.2.2-7 shows the X-Plot of the simulation data and it takes on a pattern of a series of parallel lines. The incremental oil recoveries are attributed to the effectiveness of steam as a displacing agent. Several reasons can affect the incremental recovery such as workovers that improve injection and production profiles, improved sweep efficiencies, and the formation of an oil bank, which is the most likely cause in this study. The slope of the straight lines is a result of the condensate flow and it is used in the water invasion calculation. This established a link between the X-Plot for waterflooding and the X-Plot for steamflooding. Plots of the X-value vs. cumulative oil recovery were prepared for the wells in the study. As expected, a straight line was not generated by the data but a combination of multiple straight lines with similar slopes intermixed with zones of constant water cut and condensate breakthrough.

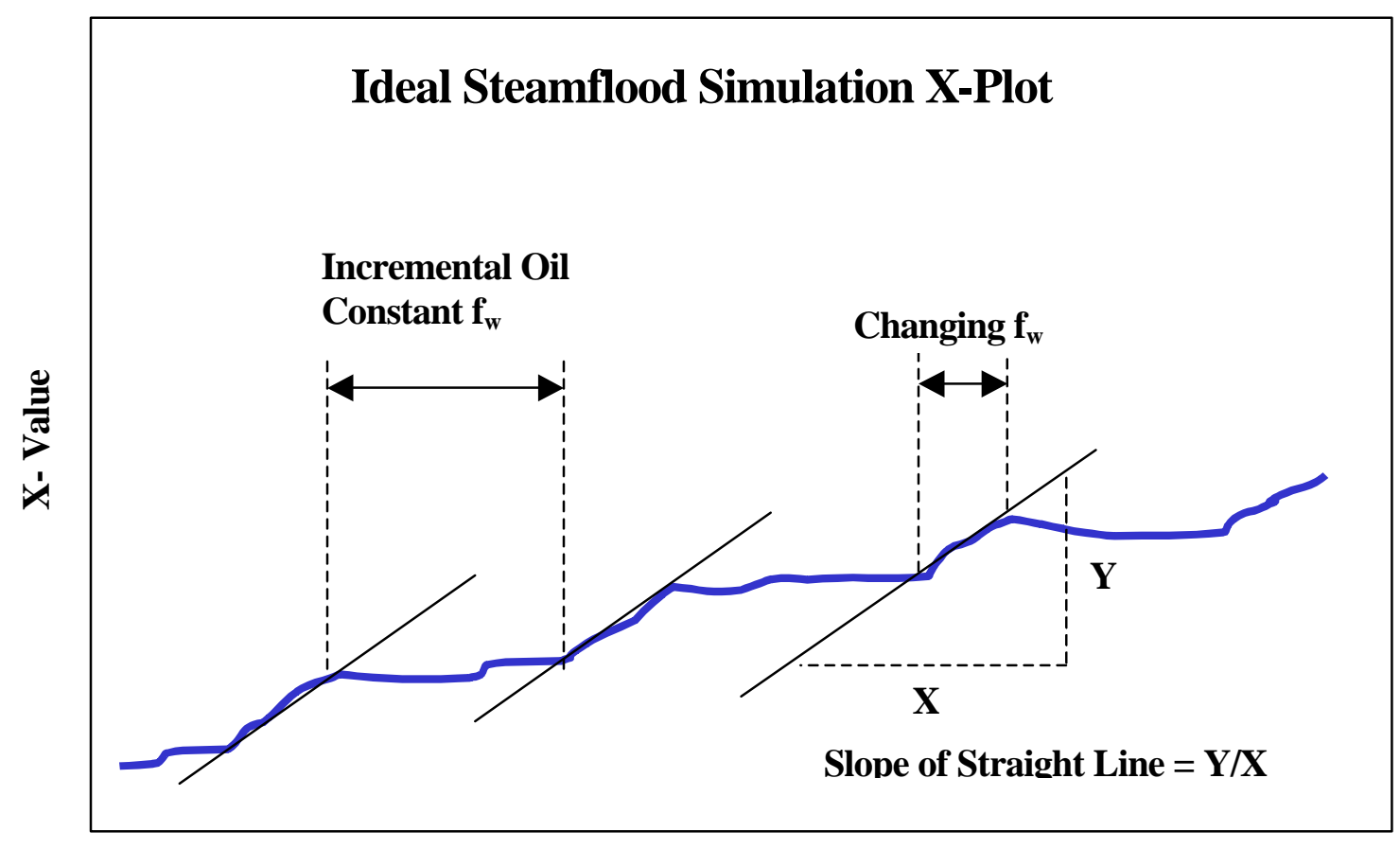

Cumulative Oil Recovery

Figure 2.2.2-7: X-Plot of Simulated Steamflood Data.

Figure 2.2.2-8 shows the X-Plot for well UP-912 with its multiple straight lines with similar slopes, incremental oil production, and condensate breakthroughs. The rest of the wells had similar type X-Plots. 


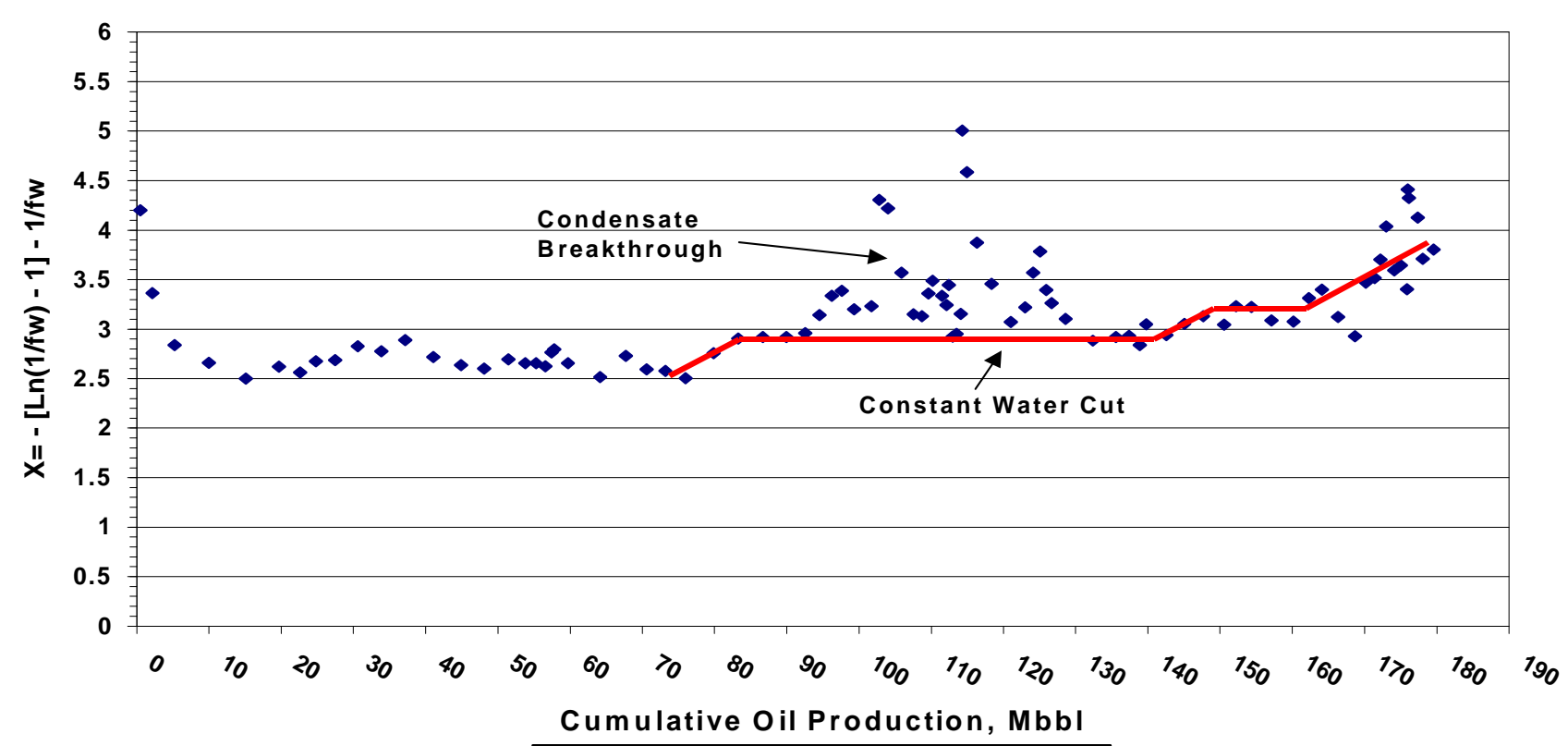

Figure 2.2.2-8: X-Plot for UP-912

The amount of water invaded into the drainage area of the wells can be calculated by using Equation 1 to calculate the $\mathrm{X}$ value from the production data ${ }^{\mathrm{F} 2}$.

$X=-\left(\ln \left(\left(1 / f_{w}\right)-1\right)-\left(1 / f_{w}\right)\right)$

Where $f_{w}$ is the water cut. Then plot the $X$ value vs. the cumulative oil recovery. The resultant plot will be a series of linear lines with similar slopes. The slope of the linear lines can be used to calculate the volume of water invaded using equation $2^{\mathrm{F}}$.

$W_{i}=-B_{o i} /\left[m^{\prime} f_{w}\left(1-f_{w}\right)\right]$

Where $B_{0 i}$ is the initial oil formation volume-factor, $m^{\prime}$ is the slope of the straight line in the X-Plot and $f_{w}$ is the last water cut value. Table 2 shows the calculated volume of water invaded for each well and the input parameters for the calculation. The volume of water invaded per well ranges from 244,357 barrels to 1,227,341 barrels. The wells with the higher volumes of water invaded, UP-912, UP-913, UP-922, and UP-927, are located in the preferential flow path of the steam condensate, which is in agreement with the salinity mapping.

Figure 2.2.2-9 shows four curves. The average salinity for each well is divided by the reservoir formation water salinity $(28,000 \mathrm{ppm})$ before steamflooding, expressed as a percentage. The cumulative oil recovered by each well is divided by the cumulative oil production for all ten producers in the study area, expressed as a percentage. The cumulative gross fluid recovered by each well is divided by the cumulative gross fluid production for all ten producers in the study area, expressed as a 
percentage. The volume of water invasion for each well is divided by the total volume of water invasion for the ten producers in the study area, expressed as a percentage. The data were sorted by increasing salinity for each well. The trend shows that as the salinity concentrations decrease, the cumulative oil and gross fluid recoveries and water invasion volumes increase. The wells with the highest oil recoveries are located in the preferential flow path of the steam condensate.

Table 2: Water Invaded

Calculation from X-Plot

\begin{tabular}{|l|r|r|r|r|c|}
\hline & \multicolumn{1}{|c|}{ Cum Oil } & & \multicolumn{2}{|c|}{ Slope of X-Plot } & Wi \\
Well No. & \multicolumn{1}{c|}{ Bbls } & \multicolumn{1}{c|}{ Fw } & Y-Value X-Value & Bbls \\
\hline UP-912 & 172,000 & 0.932 & 0.800 & 44,000 & 911,228 \\
\hline UP-913 & 136,000 & 0.933 & 1.350 & 69,333 & 862,659 \\
\hline UP-917 & 58,000 & 0.933 & 1.500 & 22,000 & 246,357 \\
\hline UP-918 & 97,000 & 0.951 & 1.000 & 18,333 & 413,091 \\
\hline UP-922 & 139,000 & 0.953 & 2.000 & 68,000 & 797,035 \\
\hline UP-923 & 93,000 & 0.915 & 1.380 & 25,000 & 244,574 \\
\hline UP-927 & 174,000 & 0.953 & 0.764 & 40,000 & $1,227,341$ \\
\hline UP-928 & 99,000 & 0.947 & 1.808 & 40,000 & 462,834 \\
\hline UP-932 & 116,000 & 0.927 & 1.190 & 30,000 & 391,166 \\
\hline UP-933 & 114,000 & 0.969 & 1.882 & 49,166 & 913,165 \\
\hline
\end{tabular}

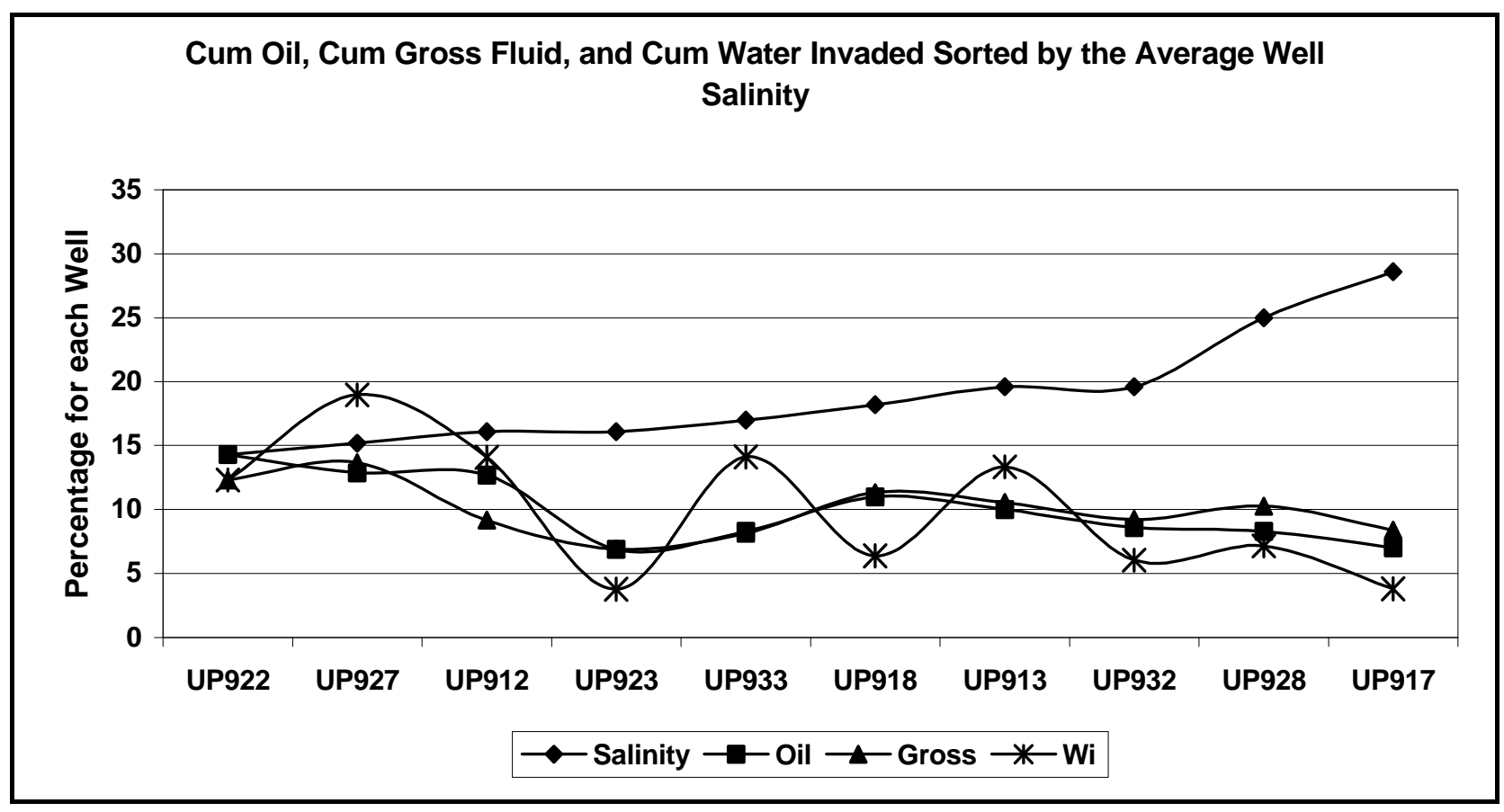

Figure 2.2.2-9: The percentage of cumulative oil, gross fluid, and water invaded for each well from the total of all the wells sorted by increasing salinity. 
When analyzing X-Plot data from wells under steamflood, the steam condensate will cause distortion of the X-Plot. This distortion must be recognized to avoid faulty calculations of the slope of the straight line. In addition, the production data used to make the X-Plot calculations for the majority of the producers were from commingled $T$ and $D$ sand production. The multiple fronts with varying $f_{w}$ could account for some of the distortion. X-Plot analysis works better when only one zone is considered.

\section{Conclusions}

1. Salinity monitoring can serve as a cost effective anisotropic mapping tool.

2. The salinity monitoring determined that the preferential path of the steam condensate and directional permeability trend run in a northeast to southwest direction, which is the same direction as the sand deposition.

3. The salinity concentration of the produced fluid has an inversely proportional correlation with the cumulative oil and gross fluid recovery and water invasion volume calculated from X-Plot analysis.

4. The X-Plot technique can be used to define reservoir heterogeneity in a steamflood operation. Improper interpretation of the X-Plot can lead to faulty calculations.

5. The conclusions made in this paper were for commingled production, which may explain some of the irregular data points. For a more accurate definition of the reservoir heterogeneity, more work should be done to allocate the production volumes to the appropriate sands.

\subsubsection{Water Composition Tests}

No activity reported this period.

\subsubsection{Oil Finger Printing}

No activity reported this period.

\subsubsection{Drill 3 Observation and 2 Core Hole / Observation Wells}

No activity reported this period.

\subsection{Deterministic 3-D Geologic Model}

\subsubsection{Three Dimensional Earth Vision Structure}

A three-dimensional (3-D) deterministic geologic model was completed using the EarthVision $^{\mathrm{TM}}$ 3-D imaging software by Dynamic Graphics, Inc. The geologic model was 
initially completed in June 1995 with ten defined sand tops in the Tar zone. The model was defined by correlating the logs, primarily the spontaneous potential and resistivity logs, of over 600 wells that penetrated the Tar II-A zone A7, A8, C1, C2.

The model assumes that all geologic stratigraphic marker elevations have remained constant since 1959 after the start of field-wide waterflooding operations. The stratigraphic marker depths for the pre-1959 wells were adjusted downward to account for historically measured surface subsidence since the initiation of field production. Formation compaction within individual producing formations was estimated based on zone productivity and casing deformation measurements. Algorithms were developed for the geologic model that mimicked the annual Tar Zone compaction effect so the stratigraphic markers for each pre-1959 well log could be corrected. Because the Tar Zone is the shallowest oil producing zone, it experienced the total formation compaction effects from the Tar through deeper producing zones, which recorded a peak surface subsidence expression of $29 \mathrm{ft}$ in Fault Block IV and about $18 \mathrm{ft}$ in Fault Block II.

The geologic model was used to drill four horizontal steamflood wells and five observation wells, two of which were conventionally cored throughout the two steamflood formations in the "T" and "D" sands. The geologic model was also used to develop the framework of the 3-D deterministic reservoir simulation model to optimize reservoir management and thermal recovery methods. Since then, the fault picks were reevaluated and the defined sand tops were increased from ten to eighteen. The model and newly acquired data have identified the existence of a northeast-southwest gradient of sand quality, the presence of a major channel sand cutting through the upper "T" sands, and the existence of previously unmapped faults.

Following the Tar II-A work, a geologic model was developed for the Tar $\mathrm{V}$ zone that applied the techniques learned from the Tar II-A modeling work. This 3-D deterministic geologic model was used for drilling the five horizontal wells for the Tar V steamflood pilot into the S subzone sands. A23, A24, A26, B7, B11, C16, C20 Prior to drilling the lateral section of the first horizontal well, FJ-204, a probe hole was drilled that penetrated all of the Tar and upper Ranger zone sands. A set of modern logs (induction, spontaneous potential, gamma ray, density-neutron, and microlog) and repeat formation pressure tests were run to get current oil saturation, porosity, permeability and reservoir pressure data and to calibrate the stratigraphic marker elevations on existing well log data to correct for formation compaction and historical well subsurface location surveys. This model will be revised to add more stratigraphic markers for individual sands within the Tar $V$ zone, including sands not currently in the steamflood pilot such as the $T, D$ and Fo subzones. In FB V, the Fo is considered to be in either the upper Ranger zone or Tar bottom, depending on the property designation. 


\section{Core Based Log Model}

\subsubsection{Core - Log Analysis Study by USC}

\section{Introduction}

A unique aspect of the Fault Block II-A Tar Zone, which makes it an ideal candidate for a stochastic geologic modeling project, is the existence of extensive information from many wells. There are 104 wells with a full suite of well logs (density, neutron, ray, SP and resistivity logs) vintage 1980 and after to develop the model. There are also twelve wells with core data among those wells. After creating the model, data from an additional 100 wells will be compared with the predictions from the model to evaluate its ability to capture the geologic features of slope and basin type reservoirs.

The Tar Zone contains unconsolidated and discontinuous sands interspersed with occasional low permeability layers, as is typical of turbidite sequences in slope and basin reservoirs. The porosity and the permeability vary rapidly laterally and vertically due to differential compaction, lack of cementation, and the rapid variation in grain size that is typical of graded and lenticular bedding of turbidite sequences. These heterogeneities have contributed to poor sweep efficiency, high water production, and steam channeling.

The Tar Zone is a submarine turbidite reservoir of outer fan and middle fan sedimentation ${ }^{21-26}$ and has turbidite sequences known as "Bouma" sequences ${ }^{\mathrm{G} 1}$ (Figure 2.3.2-1). Figure 2.3.2-2 and Figure 2.3.2-3 are fan facies maps of the Los Angeles Basin Repettian Stage with an explanation of the types of fans. This type of turbidite sequence bed can measure from inches to tens of feet and could have a full range of different lithotypes along the sequence. The sequences can have coarse sand at its bottom, medium

\section{Turbidite sequence structure}

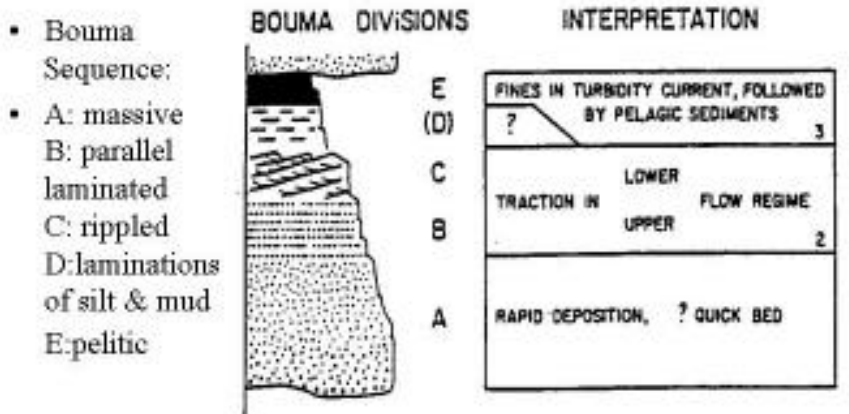

Figure 2.3.2-1: Turbidite sand sequence structure. sand in the middle, fine-silty sand near its top and shale at the top, as well changes of texture and physical properties. The sequence properties change laterally, especially along the flow direction. In addition, the sequences are often inter-cut both laterally and vertically. This heterogeneity setting influences both sweep efficiency and displacement efficiency of a reservoir development. 
For an efficient management of a turbidite reservoir, the shale beds have to be characterized properly. The continuity of these shales controls the macro sweep efficiency of the reservoir during steamflooding due to steam gravity override on the formation top. Any discontinuous inter-bedded shale within the sands can be an effective barrier to prevent steam overriding.

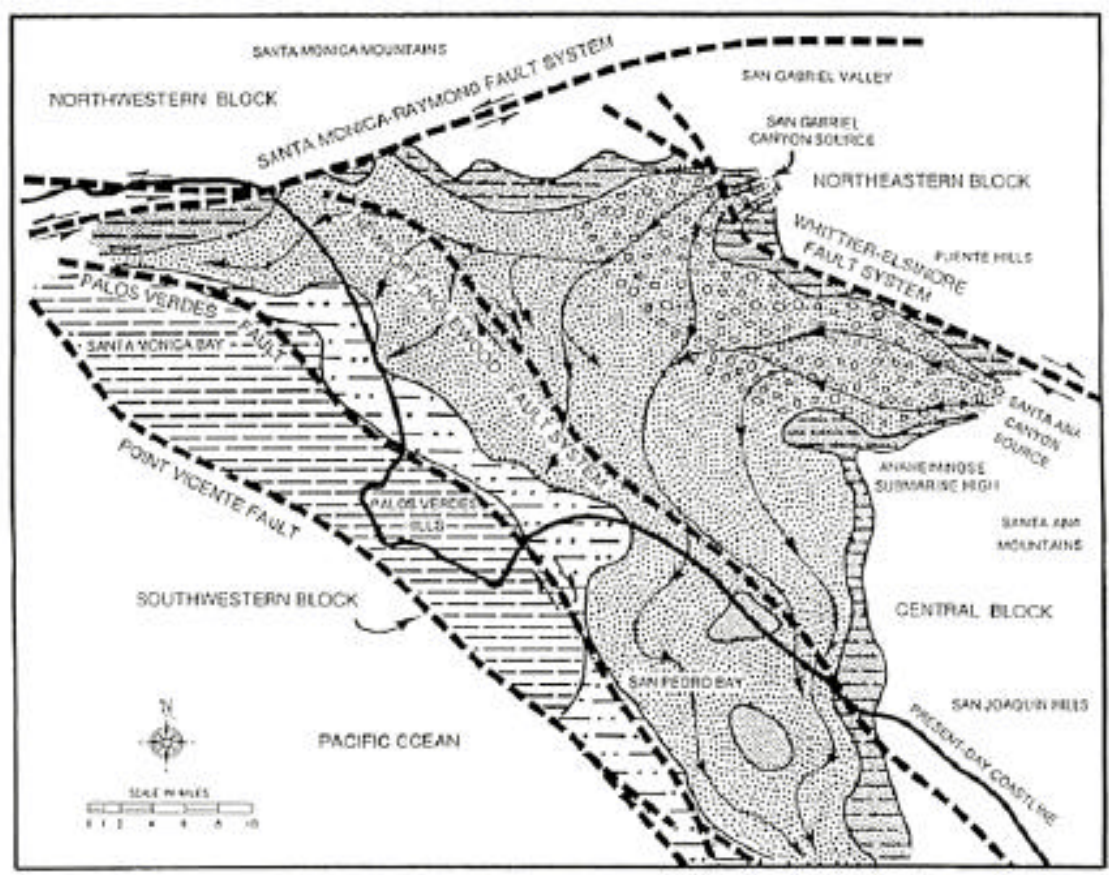

At the same time, the internal structures of turbidite sequences influence the local oil displacement efficiency. A sand sequence having increasing permeability with depth assists steam front stabilization by limiting steam override, thus improving oil displacement efficiency. Conversely, the same trend could develop an inverse bottom tongue in waterflooding and reduce oil displacement. Many studies have described various types of shale mapping, modeling approaches and shale influences on oil recoveries G2-G7. Many turbidite reservoirs contain unconsolidated sands G10G15

\section{Several studies} address stochastic modeling

Figure 2.3.2-2: Present-day Repettian-stage submarine-fan facies map.

\begin{tabular}{|c|c|}
\hline \multicolumn{2}{|r|}{ EXPLANATION } \\
\hline 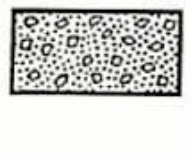 & $\begin{array}{l}\text { MIDDLE TO UFPER CHANNELIZED FAN } \\
\text { Dorninantly pebble, cobble, and boulder conglomerate bodies with sandy } \\
\text { matrix; or pebbly sandstone bodies. Beds may be massive or display } \\
\text { fabric which is crudely stratififad, imbricated, or shows preferential clast } \\
\text { orientation. Sand/shale ratio commonly exceeds 10:1. }\end{array}$ \\
\hline & $\begin{array}{l}\text { SUPRAFAN } \\
\text { Massive, fine- to coarse-sanc size, often amalgamated, sandstone todies. } \\
\text { Beds are cormmonly lenticular with scouring at the base; finely-alternating } \\
\text { parallel lamination to crude subparallel stratification. Fner-grain bodies } \\
\text { tend to grade up into a shaly division. Sand/shale ratio of } 5: 1 \text { to over 10:1. }\end{array}$ \\
\hline 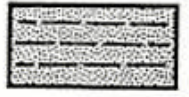 & $\begin{array}{l}\text { UPPER FAN OVERBANK AND SHELF SLOPE } \\
\text { Laminated mudstone alternating with very thin-bedded fine-grain sardstone } \\
\text { bodies. }\end{array}$ \\
\hline$\overline{\cdots \cdots}-\cdots$ & $\begin{array}{l}\text { DISTAL. TURBICITES } \\
\text { Sitt to fine sand with low sand/shale ratio of } 1: 1 \text { or less; graded bedding is } \\
\text { common. Biological activity (horizontal trails and burrows, vertical burrows) } \\
\text { is commonly preserved. Bioturbation may totally disrup: bedding, result- } \\
\text { ing in massive sitstone. }\end{array}$ \\
\hline & $\begin{array}{l}\text { SUBMARINE HIGH } \\
\text { Very thin-bedded silt to fine-grain sandstone bodies; or section missing } \\
\text { due to erosion of non-deposition. }\end{array}$ \\
\hline$-\frac{-1}{-1}=7$ & $\begin{array}{l}\text { HEMIPELAGIC SUBMARINE HIGH } \\
\text { Predominantly sily or calcareous hemipelazic shale and marl; very diute } \\
\text { suspension deposits. }\end{array}$ \\
\hline $\begin{array}{l}\text { Figure } 2.3 . \\
\text { submarine }\end{array}$ & $\begin{array}{l}\text { Explanation for Repettian-Stage } \\
\text { facies map. }\end{array}$ \\
\hline
\end{tabular}


of turbidite reservoirs ${ }^{\text {G16-G20 }}$. Dehghani et al ${ }^{\text {G19 }}$ studied the shale distribution and sand heterogeneity influence on a steamflood in a dipping formation where the shale correlation length was based on geologic data. Haldorsen ${ }^{\mathrm{G} 7}$ proposed a general random shale modeling approach based on shale geometry statistics collected from outcrops or well log data.

\section{The Fault Block II-A Tar} Zone of Wilmington Field is bounded by the Wilmington Fault to the west and the Ford Fault to the east side (Figure 2.3.2-4). Both faults are sealing. The deterministic geologic model has the Tar Zone divided into six subzones and eight sub-sands and sub-shales (Figure 2.3.2-5). This study concentrates only on the T2 and the D1 sub-sands, two major sand-rich oil producing sands, with more emphasis on the D1 sand. Within these two

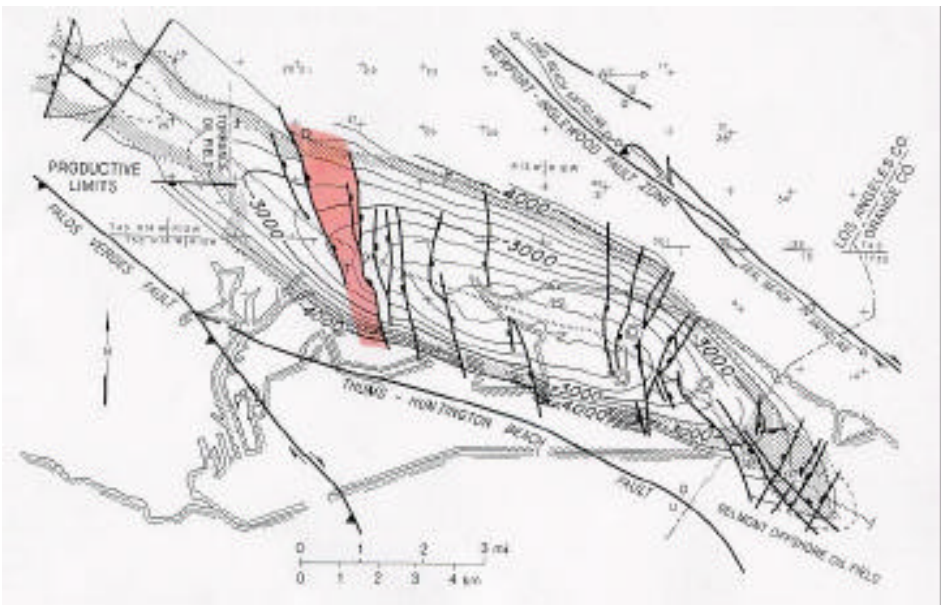

Figure 2.3.2-4: Fault Block II-A, Wilmington Field. sub-sands there are no field-wide shale barriers defined. The formation is unconsolidated sand with only oil for cementation. There are some discontinuous shales within the two sub-sands.

A systematic, comprehensive case study was conducted in order to have a better understanding of how the reservoir heterogeneity (especially with shale streaks) affects the Tar Zone production performance (primary, waterflood, and steamflood production) and simulation of future production and injection scenarios. Step 1 studied the turbidite sequence structure. Step 2 determined whether to separate the shale top modeling from the blocky sand modeling or to combine them. Step 3 showed how to calibrate the log porosity data with core analysis data. Step 4 studied the shaliness indicators and their correlations with the

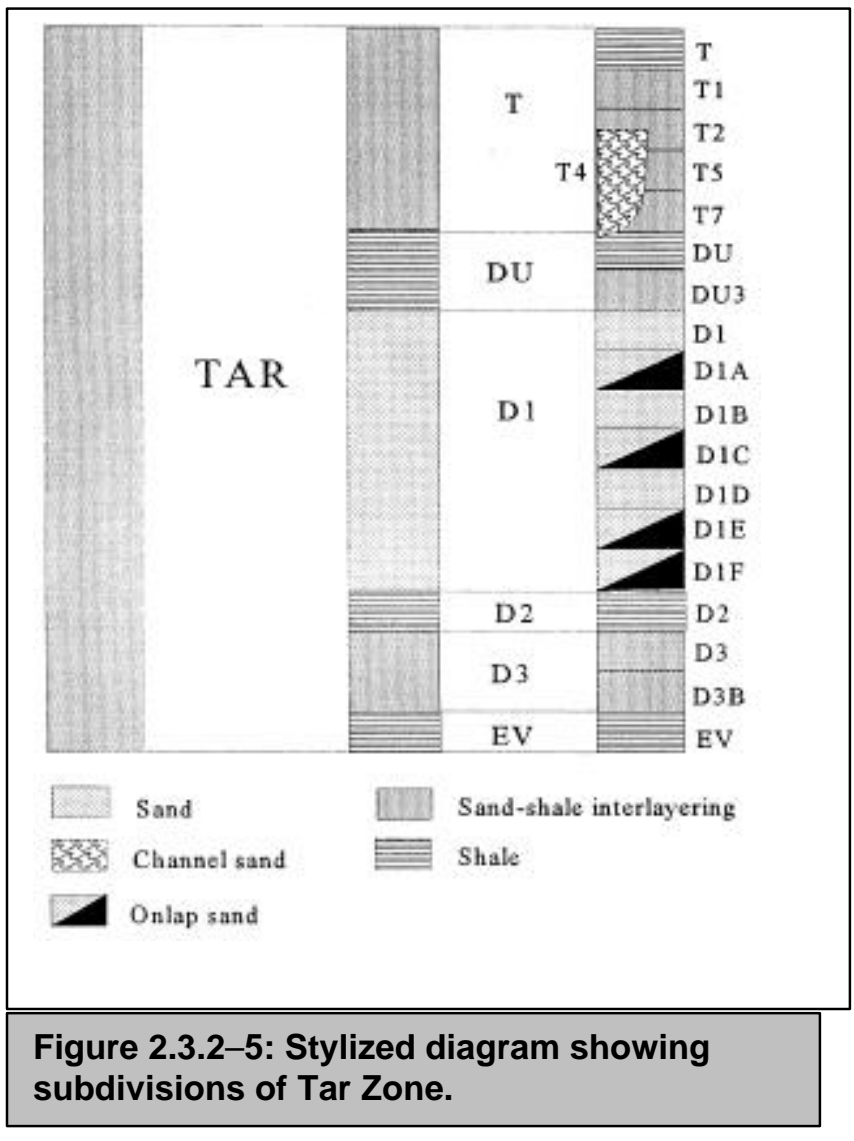


permeability data. The corrected data was used to make stochastic models of the porosity, the shaliness indicator and the permeability.

\section{Turbidite Sequence Structure}

GeoSystems, formerly David K. Davies and Associates Inc. (DKD), reviewed the core photos of the Tar Zone and made a detailed description of the sequences. Most sequences are very similar in terms of lithotypes; all sequences have coarser sand grains at the sequence bottom and a fining-up trend to the top of the sequence both with and without silty/shale tops. Some small sequences merge into one larger sequence because of the disappearance of intermediate silty/shale tops. The intermediate silty/shale tops are generally very thin and vary from 0.1 to 0.4 feet and the sequence bed thickness ranges from inches to tens of feet.

To better understand the turbidite sequences, a section of core from well OB2-3 was quantitatively analyzed for its reservoir characteristics. The cores were selected based on correlations between OB2-3 and old core photos, gamma ray and resistivity log data, and core gamma ray data from older wells. After slabbing and photographing the core-section, grain size analysis was used to identify and select several lithotype samples. Thirteen samples chosen included coarse grain, medium grain, fine grain, and silt/shale samples. The thirteen samples were taken from a typical four-foot sequence (measured
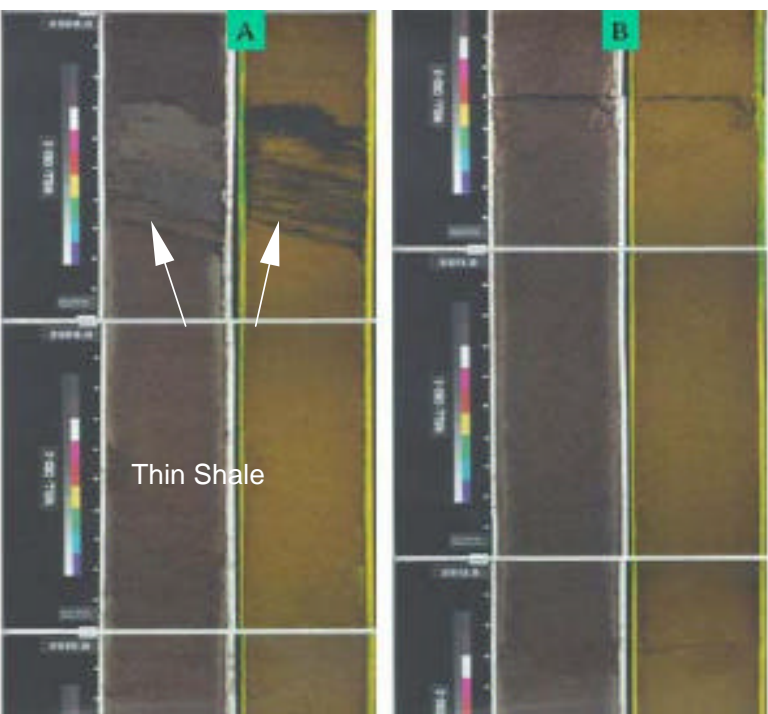

Figure 2.3.2-6: Tar II-A core photo of typical 4 ft turbidite sand sequence. depth 2508 - $2512 \mathrm{ft}$ ) close to the top of the D1 sub-sand was. Figure 2.3.2-6 is a photograph of this sequence. Two samples were taken from the 0.4 feet silty/shale located at the top and 11 samples from the 3.6 feet of sand. Detailed core analysis was performed on this sequence ${ }^{\mathrm{G} 28}$, which included grain size measurements, thin section and scanning electron microscope (SEM) photomicrograph analysis, and porosity and permeability measurements with the net overburden pressure (NOB) at 300 psi and 1800 psi with air and kerosene. The tests included measuring the changes in porosity and permeability over time (Creeping Effect) when the NOB pressure of 1800 psi was applied to a core sample. Each core plug was tested for 54 hours. Using the Dean Stark method, porosity decreased about $18 \%$ in both shales (from $42.8 \%$ to $35.2 \% \mathrm{PV}$ ) and sands (from $36.6 \%$ to $30.1 \% \mathrm{PV}$ ) with the highest reduction rate occurring during the first two minutes. The air permeabilities decreased about $90 \%$ in the shales and $62 \%$ in the sands with the highest reduction rate occurring during the first minute. Both the porosities and the permeabilities had very little change after 15 minutes. This represents a reasonable amount of lab time for additional core preparation before 
starting the routine core analysis work. The data were used to correct or normalize the previous core analysis data obtained at 300 psi to reservoir conditions at 1800 psi. See Appendix A for a detailed description of the laboratory procedures.

Before making the porosity and permeability measurement, nine of the thirteen samples were Dean-Stark cleaned with toluene and vacuum dried at $65.5^{\circ} \mathrm{C}$. The remaining four samples were solvent cleaned by either Advanced Core Analysis Method I or II. The Advanced Core Analysis Methods involved an exotic procedure for cleaning the core sample plugs with solvents to measure reservoir properties in-situ. The intent of the methods was to preserve the pore structure as well as possible. This method was effectively a solvent-based miscible flood of the core samples and was over ten times the cost of a typical core analysis job. Using solvent extraction or miscible cleaning tended to reduce measured porosity and permeability values compared to the other core analysis methods employed and was not necessarily considered more accurate.

The Method I procedure consisted of confining two of the samples at $1800 \mathrm{psi}$ of overburden pressure, then miscibly cleaning them in place using alternating cycles of toluene and methanol to measure porosity. The samples were dried in place by flowing dry nitrogen through the samples to measure air permeability. They were then flushed with kerosene to measure liquid permeability.

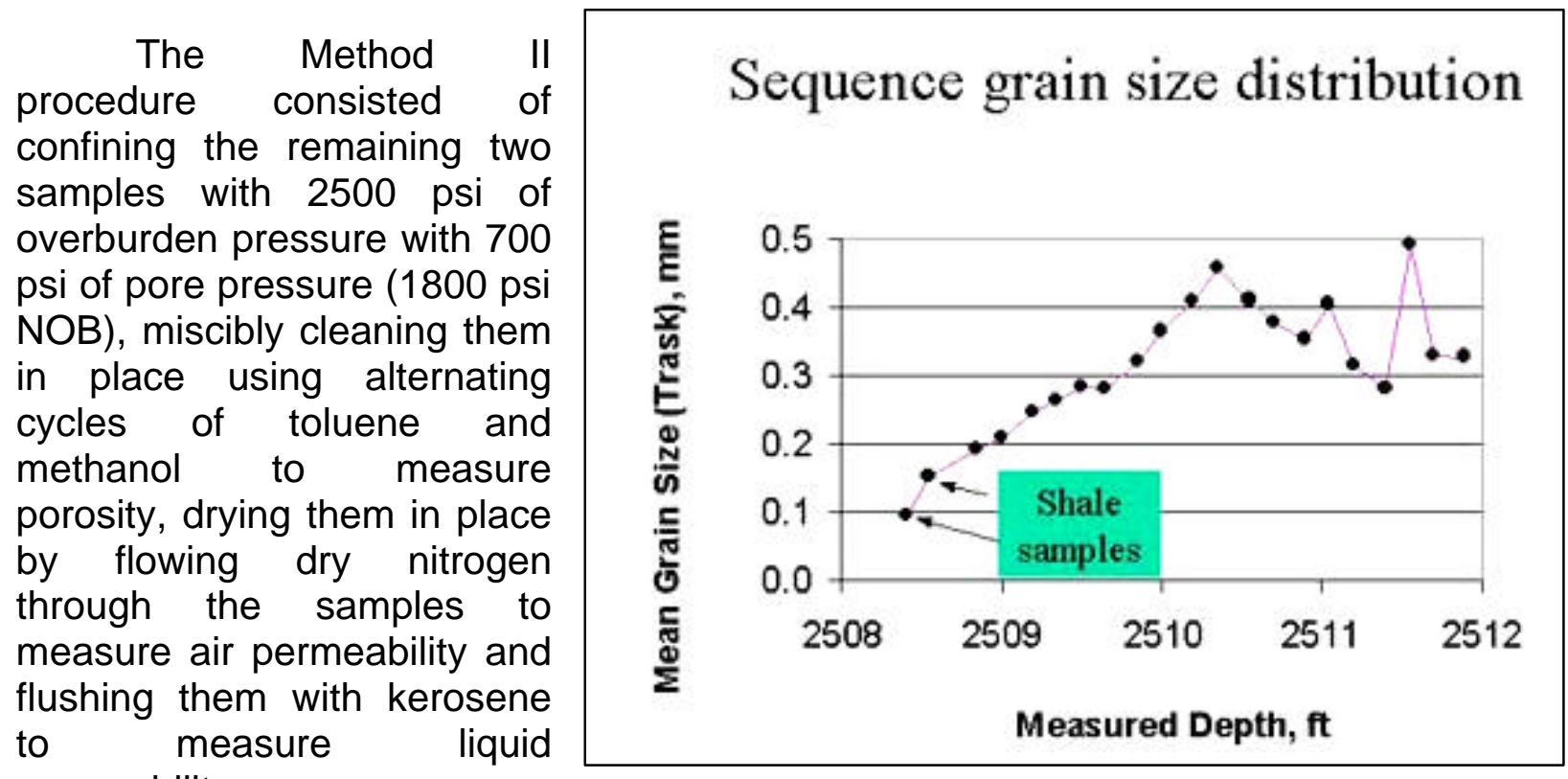

permeability.

Figure 2.3.2-7 is a plot Figure 2.3.2-7: Typical $4 \mathrm{ft}$ sand sequence showing grain size (y-axis) vs. depth (x-axis).

of the mean grain size vs. the measured depth. The silty/shales have the smallest mean grain sizes of 0.093 and $0.151 \mathrm{~mm}$. The sands have mean grain sizes that transition from finer-size grains of $0.193 \mathrm{~mm}$ at 2508.85 to coarser-size grains of $0.459 \mathrm{~mm}$ at 2510.35 feet. 
Figure 2.3.2-8 is a plot of the core porosity at 300 and 1800 psi vs. measured depth. The core porosity decreased as grain size increased. In addition, the core porosity decreased with an increase in overburden pressure. The average difference between the porosity at 300 psi and 1800 psi was a decrease of 6 pore volume units. The two-silty/shale samples had the highest porosity measurements $42.0 \%$ and $43.6 \%$ at 300 psi and $34.6 \%$ and $35.9 \%$ at 1800 psi. The sand porosity measurements using the DeanStark method at 300 psi overburden pressure ranged from $37.9 \%$ at the top of the sequence to $35.3 \%$ at the bottom of the sequence. The sand porosity measurements at 1800 psi overburden pressure ranged from $32.3 \%$ at the top of the sequence to $27.8 \%$ at the bottom. The Method I samples, at a depth of 2509.2 feet and 2510.0 feet, had porosity measurements at $300 \mathrm{psi}$ of $30.8 \%$ and $28.7 \%$ and at 1800 psi of $28.5 \%$ and $26.2 \%$ respectively. The Method II samples, at a depth of 2508.85 feet and 2510.35 feet, had porosity measurements at 300 psi of $32.2 \%$ and $29.2 \%$ and at 1800 psi of $29.7 \%$ and $26.7 \%$, respectively.

Figure 2.3.2-9 is a plot of the core Klinkenburg-corrected air permeability at 300 psi and Klinkenburg-corrected air and liquid permeability at 1800 psi vs. measured depth of the 13 samples. The silty/shale samples had the lowest permeability values of 19.3 $316 \mathrm{md}$ air for 300 psi overburden

\section{Sequence porosity distribution}

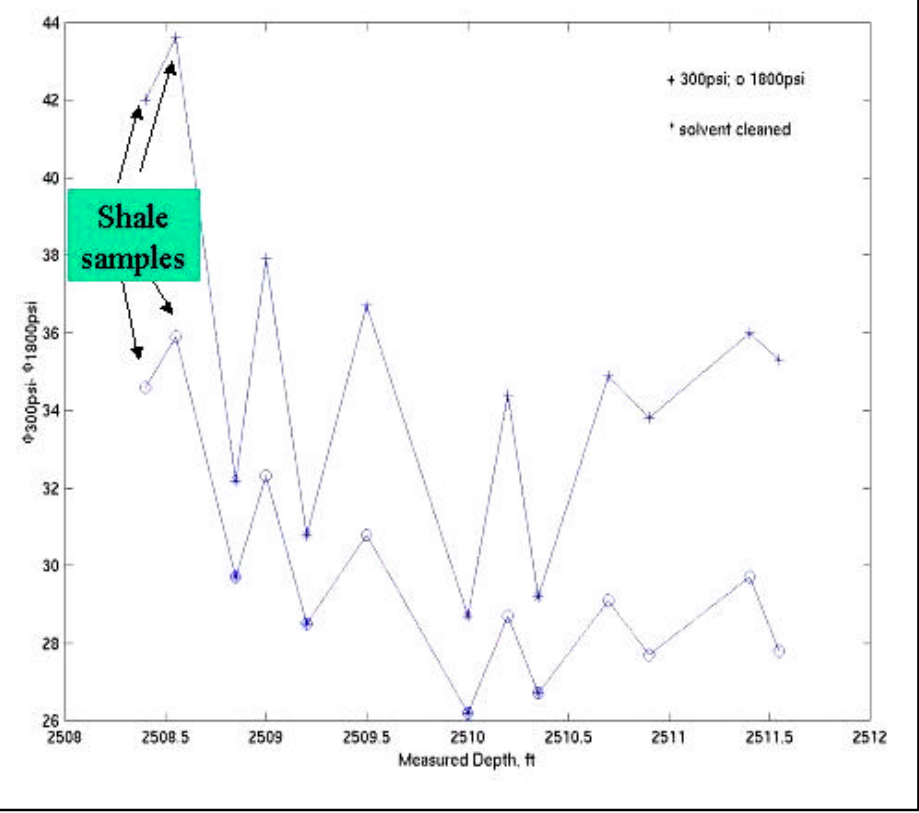

Figure 2.3.2-8: Typical $4 \mathrm{ft}$ sand sequence showing porosity (y-axis) vs. depth (x-axis).

\section{Sequence permeability distribution}

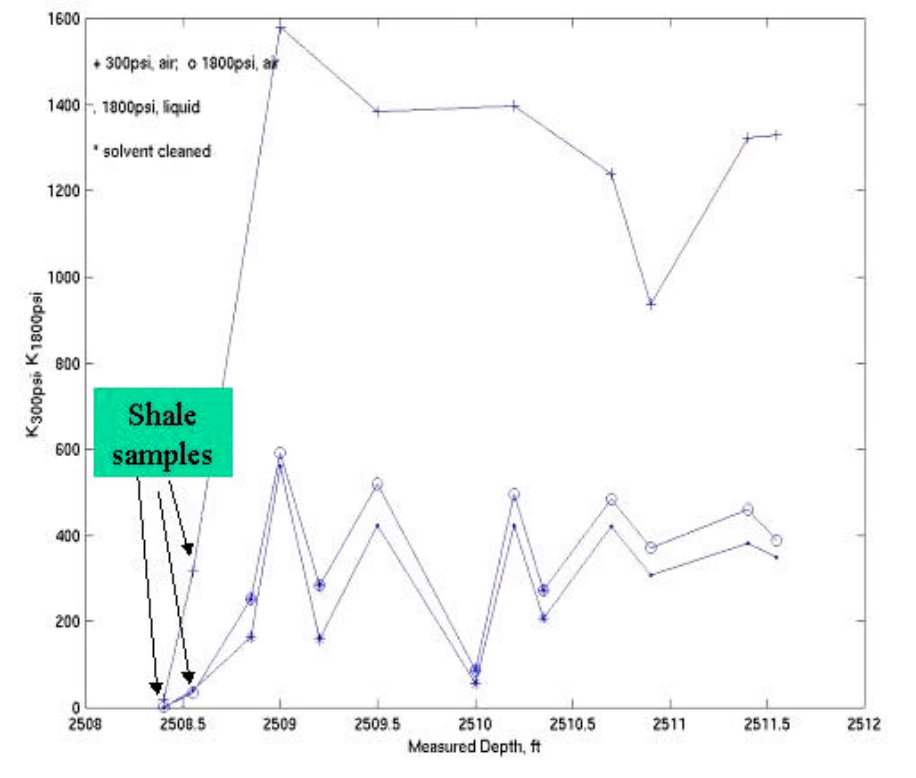

Figure 2.3.2-9: Typical $4 \mathrm{ft}$ sand sequence showing Klinkenburg-corrected permeability (y-axis) vs. depth (x-axis). 
pressure, 1.21 - $34.9 \mathrm{md}$ air for 1800 psi overburden pressure, and 0.6 - $40.8 \mathrm{md}$ liquid for 1800 psi overburden pressure. The sand samples cleaned with the Dean Stark method and at 300-psi overburden pressure had the highest air permeabilities ranging from $936-1581 \mathrm{md}$ and at 1800-psi the air permeabilities ranged from $370-591 \mathrm{md}$. The liquid permeabilities of the sand samples cleaned with the Dean-Stark method at 1800 psi overburden pressure were lower, ranging from $307-560 \mathrm{md}$; and the Methods I and II 1800-psi air and liquid permeabilities were the lowest for the sands, ranging from 56 - $284 \mathrm{md}$.

Contrary to "common" reasoning, the finer grain sands had higher permeability and porosity than the deeper coarser grain sands at the bottom of the turbidite sequence. This was attributed to better sorting of the sand grains.

Based on the above observation, the shales were initially separated from the sands for creating the stochastic geologic model because the shale/silty top is thin and only counts for less than $5 \%$ of the formation thickness and the sand portion of the sequence has relatively homogeneous properties in contrast to the shales. This implies that in the blocky sand model the volume contribution of the shale/silty top can be ignored and each formation interval can be treated as a stationary 3-D field. The shales were to be modeled independently because of their very low permeability and their affect as a vertical barrier to steam. After the shales are mapped, they can be imbedded into the blocky sand model for future up scaling.

\section{Preparing Data for Stochastic Modeling}

In order to develop a successful stochastic model, a minimum number of data points are needed to obtain a correlation function (variogram) and to condition the images. Using data only from the cored wells are hard to satisfy this requirement because of its expensive acquisition cost. The well logging data for the Tar II-A formation provided a proper amount of data if it could be calibrated to the core data. The basic procedure is to: 1). Select representative core samples and perform porosity and permeability tests under reservoir conditions to obtain reservoir property data for the sands and silty/shales. 2). Calibrate the density/neutron log porosity data with core porosity data. 3). Correlate the core permeabilities with other calibrated logging-derived information such as porosity or volume shale indicators. The core-corrected logging data can then be converted to reservoir property data, such as porosity and permeability, for the sands and silty/shales. Once this is completed, a stochastic geologic model can be developed. The next three sections discuss the three procedures for calibrating log data to the core data.

\section{Correcting Conventional Core Analysis Data to Reservoir Conditions}

Ten of the twelve wells cored in the Tar II-A were analyzed for porosity and permeability (850 data points) at a "routine" triaxial stress of $300 \mathrm{psi}$, or enough to keep the unconsolidated core sample together. The routine stress method yields much higher measured porosity and permeability data than at reservoir overburden stress conditions, estimated to be $1800 \mathrm{psi}$. This routine core analysis data was corrected to 
reservoir overburden stress conditions by correlating the porosity and permeability data obtained from the thirteen core samples measured at both 300 (routine method) and 1800 psi overburden pressures (reservoir stress conditions) as plotted in Figure 2.3.2-10 and Figure 2.3.2-11, respectively. Good correlations exist for both porosity and permeability. The routine porosity data requires approximately seven units of reduction to be normalized for reservoir stress conditions. The permeability under reservoir conditions is approximately $30.3 \%$ of the rate measured under "routine" methods. These correlation functions were used to correct more than 850 routinely analyzed core samples to reservoir conditions. The corrected core porosity and permeability data were then used to calibrate and correlate the well log data.

Core Photo DepthShifting to Match Log Measured Depths

The core depths measured on the drilling rig must be depth-shifted to agree with the well log depths to have valid correlations between core and log data. The

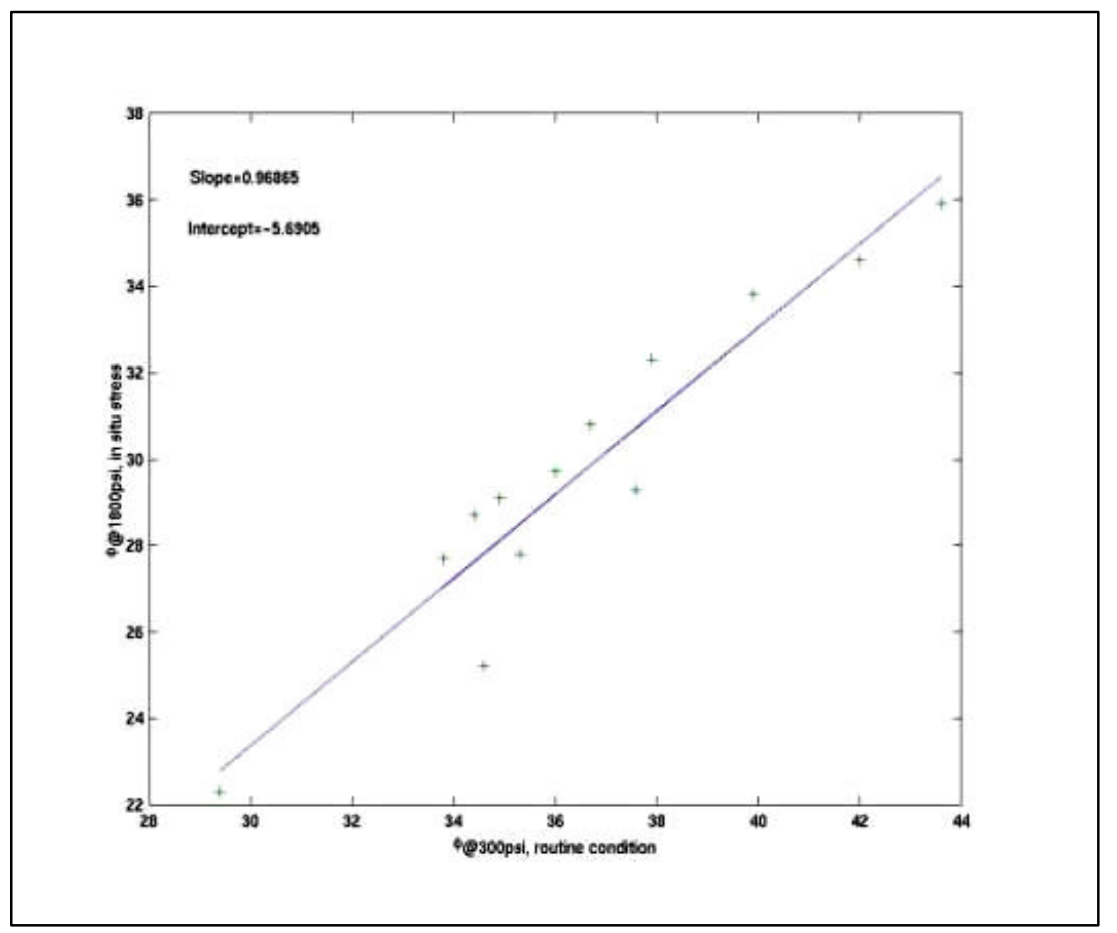

Figure 2.3.2-10: Use of special core analyses data to convert routine $\mathbf{3 0 0}$ psi core porosity data (x-axis) to in situ stress conditions (y-axis).

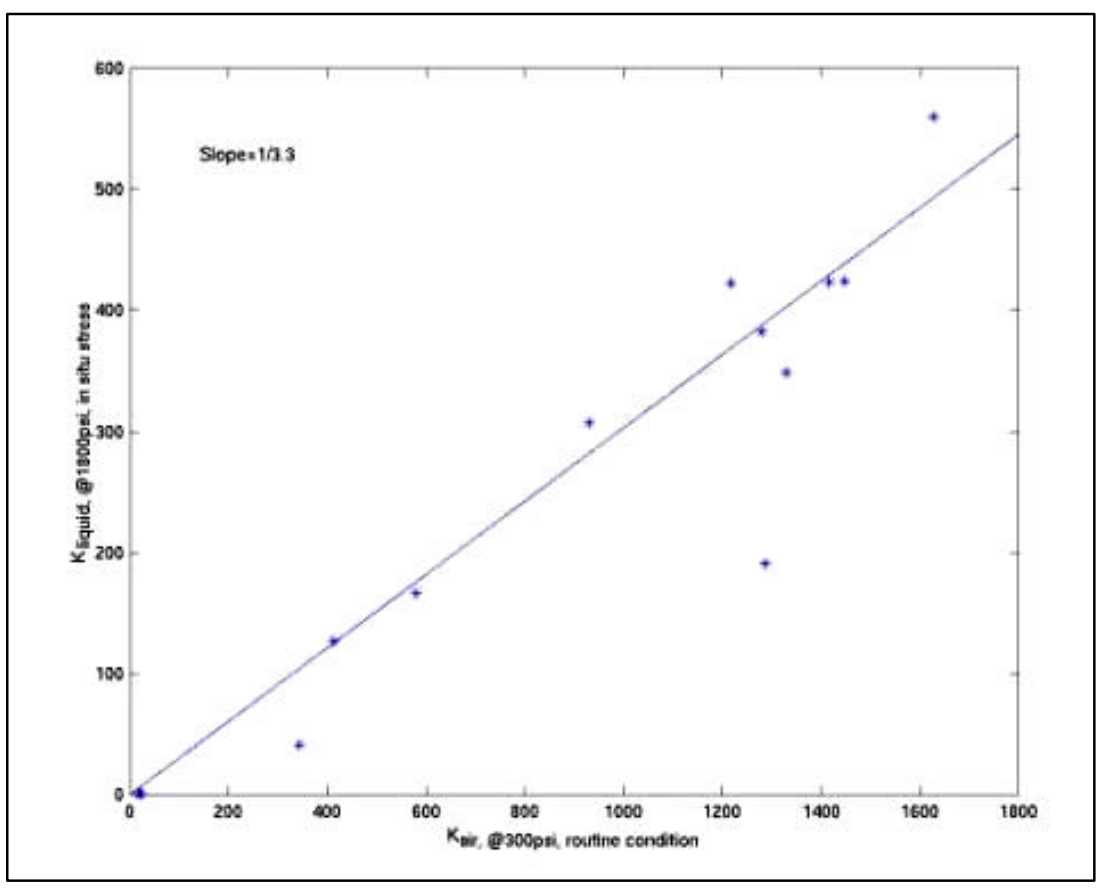

Figure 2.3.2-11: Use of special core analyses data to convert routine 300 psi permeability core data (x-axis) to in situ stress conditions (y-axis). 
measured core depths labeled on the core barrel when coring the well did not account for lost core or core expansion when the cores were brought from reservoir conditions to surface conditions. Each individual core barrel had to be depth shifted to the logs. The digitized log data is recorded every six inches, even though the accuracy of the various logs is to the foot or two feet. Therefore, even a six-inch discrepancy between the core and log depths could make a significant statistical difference in the correlation results.

A correlation study of the core photos and well log response revealed that the crossover depth of the shallow resistivity and deep resistivity curves had a very good correlation with shale streak depth on the core photos. This knowledge was very helpful and heavily used in adjusting the core depths based on the core photos. The shale streaks were easily counted in a long continuous core section. The following is the procedure for adjusting the core-measured depths to measured log depths: First, correlate the thick major shale marker depths of the core with the logging depths. Second, compress or expand the sand depths on core photos between shale marker depths. Third, compare the resulting number of shales and sand sections with the crossover depths of shallow and deep resistivity logging curves. Fourth, correlate the core analysis data and its corresponding corrected depths with the digitized well log data. Fifth, correct all core photos measured depths using this technique.

\section{Calibrating Log Density Porosity $\phi_{d}$ with Corrected Core Porosity $\phi_{\text {core }}$}

Cross-plots of the depth-shifted and reservoir corrected core porosity data (850 data points) vs. the corresponding density and neutron porosity log data show that the core porosity has a better correlation with the density log porosity. Figure 2.3.2-12 is a crossplot of the core porosity ( $\left.\phi_{\text {core }}\right)$ vs. density log porosity $\left(\phi_{d}\right)$ in the D1 sub-zone sands. The $\phi_{\mathrm{d}}$ and $\phi_{\text {core }}$ data points appear as a cloud around a one to one correlation slope line with the arithmetic means of the density porosities slightly higher than the core porosities. The mean of the $\phi_{\text {core }}$ was 0.276 and the mean of the $\phi_{d}$ was 0.290 . The deviant data points in the upper left quadrant are from

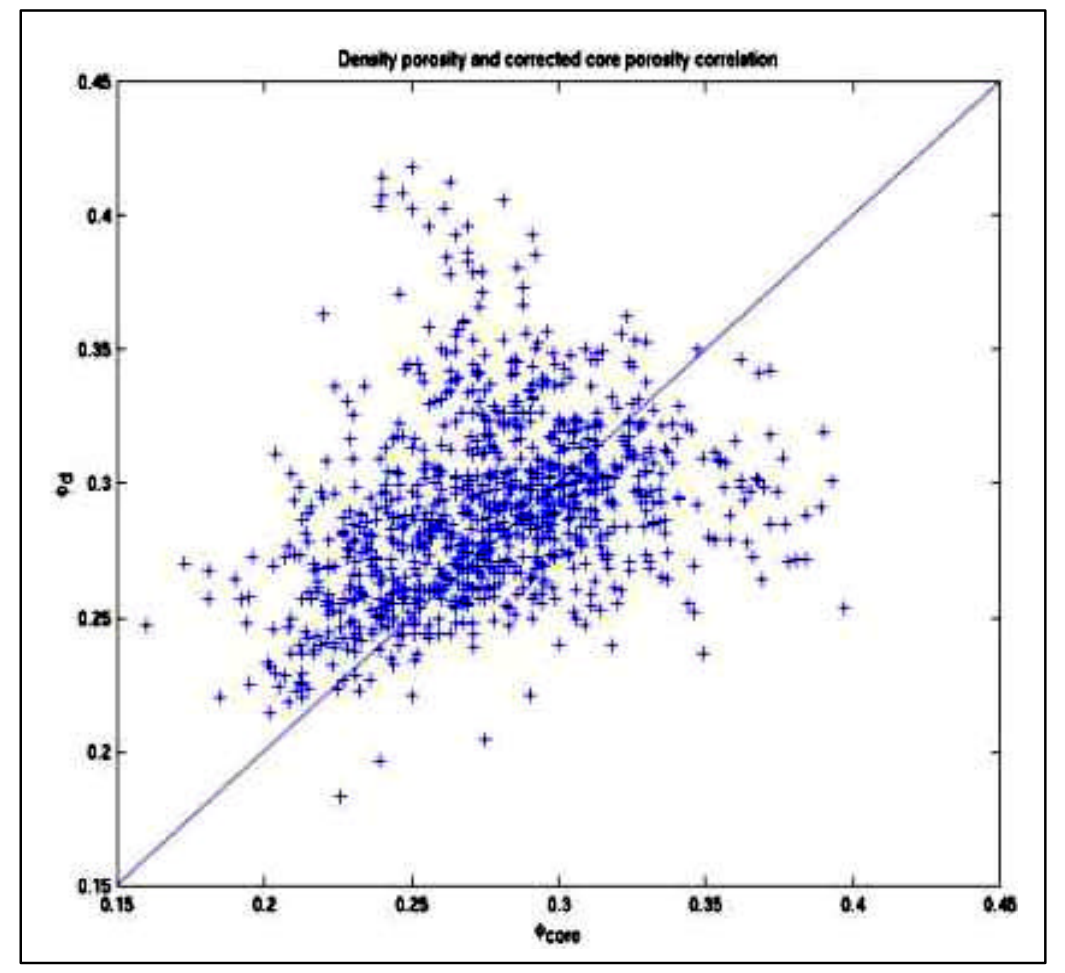

Figure 2.3.2-12: Correlation of core porosity (x-axis) vs. density log porosity (y-axis) in the D1 sub-zone sands. 
the shale sections of wells 2AT-052 and UP-919. The density log porosities for shale were much higher than the corresponding core porosities and accounted for the slightly higher average porosity readings. Comparing log and core porosities for shale is problematic because each method measures different types of porosity. The log porosity would be higher because the density log includes bound water porosity whereas the core porosity may be lower because of the low permeability of shale and the bound porosity is not measured. This problem does not exist in the D1 sub-sand modeling because the volume of silty/shales is not significant. The deviant data points in the lower right quadrant are mostly from well UP-908. Before coring UP-908, the D1 sub-sand in well UP-908 was under steamflood. The steam chest caused the density log porosity values for both the sand and the shale sections to be low, especially the shales. Without further valid lab results to support any modification, it was concluded that the density log porosity did not need further calibration and was used in building the stochastic porosity model.

Figure $2.3 .2-13$ is a revised plot of all the D1 subsand porosity log data points except for the data from UP908 and any shale data points from the other wells. The $\phi_{\text {core }}$ and the $\phi_{d}$ now have a better correlation trend.

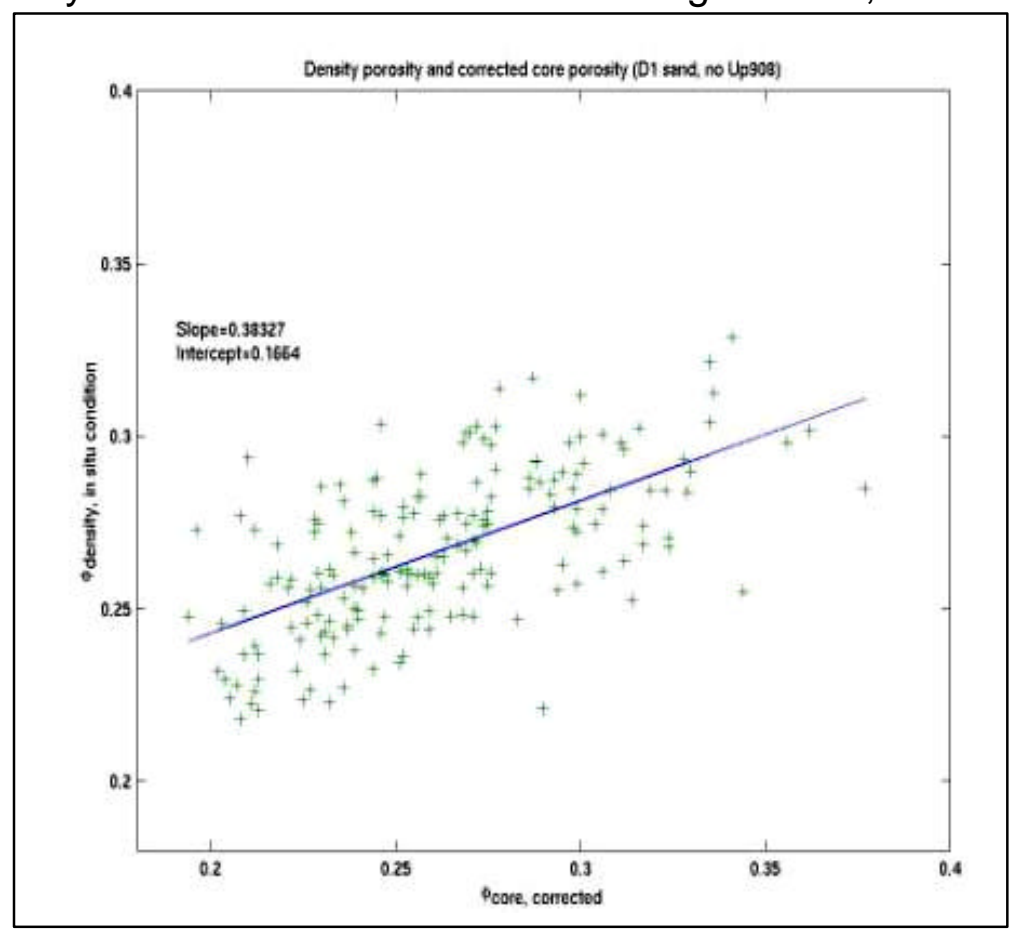

Figure 2.3.2-13: Revised correlation of core porosity and logging density porosity for D1 sand section.

\section{Estimating Permeability with Density Log and Core Data}

One of the major tasks for developing a stochastic model was to get a 3-D permeability field. Since there are no direct logging measurements for permeability with the available well logs, an algorithm for estimating permeability needed to be derived using the available digitized log and core data. The first step was to derive a porositypermeability correlation from the 850 corrected core data points in the D1 sands. Figure 2.3.2-14 is a plot of the core porosity at 300 psi corrected to an overburden stress of 1800 psi vs. air permeability at 300-psi corrected to 1800-psi liquid permeability. The correlation is widely scattered with multiple permeabilities for the same porosity. The permeability varies largely as a function of rock type in the Tar Zone. Intervals with identical porosity values will have different permeability values because they contain different rock types ${ }^{\mathrm{G} 37}$. Based on a combination of lithology (from macroscopic core analysis) and image analysis of pore body and pore throat size, five rock types have 
been quantitatively identified in the Tar IIA sands. Rock type 1 is clean sandstone with less than $5 \% \mathrm{~V}$ shale, pore body diameters ranging from 50-150 $\mu \mathrm{m}$, and pore throat radii of 5$10 \mu \mathrm{m}$. Rock type 2 is clean sandstone with less than $5 \% \mathrm{~V}$ shale, pore body diameters from 20-50 $\mu \mathrm{m}$, and pore throat radii of $2-50 \mu \mathrm{m}$. Rock type 3 is clean sandstone with less

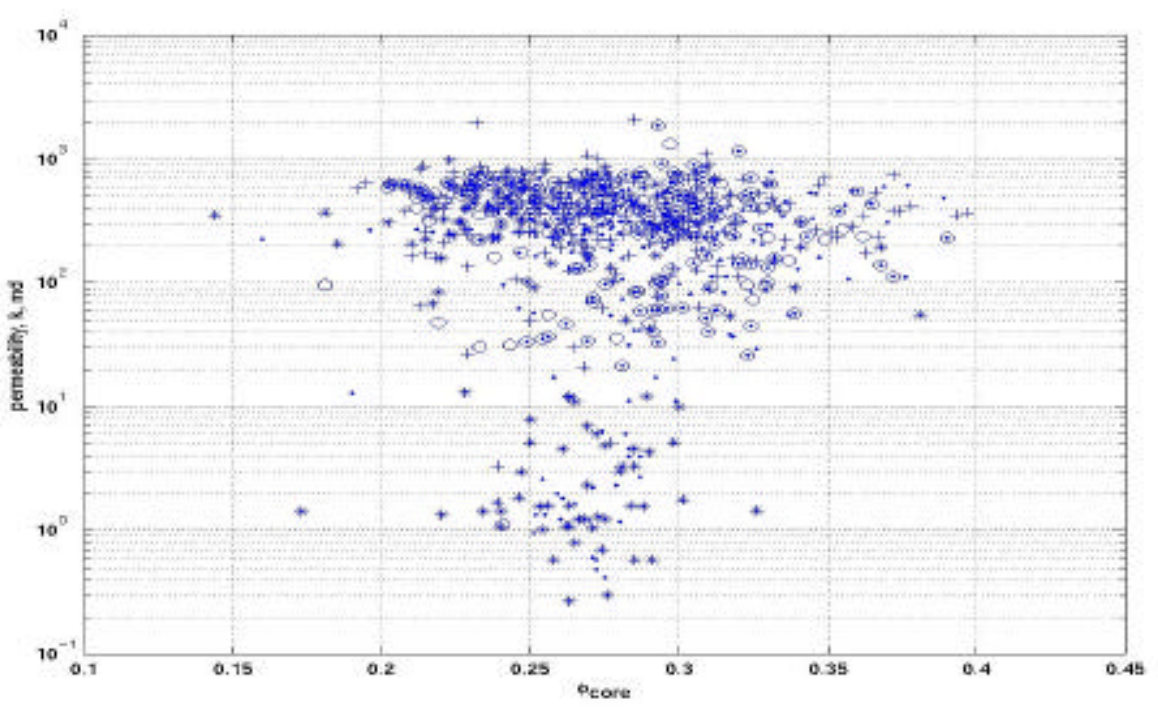

Figure 2.3.2-14: Correlation of core porosity (x-axis) vs. density log porosity (y-axis) in the D1 sub-zone sands than $5 \%$ V-shale, pore body diameters from $10-20 \mu \mathrm{m}$, and pore throat radii of $<2 \mu \mathrm{m}$. Rock type 4 is shaly siltstone/sandstone with $10 \%$ to $40 \% \mathrm{~V}$-shale, pore body diameters of $<5 \mu \mathrm{m}$, and pore throat radii $<1 \mu \mathrm{m}$. Rock type 5 is shale with greater than $40 \% \mathrm{~V}$-shale.

The second step was based on the knowledge that shaliness has significant influence on permeability. Many shaliness indicators have been derived and their correlations with permeability have been studied. Those indicators include neutron porosity $\phi_{n}$, normalized neutron porosity $l_{n}$, porosity difference $\delta \phi\left(\phi_{n}-\phi_{d}\right)$, normalized porosity difference $I \delta \phi$, gamma-ray $\gamma$ and normalized gamma-ray $I \gamma$. Wellbore collapse and the presence of steam heat in the near wellbore region have a significant influence on $\phi_{n}$ and these factors should be accounted for if present while logging. Some sections of logging curves were replaced with non-values to eliminate any influence of the bad data.

Similar to the core and density log porosity correlation, the liquid permeability data must be depth-shifted to match the corresponding depths in the shaliness indicators logs. Figure 2.3.2-15 is a plot of the normalized neutron porosity data, $I \phi_{n}$ vs. the core air permeability at 300 psi corrected to a liquid permeability at 1800 psi. Figure 2.3.2-15 has a better correlation than Figure 2.3.2-14 but still has scattered data points with multiple permeabilities for the same $I \phi_{n}$ value due to the data being from multiple rock types. In general, the higher the shaliness values, the lower the permeability. The low permeability values at lower $I_{n}$ occurred when the shale streaks in the reservoir were too thin to be detected by the neutron porosity logging tool i.e. 0.2 foot shale within a $2 \mathrm{ft}$ sand interval. The thin shaly beds that were not detected by the neutron porosity tool made correcting the core measured depths more difficult. The high permeability values at high shaliness values occurred when the sand beds were getting thinner and the shale beds were over-influencing the neutron porosity measurements. An important 
observation is that when a relatively thin sand bed has a shaliness factor of $0.4<\left.\right|_{\mathrm{n}}<0.7$, its permeability is still closer to that of a clean sand. When $\phi_{\mathrm{n}}$ is greater than 0.7 , the sand quality falls into a silty-shaly sand category (rock type 4 or 5).

The correlations of permeability versus $I \phi_{n}$ and $I \delta \phi$ are shown in Figure 2.3.2-16 and Figure 2.3.2-17 for the D1 sands after deleting low permeability and other deviant data points. Some cores with permeability less than $100 \mathrm{md}$ were believed to have come from disturbed shale tops. These correlations were used to generate a porosity - permeability cloud transform to simulate a permeability field using a Sequential Gaussian Simulator.

Used to build porosity and permeability stochastic models, the corrected porosity and permeability data generated in the above procedures was imported to the GOCAD Simulator. The 3-D Stochastic Reservoir Simulation Model will contain these stochastic models.

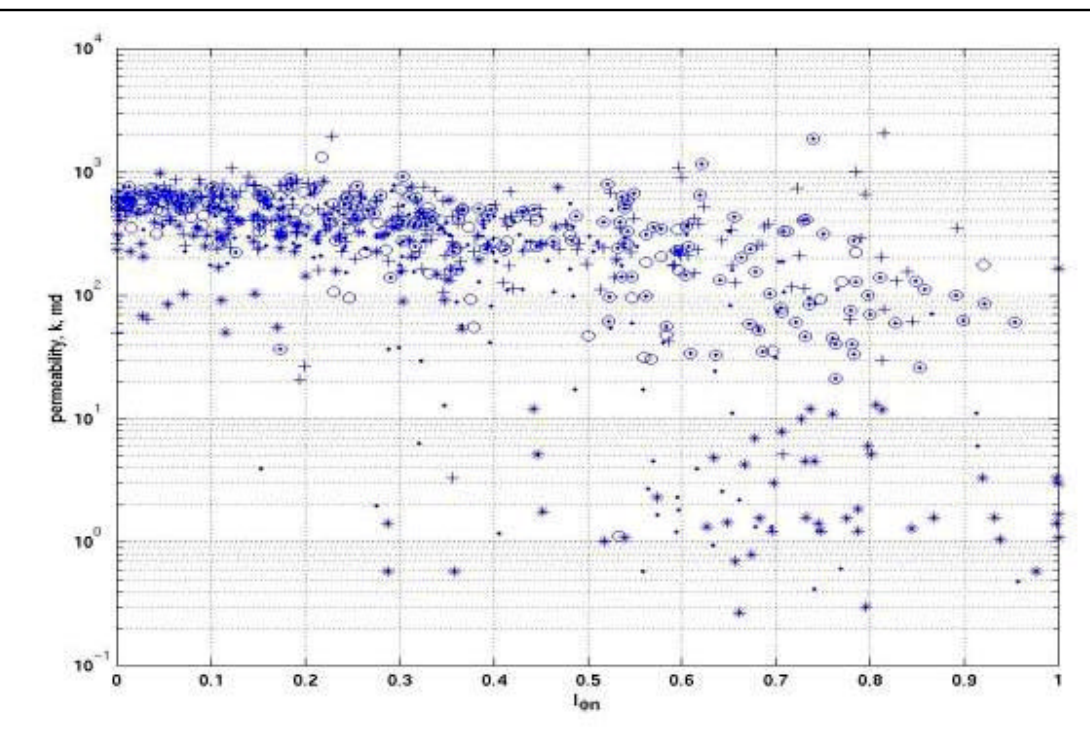

Figure 2.3.2-15: Permeability (y-axis) versus shaliness indicator I $\phi_{\mathrm{n}}(\mathrm{x}$-axis).

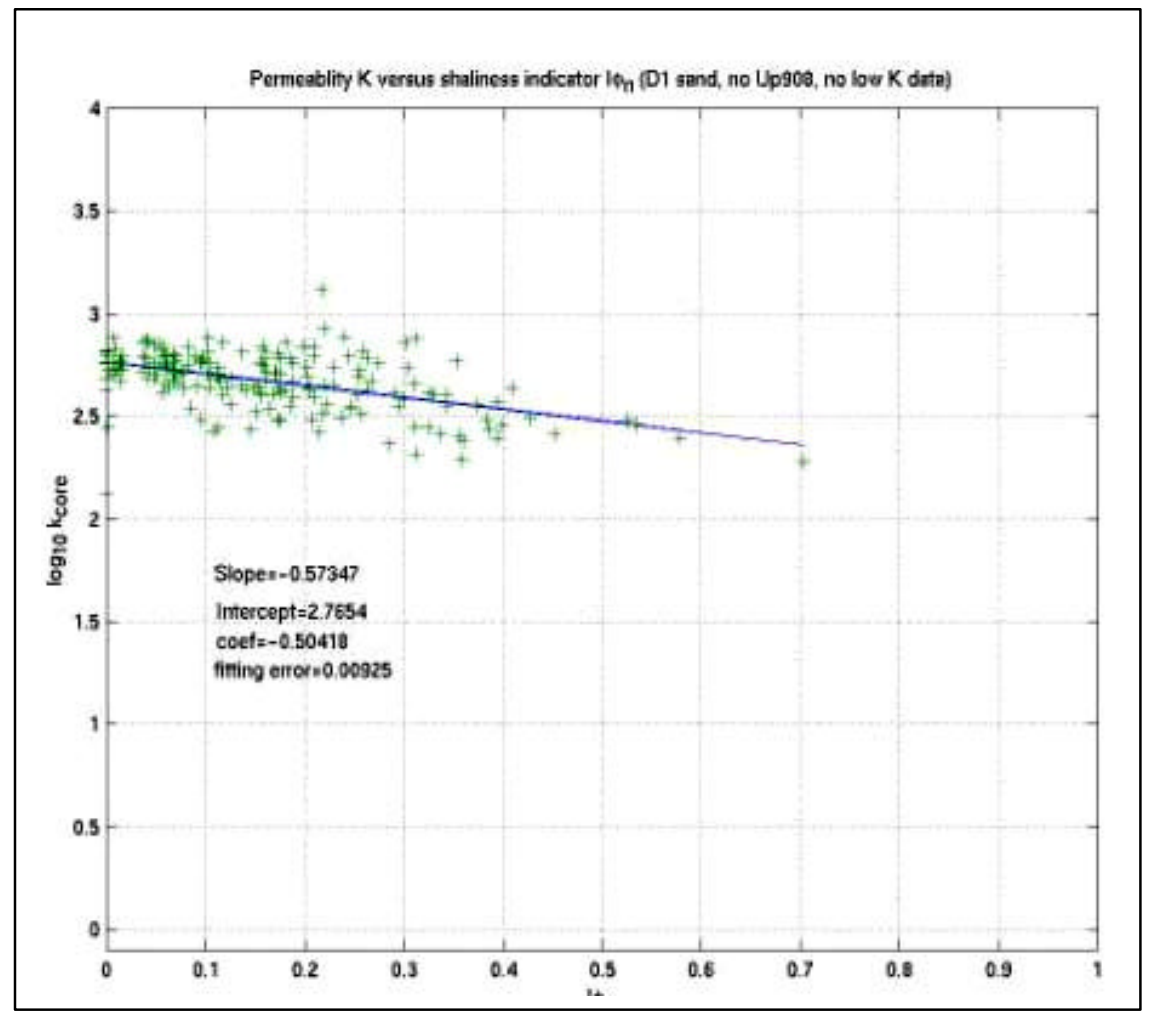

Figure 2.3.2-16: Correlating permeability (y-axis) vs. shaliness indicator I $\phi n$ (x-axis) for the D1 sands, with some low permeability data points deleted. 


\section{Conclusions}

1. A geologic model consisting of a deep marine turbidite deposition can be successfully translated into discrete reservoir property data through the use of available core and log data. Based on the sequence evaluation results, the Tar Zone stochastic model was de-coupled into a turbidite top shale model and a sand model.

2. Correlations to
convert "routine" core
porosity and permeability
data analyzed under 300 psi stress conditions to reservoir overburden stress conditions were successfully developed. These correlations were used to convert more than 850 routine core porosity and permeability data to reservoir conditions.

3. The density log, with some corrections, provided relatively accurate porosity data when compared with the stress corrected and depth-shifted core data.

4. A log-based method for determining formation permeability was derived by correlating log porosity shaliness indicators with the core permeability data. The procedure and correlations can apply to similar fields.

5. Discussion of detailed porosity and permeability stochastic modeling processes.
Figure 2.3.2-17: Correlating core permeability (y-axis) vs. shaliness indicator $I \delta \phi$ (X-axis) for the D1 sands, with some low permeability data points deleted. 


\subsubsection{Core-log Analysis Study by Dave Davies}

Techniques of reservoir description were based on the detailed analysis of: i) small rock samples, taken from existing conventional cores from ten wells, and ii) wireline logs. The cores represented pre- and post-steam conditions in the reservoir. Emphasis was placed on measurement of pore geometrical characteristics, particularly pore body size, using a scanning electron microscope that was specially equipped for automated image analysis procedures. An understanding of pore geometrical characteristics was fundamentally important to reservoir characterization because the displacement of hydrocarbons was controlled at the pore level. Quantitative analysis of pore geometry was used to develop the vertical layering profile in cored intervals. This profile was developed for all wells (cored and non-cored) and was used as the basis for lateral correlation of flow units.

The specific analyses and data sets used in the study included:

1. Routine measurements of porosity and permeability, undertaken by an independent laboratory that specialized in analysis of "soft" (friable) core samples.

2. Detailed macroscopic core description to identify vertical changes in texture and lithology for all cores.

3. Petrographic analysis of 100 small rock samples taken from the same locations as the plugs were used in routine core analysis. The work Included thin section point count, $X$-ray diffraction and scanning electron microscope analysis (secondary electron imaging mode - SEI). The analysis provided direct measurement of V-shale, V-clay, grain size, sorting and overall composition for the 100 core samples.

4. Rock Types (intervals of rock with unique pore geometry) were identified for each of the 100 rock samples using i) data on pore body size as measured directly during automated image analysis in the scanning electron microscope (back scatter electron mode -- BSE) and ii) pore throat size as determined from direct measurement in the scanning electron microscope (SEI mode) and from the results of capillary pressure analysis of selected samples.

5. Algorithms were developed that relate porosity and permeability for each Rock Type in cored wells.

6. Log analysis was performed using normalized and environmentally corrected logs. The log shale indicators were calibrated to data from petrographic analysis, specifically $\mathrm{V}$-shale from thin sections, to allow for improved accuracy in the determination of porosity.

7. Identification of Rock Types using log responses in cored intervals, and comparison with core data.

8. Extend the rock-log model to all wells with sufficient logs in the field. Specific algorithms were developed that allow for the identification of Rock Types from log data.

9. Predict permeability, foot-by-foot, in all wells using algorithms that relate porosity to permeability by Rock Type.

\subsubsection{Porosity-Permeability Model}


The statistical relationship between porosity and permeability is generally recognized to be asymptotic when plotted arithmetically. For values of porosity between $0 \%$ to $\pm 5 \%$ porosity, the rate of permeability increase is low (the least squares line has low slope). For porosity values between \pm 5 to $25 \%$, the rate of permeability increase is relatively high (the least squares line has high slope). Above $\pm 25 \%$ porosity, the rate of permeability increase is also low.

Routine core analysis data from Tar II-A reveals that all rock samples have high values of porosity, generally $>25 \%$. This is confirmed by log analysis. The relationship between porosity and permeability in the Tar II-A reveals that:

i) Between values of $25 \%$ and $40 \%$ porosity, values of permeability increase slowly as predicted from general theory; and

ii) The basic relationship exhibits a considerable degree of scatter (more than 3 orders of magnitude variation in permeability for a given value of porosity).

The wide dispersion of porosity / permeability data reflects changes in the distribution of pore types (pores with bodies and throats of varying size) within the Tar II-A. The co-ordination number (number of pore throats per pore) is uniform for all pore types $( \pm 6)$. The difference between the pore types is the pore body size and the size of the pore throats that interconnect the adjacent pores. Virtually all pores in the sandstones (>95\%) are of primary intergranular origin.

Permeability varies largely as a function of pore geometry in the Tar II-A. As stated previously, lithologic intervals with identical porosity values can have significantly different values of permeability. When formation samples are categorized by similar pore body and pore throat sizes, porosity and permeability become more closely related. For purposes of this study, five petrographic categories were identified and called Rock Types. Permeability and porosity are only weakly related to grain size. Sorting (standard deviation of grain size) and skewness (asymmetry of the grain size distribution) are the fundamental controls on porosity and permeability.

Algorithms have been developed that relate porosity to permeability for the four sandstone Rock Types with routine core analysis measurements (Rock Types 1 through 4). Porosity / permeability algorithms for values of porosity $>25 \%$ are based on the measured core data. No core data exists for low porosity rock in this area. No petrophysical measurements exist for Rock Type 5 (Shale) and permeability has been estimated as $<0.01 \mathrm{md}$ based on measurement of pore throat size from direct scanning electron microscope analysis.

One factor of major concern in high porosity, friable rocks is the reliability of the core- measured values of porosity and permeability. Petrographic analysis reveals that the productive sandstones (Rock Types 1,2 and 3) are virtually devoid of antigenic cements and generally contain $<1 \% \mathrm{~V}$-shale (measured directly in rock samples). The rocks consist almost exclusively of sand grains and heavy oil. Laboratory cleaning of the samples with solvents prior to routine analysis removes the oil. Thus, the potential 
exists for grain movement and reorganization that could significantly affect measurement of petrophysical and petrographic properties. The core analysis results were evaluated for this potential problem and were considered valid for the following three reasons:

1) Comparison with data from other fields: Published core measurements of porosity and permeability from similar reservoirs (high porosity, heavy oil) in California display the same general data dispersion as observed in the Tar II-A. By itself, this may simply reveal that the same problems exist in all data sets, irrespective of operating company and field. Thus, additional lines of reasoning are required.

2) The specific environment of deposition of each cored sand bed in the Tar II-A has been identified (for example, mid fan and outer fan turbidites and basin plain sediments have been differentiated in all cores). Comparison of the sand grain density and pore geometry with environments of deposition reveals a close relationship between depositional environment and the five Rock Type categories. Each Rock Type has a distinct range of permeability values and a relatively good and unique correlation between permeability and porosity.

3) There are obvious textural differences between each Rock Type. The grain size and sorting of the samples are not affected by sample cleaning.

Petrographic analysis revealed that some of the samples were obviously damaged during sampling or analysis. The data for these samples were removed from the data set used in this study.

\subsubsection{Rock-Log Model}

A petrophysical rock-log model ${ }^{\mathrm{A} 21-22,} \mathrm{C} 6, \mathrm{C}^{2} 2$ was completed that provides a consistent procedure to describe the sands and shales within the "T" and "D" formations using only log data. Five (5) Rock Types were quantitatively identified in the Tar II-A on the basis of pore body size, pore throat size and lithology (from core analysis data). Rock Types 1, 2 and 3 (shale-free sands) are differentiated solely based on measured pore geometrical characteristics. The pore geometry in these sandstones is a function of textural controls, specifically median grain size and sorting (standard deviation and skewness of grain sizes). These characteristics can be readily identified in thin section analysis. There is no compositional difference between each of these Rock Types. Rock Type 1 is well sorted and has a coarser grain size than Rock Type 2. Rock Type 3 is finer grained and more poorly sorted than Rock Type 2 . In these rocks, the pore size decreases with a decrease in grain size and with an increase in the standard deviation of the grain size. The textural changes are directly related to depositional environment. Rock Type 1 is most common in proximal mid fan turbidites (>95\% of all samples of Rock Type 1 are restricted to this facies). Rock Types 2 and 3 are most abundant in mid fan to outer fan turbidites, respectively. Rock Types 4 and 5 can be readily differentiated based on grain size and total shale content. These differences are also related to depositional environment. Rock Type 4 is commonly associated with outer fan turbidites while Rock Type 5 consists of shales of the basin plain environment. 
Rock Types 4 and 5 are also differentiated lithologically, specifically the volume of shale (Rock Type 4, V-shale 5 to 40\%: Rock Type 5, V-shale >40\%).

The pore structure of each Rock Type has also been determined using nuclear magnetic resonance (NMR) analysis, specifically T2 relaxation time. Each Rock Type is characterized by a distinctly different $\mathrm{T} 2$ relaxation time, indicating differences in the pore geometry of the Rock Types. The wide dispersion of porosity / permeability data reflects these variations in pore geometry.

Individual Rock Types are identified using specific "cut-off" values based on analysis of environmentally corrected and normalized well log responses and using the comparison of the core-based determination of Rock Type. Rock Types 1 through 4 are identified using a cross-plot of apparent grain density versus the logarithm of the absolute value of the separation between Rxo and Rt. Rock Type 5 (shale) is identified using gamma ray readings $>37 \mathrm{API}$ units based on macroscopic core description. Rock Types can be identified, foot-by-foot, in all wells with a sufficient logging suite. Since Rock Type and porosity can be determined from well log response, permeability can be predicted using well log response only.

Log-based predictions of Rock Types and permeability document the field-wide, lateral and vertical distribution of reservoir quality in the Tar II-A sands. The D Sand interval has lateral and vertical changes in sand thickness, Rock Type, porosity and permeability. The D Sand interval in Well UP931 (located close to sediment source) is relatively thin, but has a significantly greater proportion of Rock Type 1 and therefore higher permeability than the thicker $D$ Sand interval penetrated in wells drilled further to the West (UP911, 2AT21B). This work showed that i) variations in the proportions of Rock Types and permeability thickness occur laterally in the field, and ii) allows a distinction to be made between wells that are poor producers because of low permeability and wells that are damaged. The reasons for variations in the distribution of Rock Types across the field have been evaluated through detailed analysis of depositional environments and sediment grain size.

Defining the five rock types with similar log and reservoir characteristics is critical for the stochastic geologic modeling as it provides an objective means of predicting petrophysical rock types and permeability profiles for "T" and "D" sands in locations where only minimum log data and no core data are available. The model has been applied to uncored wells within the area to aid in reservoir description and permeability modeling for the stochastic and reservoir simulation models. Another important outcome of this study is that traditional log analysis techniques can significantly overestimate shale content and consequently underestimate oil saturation and net oil sand picks in thin-bedded sands. This modeling technique corrects for that problem.

The rock-log model provides a means to determine the geometry, internal heterogeneity and permeability distribution in a deep water, unconsolidated turbidite sand reservoirs of Wilmington Field, California. These reservoirs were deposited in a variety of environments associated with a deep-sea submarine fan system. The 
external form and internal heterogeneity of the reservoirs is controlled fundamentally by depositional environment. Production (rate and volume) is anisotropic and parallels the depositional trends. Tar II-A production data indicate relatively high sweep efficiency and preferential permeability in a NE-SW direction (down depositional dip).

\subsubsection{V-Shale Model}

One of the evaluation problems in the Tar Zone is that traditional log interpretation techniques yield incorrect values of shale volume. An average V-shale of $17 \%$ is computed using traditional log analysis techniques. The traditional analysis also shows shale volume varying with slight fluctuations in log responses. This is a significant error because the clean Tar II-A sands contain $<1 \% \mathrm{~V}$-shale, based on direct measurement of rock samples using thin section analysis. To correct the problem, log shale indicators have been calibrated to actual values of measured shale from core petrographic analysis. The reasons the logs are reading $\mathrm{V}$-shale incorrectly are because their resolutions cannot differentiate the thin bed effects within the formation and because they are affected by non-shale components (radioactive sand grains such as orthoclase feldspar, mica and metamorphic rock fragments: heavy minerals such as siderite, pyrite: grains with high Hydrogen content -- altered metamorphic and igneous rock fragments). Traditional techniques of evaluation using Gamma Ray logs, NeutronDensity log separation or Rhomaa incorrectly calculate these structural (framework) components as shale.

All wireline log shale indicators were calibrated to the results of petrographic analysis. Silty sands, silts, clays and shale can be readily differentiated on the basis of grain size and total shale content. These differences are also related to depositional environment. The silty sands are commonly associated with mid to outer fan turbidites while the shales are believed to have been deposited in a basin plain environment. The log indicators include the Gamma Ray, Rhomaa, PhiN and Neutron-Density Separation data. A composite algorithm was developed for log-based, shale volume determination. In simpler terms, most shale was identified whenever gamma ray log readings $>37 \mathrm{API}$ units. Additionally, thin bed effects were corrected using macroscopic core descriptions and the logarithm of the absolute values of separation between Rxo and Rt versus fractional neutron porosity. The study showed that sands and shale can be identified, foot-by-foot, in all wells with a sufficient logging suite. The accuracy of routine core analysis results for shale porosity and permeability were suspect, therefore shales identified through petrographic analysis were given permeability values estimated at $<0.01 \mathrm{mD}$ based on measurement of pore throat sizes of Tar II-A shale using direct scanning electron microscope analysis. 


\subsubsection{Qualitative Conditioning}

In reservoirs with complex structure, such as turbidite sequences, rock facies exhibit great variations both vertically (example-Bouma sequences) and laterally. In such formations, patterns observed and interpreted by conventional methods from electric log data may show considerable differences. A neural network model was developed to Identify key lithologic formation markers utilizing electric log data.

Understanding the lithological structure of a formation is the first step toward initiation of deterministic or stochastic geologic models. The complexities observed in electric log data are directly related to the degree of heterogeneity of the formation. Figure 2.3.6-1 shows a schematic of a cross-section where the correlation among individual wells is clear and deterministic. However, correlation studies can become quite complicated in formations consisting of sand intervals separated by thin shale layers. A turbidite sequence, shown in Figure 2.3.6-2, is an example of a complex sedimentary structure in which a considerable variety of sedimentation processes has occurred. Both gravitational sequencing and variations in distance from the sediment source cause these characteristics. In cases where small laminations are involved, lithologic log responses resulting from sedimentation processes also exhibit cyclical variation. In this type of formation, identifying separate oil-bearing zone boundaries can become very cumbersome.

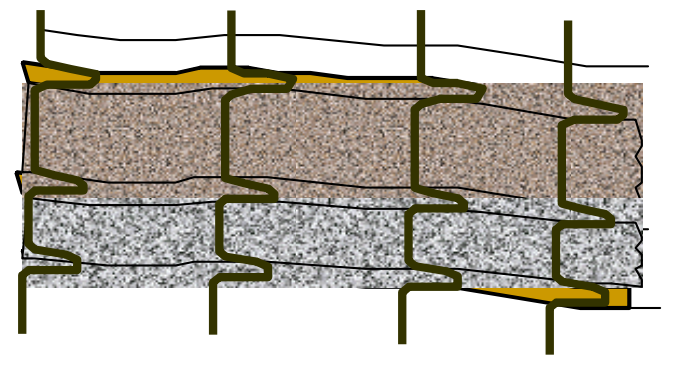

Figure 2.3.6-1: An example of a formation with clean intervals.

The Wilmington oilfield in Long Beach, California (Figure 2.3.6-3) is an excellent example of the complexities of such fields. This field consists of about 6000 feet of interbedded turbidite sands and shales overlaying fractured shales and basement metamorphic rocks covering over 20 square miles. Constructing rational and meaningful correlation models consistent with all the lithological signatures can be an
Well A Well B Well C Well D

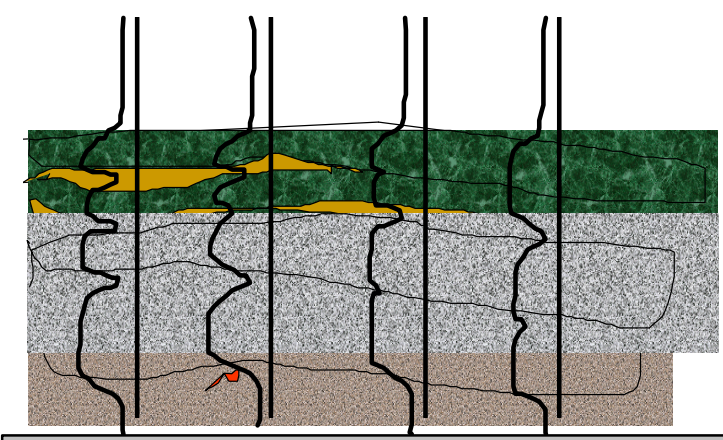

Figure 2.3.6-2: An example of a formation with small and dirty intervals.

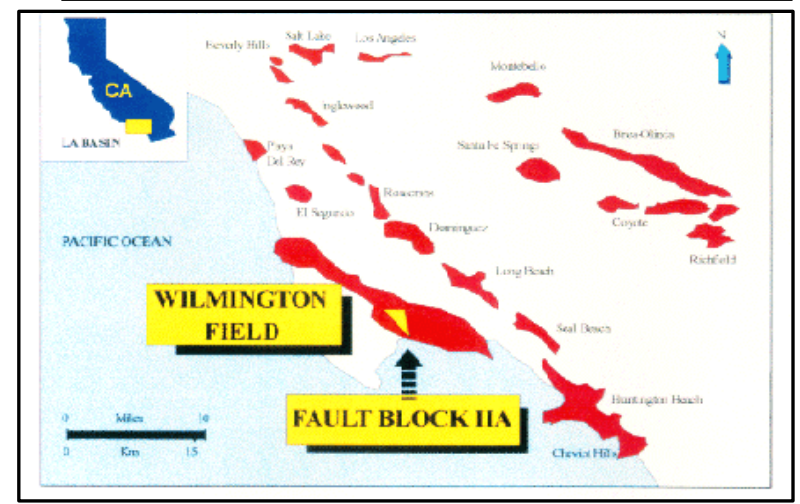

Figure 2.3.6-3: Location Map of Wilmington Field. 
enormous task before conceptualization of data in a 3-D geologic model. Commonly, lithological pattern classification is a task handled by human experts. However, in complex situations the result is not always satisfactory. In fact, manual manipulation of quantitatively large data sets is a very complicated task subject to misinterpretation. A more practical alternative is to get assistance from a computer aided technique to automate the pattern classification and similarity analysis processes.

Neural network modeling can serve as an important pre-processing step to minimize the requirements of human expert input in selecting lithologic sub-markers for a substantial number of well logs. This approach can substantially reduce the time to build detailed geological images, which are essential for accurate illustration of the continuous or discontinuous sedimentary deposits. Important tools for pattern recognition dealing with images are the technology of artificial intelligence, neural network, and statistical pattern classification such as K-means and vector quantization. The automated techniques of pattern classification enhance the characterization and identification of stratigraphic features of laminated type reservoirs. The approach uses basic lithological and marker information from electric logs. It incorporates noise filtering and pattern recognition to identify separate, distinct reservoir compartments. This helps in delineating the lateral continuity of more reservoir sand bodies and shale laminations than are normally accounted for.

Conventional geological models are typically generated using only the major markers. Figure 2.3.6-4 is a pictorial representation of a 3-D geologic model of Fault Block II of the Wilmington field. This model only includes information derived from mapping the major markers. The interbedded "minor" shale intervals are not incorporated into its construction. In reality, lithologic marker characteristics are more likely to be as shown in Figure 2.3.6-5. Four hypothetical markers are depicted in which two of them are analyzed for small lamination characteristics. The top representative marker is considered as a consistent marker

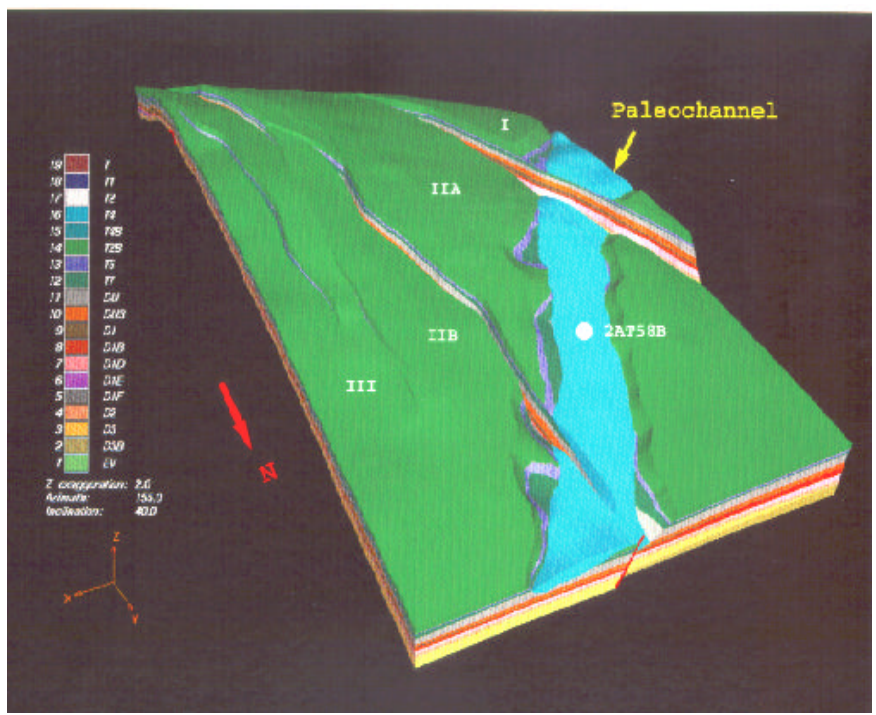

Figure 2.3.6-4: 3-D geological model from Wilmington Field. because of the lateral uniformity of lamination pattern. However, the next one does not exhibit similar characteristics, and in fact represents an inconsistent marker. The quality of a geologic model is greatly dependent on determining how consistent these layers are. Neural network modeling allows an automatic lithological pattern classification process for identification of reservoir compartments based on these subsidiary layers, followed by a lateral correlation process to map the extent of smaller sedimentary layers within major markers. 


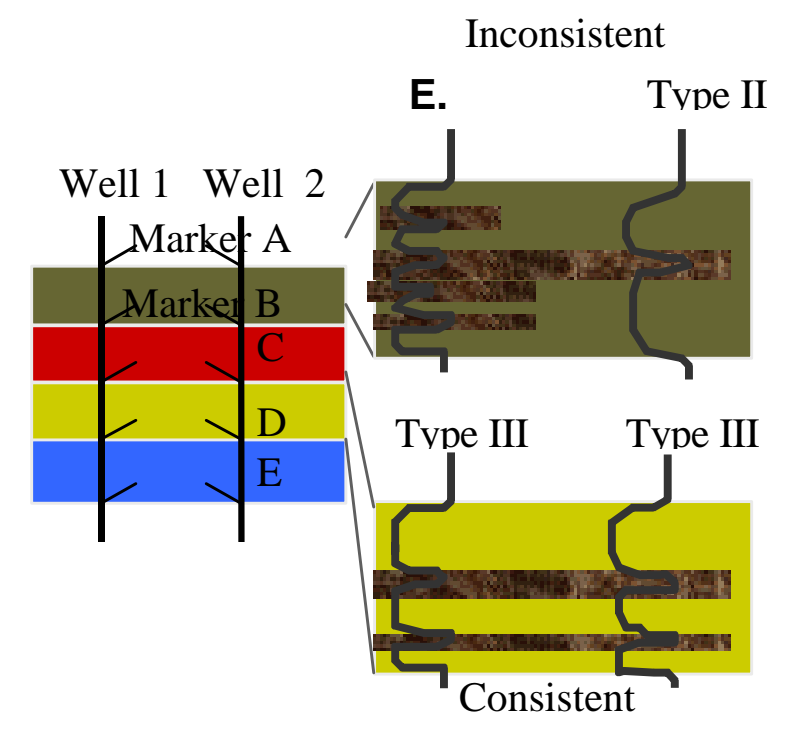

Figure 2.3.6-5: Examples of consistent and inconsistent markers.

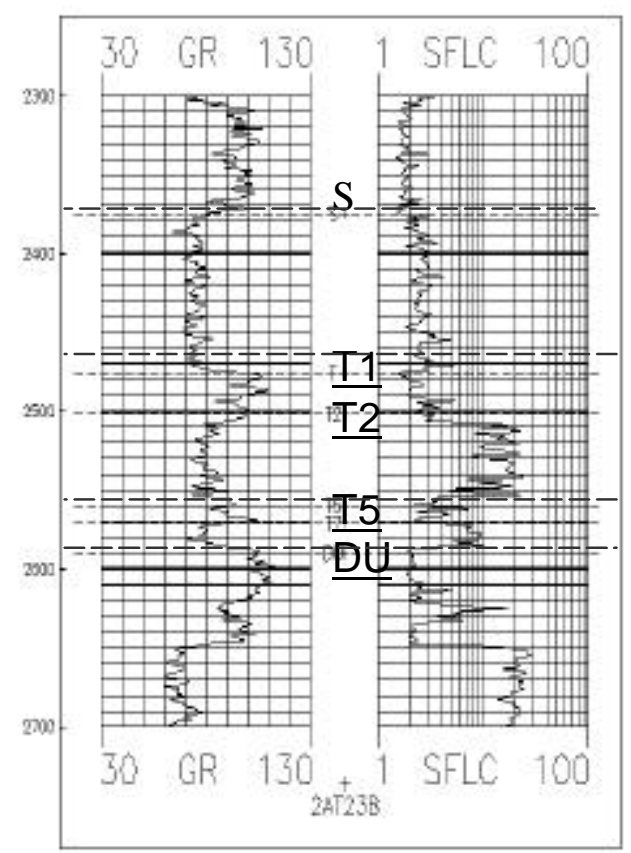

Figure 2.3.6-6: Typical well log responses in the Tar zone of the Wilmington Field, California.

The main focus of the study is the Tar zone of Fault Block II-A, the shallowest of the oil reservoirs comprising the Wilmington Field. This zone is sub-divided into smaller intervals by well-known major markers. Figure 2.3.6-6 illustrates typical GR and SFLC log response characteristics for this zone and identifies major markers such as S, T1, T2, T5, etc. In this study the interval between markers T5 and DU was selected for pattern classification and identification of reservoir compartmentalization.

Log responses from this interval are processed with a smoothing program. The smoothed patterns are subjected to the shale-sand indicator process. Finally, these shale-sand indicator patterns are used as input to the pattern classification algorithm. Figure 2.3.6-7 and Figure 2.3.6-8 consist of original, smoothed, and shale-sand indicator patterns belonging to two different wells, UP-908 and 2AT37B0, respectively. The lithological patterns from these two wells are recognized as similar patterns by the program. In pattern recognition process, the thickness of rock bodies is not incorporated in constructing the input set to the program. 

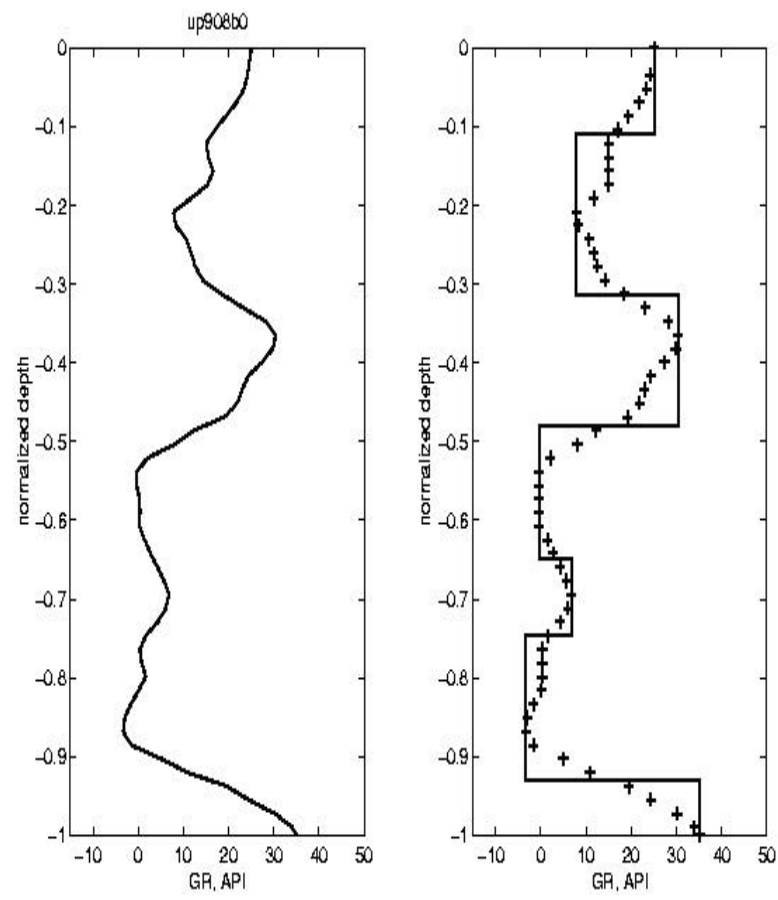

Figure 2.3.6-7: Original (left signal), smoothed (star sign), and shale-sand indicator (rectangular shape) signals, representing model A in interval T5 for well UP-908.
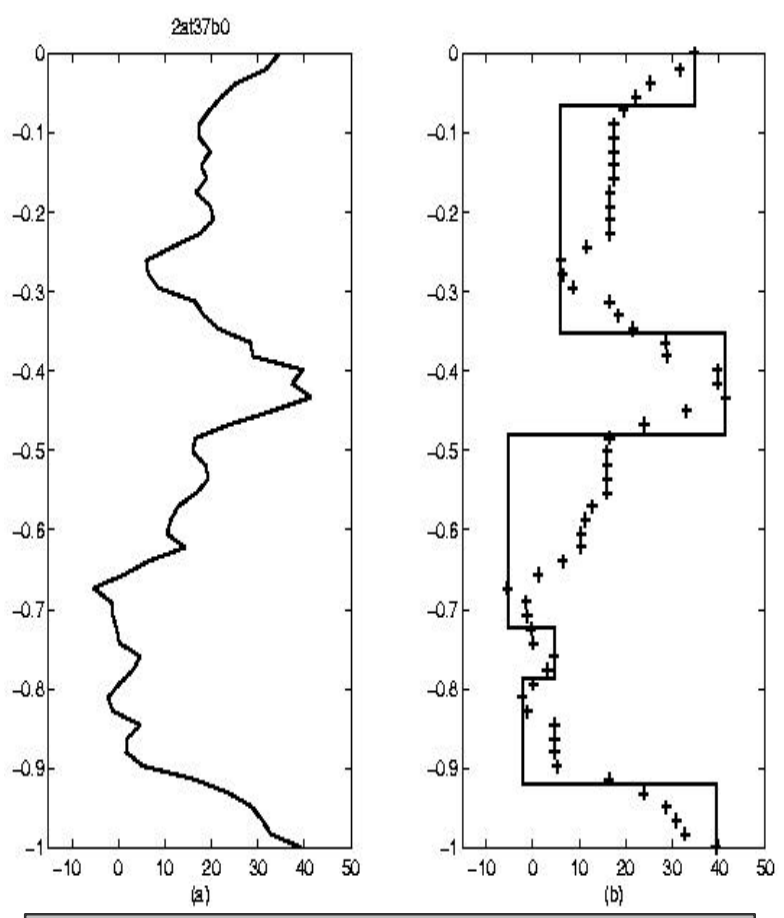

Figure 2.3.6-8: Original (left signal), smoothed (star sign), and shale-sand indicator (rectangular shape) signals, representing model $A$ in interval $T 5$ for well 2AT-37.

To anticipate the compartment boundaries, the areal distribution of existing models is mapped as shown in Figure 2.3.6-9. Four distinct compartments are identified in this figure. After sketching the compartment boundaries, an automated crosscorrelation algorithm is used to construct the reservoir cross-sections, showing lateral continuity of the interval. As might be expected, more than one solution is found to match the existing data. In Figure 2.3.6-10, one of the representing cross sections is depicted. It specifically illustrates the way that different laminations are communicating across that particular cross-section. This

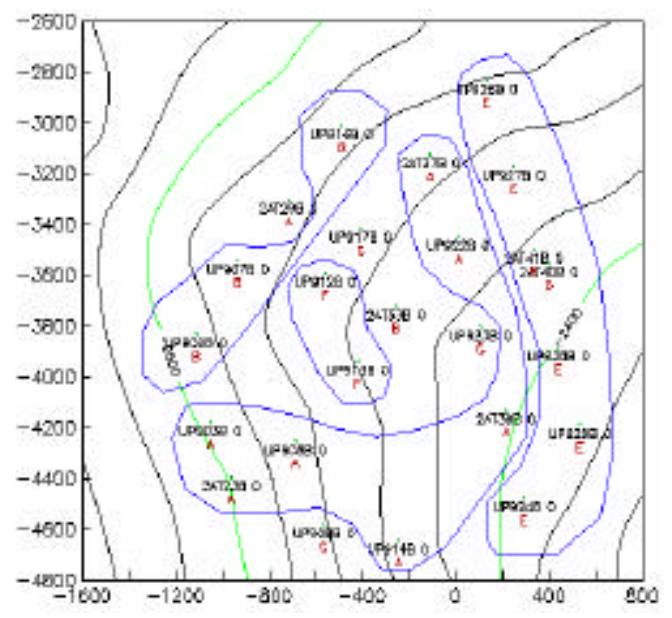

Figure 2.3.6-9: Areal distribution of lithological models for marker T5. cross section can help to distinguish micro lamination distribution within a major interval. Using this information, more comprehensive and accurate geological models can be developed. 


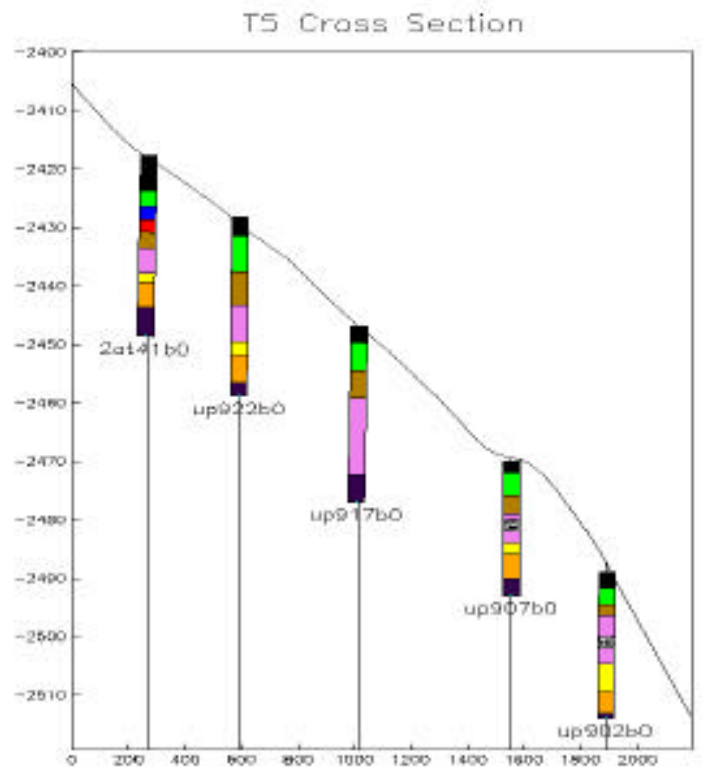

This study was based on a PhD doctoral thesis by Hassibi entitled "A Method For Automating Delineation of Reservoir Compartments and Lateral Connectivity From Subsurface Geophysical Logs"A29 and on SPE Paper 56818 by Hassibi and Ershaghi entitled "Reservoir Heterogeneity Mapping Using an Automated Pattern Recognition Approach" A33.

Figure 2.3.6-10: A cross section for marker T5, showing micro lamination distribution.

\subsubsection{Basin Modeling}

No activity reported this period.

\subsubsection{Updating}

No activity reported this period.

\subsection{Stochastic 3-D Geologic Modeling}

Systematic reservoir characterization and stochastic modeling of the Tar Zone Fault Block II-A in the Wilmington Field has been completed through Sub-task 2.4.1 on "Vertical and Horizontal Geostatistical Spatial Correlation Studies". The original intent of the 3-D stochastic geologic modeling work was to address the lateral variations in rock geology using geostatistical correlation methods. Upon completion of the geostatistical work, the plan was to convert the 3-D deterministic geologic model and examine various stochastic realizations of reservoir conceptual models for simulation purposes. With the extended time to complete the core analysis work and the unexpected shutdown in January 1999 of the steam injection process in the Tar II-A zone, the project priorities were modified by the City of Long Beach to address their concerns about steamflood-related surface subsidence and how to safely operate the Tar II-A wells during the post-steamflood phase. In mid-1998, stochastic geologic modeling work was discontinued so the project team could concentrate on developing a post-steamflood operating plan. 
The Tar Zone is a turbidite reservoir consisting of unconsolidated sands with interbedded shale streaks. The reservoir characterization work was first partitioned into sand modeling and shale description projects. For sand modeling, conventional core data were first calibrated to reservoir conditions. The calibrated core data were then used to check and correct the density log porosity. Shaliness indicators were identified from density and neutron logs and correlated with the corrected core permeability.

The stochastic model was created by the sequential gaussian simulator. For input, the simulator used the variogram models of the porosity and permeability fields, density log porosity data, permeability cloud transforms, and permeability-normalized neutron log porosity data. Stochastic simulations were conducted on porosity and shaliness indicators. Permeability fields were generated from shaliness indicator results through cloud-transforms. Detailed shale mapping was partially created based on resistivity and density log responses to define the shale streaks accurately. The shale streaks control the effective vertical permeability. A method for upscaling the model is discussed for porosity, sand permeability and the combination of the shale spatial continuity information and the sand permeability.

The stochastic geologic modeling work described herein is based on a report written by Du, Mondragon and Ershaghi entitled "Reservoir Characterization and Stochastic Modeling of Fault Block IIA Turbidite Sand Formation of Wilmington Oil Field, Long Beach, California." A35

\subsubsection{Vertical and Horizontal Geostatistical Spatial Correlation Studies}

\section{Introduction}

A unique aspect of the Fault Block II-A Tar Zone (Tar II-A), which makes it an ideal candidate for a stochastic geologic modeling project, is the existence of extensive information from many wells. There are 104 wells with a full suite of well logs (density, neutron, gamma ray, spontaneous potential and resistivity logs) vintage 1980 and after to develop the model. There are also twelve wells with core data among those wells. After creating the model, resistivity and spontaneous potential log data from an additional 100 older wells that penetrate the Tar sands (of about 600 wells available) will be compared with the predictions from the model to evaluate its ability to capture the geologic features of slope and basin type reservoirs.

The Tar Zone contains unconsolidated and discontinuous sands interspersed with occasional low permeability layers, as is typical of turbidite sequences in slope and basin reservoirs. The porosity and permeability vary rapidly laterally and vertically due to differential compaction, lack of cementation, and the rapid variation in grain size that is typical of graded and lenticular bedding of turbidite sequences. These heterogeneities have contributed to poor sweep efficiency, high water production, and steam channeling. 
The Tar Zone is a submarine turbidite reservoir of outer fan and middle fan sedimentation ${ }^{\mathrm{G} 21-\mathrm{G} 25, \mathrm{G} 38}$ made up of layers known as "Bouma" sequences ${ }^{\mathrm{G} 1}$ as shown in Figure 2.4.1-1, Figure 2.4.1-2 and Figure 2.4.1-3 are fan facies maps of the Los

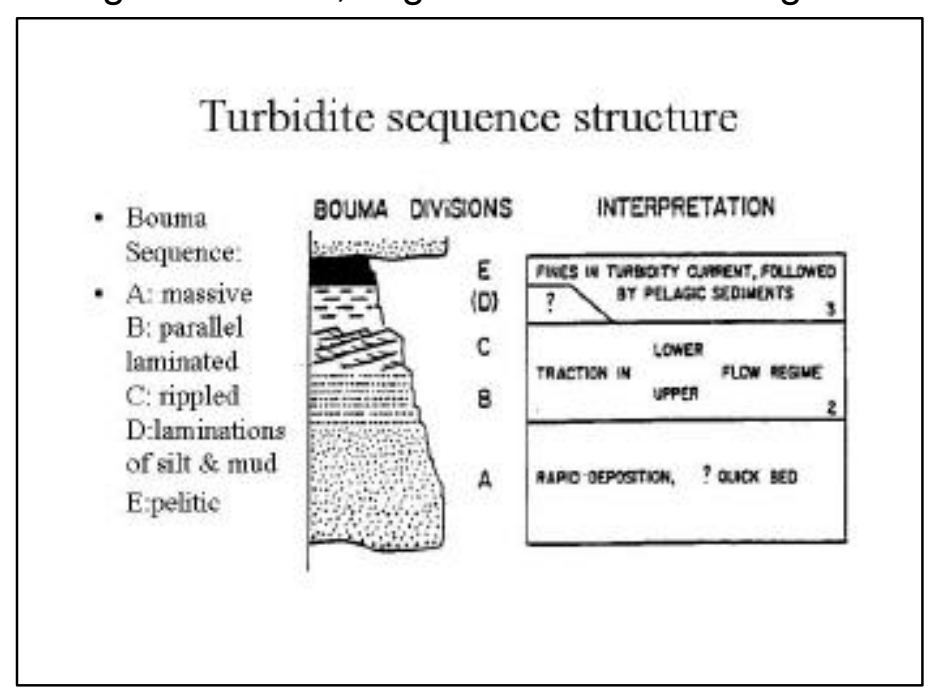

Figure 2.4.1-1: Turbidite sequence structure.

Angeles Basin Repettian Stage (lower Pliocene age) with an explanation of the types of fans. This type of turbidite sequence beds can measure from inches to tens of feet thick and could have a full range of different lithotypes along the sequence. A typical sequence will have coarse sand at its bottom, medium sand in the middle, fine-silty sand near its top and shale at the top that describes a depositional environment of reduced water velocities over time. The sand grains within a Bouma sequence have a variety of textural and physical properties and can change laterally, especially along the flow direction. In addition, the sequences are often intercut both laterally and vertically. This heterogeneity influences both sweep efficiency and displacement efficiency of a reservoir development.

For efficient management of a turbidite reservoir, the shale beds must be characterized properly. The continuity of these shales controls the macro-sweep efficiency of the reservoir during steamflooding due to steam gravity-override on the formation top. Any discontinuous inter-bedded shales within the sands can be an effective barrier to prevent steam overriding.

At the same time, the internal structures of turbidite sequences influence the local displacement efficiency. An upward vertically decreasing permeability trend within each sequence can stabilize the steam front, which has a positive effect on high

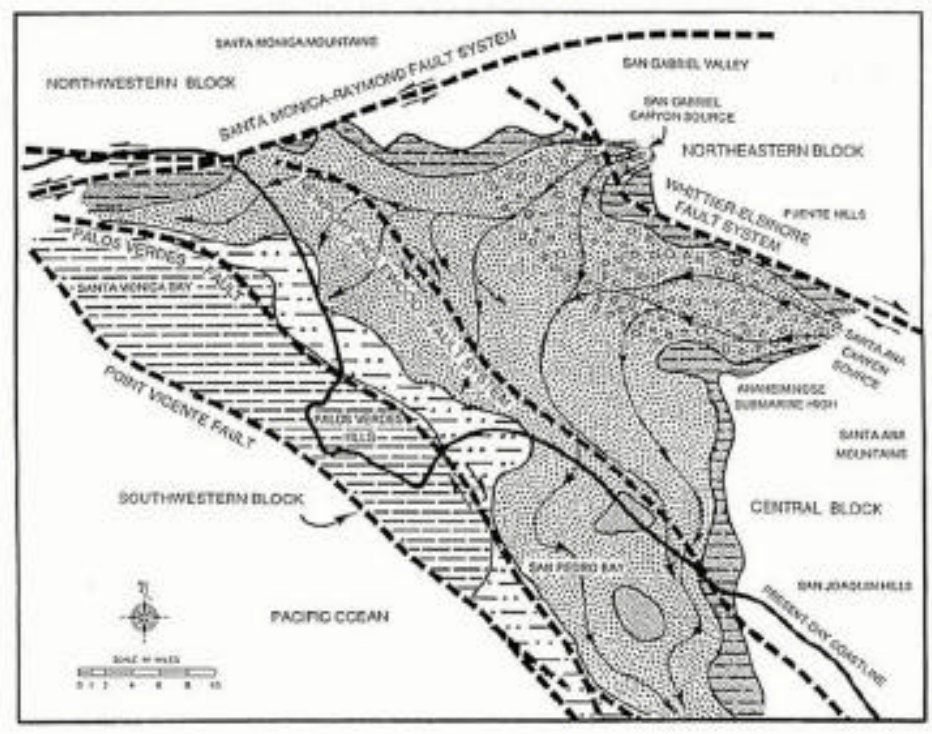

Figure 2.4.1-2: Present-day Repettian-Stage submarine-fan facies map. displacement efficiency. Conversely, the same trend will develop an inverse bottom tongue in waterflooding. Many studies have demonstrated various types of shale 
mapping, modeling approaches and shale influences on oil recoveries ${ }^{\mathrm{G} 2-\mathrm{G} 9}$. turbidite reservoirs exist as unconsolidated formations ${ }^{\text {G10-G15. }}$.

There are several studies that address stochastic modeling of turbidite reservoirs G16-G20. Dehghani et al G19 studied the shale distribution and sand heterogeneity influence on a steamflood in a dipping formation where the shale correlation length was based on geologic data. Haldorsen ${ }^{\mathrm{G} 7}$ proposed a general random shale modeling approach based on shale geometry statistics collected from outcrops or well log data.

The Tar II-A has the Wilmington Fault on the west side and the Ford Fault on the east side as shown in Figure 2.4.14. Both faults are sealing faults. The deterministic geologic modeling team divided the Tar II-A into six sub-zones and eight sub-sands and sub-shales as shown in Figure 2.4.1-5. This study concentrates only on two major sand-rich producing sub-sands,

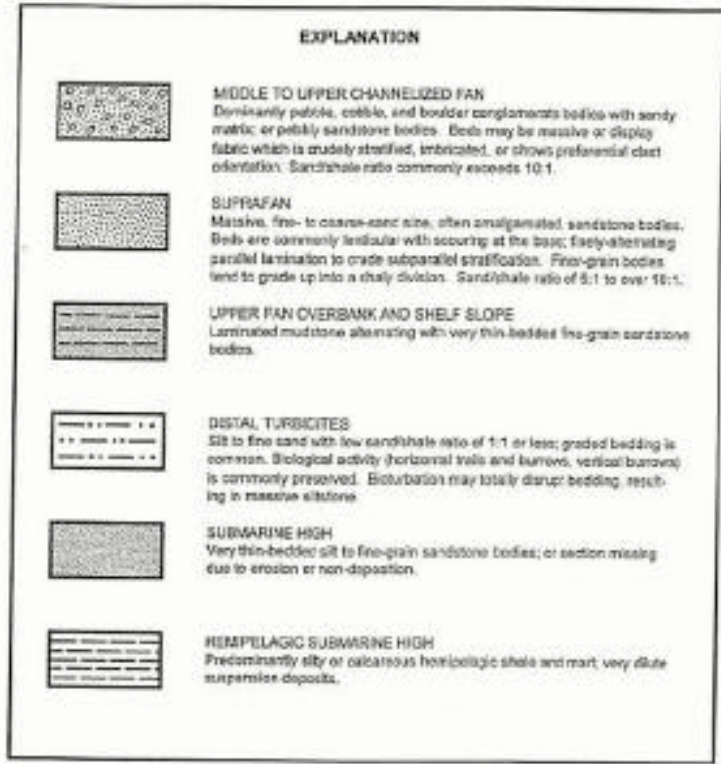

Figure 2.4.1-3: Explanation for Repettian-Stage submarine-fan facies map. the T2 and the D1, with more emphasis on D1 sub-sand. Within these two sub-sands there are no field-wide shale barriers defined, although there are some discontinuous shales. The formation sands are unconsolidated with only oil for cementation.

A systematic, comprehensive case study was conducted in order to have a better

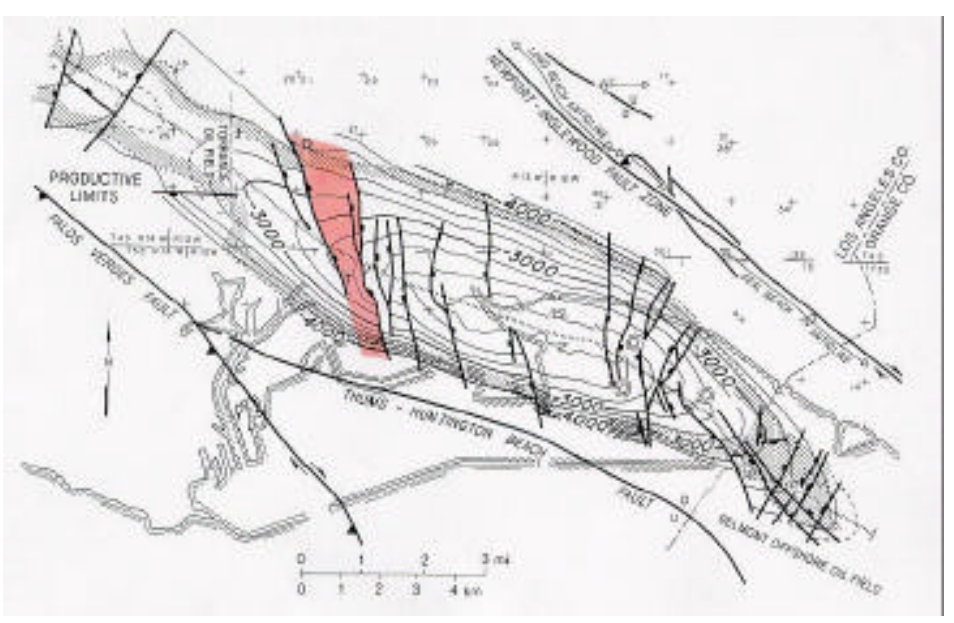

Figure 2.4.1-4: Fault Block II-A, Wilmington Field. understanding of how the reservoir heterogeneity (especially with shale streaks) affects the Tar Zone production performance (primary, waterflood, and steamflood production) and simulation of future production and injection scenarios. The first step was to study the turbidite sequence structure. The next step was to determine whether to separate the shale top modeling from the blocky sand modeling or to combine them. The following step focused on how to calibrate the log porosity data with core analysis data. The shaliness 
indicators and their correlations with the permeability data were studied next. The corrected data was then used to make stochastic models of the porosity, the shaliness indicator and the permeability. Upscaling issues are discussed. Conclusions and future work are given at the end of the summary.

\section{Turbidite Sequence Structure}

David K. Davies and Associates Inc. (DKD) reviewed the core photos of the Tar Zone and made a detailed description of the lithologic sequences. Most sequences are very similar in terms of lithotype constitution: all sequences have coarser sand grains at the sequence bottom and a fining-up trend to the top of the sequence with/without silty/shale tops. Some small sequences merge into a larger sequence because of the disappearance of intermediate silty/shale tops. The

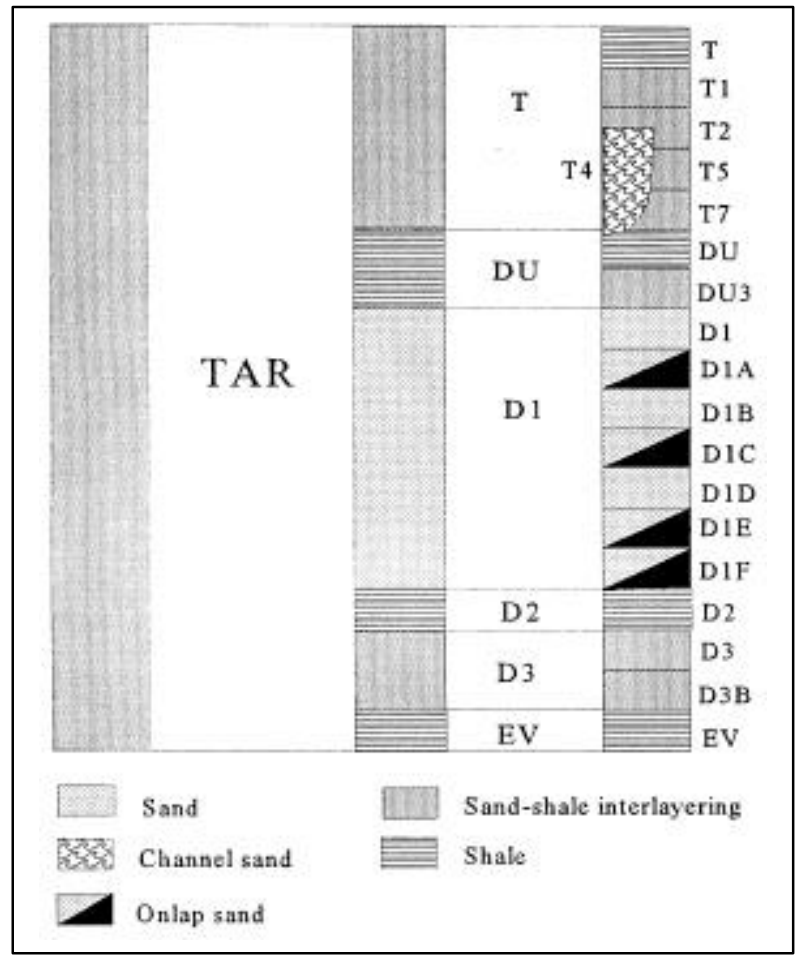

Figure 2.4.1-5: Stylized diagram showing subdivisions of Tar Zone. intermediate silty/shale tops are generally very thin vary from 0.1 to $0.4 \mathrm{ft}$ (more detailed discussion later) and the sequence bed thickness ranges from inches to tens of feet.

\section{Stochastic Modeling - Basic Procedure and Software}

Stochastic modeling has been used for reservoir property characterization over many years G16-G20, G29-G32. It offers a unique approach to map and model reservoir heterogeneity and populate reservoir properties on more detailed numerical grids. The multi-realizations of the stochastic image are heavily used in performance prediction and risk analysis and evaluation.

In this stochastic geologic modeling study, the porosity and the permeability were modeled. The property data used for this model were the porosity data and the shaliness indicators. The Core-Log Analysis Study converted the property data to generate permeability data. A total of 76 wells that are located in the central-north area of F.B. II-A and penetrate the Tar Zone have both data sets. This portion of the stochastic modeling concentrated on the D1 sub-sand. The deterministic geologic modeling group provided the tops and bottoms of the D1 sub-sand surfaces, which were needed to limit the vertical range of variogram analysis ${ }^{\mathrm{G} 33}$. The stratigraphic grid system used was the same as the $x$-y grid system used in the deterministic reservoir simulation study. The stratigraphic grid system was populated with the stochastic simulation results and the vertical grid thicknesses were proportional to the formation intervals. 
The stochastic modeling software used was called GOCAD, which is the product of a consortium from the Nancy Geological School of France. GOCAD is a computer application that imports, modifies, integrates, views, and exports geological objects, all in 3-D. GOCAD also offers a variety of geological, geophysical and geostatistical analyses that can analyze and visualize reservoir properties in 3-D. GOCAD mainly does geological model construction, which includes point, line, surface, 3-D object, stratigraphic layering, geo-shaping creation functions (such as channels and faults), property mapping, variogram analyzers, and interpolating and Kriging on any property data. GOCAD provides five types of geostatistical simulations to generate multiple equally probable numerical models of reservoir properties that honor a hard data set, a variogram model, and possibly some additional soft data sets: Sequential Gaussian Simulations (SGS), Block SGS, Sequential Indicator Simulation, Cloud Transform, and Simulated Annealing. For continuous properties such as porosity and permeability, the most proper way is to use SGS. This study utilized the Variogram Analyzer, Cloud Transform, and Sequential Gaussian Simulation to build stochastic porosity and permeability models ${ }^{\mathrm{G} 4}$.

\section{Variogram}

A variogram is a cross-plot showing how data becomes uncorrelated as distance between data points increases. The variogram analysis is performed for 2-D areal variograms in four azimuths (directions), $0^{\circ}, 45^{\circ}, 90^{\circ}$, and $135^{\circ}$ and a vertical variogram using the exponential model. The $X$ value where the fitted curve starts to level off is called the Range or correlation length showing the distance when the correlation becomes zero. The $Y$ value where the fitted curve starts to level off is called the Sill and represents the variance of the data pairs defined by distance. The long axis direction is the angle from zero degrees where the range is at a maximum. The short axis direction is perpendicular to the long axis and is the minimum value for the range. The variogram model is part of the input data for the SGS porosity and permeability models.

\section{Cloud Transform}

A liner inversion transforms one type of data into another type by using a one-toone conversion function that correlates the two data types. The function may be quite complicated, but for the same input value, you always get the same output value. A common practice is converting porosity data into permeability data using a best-fit line or curve. The result of such a conversion is that the scattering (uncertainty) in the data relationship is lost. A Cloud Transform, however, allows such a conversion to be done via a 2-D cross plot (scattergram) rather than a perfect linear fit, thus preserving the variability of the relationship. The cloud transform model is part of the input data for the SGS permeability model. 


\section{Sequential Gaussian Simulations}

Kriging provides estimations that honor geological trends specified via variogram models. Geostatistical simulations add a random residual to the kriged value at any given point to simulate the uncertainty of that value. In Sequential Gaussian Simulation (SGS), the simulated value at any given point is sampled from a Gaussian probability distribution. The mean of the Gaussian curve is the Kriging estimate and the sigma is the Kriging variance at that point. The simulated values can be imported into other reservoir simulators such as the Computer Modelling Group Inc.'s STARS 3-D thermal reservoir simulator.

\section{Stochastic Modeling of Porosity Field}

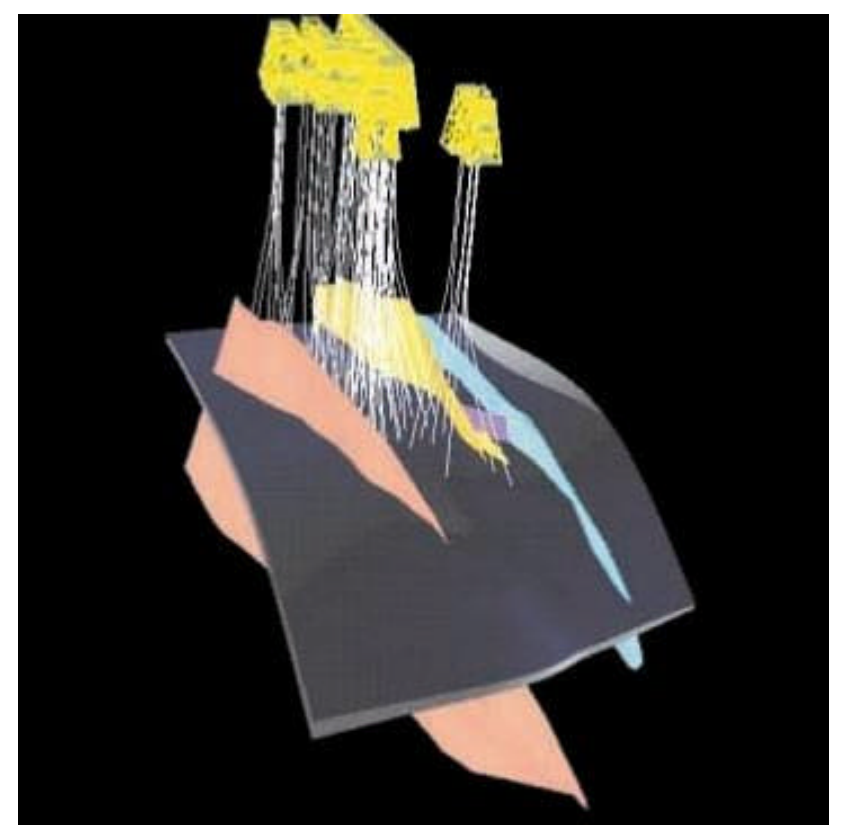
of the analysis area and where wellbores penetrate the D1 sub-sand is shown in Figure 2.4.1-6. The two horizontal surfaces are the D1 top and D1 bottom (D2 layer top). Starting to the west (left) and moving east are the Wilmington, Ford, and Cerritos faults. The vertical scale for this figure was exaggerated 2 times. Figure 2.4.1-7 shows the reservoir simulation grid orientation and the stratigraphic grid system generated based on the reservoir simulation grid orientation. The stratigraphic grid system is enlarged 10 times vertically to show the D1 top, the D1 middle, and the D1 bottom. The porosity data from each well between the two surfaces was analyzed and used in the model.

Variogram plots for the porosity correlation data used corrected core porosity at 1800 psi overburden pressure and density log porosity from the cored wells. Figure 2.4.1-8 shows the variogram plots_for the areal analysis and Figure $\overline{2} \cdot 4.1-9$ for the vertical analysis. Both the areal and vertical variogram fittings are quite good

Figure 2.4.1-6: Schematic modeling area of FBIIA.

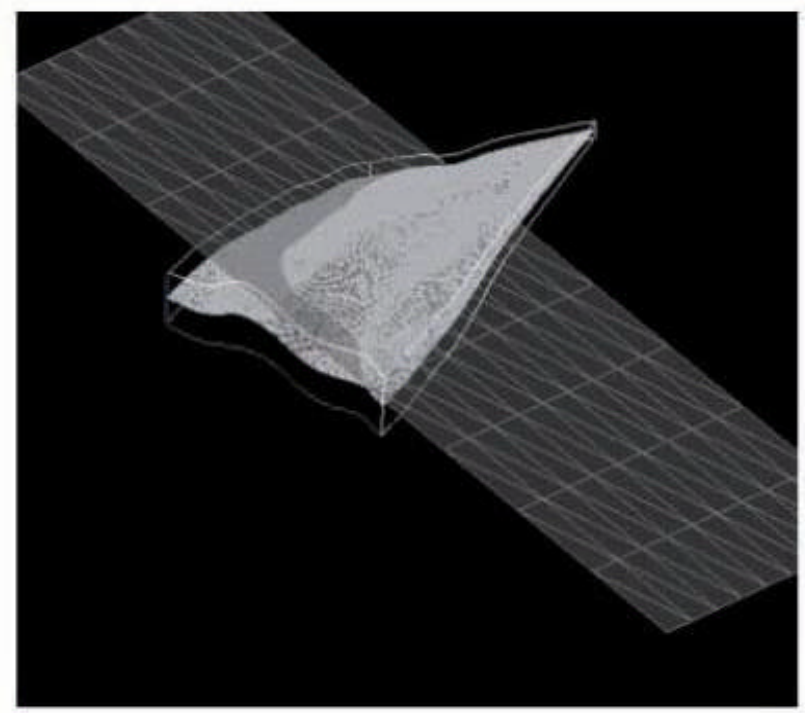

Figure 2.4.1-7: Stochastic modeling stratigraphic grid system. 
and reliable. The areal variogram model fittings in Figure 2.4. 1-8 show a slight evidence of longer correlation length in the direction of $135^{\circ}$. The calculated long correlation axis direction was $137.3^{\circ}$ with a correlation length of $584 \mathrm{ft}$. The short correlation axis direction was $47.3^{\circ}$ with a correlation length of $242 \mathrm{ft}$. The good fit of the variogram model shows that the SGS can suitably represent the reservoir porosity heterogeneity. The areal variogram sill was 0.9 and the vertical variogram sill was 0.8 . This difference reveals that the vertical porosity variation is smaller than the areal variation, although vertically the shale streaks are interweaving within the sands. The areal porosity heterogeneity is significant and needs to be modeled properly. The assumption of constant porosity within a lithologic layer in the deterministic geologic model does not adequately

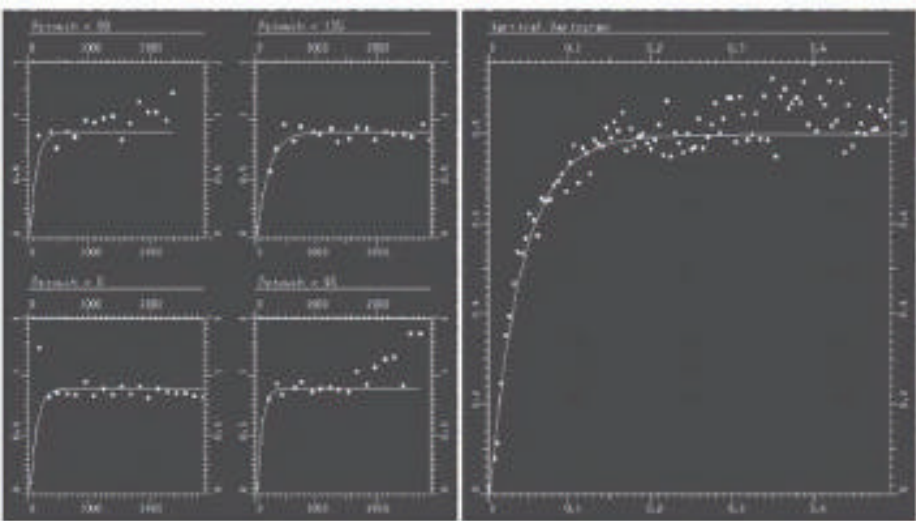

Figure 2.4.1-8 \& 2.4.1-9: Areal \& vertical variogram analysis plot for porosity area. portray the reservoir's heterogeneity.

The porosity field was stochastically modeled by using the generated porosity variogram model and the density log porosity data from the 76 wells input into SGS. Figure 2.4.1-10 through 2.4.1-12 are image slices of the porosity field taken at $10 \mathrm{ft}$ below the D1 top, in the middle of the D1 sands, and $10 \mathrm{ft}$ above the D1 bottom. The porosity scale ranges from 0.199 to 0.388 , which accounts for $99 \%$ of all values. All porosity values outside this range are shown in both the end colors.

The pictures show the clear spatial porosity changes and the directional correlation in the northeast-

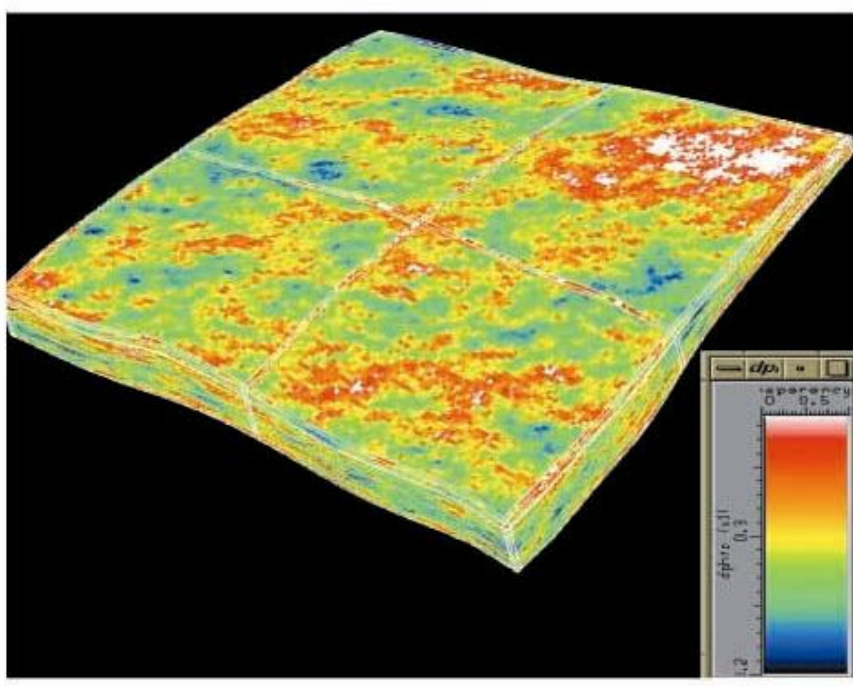

Figure 2.4.1-10: Porosity (SGS) image: realization one, slice at $-10 \mathrm{ft}$ below D1 top.

southwest direction. Figure 2.4.1-13 is a cross-sectional view of the porosity field. The porosity SGS results can be exported in an ASCII format (plain text and numerical numbers, which can be used by any file operation and for viewing. The ASCll files can be easily read and manipulated by any upscaling method. The porosity field can be used for future upscaling calculations. 


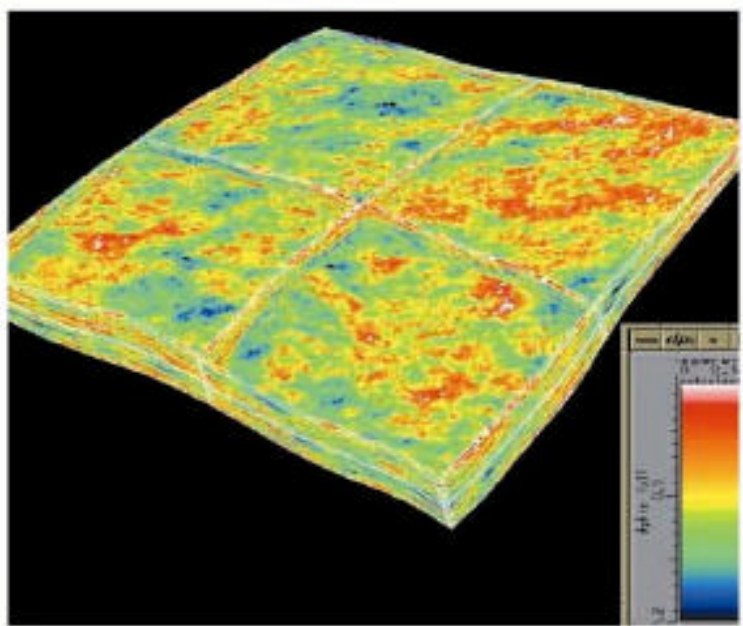

Figure 2.4.1-11: Porosity (SGS) image: realization one, slice at middle of D1.

\section{Porosity Data Quality Influence on Stochastic Simulation Results}

To qualitatively measure the porosity data quality's influence on the SGS results, the uncorrected core porosity data at 300 psi overburden pressure was used instead of the core porosities corrected to 1800 psi. The uncorrected core porosity data tended to show $10-20 \%$ higher pore volumes. The areal variogram is shown in Figure 2.4.114. The calculated long correlation axis direction is $156^{\circ}$ with a correlation length of

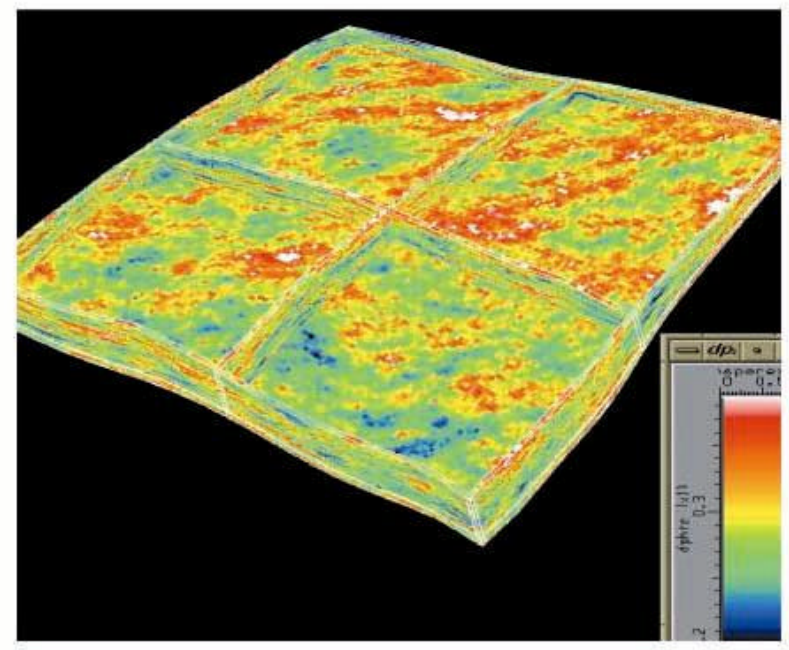

Figure 2.4.1-12: Porosity (SGS) image: realization one, slice at $-10 \mathrm{ft}$ below D1 bottom.

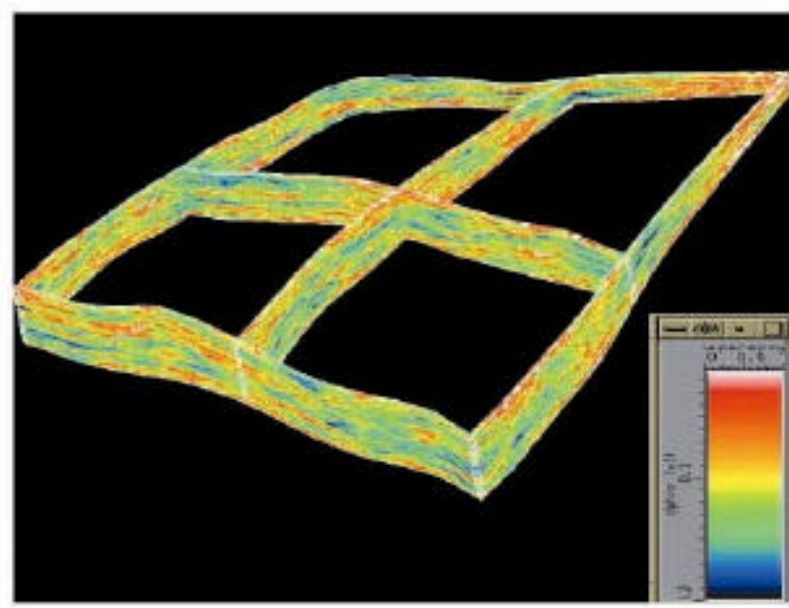

$675 \mathrm{ft}$. The short correlation axis direction is $66^{\circ}$ with a correlation length of $486 \mathrm{ft}$. Figure 2.4.1-15 shows the vertical analysis. Both

Figure 2.4.1-13: Porosity (SGS) image: realization one, cross-section view.

areal and vertical variogram data points are more scattered and the curve fittings are not as good as the corrected core variograms in Figure 2.4.1-8 and Figure 2.4.1-9. A slice of the SGS image in the middle of D1 interval is shown in Figure 2.4.1-16. The northeast to southwest trend was distorted to more of a north to south trend. The uncorrected data generate a different image. The quantitative analysis may be conducted in the future. The above result reveals the importance of using corrected porosity data. 

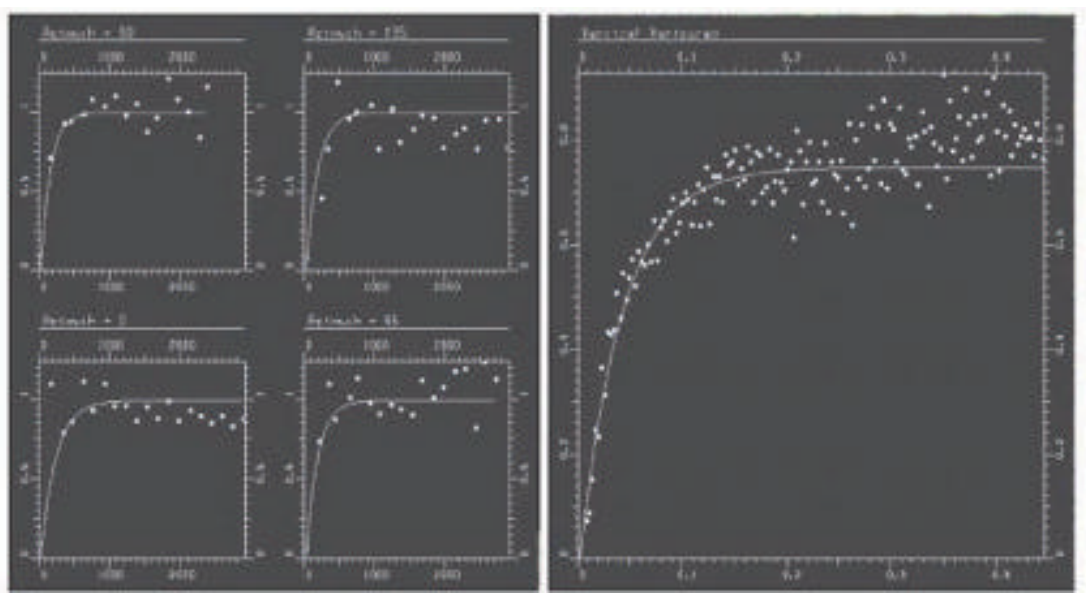

Figure 2.4.1-14 \& 2.4.1-15: Areal \& vertical variogram analysis plot for original logging porosity data.

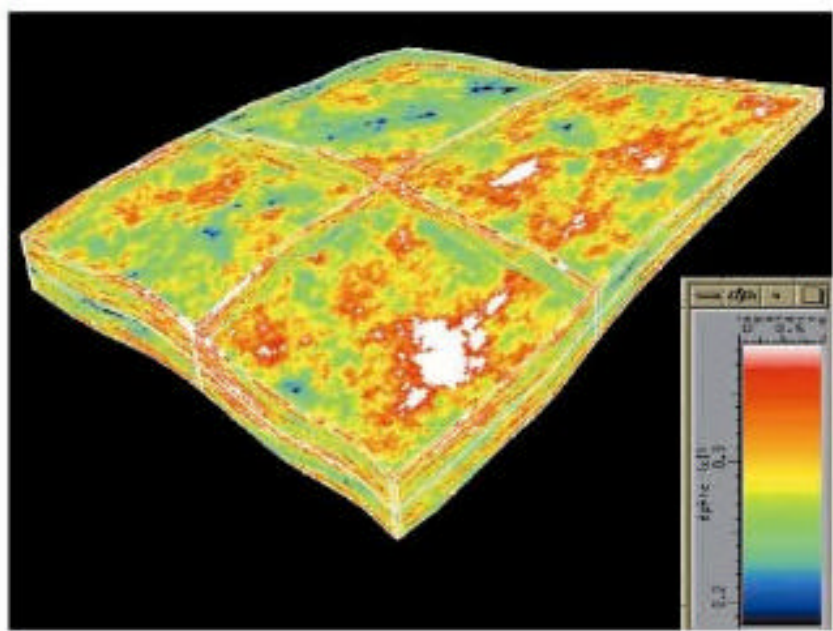

Figure 2.4.1-16: Porosity (SGS) image on using the original logging porosity realization one, slice at middle of D1.

\section{Stochastic Modeling of the Shale Indicator and Permeability Field}

Shaliness indicator 1 Øn variogram plots are shown in Figure 2.4.1-17 \& 2.4.1-18 for areal and vertical analysis, respectively, using the 300 psi air permeability core data corrected to an 1800 psi liquid permeability and normalized neutron log porosity data from the cored wells with $X Y Z$ coordinates. Again, the quality of the variogram model fitting was satisfactory. The calculated long correlation axis direction was $127^{\circ}$ with a correlation length of $638 \mathrm{ft}$. The short correlation axis direction was $37^{\circ}$ with a 
correlation length of $369 \mathrm{ft}$. The areal variogram sill was 0.8 and the vertical variogram sill was 0.9. The variance of the shaliness indicator lØn was larger in the vertical direction than in the areal direction, which was expected. There was a large difference between the shaliness indicator $1 \varnothing n$ for sands and shales and thus a large difference between the permeability of sands and shales. The vertical interleaving of shale beds within a
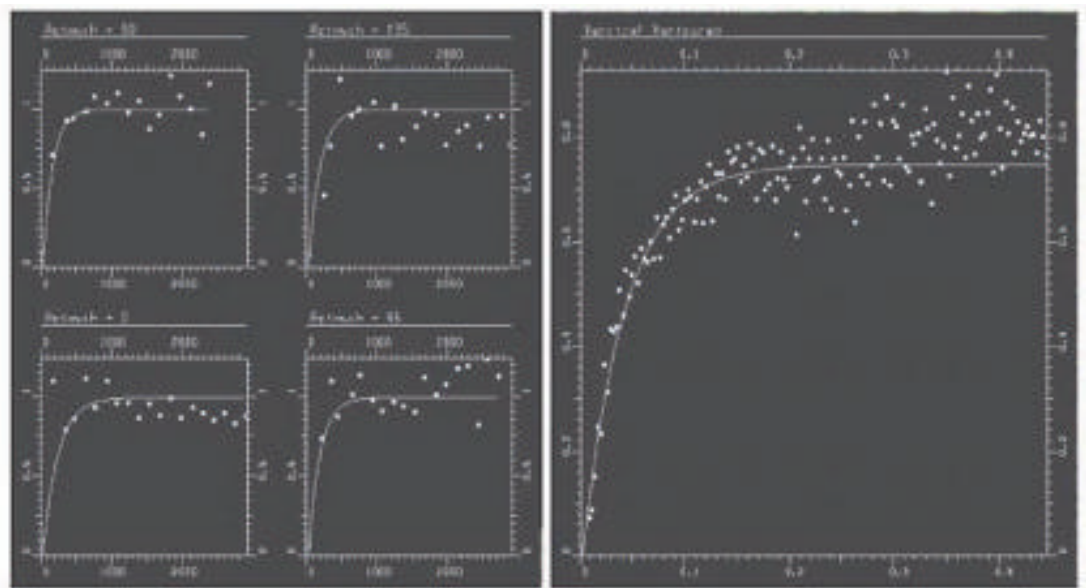

sand makes the vertical variogram calculation have a larger variance

Figure 2.4.1-17 \& 2.4.1-18: Areal \& vertical variogram analysis plot for shaliness indicator data.

than the areal variogram. On the other hand, the areal variogram was small because the sands have good lateral continuity and all sands have similar shaliness values. The vertical variogram data also shows the non-stationary influence of the shale streaks. The short distance variogram partly represents the sand influence. In spite of the differences mentioned above and non-existence of correlation between porosity and permeability, it was noticed that the porosity and permeability fields share similar directional heterogeneity information, i.e., the direction of the long correlation axis for the porosity was $137^{\circ}$ and the direction of the long correlation axis for the permeability was $128^{\circ}$.

A cloud transform of the normalized neutron log porosity and the corrected core permeability data for the D1 and T2 sub-sands is shown in Figure 2.4.1-19. This data set contains data from the T2 sub-sand for $0.4<1 \varnothing n<0.7$, the D1 sub-sands for $1 \varnothing n<0.7$, and synthetic data for $1 \varnothing n>0.7$. This ensures that in different $1 \varnothing n$ ranges, proper permeability values can be obtained and makes the image more clean and easy for data processing.

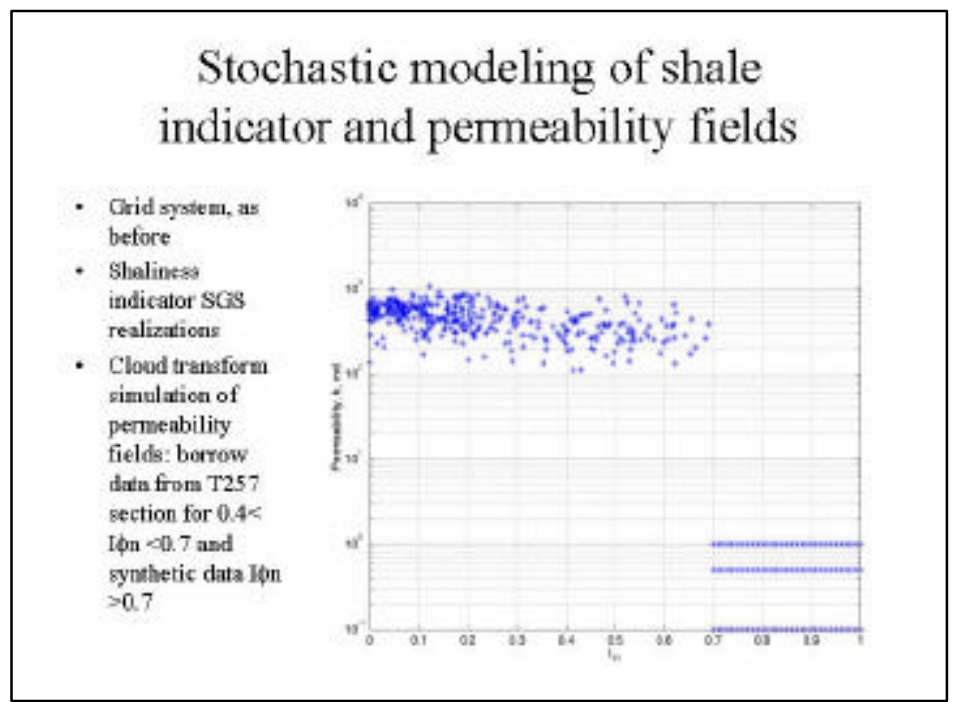

Figure 2.4.1-19: Stochastic modeling of shale indicator and permeability fields. 


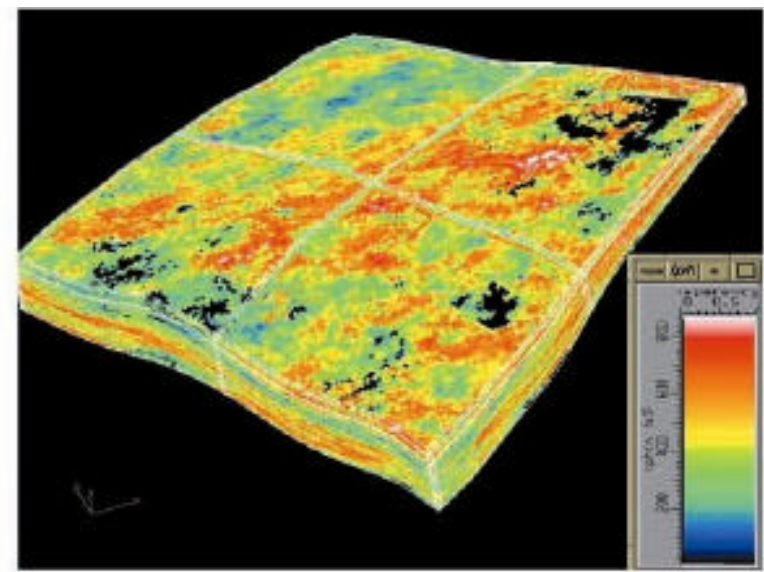

Figure 2.4.1-20: Permeability (SGS) image: realization one, slice at $-10 \mathrm{ft}$ below D1 top.

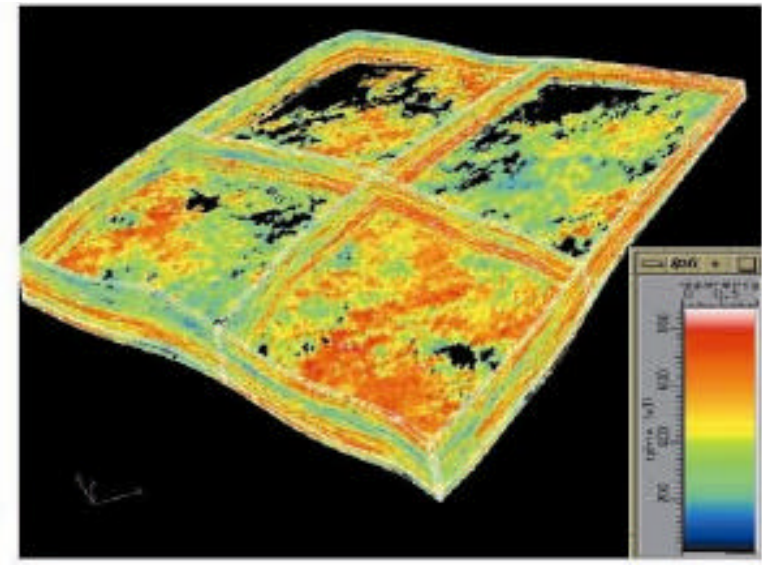

Figure 2.4.1-22: Permeability (SGS) image: realization one, slice at $-10 \mathrm{ft}$ below D1 bottom.

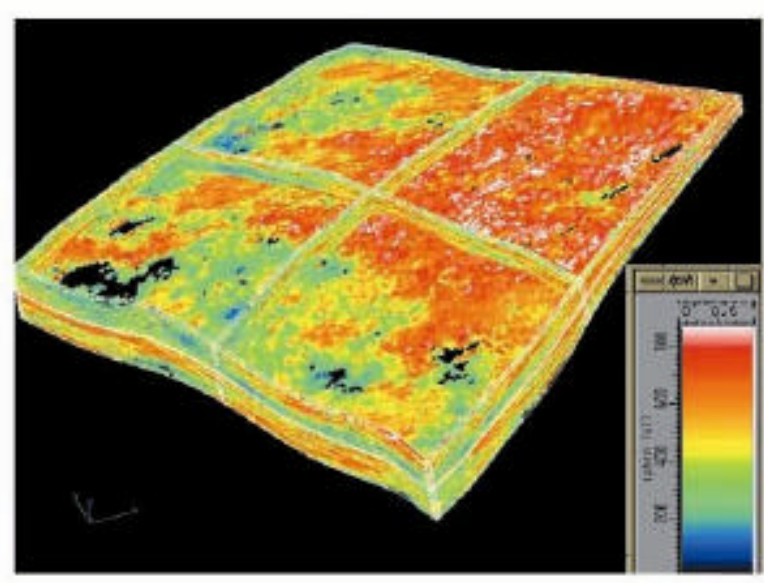

Figure 2.4.1-21: Permeability (SGS) image: realization one, slice at middle D1.

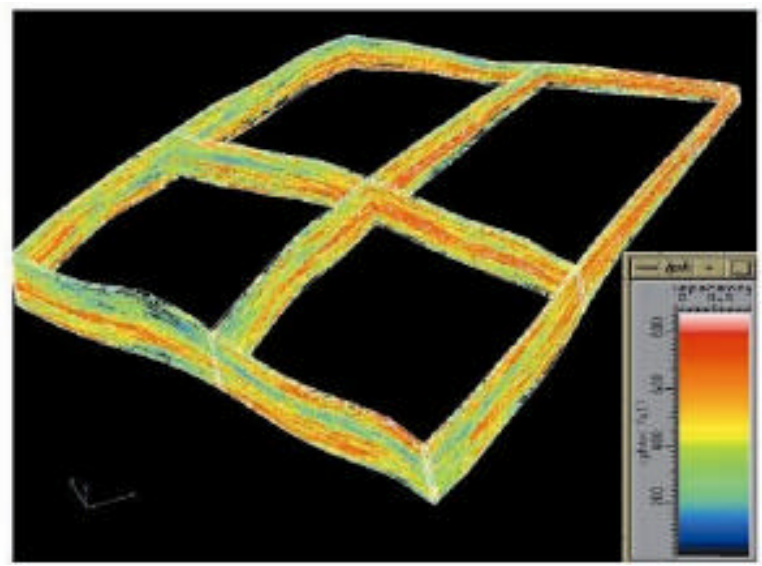

Figure 2.4.1-23: Permeability (SGS) image: realization one, cross-section view.

Stochastic modeling of the permeability field was generated using the permeability variograms, the cloud transform, and the normalized neutron log porosity data from the 76 wells as input into the SGS simulator.

Figures 2.4.1-20 through 2.4.1-23 are image slices of the permeability field taken at ten feet below the D1 top, in the middle of the D1, and ten feet above the D1 bottom and a cross-sectional view, respectively. Strong heterogeneity (high and low permeability areas) can be seen from the images, especially a northeast - southwest directional trend. The simulated permeability data can be also exported in ASCII format and used for upscaling. 


\section{Shale Description}

The thin shale bedding influence on vertical permeability reduction is mainly due to its lateral sizes. To be an effective barrier, a shale layer has to be continuous, although it reduces vertical permeability at all scales in comparison to the homogeneous case. As pointed out before, the Tar II-A sediments are submarine turbidites. Studies G2, G3, G7 have shown that for turbidites and other submarine fan systems, shales can extend tens to thousands of meters. The category, "submarine turbidite," is a generic term as there are no geologic turbidite environments that are the same in the world. Weber and Haldorsen reference far different size statistics for turbidite environments ${ }^{\mathrm{G} 3}$, G7. Thus, any other source of data can only be useful as a reference. The best way to achieve reliable shale continuity data is to study the field of interest.

The Tar II-A sediments are classified as mid-fan to outer fan turbidites ${ }^{\text {G21-G25, G38 }}$ and should be relatively continuous and extend hundreds to thousands of feet. The shale continuity mapping should be achievable with a well spacing of 300 feet or less. A method is described to recognize shale streaks through logging curve responses. The log-defined shale streaks were used to map the lateral shale geometry. The shales were then incorporated into the stochastic geologic model and reservoir simulation grid system. McGill, et al ${ }^{\mathrm{G} 35}$ has a more complete discussion of the technique.

\section{Correlation of Core Photo Shales with Resistivity \& Neutron Logs}

The shale streaks observed on core photos have very sharp correlation with logging resistivity curves and to a lesser degree with neutron log porosity. Figure 2.4.124 is an example of this phenomenon from the T2 sub-sand in well UP-911. The circles represent shale streaks read from core photos. Most of the circles correspond to the short resistivity (Rs) and the deep resistivity (Rd) crossover points and the normalized neutron shale indicator IØn high peaks. From this observation, a simple procedure based on the resistivity difference of $\Delta$ Res $=(R s-R d)$ was developed to help recognize a shale streak from logging curves. If " $\Delta$ Res $\leq 0$ " or "close to zero," the resistivity low point was considered a shale streak. The neutron log porosity and gamma ray logs were also used occasionally to assist in this process.

All shale streaks from core photos were compared with $\Delta$ Res values. Some shales "shared" the same " $\Delta$ Res $\leq 0$ or close to zero" response. Those shales were aggregated within an interval of 1-2 feet with interleaving thin sand beds and the resistivity-log curve did not have enough resolution to recognize those close-distance shales. Most of these aggregated shales contained 2-3 thin shale streaks a few inches thick, but some of them have relatively thick individual members. The T2 has one shale aggregation of $2.4 \mathrm{ft}$ thick with $1.1 \mathrm{ft}$ of net shale. The D1 has one $2.5 \mathrm{ft}$ thick shale aggregation with $2.1 \mathrm{ft}$ of net shale.

It is interesting to note that those aggregated shales consist of thinner real shales, not silty tops. This is in accordance with the nature of geologic sedimentation. Layers of shale represent an overall calm, low energy environment of deposition and 
thus interbedded sands would be expected to be thinner. On the other hand, silty sand layers represent a higher-energy environment and the sand beds would probably be relatively thicker.

Based on the above observation, all the shales that corresponded to the same " $\Delta$ Res $\leq 0$ " response were grouped together as one "shale" streak. Since those shales are parallel and perpendicular to the vertical direction, their total thicknesses were considered as the thickness of single shale with the same shale permeability value. After regrouping the aggregated shales, the core photo shale streak and the $\Delta$ Res correlation from the eight cored wells were analyzed.

For the T2 sands of mid fan and outer fan sedimentation, there were 33 shale/silty streaks observed from core photos. One had a silty top. Two shale tops observed from core photos had too small of deflections on resistivity logs and were not detected by the $\Delta$ Res indicator. Three shales with $\Delta \operatorname{Res}>$ 0 were detected by referencing to other shale responses. The

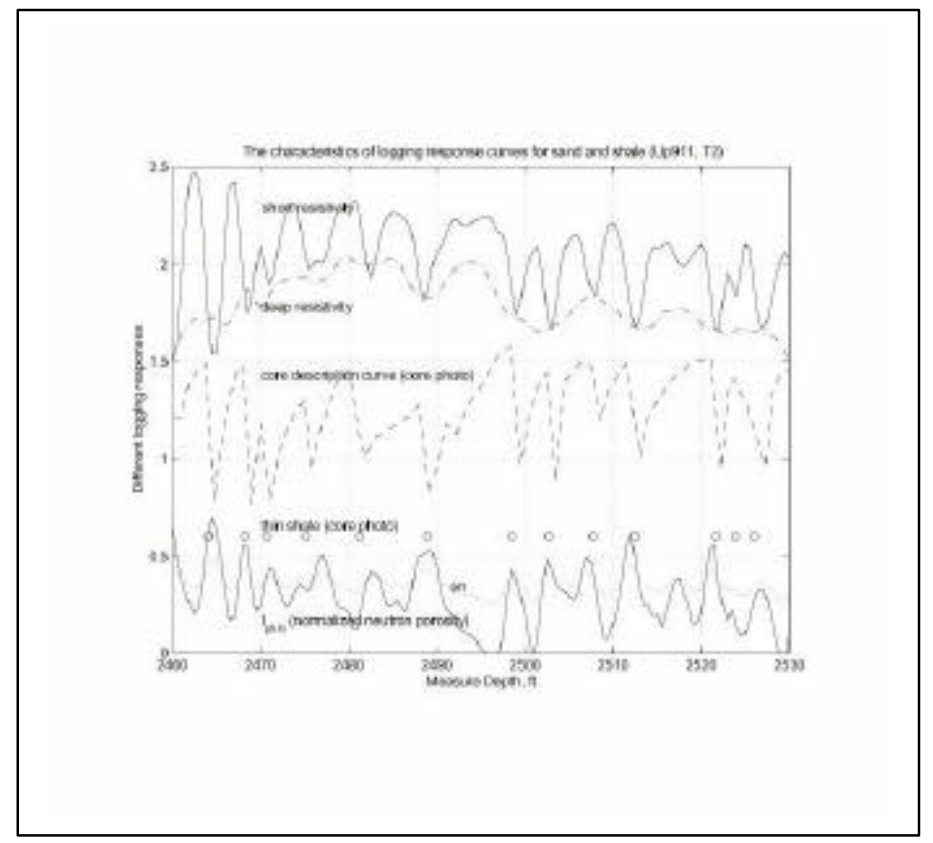

Figure 2.4.1-24: A schematic correlation of shale strikes versus logging curve responses. remaining 27 shale streaks were detected by $\Delta$ Res $<0$. The percentage of shales detected by $\Delta$ Res indicator was $94 \%$ (30 of 32 ). This can be thought as a very reasonable indicator for T2 layers.

For the D1 sands of mid fan sedimentation, there were 24 shale/silty tops read from core photos. Eight of them had silty tops. Of these eight silty internals, two had $\Delta$ Res $>0$ and were detected by referencing to other shale responses. Future core permeability $\mathrm{K}$ should be tested for these tops. Of the 16 shales, two could not be detected by $\Delta \operatorname{Res}<0$. There was one $\Delta$ Res $<0$ log response with no shale streak found on core photos. For the D1 sands, the accuracy decreased to $79 \%$ (19 of 24). These results show that a mid fan D1 sand environment (thick blocky sand) has lower shale continuity than a T2 mid fan to outer fan environment. This is because the high energy of new sediments has eroded some of the old shale tops. Since some of the silty tops may be detected as "shale," the shale top permeability should be randomized with silt and shale permeability values. To improve this situation in future studies, special core cleaning and testing should be performed on the silt and shale samples because conventional core cleaning may disturb the silt/shale samples and increase their porosity and permeability. 


\section{Shale thickness statistics}

the Figure 2.4.1-25 is a plot of percentages of the shale streaks within the sands vs. the varying thickness of individual shale steaks for the T2 and D1 sub-sands from eight cored wells. The T2 shales had a mean thickness of 0.38 feet and a median of 0.3 feet. The D1 shales had a mean thickness of 0.32 feet and a median of 0.2 feet. The two accumulative curves have exponential shapes, which may offer an easy way for modeling in the future.

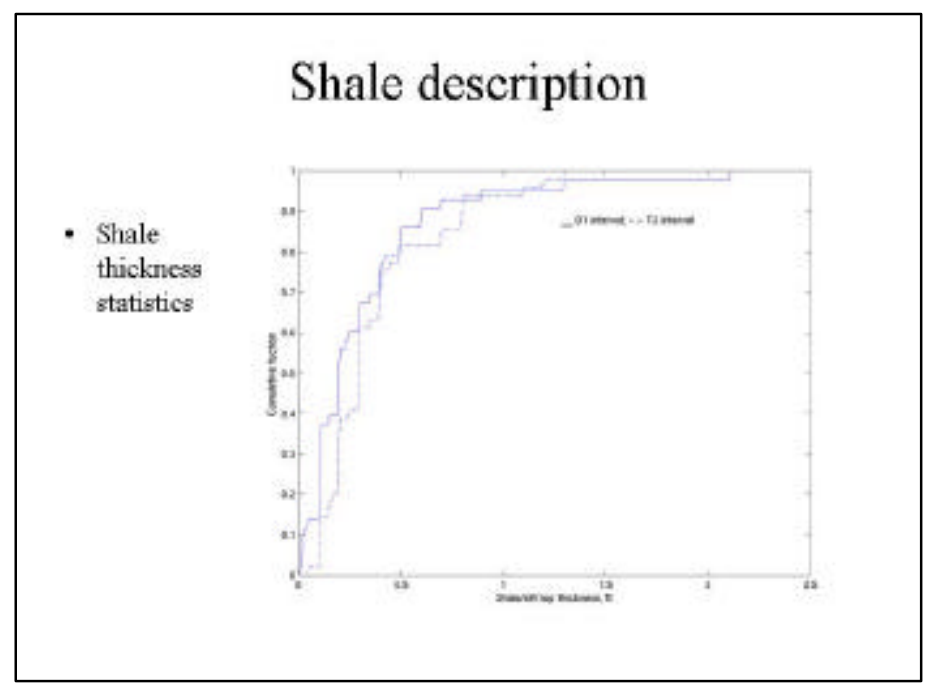

Figure 2.4.1-25: Shale thickness accumulative distribution functions for D1 and T2 intervals.

\section{Spatial continuity mapping}

To do shale continuity mapping, wells with modern logs (after 1980) were used. Logging curves (resistivity, gamma ray, SP, and bit size) for the specified D1 interval for each well were laid out according to their spatial position. Based on the criterion developed to recognize shale streaks, each well's resistivity curves were labeled with "shale" at certain spots. The shale correlation between wells was done from three aspects: the shale streak terminated or not, the sand bed thickness between two shale streaks and the general pattern change for a whole interval. Starting from one well, a shale interval was given a mark (numerical number or alphabetic label). The same mark was correlated with and labeled on the adjacent wells. The process was repeated for all available wells until the shale streak terminates. For the same mark, a list of wells and their corresponding measured depths for the mark were recorded. This correlating process was repeated for all shales found from one well. The process always started with the most significant shale streak first (resistivity values drop sharply with large difference between shale and sand, Res $<<0$, and the cross over thickness is thick, etc.).

\section{Irregular shale geometry simplification and its calculation}

After all the shales were identified for each well, a shale data sheet was made showing each shale and its corresponding $X-Y$ coordinate at measured depth. Each of the shales were displayed in 2-D view to measure its geometry. All points were differentiated between a real data point and a missing point with a list of all the shales by well. If a location showed a well existed but had no shale mark, it was considered a shale discontinuity point. Most of the shales have irregular areal shapes. To simplify the upscaling work later on, the reservoir simulation grid system was taken as a reference coordinate system. Figure 2.4.1-26 shows an example of how the shales 
were divided into rectangular grids and the two edges of each rectangle were aligned with the reference system coordinates.

To make the shale geometry data comparison with other fields, the areas of each shale layer were added together and the square root of the total area was obtained as the shale size (square shape approximation). The accumulative curve of the D1 shale size is shown on Figure 2.4.1-27 together with the data from Haldorsen ${ }^{\mathrm{G} 7}$. For the T2 and D1 sands, there are very few shales with areas less then 2500 square meters (26,900 square ft) or lengths less than 50 meters long (164 feet). One reason for the lack of smaller-size shale areas is because shale streaks that existed in only one well were assumed to have a minimum half-well distance extension. However, there were only five cases of single point shales, so their effect on the model was minor. This study showed that the T2 and D1 sands tend to have longer discontinuous shales than the Haldorsen study for discontinuous shales for mid-fan sediments. The largest shale size may be limited by the size of our study area G34.

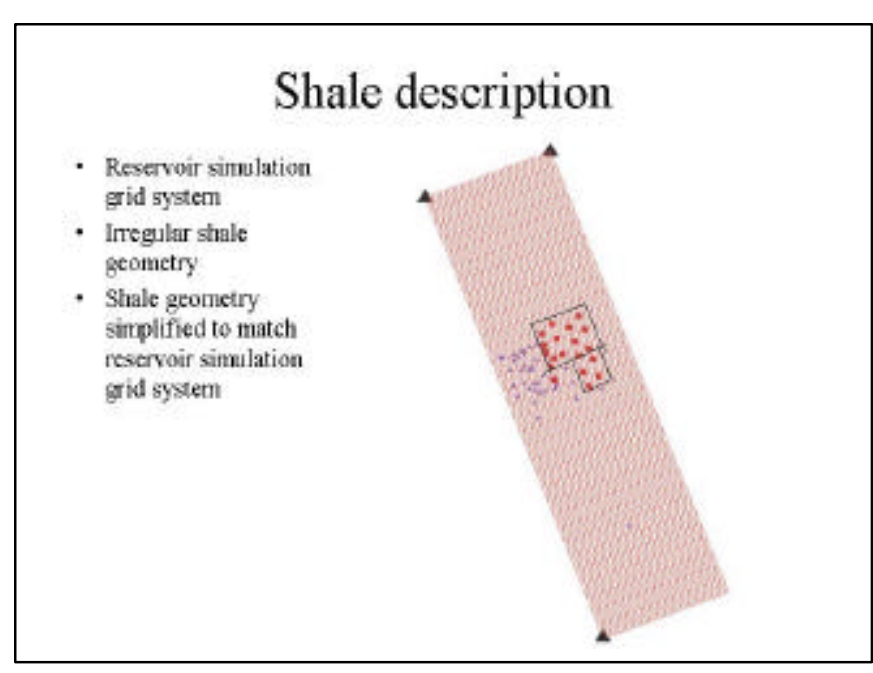

Figure 2.4.1-26: Shale geometry divided into rectangular grids.

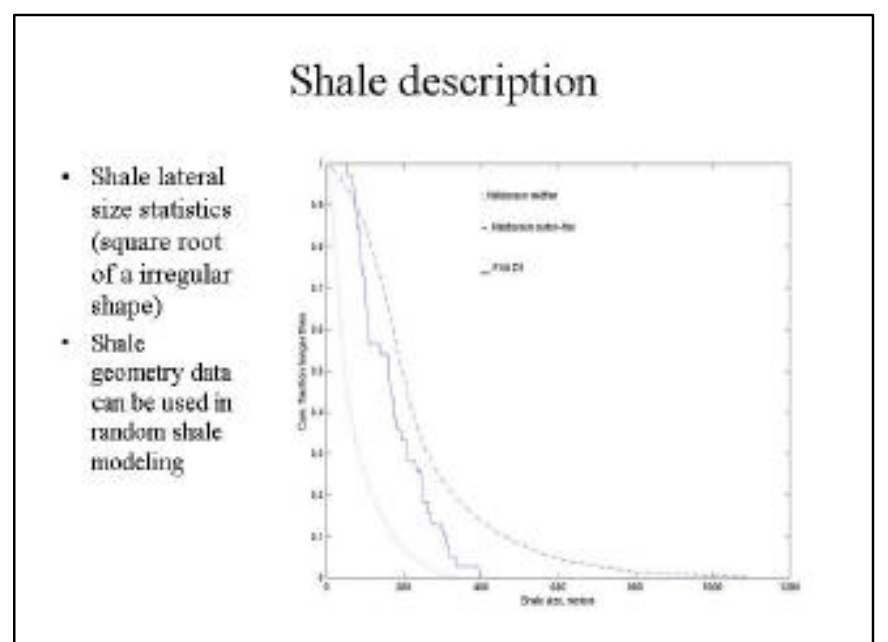

Figure 2.4.1-27: The accumulative distribution function of the equivalent square-shaped shale sizes, for D1 interval.

\section{Normalizing Shale Location and Transform Shale Center Coordinates}

The shale data were further modified to make the shale and sand system upscaling easier. First the $X Y$ coordinates for the center of each rectangular piece of shale were determined and then the coordinates were transformed to match the stochastic modeling stratigraphic grid system. The vertical location of each shale piece was given a measured depth at a representative well. Then all pieces of shale vertical locations were normalized to the interval thickness at each representative well. The number of shales to be included in a reservoir simulation grid was based on the number of vertical grid layers used in the reservoir simulation model. Combined with the 
upscaled stochastic SGS permeability values, the effective vertical permeability of a reservoir simulation grid was calculated. The upscaling of each parameter is discussed in next section.

\section{Upscaling Issues}

Upscaling is a complicated problem. For volumetric quantities, such as porosity, the upscaling is a simple arithmetic average of small grids. For vector quantities, such as permeability, there are no generally accepted methods, especially when multi-phase flow of relative permeability is considered. The following three sections review upscaling techniques and suggestions are given for dealing with upscaling problems.

\section{Arithmetic Average for Porosity}

The arithmetic average method for porosity data is accepted because porosity is a volumetric scalable quantity. The process can be very simple: 1) Select a reservoir simulation grid; 2) Identify all stochastic grids it contains; and 3) Calculate the arithmetic average value of all the stochastic grids. Repeat steps 1,2 and 3 for all reservoir simulation grids using the RESGRID system. For an efficient and simple calculation, use the stochastic simulation stratigraphic grid (SGRID) system because it matches the coordinate directions of the reservoir simulation grid system and a RESGRID contains full SGRIDs.

\section{Renormalization Upscaling for Sand Permeability}

For the steamflood process, upscaling should be done for the phase permeability. There is no generally accepted and valid method currently available. In most cases, the permeability upscaling is simplified only for absolute permeability. Even for absolute permeability upscaling, there are many methods referenced in the literature, each having various pluses and minuses. McGrill, et al ${ }^{\mathrm{G} 35}$ compared different methods and pointed out that the renormalization technique developed by King G36 has an accuracy of $10-20 \%$. The major advantage of this method is that the calculation is fast and the method is used often.

For a 2-D system example, the renormalization procedure breaks a large heterogeneous system down into a sequence of multilevel, easy-to-manage smaller $2 \times 2$ sub-blocks. Subsequently, the system is rebuilt in a hierarchical fashion in order to account for the tortuous paths of a heterogeneous media. The effective permeability of each sub-block can be calculated analytically, yielding a new higher level with onefourth the blocks. This process is repeated until only one-block remains. The final block has the effective permeability of the original system. A 3-D system should be done using the same procedure as referenced in King ${ }^{\mathrm{G} 36}$.

For the convenience of calculation, the SGRID system needs to satisfy the same requirements as for the stochastic simulation of porosity. Also, the number of SGRIDs within each RESGRID should be an exponential number with a base of 2 . This can be 
done with a 2-D horizontal system. More consideration may be needed for a 3-D system where the vertical direction has limited thickness.

\section{Stream Line Approach for Shale / Sand Vertical Effective Permeability}

Begg, et al. ${ }^{\text {G5 }}$ developed a simple procedure to calculate the effective vertical permeability for a reservoir containing discontinuous shales. The major advantage is the calculation is fast and the accuracy is very satisfactory. The system setting for each RESGRID block contains sand and stochastic shales distributed inside the block. The shales are parallel to the block bottom. The upscaling process is summarized as discussed below.

First the number of streamlines is chosen. The starting points of those streamlines are evenly distributed on the RESGRID block bottom surface. The length of each streamline is calculated as follows: 1) Trace the streamline upwards until it meets the first shale and then move it to the end of the shale closest to its current position; 2) Repeat process (1) to meet second, third, etc. shales until the top of the block is reached and then move the streamline to its initial starting horizontal position. Steps 1 and 2 are repeated for all streamlines. In tracing a streamline movement, the total distance moved and the sum of the distances moved in different permeability layers (if layering exists) should be recorded so that both its real length and its effective length can be calculated. Then an average streamline length can be obtained by averaging all streamlines lengths. The effective vertical permeability is calculated by a simple equation using the streamline data. See Begg, et al. ${ }^{\text {G5 }}$ for more details.

One difficulty of this method is that their work did not explicitly discuss how to calculate effective permeability of a block if a piece of shale is larger than the block size, i.e. the block is totally "sealed" by a shale (shale touches all 4 boundaries). Begg and King ${ }^{\mathrm{G} 6}$ mentioned that this case and shale overlapping were handled by a "routine", however, they did not give the routine in their paper. As such, this case should be treated as layers of sand and shales to obtain the harmonic average vertical permeability value. Another question is that the reservoir block is reasoned to have enough discontinuous stochastic shales in order to obtain reliable streamline-upscaling results. The Tar II-A deterministic reservoir grid model only has shales that separate the major sands. Begg and King did show one single shale test result, which has a very good match of streamline results with other standard results, but they did not provide all of the test conditions. It is recommended that these two problems have be clarified before using the streamline method.

\section{Conclusions}

For the detailed, systematic reservoir characterization and stochastic geologic modeling for the FB II-A Tar Zone, the following can be concluded:

1. Geological turbidite concepts have been successfully applied to direct engineering evaluation of turbidite depositional sequences. Based on the sequence 
evaluation results, the Tar Zone stochastic modeling problem is de-coupled into a turbidite top shale model and a sand model.

2. The means for developing detailed porosity and permeability stochastic modeling processes were discussed.

3. GOCAD was used to generate Variograms and Cloud Transforms to be used in the Sequential Gaussian Simulator to generate geologic stochastic porosity and permeability models to be incorporated into the stochastic reservoir simulation model.

4. The reservoir simulation grid system was the framework for creating the stochastic stratigraphic grids, which will lead to easy upscaling operations in the future.

5. Detailed shale continuity mapping methods, procedures and results were given. The procedures and results can be used in similar turbidite reservoir shale modeling studies such as in the neighboring fault blocks.

6. Upscaling procedures for different reservoir properties were discussed. This should be very helpful for the future continuation of this work.

\section{Future Work}

1. Generate variograms and cloud transforms to be used in the Sequential Gaussian Simulator to generate geologic stochastic porosity and permeability models that will be loaded into the stochastic reservoir simulation model.

2. The T2 layer will probably have much stronger vertical non-stationary influence because of the stronger interleaving of shale streaks within sand intervals. To avoid this, the formation can be divided into reservoir simulation grid intervals. For each interval, delete the high shaliness streaks and obtain the interval average shaliness indicator values. The average shaliness indicator value can be the conditioned values for each well and 2-D SGS simulation can then be performed for all intervals. To convert shaliness indicator to permeability, the cloud transform curves need to be corrected by deleting low permeability $K$ streaks. Similarly, shales can be independently mapped and partially combined with sands.

3. Use the Sequential Indicator Simulation (SIS) to investigate the shale spatial continuity and compare with the deterministic approach results from this study.

4. Shale/silt samples have to be selected and tested with caution. Some of the shale/silt samples had unreasonably high porosity and permeability values for the past tests. This is possible due to improper sample preparation and test conditions. This work can significantly affect shale characterization.

5. Shale/silt top identification may be further investigated. A simple approach is to correlate the Res values and/or resistivity, and other shaliness indicator values with the observed "silt" and "shale" and then use these values to determine if a streak is really a shale. This can lead to faster and more accurate shale continuity mapping.

6. Complete the mapping of the silt/shales based on resistivity and density logging data.

7. Determine which upscaling procedures will be used for the porosity, permeability, and silt/shale model. 


\section{ACTIVITY 3 - RESERVOIR SIMULATION}

\subsection{Deterministic 3-D thermal Reservoir Modeling}

\section{Introduction}

A three dimensional (3-D) deterministic reservoir simulation model of the Tar II-A sands was developed, history-matched and validated, and used to develop revised operational strategies that were successfully implemented. The Tar II-A sands presented a formidable simulation challenge in part because of the significant formation compaction and rebound they underwent due to primary production and subsequent waterflooding. The reservoir's apparent sensitivity to pressure changes and fluid displacement as well as the dynamic operational changes complicated the simulation because physical properties normally considered constant varied significantly over the reservoir's productive life.

To accurately portray the reservoir, a model was needed that could treat porosity, permeability, compressibility, and formation thickness as variables. Once the STARS ${ }^{\text {TM }}$ Thermal model by the Computer Modelling Group (CMG) was selected, a compactionrebound algorithm was developed and incorporated into the model based on rock mechanics considerations. Adding this level of sophistication resulted in the ability to model compaction/rebound dynamics as a function of pressure at any given point in the reservoir.

The resulting model accurately history matched primary and waterflooding production, quantitatively determined formation compaction / rebound, estimated the contribution from the Tar Zone to the total surface subsidence caused by the pressure depletion and compaction of the upper four producing zones (Tar, Ranger, Upper Terminal, and Lower Terminal), and was used as an integral tool in developing, testing and implementing a critical realignment of operational strategy.

\subsubsection{Reservoir and Geologic Description}

Figure 3.1.1-1 shows the location of Fault Block II-A in the Wilmington Oil Field, extending across an area 3 miles long and 1 mile wide. The Tar formation has an area of approximately 265 acres, with the steamflood area encompassing about 250 acres.

Structurally, the Tar Zone is a broad anticline bounded on the west by the Wilmington Fault and

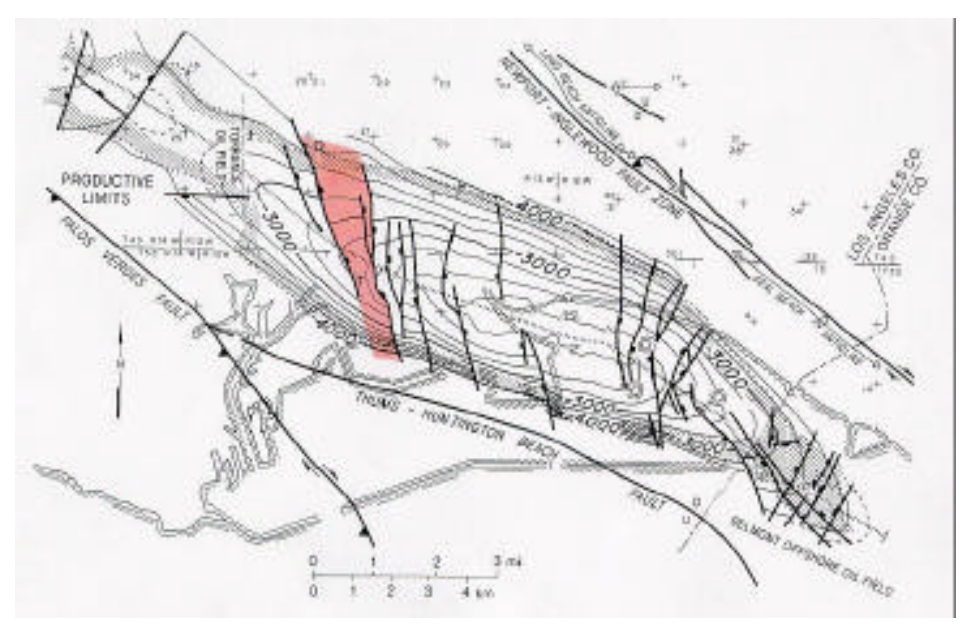

Figure 3.1.1-1: Fault Block II-A, Wilmington Field. 
on the east by the Ford Fault. The reservoir is a slope and basin clastic type and falls under the U.S. DOE's Class III classification. Its deep marine turbidite sand deposition lies in a northeast to southwest direction.

Oil production from the Tar formation is from the $T$ and $D$ sands with an average producing depth of about 2,200 $\mathrm{ft}$ for the $\mathrm{T}$ sand and $2,450 \mathrm{ft}$ for the $\mathrm{D}$ sand and a net oil sand thickness of approximately 120 feet. A type log of the Tar formation is given in Figure 3.1.1-2. The $T$ and $D$ sands produce heavy oils, with gravities approximating $14^{\circ} \mathrm{API}$ and viscosities averaging $280 \mathrm{cp}$ at a $123^{\circ}$ $F$ reservoir temperature. The $T$ and $D$ producing sands are Lower PlioceneRepetto in age. These unconsolidated sands have an average porosity of about 30 percent and permeabilities ranging from 1,000-1,500 millidarcies.

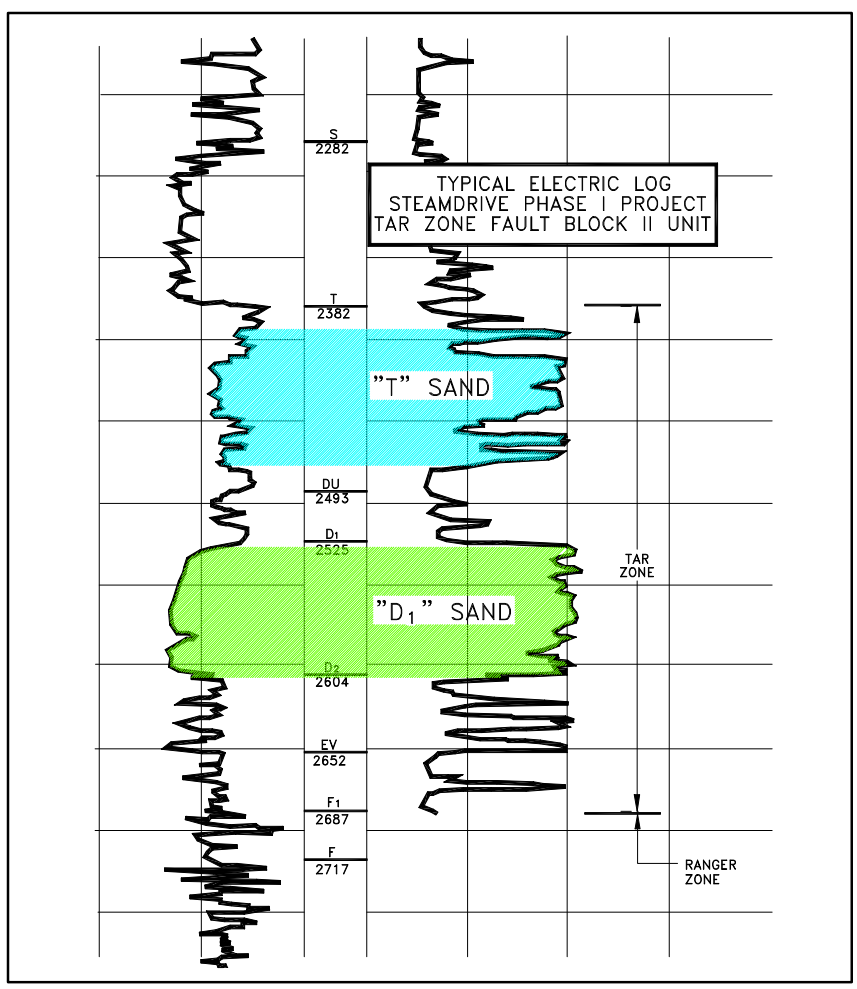

Figure 3.1.1-2: Typical Tar Zone Electrical Log Pattern

\subsubsection{Production and Operational History}

Production began in 1937 with original oil in place (OOIP) estimated at 98.5 MMBO. Total production through March 2000 was $34.6 \mathrm{MMBO}$ or $35.1 \%$ of OOIP.

The Tar formation has undergone several revisions to its reservoir management. After being produced under primary production for over two decades, it was converted to waterflood to arrest surface subsidence. This was followed in 1982 by steamflood injection. The primary production mechanism was a combination of compaction and solution gas drives as well as partial water drive support from the north and south flanks. Through 1960, cumulative primary production accounted for $15 \%$ of the OOIP.

Reduced reservoir pressure caused formation compaction in the top four producing intervals, including the Tar formation, and resulted in significant surface subsidence. By the 1950s, Fault Block II-A had experienced an estimated total subsidence of 15.5 feet. Subsidence was arrested by the initiation of water injection in 1960 into these stress-sensitive unconsolidated sands. Water injection not only arrested declining reservoir pressures but caused partial surface rebound, though not to the magnitude of subsidence levels. Less than 10 percent rebound has occurred to date, indicating the irreversibility of the compaction/rebound process. The initiation of waterflooding accounted for an additional $8.45 \%$ of the OOIP being produced. 
The Tar Zone's heavy gravity and high viscosity crude oil proved resistent to the waterflooding displacement mechanism, and in 1982 a 20-acre steamflood pilot project was initiated using four inverted 5 -spot patterns. The pilot project was very successful. In 1989, the Tar Zone was converted to a full, 7-spot steamflood operation (Figure 4). Several expansion phases followed, including a conversion of some steam injection to hot water injection and the drilling of four horizontal wells drilled to the south to utilize a pseudo steam-assisted gravity drainage (SAGD) recovery method. Steamflood recovery of oil from $1982-1999$ was $46 \%$ of OOIP.

In early 1999, the steamflood and hot water injection area was converted to cold water flank injection with an cumulative production from February 1999 to March 2000 of $330,000 \mathrm{BO}$.

\subsubsection{Description of the Model}

After a thorough review of competitive simulation packages, the STARS ${ }^{\text {TM }}$ Thermal model by the Computer Modelling Group (CMG) was selected. The advantage offered by STARS was its ability to handle the compaction-rebound process in the simulation. CMG allowed the compaction-rebound process algorithm developed by USC to be incorporated into all future STARS models.

Efforts to build the geological basis for the simulation were aided by the prior development of a 3-D deterministic geological model using the EarthVision ${ }^{\mathrm{TM}}$ model by Dynamic Graphics Inc. The database used was Production Analyst ${ }^{\mathrm{TM}}$ by Geoquest.

The STARS thermal model consisted of 26,660 grid blocks ( $43 \times 155 \times 4$ grids), with aquifers on the north and south flanks. The model's four layers were expanded to 13 layers to account for steam gravity override to simulate the 20 -acre steamflood pilot and 150 acres of steamflood expansions. This increased the number of grid blocks to 86,645 .

\subsubsection{Development of the Compaction/Rebound Algorithm}

Development of a model that could simulate compaction and rebound was crucial. Conventional models that describe compaction and rebound and predict their effects on the reservoir use one of two approaches. In the first, more conventional approach, fluid flow systems are calculated as functions of variations in formation pore compressibilities $^{\mathrm{H} 1}$. In the second, more sophisticated approach, fluid flow systems are coupled with geomechanical descriptions in simultaneous or sequential numerical schema. This procedure, known as the coupled method, is more rigorous and theoretically more accurate but was considered impractical for modeling the expansive Tar II-A reservoir. The level of accuracy of the geomechanical data was not high enough to warrant the rigorous mathematical treatment and the computational requirements were considered too cumbersome. Sattari theorized that using the 
coupled approach could increase computation time by an order of magnitude over the conventional approach ${ }^{\mathrm{H} 2}$.

\subsubsection{Mathematical Derivation of Compaction/Rebound Algorithm}

For this compaction/rebound model, the conventional approach was modified through development and employment of an algorithm that considered geomechanical variations caused by changes in effective stress and formation compressibilities. The algorithm was developed and is described by Yang, Ershaghi, Mondragon \& Hara [SPE paper 49314].

To model compaction due to pressure depletion, the model solves the fluid flow equations as a function of variations in formation compressibility. Formation porosity, a function of formation compressibility, can be expressed as follows ${ }^{\mathrm{H} 2}$ :

$\phi^{*}=\phi^{0}\left[1+c_{p}\left(p-p^{0}\right)-c_{T}\left(T-T^{0}\right)\right]$

where $p$ and $T$ are reservoir pressure and temperature (the superscript ' 0 ' indicates initial conditions.), $\phi{ }^{*}$ is the equivalent porosity assuming formation compaction, and $c_{p}$ and $c_{T}$ are formation compressibility and thermal expansion coefficient, respectively.

In the geomechanical equations, the volumetric strain $\varepsilon_{V}$ is approximated as ${ }^{\mathrm{H} 4}$

$\varepsilon_{V}=-\frac{d V_{b}}{V_{b}^{0}}=c_{b}\left(I_{1}-I_{1}^{0}\right)-\left(c_{b}-c_{r}\right)\left(p-p^{o}\right)-\alpha_{d r}\left(T-T^{o}\right)$

Where $c_{b}$ and $c_{r}$ are the bulk and rock matrix, $\varepsilon_{d r}$ is a volumetric thermal expansion coefficient, $V_{b}$ is the bulk volume, and $\left.\left.l_{1}\left(=\sigma_{1}+\sigma_{2}+\sigma_{3}\right) / 3\right)\right)$ is the average principle stress.

If the average principle stress could be expressed as a function of a change in pressure, the geomechanical component can be separated from the fluid flow components.

Total strain $\varepsilon_{t i}$ in a reservoir is the summation of elastic strain $\varepsilon_{e i}$ and plastic strain $\varepsilon_{p i}$, as follows:

$\varepsilon_{t i}=\varepsilon_{e i}+\varepsilon_{p i} \quad(\mathrm{i}=1,2,3)$

According to work by Geertsma ${ }^{\mathrm{H} 5}$, the elastic strain in the principle direction can be expressed as

$\varepsilon_{e i}=-\frac{1}{3}\left(c_{b}-c_{r}\right) d p+\frac{d \sigma_{i}-d I_{1}}{2 G_{b}}+\frac{1}{3} c_{b} d I_{1}$

where $G_{b}$ is a shear modules. 
Plastic strain is a function of elastic and plastic deformations. The plastic deformation rate $\left(\dot{\varepsilon}_{p i}=\frac{d \varepsilon_{p i}}{d t}\right)$ can be described as ${ }^{\mathrm{H} 3}$

$$
\dot{\varepsilon_{p i}}=-\frac{1}{3}\left(\frac{1}{\xi_{b}}-\frac{1}{\xi_{r}}\right) d p+\frac{d \sigma_{i}-d I_{1}}{2 \mu_{b}}+\frac{1}{3 \xi_{b}} d I_{1}
$$

where $\xi_{\mathrm{b}}, \mu_{\mathrm{b}}$ and $\xi_{\mathrm{r}}$ are the coefficients of bulk volume viscosity, bulk shear viscosity and rock matrix volume viscosity, respectively. Assuming that $d p, d \sigma_{i}$ and $d l_{1}$ are independent of $d t$, the plastic strain can be expressed by integrating (5) as a function of time as:

$\varepsilon_{p i}=-\frac{t}{3}\left(\frac{1}{\xi_{b}}-\frac{1}{\xi_{r}}\right) d p+\frac{d \sigma_{i}-d I_{1}}{2 \mu_{b}} t+\frac{t}{3 \xi_{b}} d I_{1}$

Substituting elastic and plastic strains, total strain can be expressed as

$$
\begin{aligned}
\varepsilon_{t i i}= & -\frac{1}{3}\left(c_{b}+\frac{t}{\xi_{b}}-c_{r}\right) d p+\frac{1}{2}\left(\frac{1}{G_{b}}+\frac{t}{\mu_{b}}\right)\left(d \sigma_{i}-d I_{1}\right) \\
& +\frac{1}{3}\left(c_{b}+\frac{t}{\xi_{b}}\right) d I_{1}
\end{aligned}
$$

where $\xi_{r}=\infty$ is assumed beforehand.

The stress-strain boundary condition for a reservoir can act as a constant stress in the vertical direction with no bulk deformation in horizontal plane as follows:

$$
d \sigma_{2}=d \sigma_{3}=\frac{3}{2} d I_{1}
$$

Using this boundary condition, average principle stress can be shown as a function of pore pressure as follows ${ }^{\mathrm{H} 3}$

$$
d I_{1}=\frac{c_{b}+\frac{t}{\xi_{b}}-c_{r}}{\left(c_{b}+\frac{t}{\xi_{b}}\right)+\frac{3}{4}\left(\frac{1}{G_{b}}+\frac{t}{\mu_{b}}\right)} d p=f_{1} d p
$$

Eq. (9) can be simplified by combining the elastic and plastic components into the term $f_{1}$ as follows:

$$
\left(I_{1}-I_{1}^{0}\right)=f_{1}\left(p-p^{0}\right)
$$


Eq. (9A) describes the relationship between changes in average principle stress as a function of the geomechanical components expressed by the term $f_{1}$ and changes in pressure providing for the separation of geomechanical equations and fluid flow equations. The average principle stress given in Eq. (2) can now be expressed in term of pore pressure as follows:

$\varepsilon_{V}=-\left(c_{b}-c_{r}-f_{1} c_{b}\right)\left(p-p^{0}\right)+\alpha_{d r}\left(T-T^{0}\right)$

Equivalent formation porosity $\phi^{*}$ is a function of true porosity $\phi$ and volumetric strain $\varepsilon_{V}$ as follows:

$\phi^{*}=\phi\left(1-\varepsilon_{V}\right)$

where true porosity $\phi$ can be expressed as ${ }^{\mathrm{H} 2}$.

$$
d \phi=d\left(V_{p} / V_{b}\right)=c_{b}\left(1-\phi-\frac{c_{r}}{c_{b}}\right)\left(d p-d I_{1}\right)
$$

Upon substitution of Eq. (9) and integration,

$$
\begin{aligned}
\phi & =\phi^{0}+\left[c_{b}\left(1-\phi^{0}\right)-c_{r}\right]\left(\Delta p-\Delta I_{1}\right) \\
& =\phi^{0}+\left[c_{b}\left(1-\phi^{0}\right)-c_{r}\right]\left(1-f_{1}\right)\left(p-p^{0}\right)
\end{aligned}
$$

Substituting Eqns. (13) and (10) into Eq. (11), equivalent formation porosity can be expressed as

$$
\phi^{*}=\phi^{0}\left[1+c_{p 1}\left(p-p^{0}\right)-c_{T 1}\left(T-T^{0}\right)\right]
$$

Where the equivalent formation compressibility $c_{p 1}$ and thermal expansion coefficient $c_{T 1}$ can be calculated if pressure is known as follows:

$$
\begin{aligned}
c_{p 1}= & \frac{\left[c_{b}\left(1-\phi^{0}\right)-c_{r}\right]\left(1-f_{1}\right)}{\phi^{0}}+\left[\left(1-f_{1}\right) c_{b}-c_{r}\right] \\
& +\frac{\left[c_{b}\left(1-\phi^{0}\right)-c_{r}\right]\left(1-f_{1}\right)}{\phi^{0}}\left[\left(1-f_{1}\right) c_{b}-c_{r}\right]\left(p-p^{0}\right)
\end{aligned}
$$

and

$c_{T 1}=\alpha_{d r}\left\{1+\frac{\left[c_{b}\left(1-\phi^{0}\right)-c_{r}\right]\left(1-f_{1}\right)\left(p-p^{0}\right)}{\phi^{0}}\right\}$ 
Assuming that pressure dependency is small enough to be neglected, Eqns. (5) and (16) can be simplified to

$$
\begin{aligned}
& c_{p 1}=\frac{\left[c_{b}\left(1-\phi^{0}\right)-c_{r}\right]\left(1-f_{1}\right)}{\phi^{0}}+\left[\left(1-f_{1}\right) c_{b}-c_{r}\right] \\
& c_{T 1}=\alpha_{d r}
\end{aligned}
$$

By calculating the compressibility and thermal coefficients using the above equations and then solving for equivalent formation porosity, reservoir compaction is quantified without having to couple the geomechanical equations.

Focusing on developing an algorithm to represent reservoir rebound, the relationship between elastic and plastic deformation must be understood. Elastic deformation will recover when load is released, while plastic deformation will not recover upon release. Figure 3.1.5-1 indicates the laboratory results ${ }^{\mathrm{H} 4}$ comparing stress $\sigma_{z}$ and strain $\varepsilon_{z}$ for porous media. Uniaxial stress $\sigma_{z}$ represents pore pressure and, if bulk deformation is assumed zero in the horizontal direction, strain $\varepsilon_{z}$ represents volumetric strain $\varepsilon_{V}$. Since porosity $\phi^{*}$ is a function of volumetric strain (Eqn. 11), the

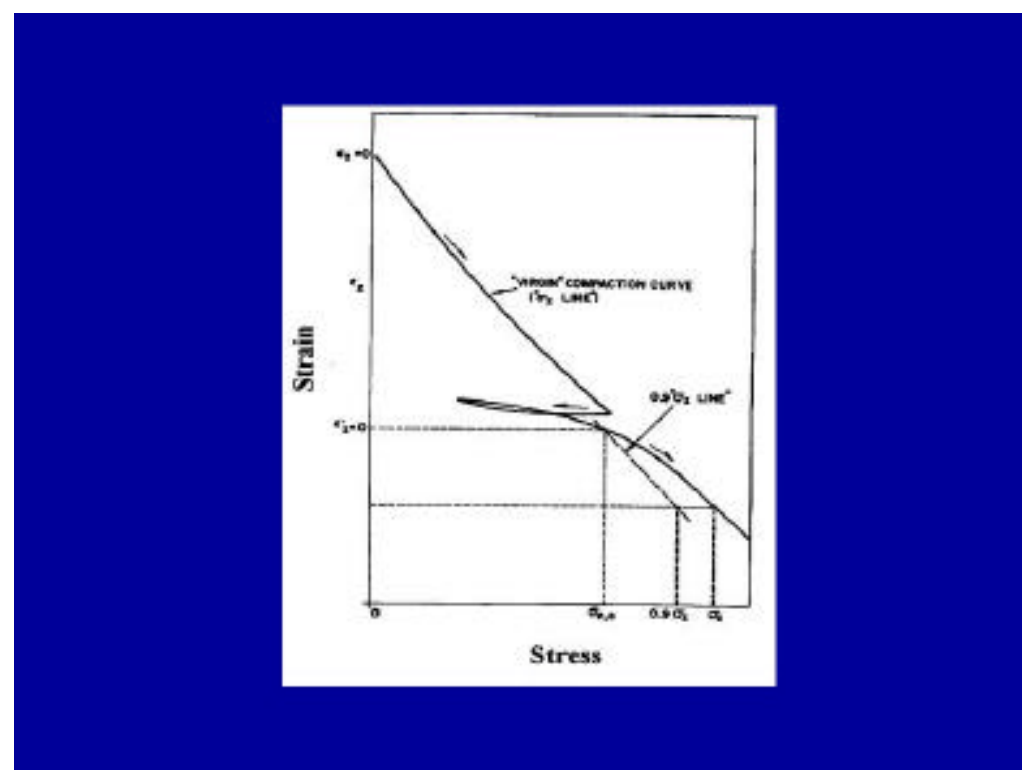

Figure 3.1.5-1: Stress-strain relationship for porous media

porosity-pressure relationship will behave similarly to the stress-strain relationship. (Hysteresis of the unloading and reloading loop is neglected since it is small relative to hysteresis between compaction and rebound.) During pressure depletion, the porosity variations will follow the compaction curve; however, porosity variation will follow the unloading/reloading curve when the system is unloading or reloading. At some minimum pressure, pressure $p_{\min }$, porosity returns to its value before unloading. Therefore, using a similar progression of logic presented above for development of the compaction algorithm for porosity, porosity values in a rebounded reservoir become:

$$
\phi^{*}=\phi_{\text {min }}\left[1+c_{p 2}\left(p-p_{\text {min }}\right)-c_{T 2}\left(T-T_{\text {min }}\right)\right] \quad \text { For } \mathrm{p}>p_{\text {min }}
$$

where 
$\phi_{\min }=\phi^{0}\left[1+c_{p 1}\left(p_{\min }-p^{0}\right)-c_{T 1}\left(T_{\min }-T^{0}\right)\right]$

and

$c_{p 2}=\frac{\left[c_{b}\left(1-\phi_{\min }\right)-c_{r}\right]\left(1-f_{2}\right)}{\phi_{\min }}+\left[\left(1-f_{2}\right) c_{b}-c_{r}\right]$

$c_{T 1}=\alpha_{d r}$

where $p_{\min }$ is the pressure at the point where unloading starts. The parameter $f_{2}$ is similar to $f_{1}$, but only includes the elastic deformation term. Values for $f_{1}$ and $f_{2}$ can be determined from history-matching both the formation compaction and rebound stages.

Focusing on a grid block, changes in reservoir thickness during compaction can be described by Eq. (2) as

$\varepsilon_{V}=-\frac{\Delta Z}{Z^{0}}=-\left(c_{b}-c_{r}-f_{1} c_{b}\right)\left(p-p^{0}\right)+\alpha_{d r}\left(T-T^{0}\right)$

where $\Delta Z=Z-Z^{0}$ is the change in reservoir thickness. For compaction, $\Delta Z=\Delta Z^{C}$ is considered negative and Equation (21) becomes

$\Delta Z=Z^{0}\left[\left(c_{b}-c_{r}-f_{1} c_{b}\right)\left(p-p^{0}\right)-\alpha_{d r}\left(T-T^{0}\right)\right]$

For rebound, the net thickness change of a grid is the sum of the compaction and rebound, which is

$\Delta Z=\Delta Z^{c}+\Delta Z^{r}$

where the amount of rebound is

$$
\Delta Z^{c}=Z^{0}\left[\left(c_{b}-c_{r}-f_{1} c_{b}\right)\left(p_{\min }-p^{0}\right)-\alpha_{d r}\left(T_{\min }-T^{0}\right)\right]
$$

where $\Delta Z^{r}$ is positive for rebound.

Geertsma ${ }^{\mathrm{H} 3}$ showed that $G_{b}=\frac{3}{4} \frac{M_{e b}}{c_{b}}$ and $M_{e b}=\frac{2\left(m_{e b}-2\right)}{\left(m_{e b}+1\right)}$. Within the applicable range of the Poisson constant $m_{e b}, M_{e b}$ may be taken as unity; therefore $G_{b} \approx \frac{3}{4 c_{b}}$. Therefore, during rebound, the processes can be considered reversible and

$$
f_{2}=\frac{c_{b}-c_{r}}{2 c_{b}} \approx 0.5
$$


where $c_{r}$ is assumed to be much smaller that $c_{b}$.

Assuming compaction, $f_{1}$ can be estimated by fitting production history data to Eq. (7). However, as an approximation, Geertsma ${ }^{\mathrm{H} 5}$ used the following elastic, spherical-tension model to approximate compaction:

$\varepsilon_{z}=\frac{1}{3}\left(\frac{1+v}{1-v}\right)\left(1-\frac{c_{r}}{c_{b}}\right) c_{b} d p$

Comparing Eqns. (26) with (10)

$f_{1}=-\left(1-\frac{c_{r}}{c_{b}}\right)\left[\frac{1}{3}\left(\frac{1+v}{1-v}\right)-1\right]$

where $v$ is Poisson's ratio.

If Poisson's ratio for oil sand is assumed to be $0.25, f_{1}=0.44$.

In the laboratory, it was shown that dependence of permeability on porosity is independent of stress and that changes in permeability are 4-5 times larger than porosity changes ${ }^{\mathrm{H}} 6$. Assuming that the reservoir's initial stress state and initial pressure are constant,t changes in porosity and permeability can be derived from changes in pressure ${ }^{\mathrm{H7}, \mathrm{H} 8}$.

The algorithms representing compaction and rebound developed above were incorporated into the CMG STARS $^{\text {TM }}$ model, the results of which are shown in Figure 3.1.5-2. The porosity irreversibility is illustrated using several different equivalent formation

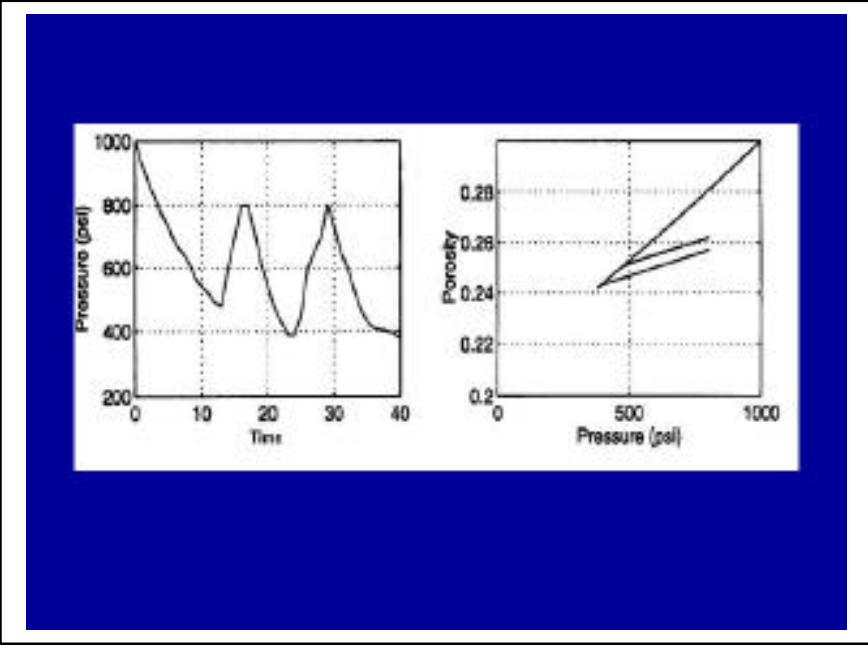

Figure 3.1.5-2: Demonstration of the compaction / rebound formulation. compressibilities for compaction and rebound processes, and the simulator selects the path dynamically according to the feature developed.

\subsubsection{Model Validation}

The simulation was history-matched to 23 years of primary production and 22 years of waterflood production. The model was validated when a seven-year projection of oil and water production for the 20-acre steamflood pilot compared favorably with actual total project production data. The model subsequently was able to closely match ten years of production from the 150 acres of steamflood expansion projects. 
The major reservoir parameters were determined as a function of the history match for the primary depletion and waterflooding processes. The formation compaction / rebound irreversibility was quantitatively determined and the contribution of the Tar Zone to the total surface subsidence was also estimated.

\subsubsection{History Match of Primary Depletion}

Since compaction occurred in the reservoir during primary depletion, a successful history match for this time-period was critical for full simulation validation. In addition, subsequent simulation of the waterflooding and steamflooding periods was dependent upon the formation compaction compressibility calculated during primary depletion. History matching considered the following parameters: equivalent formation compressibility, porosity, permeability, relative permeability, residual and initial water saturation, aquifer support and interactions with adjoining fault blocks.

One of the challenges in history matching during primary depletion was determining the relative contributions of formation compaction and natural water drive. Figure 3.1.7-1 depicts changes in reservoir pressure predicted by the model assuming no aquifer support and only formation compressibility contributing to the production. Using this assumption, there was not sufficient drive energy in the reservoir during its later stages to get a satisfactory history match. If formation compressibility is increased in the later stages, the

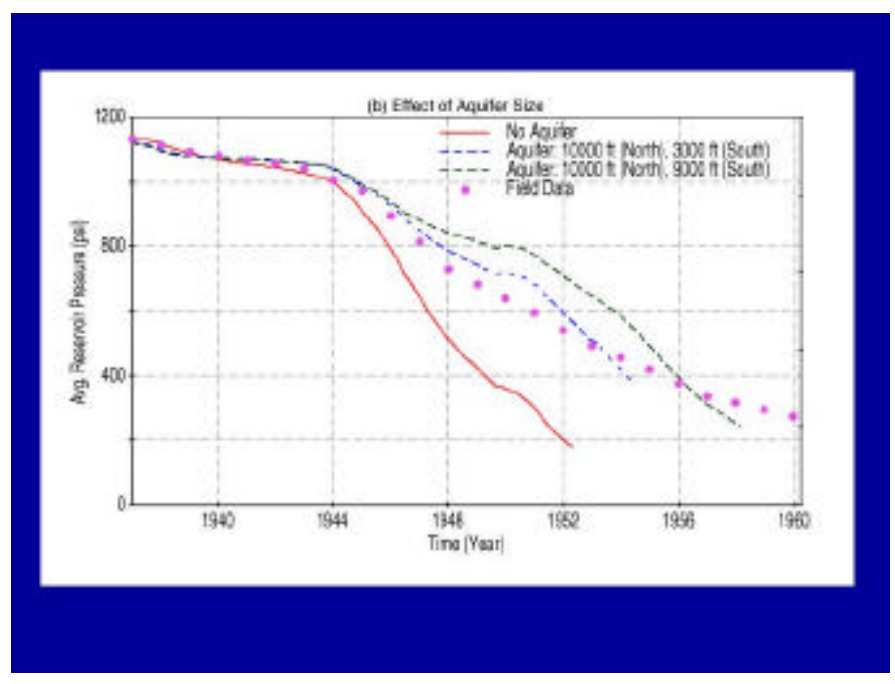

Figure 3.1.7-1: Effect of Formation Compressibility.

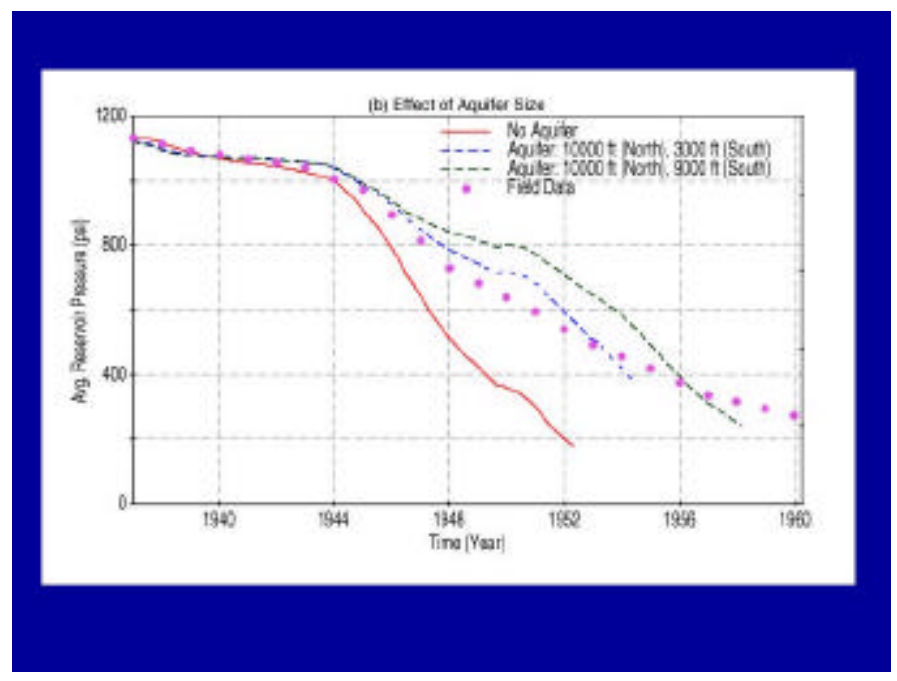

Figure 3.1.7-2: Effect of Aquifer Size early stage pressures are not history matched. This pressure differential is indicative of the order of magnitude of the aquifer support. Figure 3.1.7-2 shows the contribution of 
different aquifer sizes. It was determined that a northern aquifer matched the water production from the transition zone on the north side of the reservoir. It was also observed that an aquifer on the south side of the reservoir could not match the water production from the transition zone on the south side of the reservoir. Geological data supports this behavior as shown in Figure 3.1.7-3. The Tar II-A formation is bounded by faults on the east and west sides; however, on its southwest side which flanks Fault Block I, an open fault system exists where the Wilmington Fault fades. South of this location, both blocks share

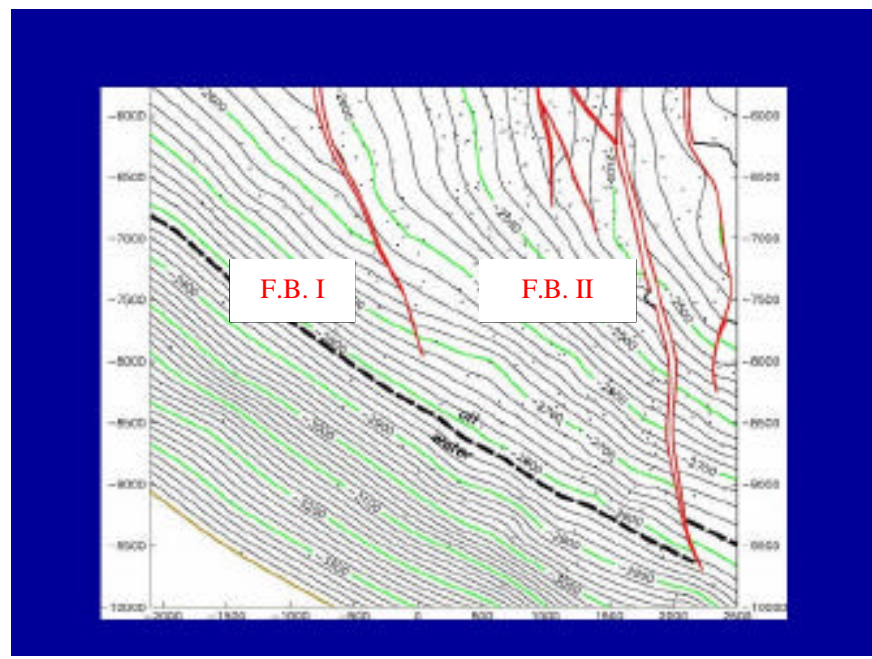

Figure 3.1.7-3: Structural contour map and location of WOC in the Tar of Fault Block II A. a common aquifer. A dynamic aquifer contribution model would therefore be required to successfully history-match production in Tar II-A formation.

To successfully determine formation compaction, field production history was analyzed. Figure 3.1.7-4 shows the of field data for the number of active producers, total liquid rate, and the pressure derivative for the primary depletion stage. During early primary depletion (1938-43), the number of active producers, the total liquid rate and the pressure derivative are constant. This result is indicative of the reservoir having reached a semi-steady state condition. The pressure derivative information during this state reflects the area's size and compressibility of the affected area.

Any additional energy required in the later stages of primary production was supplied from aquifer support and/or contributions from Fault Block I to the south. Based on this simplistic model, the magnitude of the northern aquifer was fixed at 10,000 feet and the contributions by the aquifer to the south were broken into a fixed

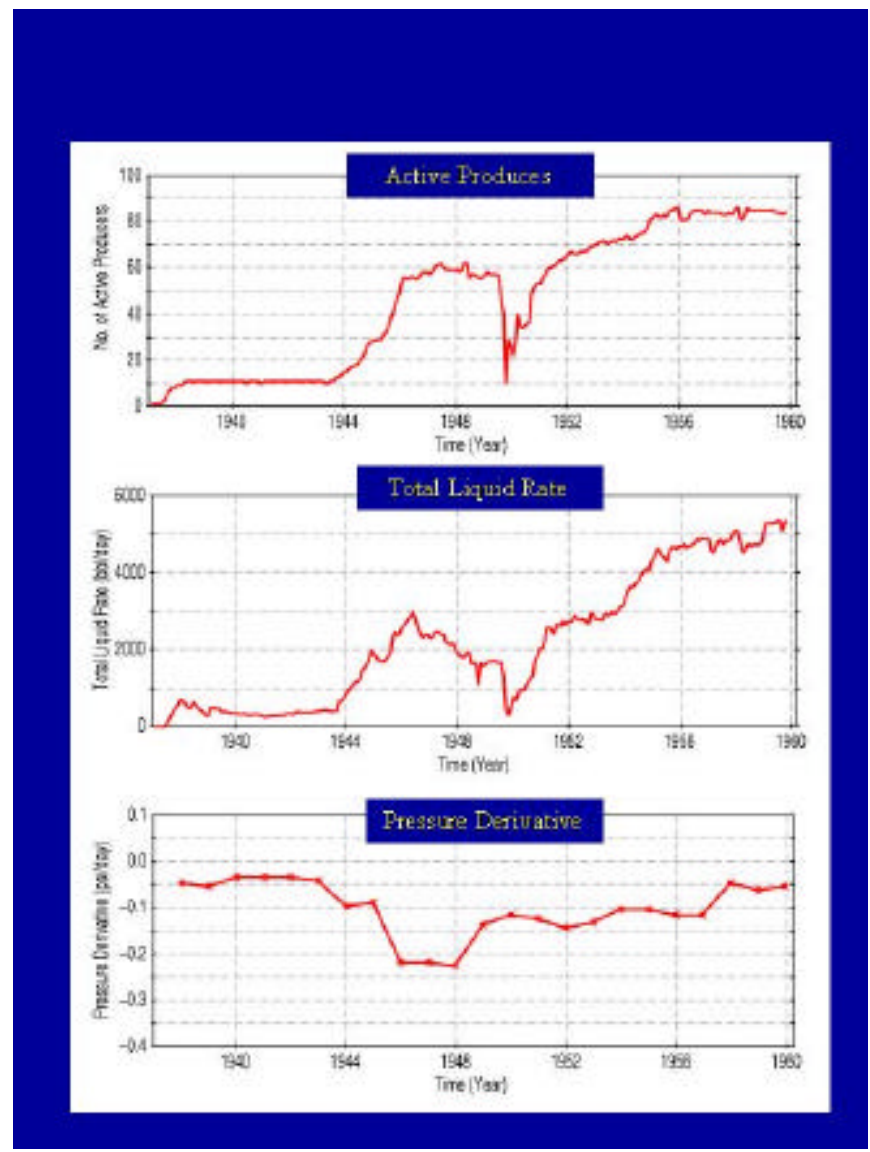

Figure 3.1.7-4: Field production history for the Tar Zone in Fault Block II. 
and variable component. The fixed contribution was 3,000 feet and the variable contribution as shown in Figure 3.1.7-5. Using these assumptions to model the aquifers, history matching of average reservoir pressure, oil, and water production rates was achieved as shown in Figure 3.1.7-6. The contributions of the aquifers were determined by matching WOR's in the transition zones as shown in Figure 3.1.7-7.

The model also calculated the change in formation thickness due to compaction. Figure 3.1.7-8 shows the formation compaction and equivalent

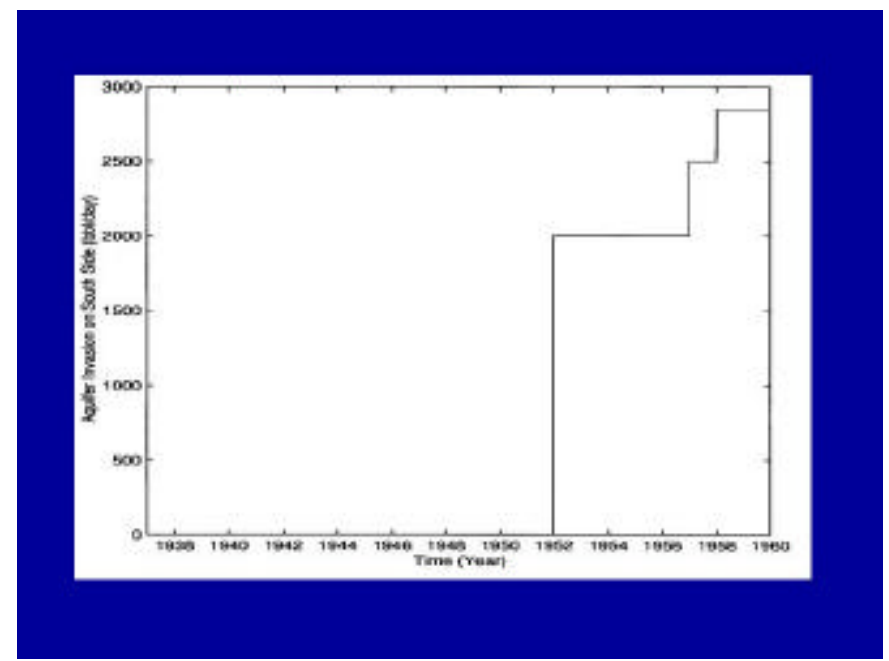

Figure 3.1.7-5: Dynamic aquifer invasion required for history matching the primary depletion stage.
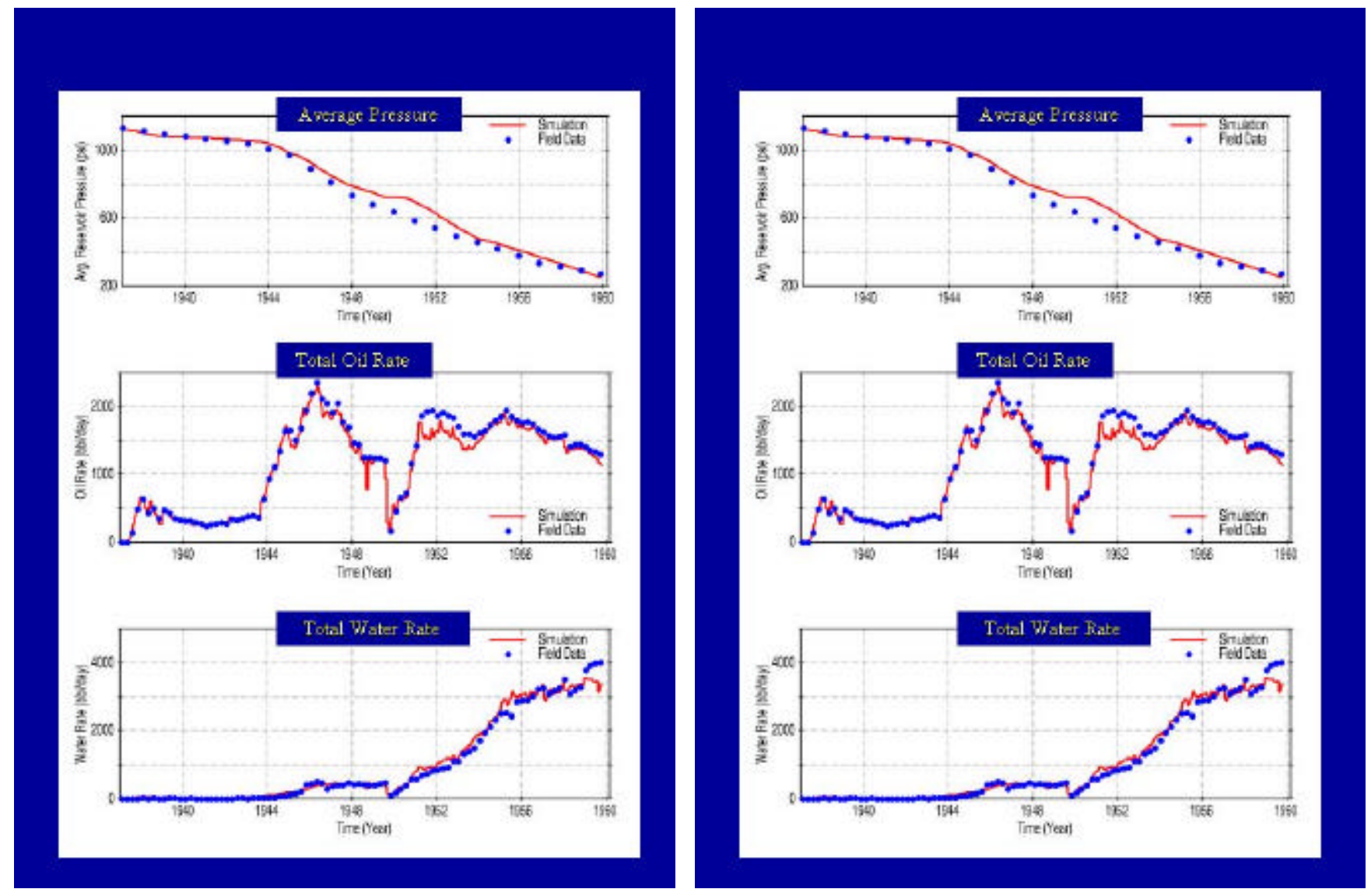

Figure 3.1.7-6: History matching results for the Fault Block II A.

Figure 3.1.7-7: WOR match for different regions in the Tar Zone of Fault Block II A. 
volumetric change as calculated from a material balance. The contribution from the Tar formation to the total subsidence in the block is slightly less than 2 feet, agreeing with estimates from a geological study $\mathrm{H} 1$ that sought to quantify compaction in the Tar formation.

\subsubsection{History Match of Waterflood}

Whereas primary depletion is characterized by a compaction process, waterflooding is characterized by a rebound process. Because of the irreversibility of the

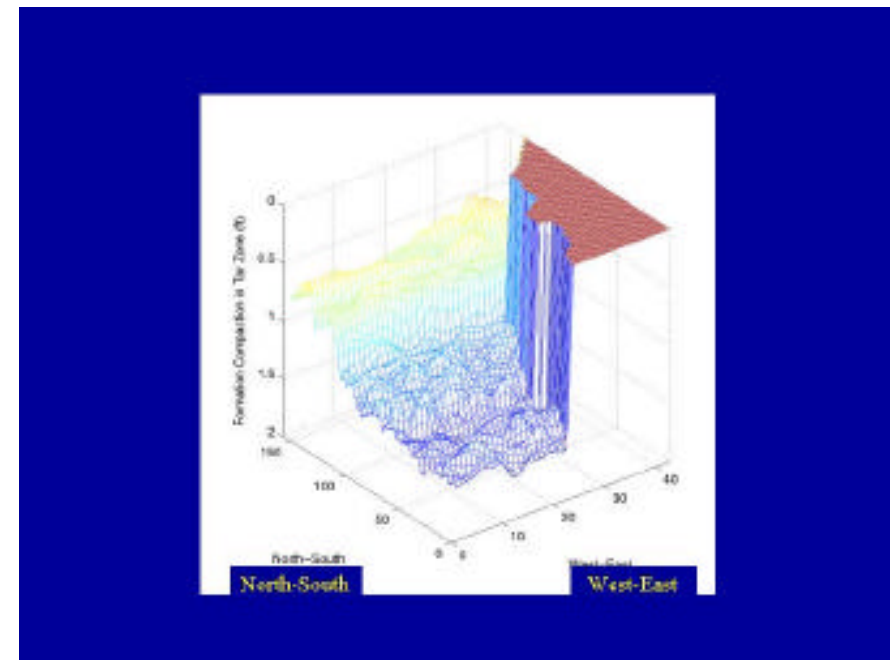

Figure 3.1.7-8: formation compaction in the Tar Zone of Fault Block II A.

compaction/rebound process, formation compressibility for waterflooding should be smaller than for primary depletion. In addition, primary production is a drainage process and waterflooding is an imbibition process. Relative permeability curves for both periods are given in Table 1.

Table 1. Reservoir Description

Structural data:

Net thickness, $\mathrm{ft}$, in $\mathrm{T} 1$ in $\mathrm{T} 2-\mathrm{T} 7$

in $\mathrm{D} 1$

in $\mathrm{D} 3$

Initial conditions:

Pressure (depth $2500 \mathrm{ft}$ ), psi

Temperature(depth $2500 \mathrm{ft}$ ), ${ }^{\circ} \mathrm{F}$

Initial Oil Saturation, \%

Rock Properties:

Porosity, \%

Permeability, md,

Compressibility, 1/psi, compaction, rebound

Oil Properties:

Density, API,

Compressibility, 1/psi

Thermal expansion, 1/F

Viscosity $\left(123^{\circ} \mathrm{F}\right)$

$$
\left(400^{\circ} \mathrm{F}\right)
$$

Initial GOR (scf/bbl)

Relative permeability curves

Swir $=0.23$

Sorw $=0.2$

Sorg $=0.05$
$8 \sim 14$

$40 \sim 80$

$55 \sim 65$

$12 \sim 18$

1120

123

76.5

29

1000

$2.75 \times 10^{-5}$

$5.00 \times 10^{-6}$

14

$5 \times 10^{-6}$

$4 \times 10^{-4}$

194.0

2.2

113

Formation compressibilities during this period were matched to pressure responses in the reservoir as shown in Figure 3.1.8-1. In the early stages of waterflooding, the model predicted high reservoir pressures than field measurements, indicative of the dynamic

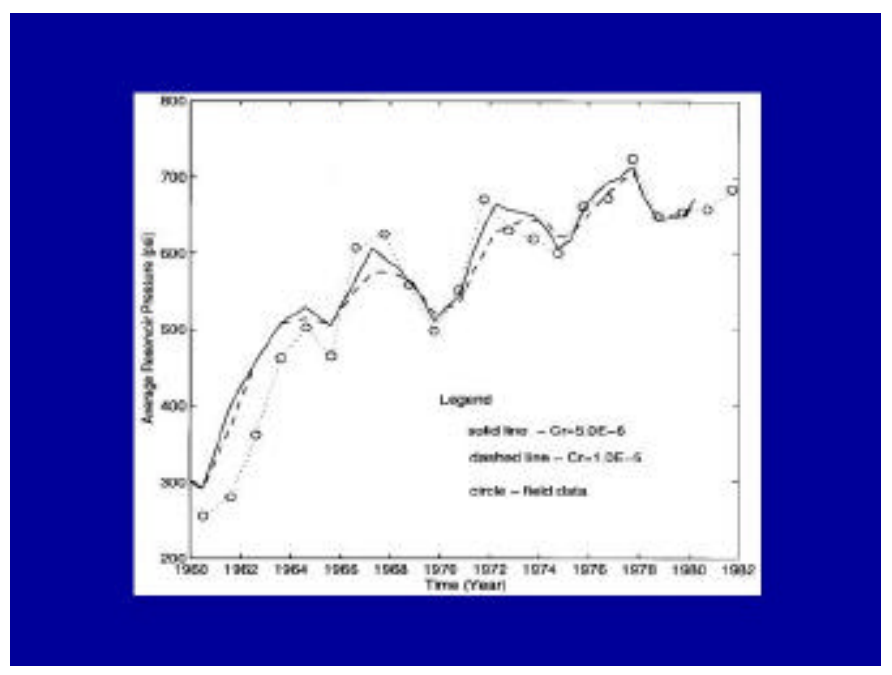

Figure 3.1.8-1: Estimation of formation compressibility for rebound process. 
aquifer conditions on the south flank. A history match can be achieved during rebound if equivalent formation compressibilities are assumed to be approximately $5 \mathrm{E}-6$ as shown in Figure 3.1.8-2.

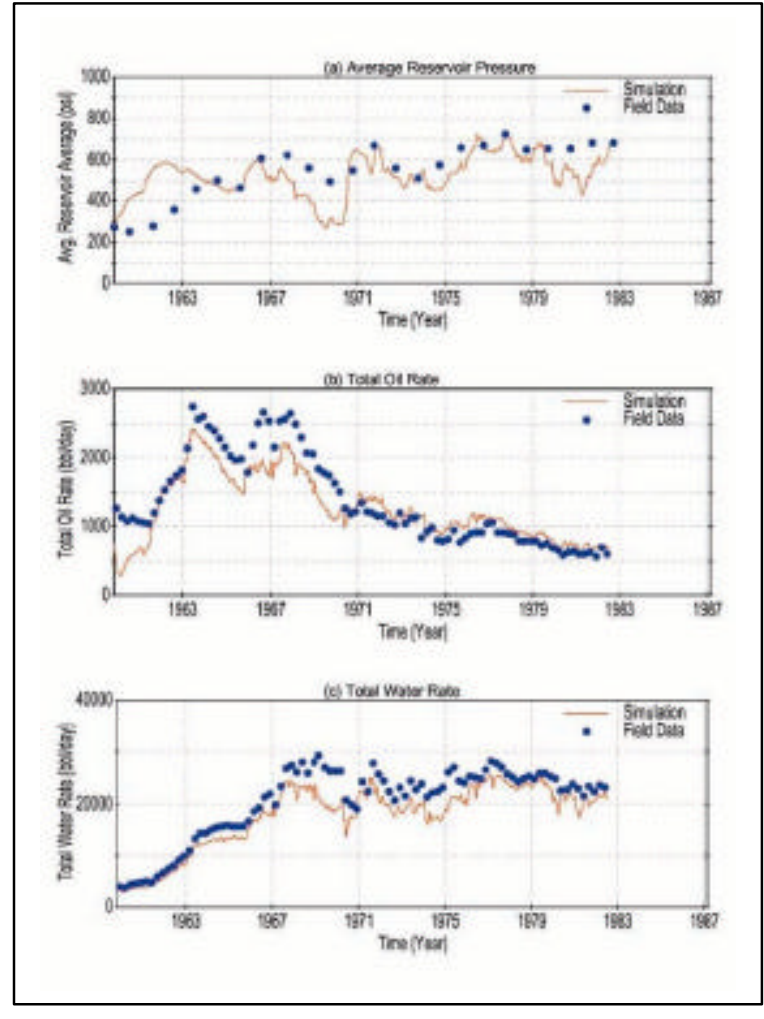

Figure 3.1.8-2: History matching results for the waterflooding stage.

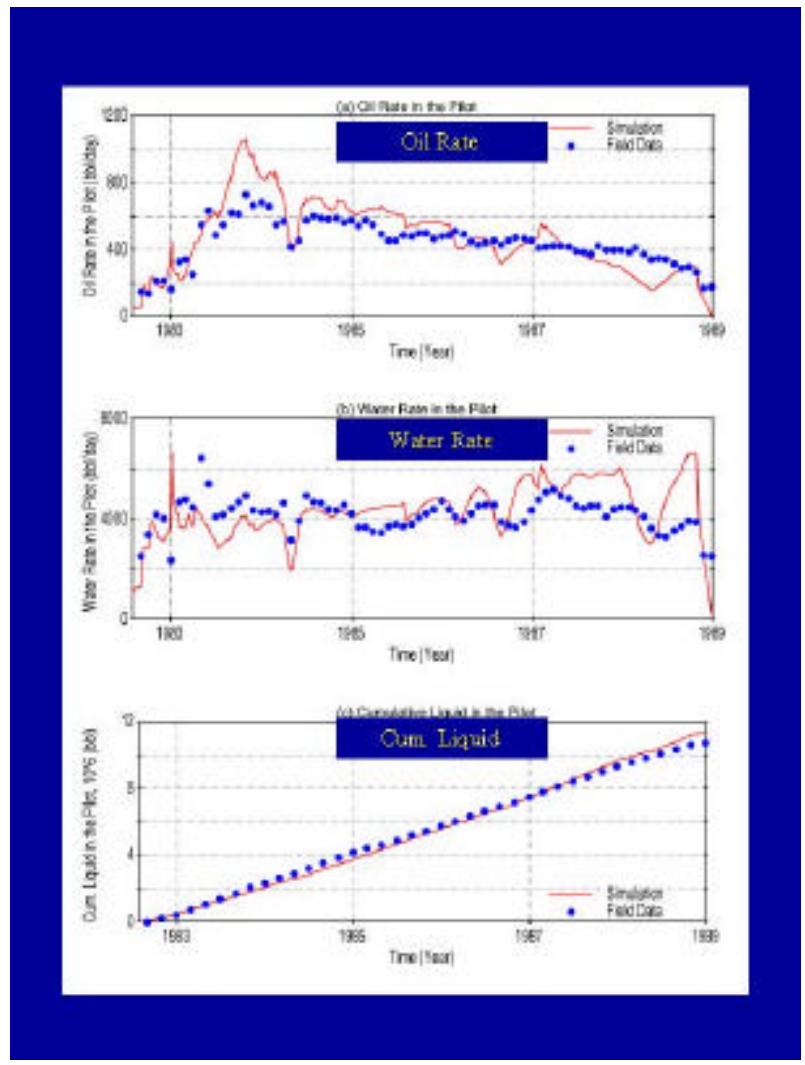

Figure 3.1.9-1: Comparision of and field results for steamflooding pilot in the Tar Zone of Fault Block II-A.

\subsubsection{History Match of Steamflood Pilot}

Between August 1982 and January 1989, a successful pilot steamflood project was conducted in the D1 sand of the Tar formation. It was a 20-are pilot area containing four inverted 5-spot patterns. The steamflood was history-matched using well injection data and fixing bottom hole pressures in the producers at 250 psi as shown in Figure 3.1.9-1. The model successfully predicted field production rates. History matching of individual wells in shown in Figure 3.1.9-2 and 3.1.9-3. The majority of wells were successfully matched except for two wells on the northwest and southeast corners of the model. Variations in fluid levels and heterogeneities in reservoir permeability and porosity most likely accounted for the differences between field measurements and simulated results.

\subsubsection{Development of Revised Operating Scenario}




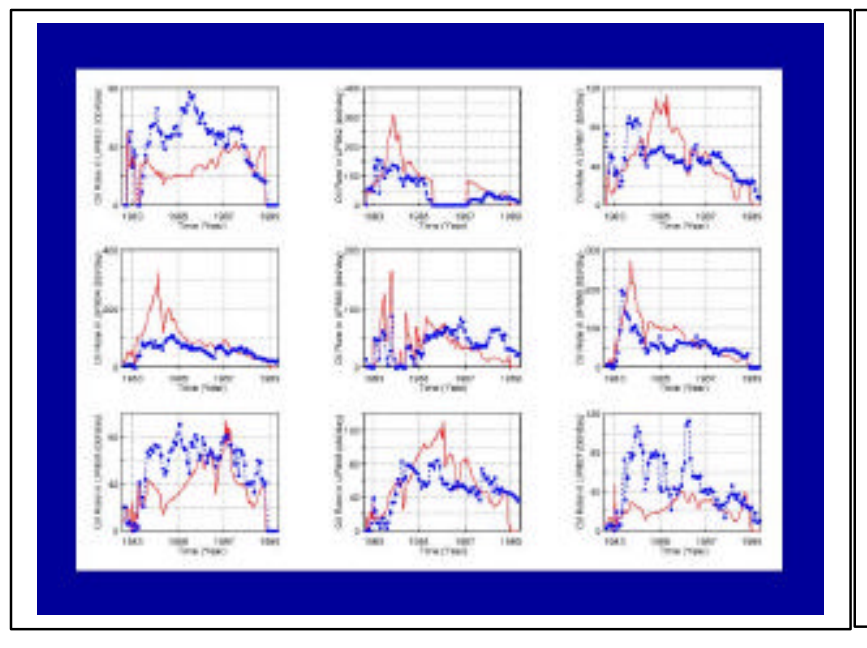

Figure 3.1.9-2: Prediction of individual pilot well responses, oil rate.

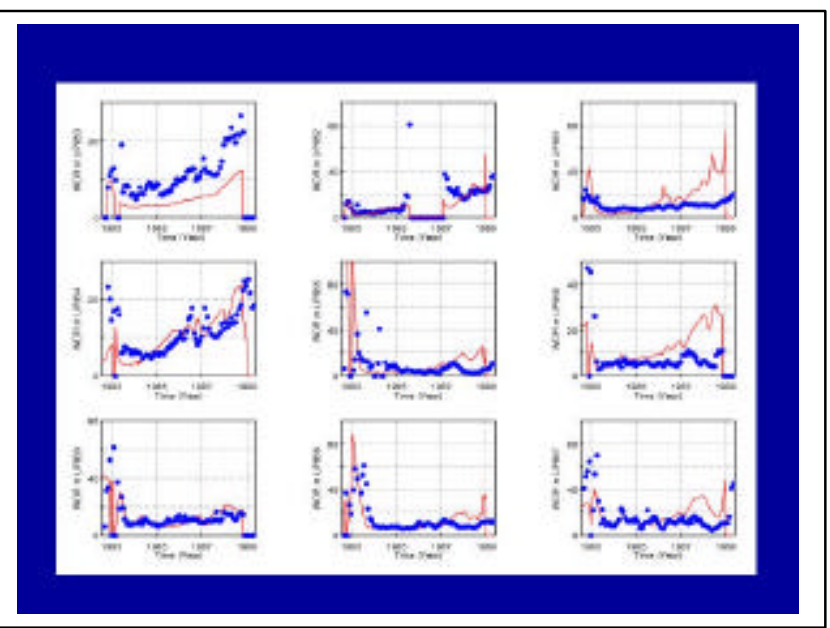

Figure 3.1.9-3: Prediction of individual well responses, WOR.

In mid-1998, the Tar formation steam operation was faced with a threat to its steam source and a new concern that high-temperature steam injection may cause compaction of the formation. A new operating strategy needed to be developed and implemented quickly, especially in light of California's eminent deregulation of its utilities that would affect the local cogeneration plant that provided the steam supply for thermal operations. Not only did the changes to the operating plan need to be implemented swiftly due to a rapidly changing regulatory environment, but also the management of those changes was crucial to the future production of the Tar formation.

The dynamic nature of the reservoir pointed to using a simulator to model a conversion from a full steamflood operation. Thermal cool-down effects on reservoir pressure needed to be studied and determined and heat loss effects needed to be quantified. A prediction of the steam chest collapse was required and was dependent upon the movement and production of reservoir fluids.

Fortunately, the creation of the 3-D thermal simulation model had been completed and successfully history-matched so it was available for developing and testing various operating scenarios for eliminating or cutting back on steam injection.

\subsubsection{Objectives for Operating Strategy}

The objectives for the new operating strategy included a plan for reduced or eliminated steam injection that would protect against formation damage due to compaction while ensuring stable surface elevations and optimizing the recoverable reserves. The conversion from steam injection meant that there was a fill-up timeperiod as the steam chest gradually collapsed due to reservoir depressurization. Reservoir oil and water would replace the void left by the collapsing steam chest. During fill-up time, it was critical that reservoir pressures be held relatively constant to ensure against reservoir damage and surface subsidence. Taking into account the heat 
losses and various processes associated with extreme temperature changes caused by conversion from steam injection to cold-water injection, a simulation approach was the only tool left for prudent management of the process. The simulator predicted fill-up time, reservoir pressures, temperatures, and the size of the steam chest. It also provided optimal injection rates and locations to minimize surface subsidence.

The following broad constraints were applied to the model:

- Minimize steam chest fill-up time

- Constrain pressures so they do not exceed fracture pressures

- Minimize reservoir cooling

- Maximize oil production and minimize required injection

\subsubsection{Choosing the Optimal Operating Scenario}

Ninety simulation evaluations were made between July 1998 and September 1999. Four milestone scenarios evaluated were:

1. Shut-in all of the steam and hot water injectors and all of the producers.

2. Convert all steam and hot water injection wells to cold water injection and produce only best producers.

3. Convert some steam and hot injection wells to cold water injection and produce until 12/98.

4. Shut-in all steam injection and only inject water in the flanks and produce only the best producers.

1. Complete shut-in of steam injection and all production: In this scenario the steam, injection wells and producing wells were shut-in in 7/98. Even before simulation, it was suspected that this alternative would not be viable because of the resultant rapid cool down and probable rapid collapse of the steam chest and surface subsidence.
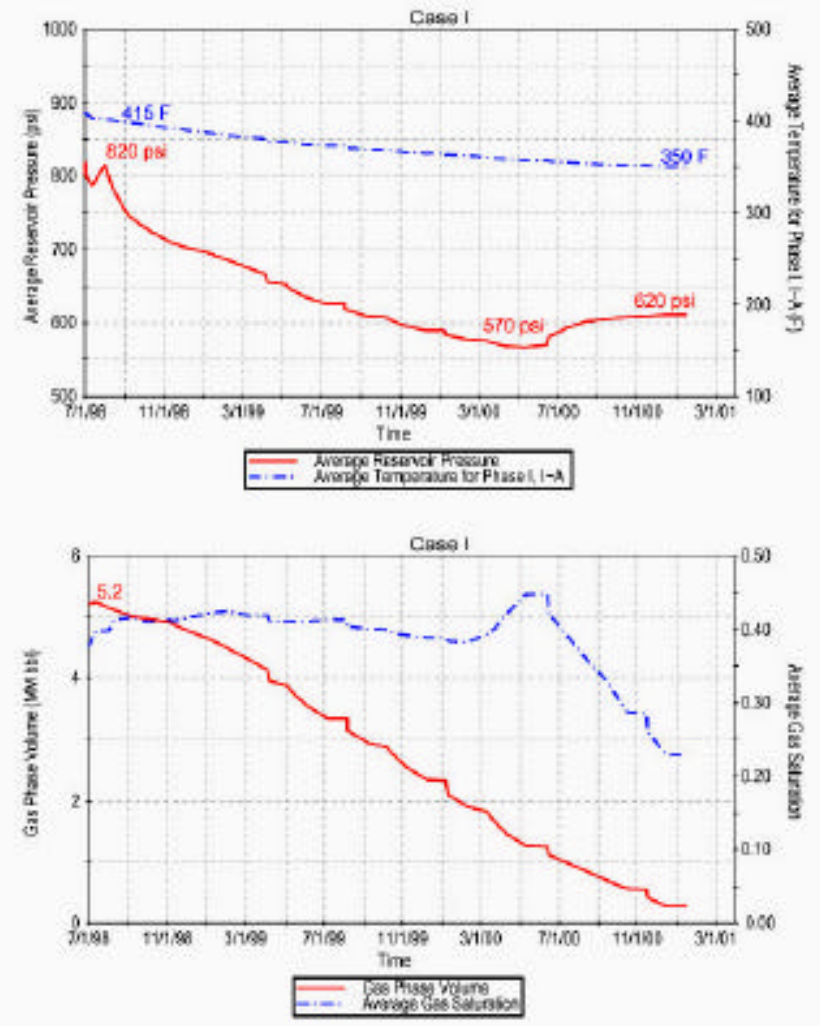

Figure 3.1.12-1: Predicted steam chest volume scenario I. 
The simulation results of average reservoir pressure and temperature over time are shown in Figure 3.1.12-1 (upper graph). Gas phase volumes and average gas saturations over time (Figure 3.1.12-1 lower graph) indicate the partial collapse of the steam chest. Reservoir pressures declined during fill up from 820 psi in 6/98 to 570 psi in 6/00. Pressures increase slightly two years after conversion, indicating the effects of flank aquifer pressure maintenance. The dip in pressure to $570 \mathrm{psi}$ is not considered high enough to maintain reservoir integrity, and this scenario presented a high risk for surface subsidence to occur. In addition, because production is shut-in, oil recovery is not maximized.

2. Convert all steam and hot water injection wells to cold water injection and produce only the top producers: This option offered the quickest method for achieving reservoir fill-up and pressure maintenance. In this scenario, an average rate of 1,500 $\mathrm{b} / \mathrm{d} / \mathrm{w}$ of cold water was injected into each of the 39 steam injectors (total injection $58,500 \mathrm{~b} / \mathrm{d}$ ). Only the highest oil cut wells were maintained on production ( $960 \mathrm{~b} / \mathrm{d}$ oil and $9,200 \mathrm{~b} / \mathrm{d}$ gross, $10.4 \%$ oil cut).

The model predicted steam chest fill-up in 12/98; however, the compaction-rebound simulation component predicted that this rapid fill-up and pressurization would result in surface rebound five months after conversion (Figure 3.1.12-2). It also indicated localized areas of high reservoir pressures exceeding the fracture gradient. In addition to the rebound problem, this alternative was rendered uneconomic because the vast volumes of water were not available. The injected cold water quenched hot reservoir fluids, reducing the long term thermal benefits.

3. Convert some flank steam injection wells to water injection and produce until 12/98: This option assumed that the pattern hot water injectors and the steam injection wells on the flanks were converted to cold water injection while maintaining steam injection in certain patterns.
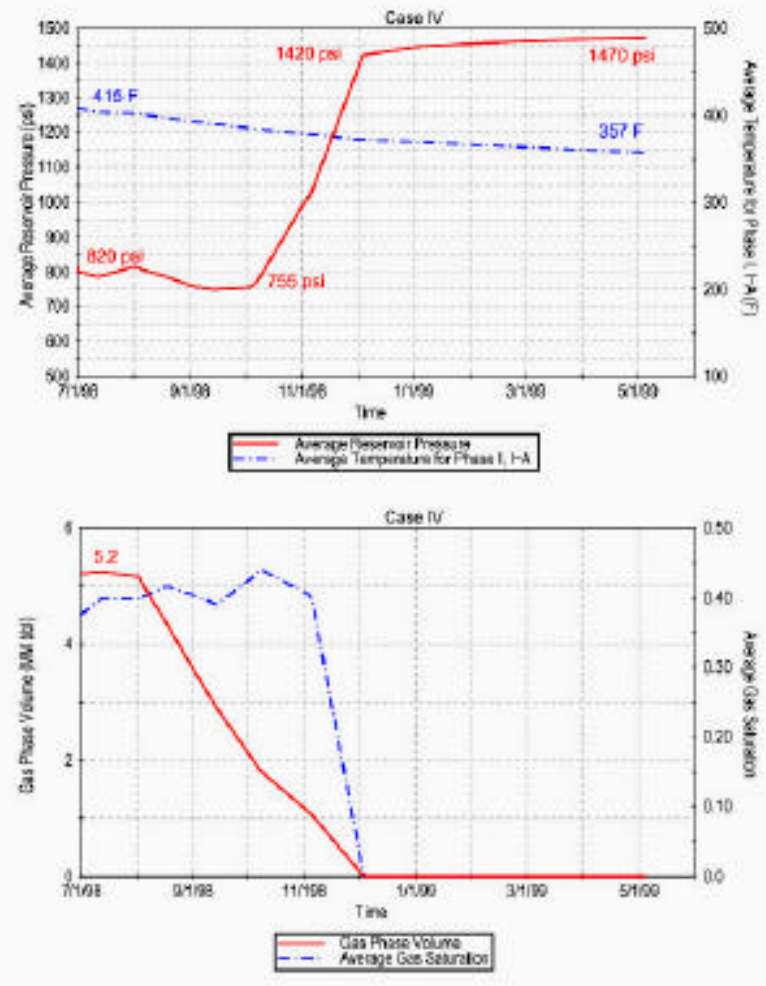

Steam and hot water injection was maintained until 12/98 and then 18,000 b/d of cold water was injected into the middle of the reservoir where the hot water flood patterns 
were located a well as into the flank injectors. Producing wells in the hot water injection area were shut-in in 10/98 and the remaining producing wells were shut-in in 12/98.

The simulation results are shown in Figure 3.1.12-3. The model indicated steam chest fill-up in $8 / 99$. Predicted pressures were at reasonable levels and appeared stable and predicted injection rates were not exorbitantly high. However, the cold water injection in the middle of the steamflood area resulted in very high heat losses in the middle of the reservoir lowering estimated ultimate recovery.

4. Shut-in all steam injection and inject water in the flank injectors only and produce only the best producers. This alternative proved the most viable, offering pressure maintenance, relatively quick fill-up and minimal heat losses (see Figure 3.1.12-4). The simulation began in $9 / 99$ with north and south flank cold-water injection beginning on 11/98. The simulation predicted steam chest fill-up at 12/99 and that a 1.22 injection/production ratio was required to prevent the steam

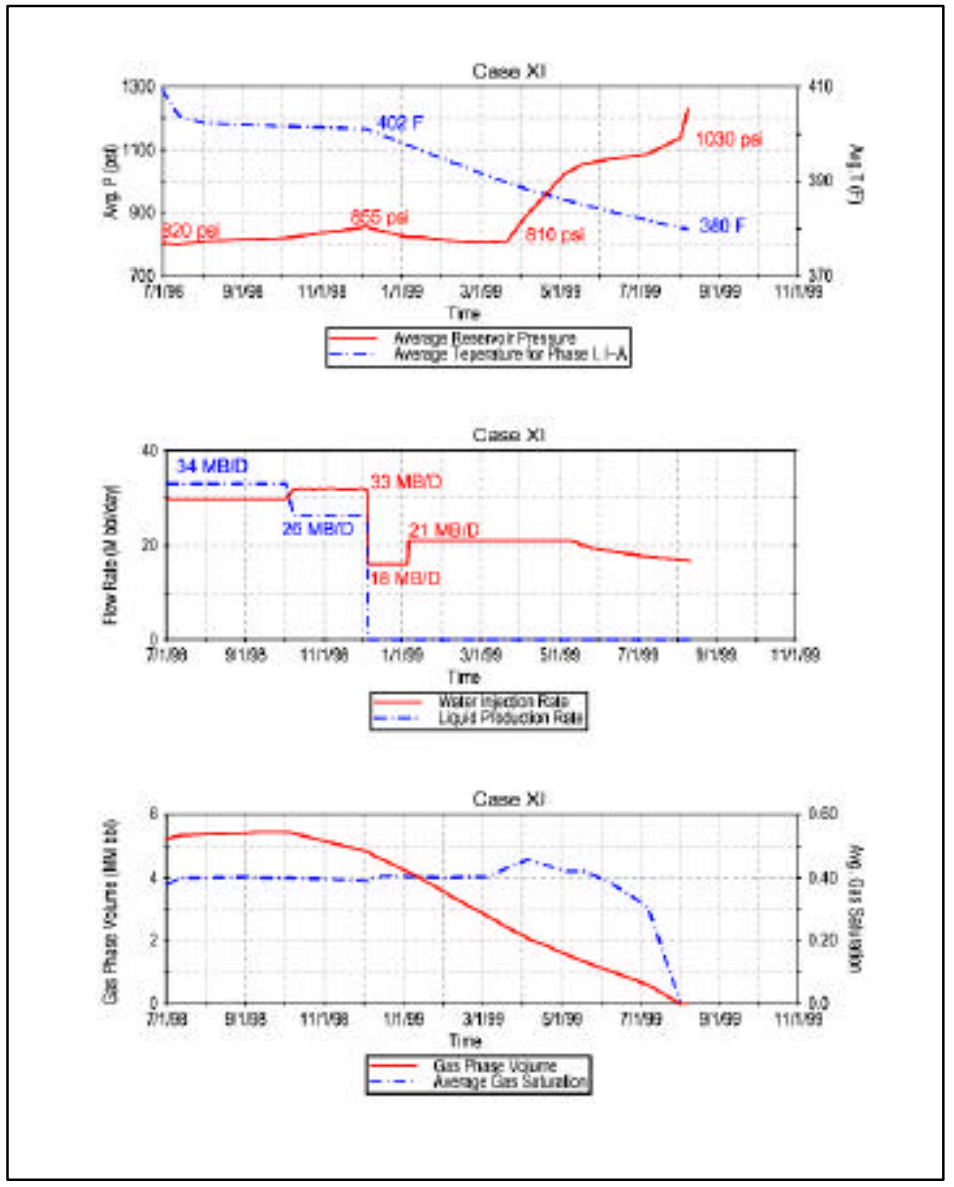

Figure 3.1.12-3: Prediction reservoir pressure, temperature, and steam chest volume - scenario III.

chest from reforming. It also indicated that the optimal flank injection well location was located on the southern, down-dip side of the reservoir.

This scenario was adopted and implemented very successfully with rapid fill-up, pressure maintenance and maintenance of surface elevations. The simulation results were implemented by first targeting injection rates for each active injection well based on the rates predicted by the simulator. Actual pressures were then monitored in each well, added to the model and the simulator was run with the updated pressures to gauge where field adjustment had to be made (see Figure 9). The simulation acted as a blue print for the operating strategy, providing guidance and insights into operational parameters. For example, when the $\mathrm{D}$ sand began achieving fill-up quicker than the $T$ sand, the model provided guidance as to ideal injection volumes by well to ensure fill-up in both sands occurred concurrently, with steam-chest collapse occurring concurrently. 
Figures 3.1.12-5 through 3.1.12-18 on the following pages show a simulation visualization of the steam-chest collapsing.
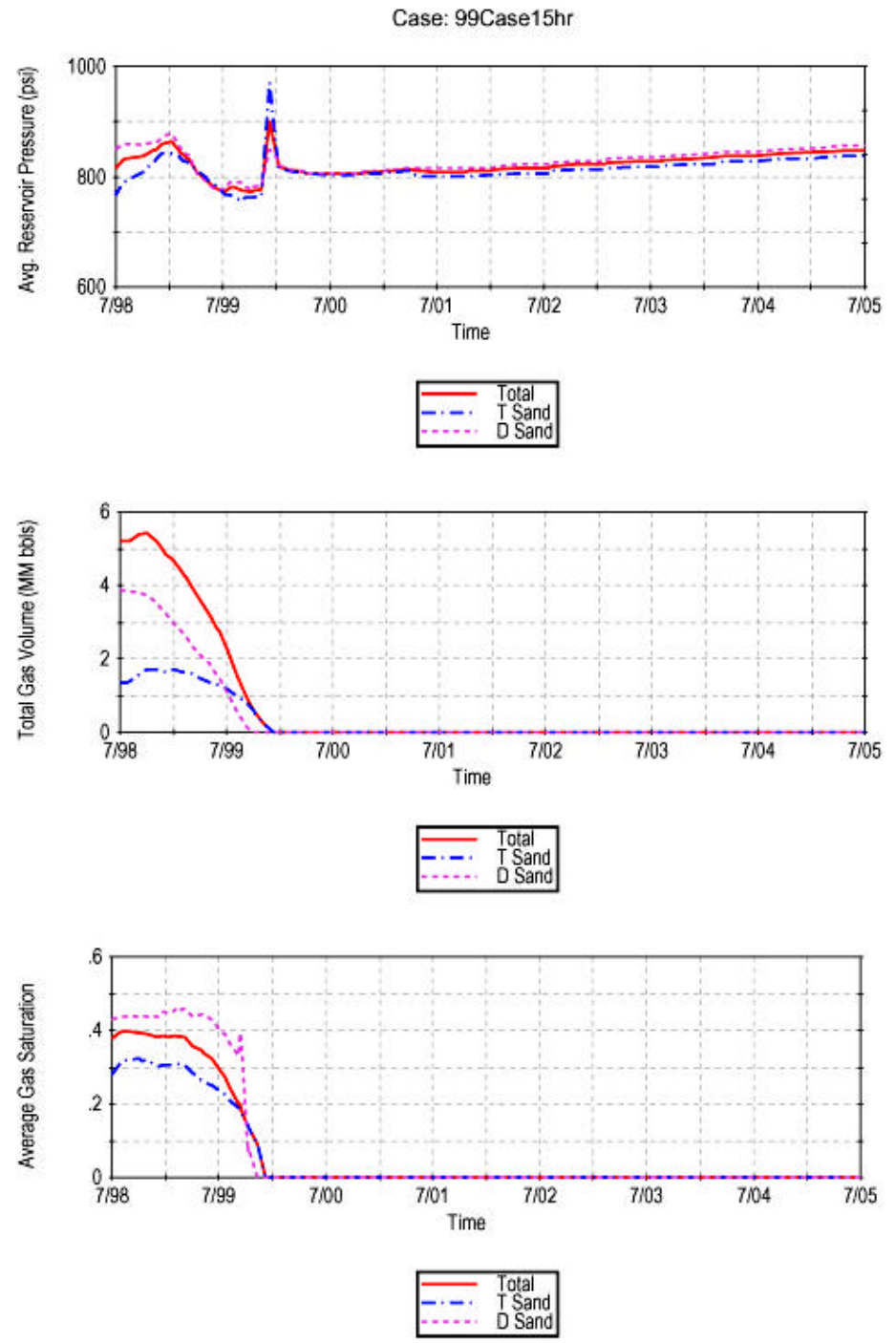

Figure 3.1.12-4: Prediction of reservoir pressure, temperature, steam chest volume and the impact of subsequent rate adjustments for scenario IV. 

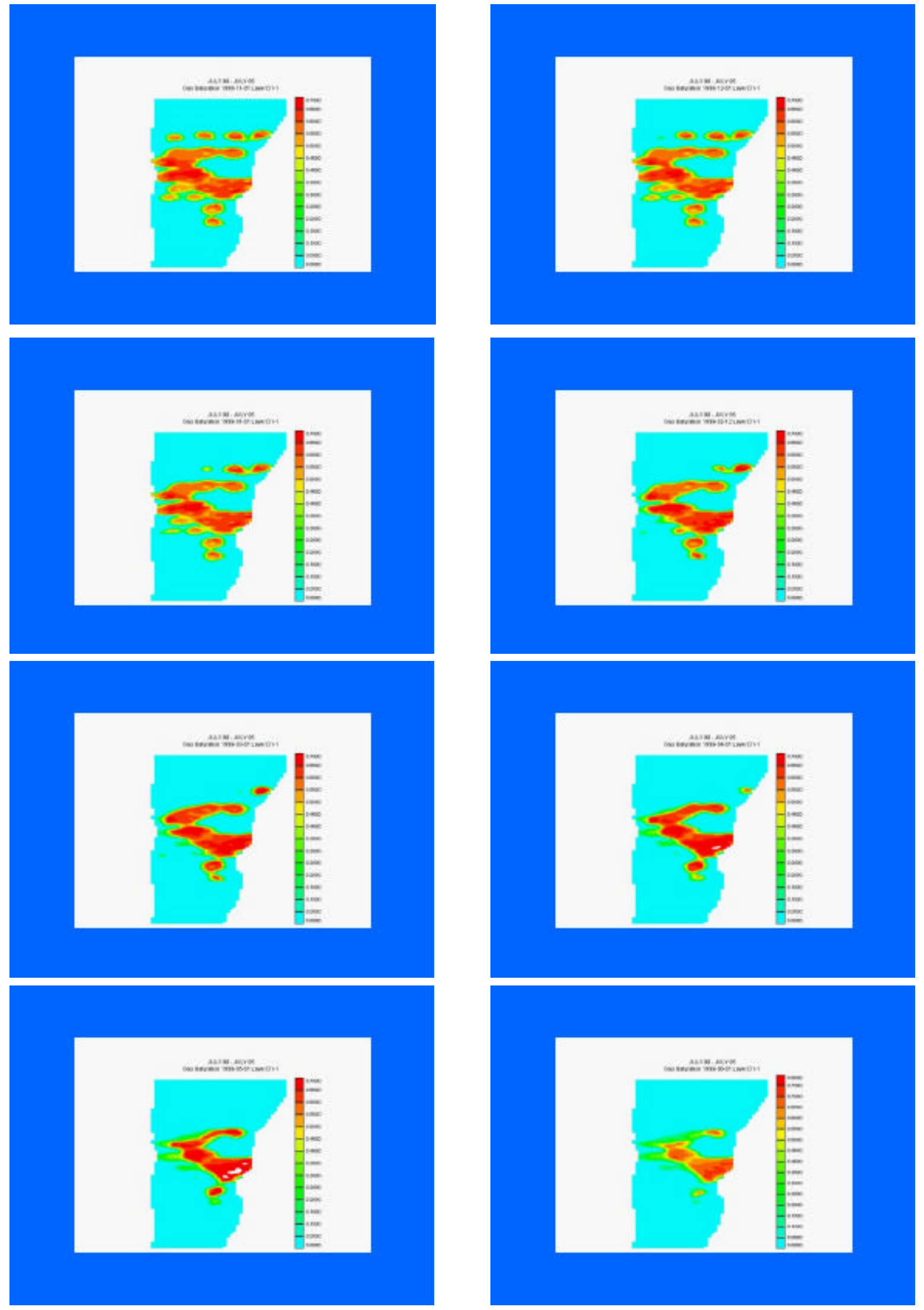

Figure 3.1.12-5 through 3.1.12.12: Visualizations of the steam-chest collapsing. 

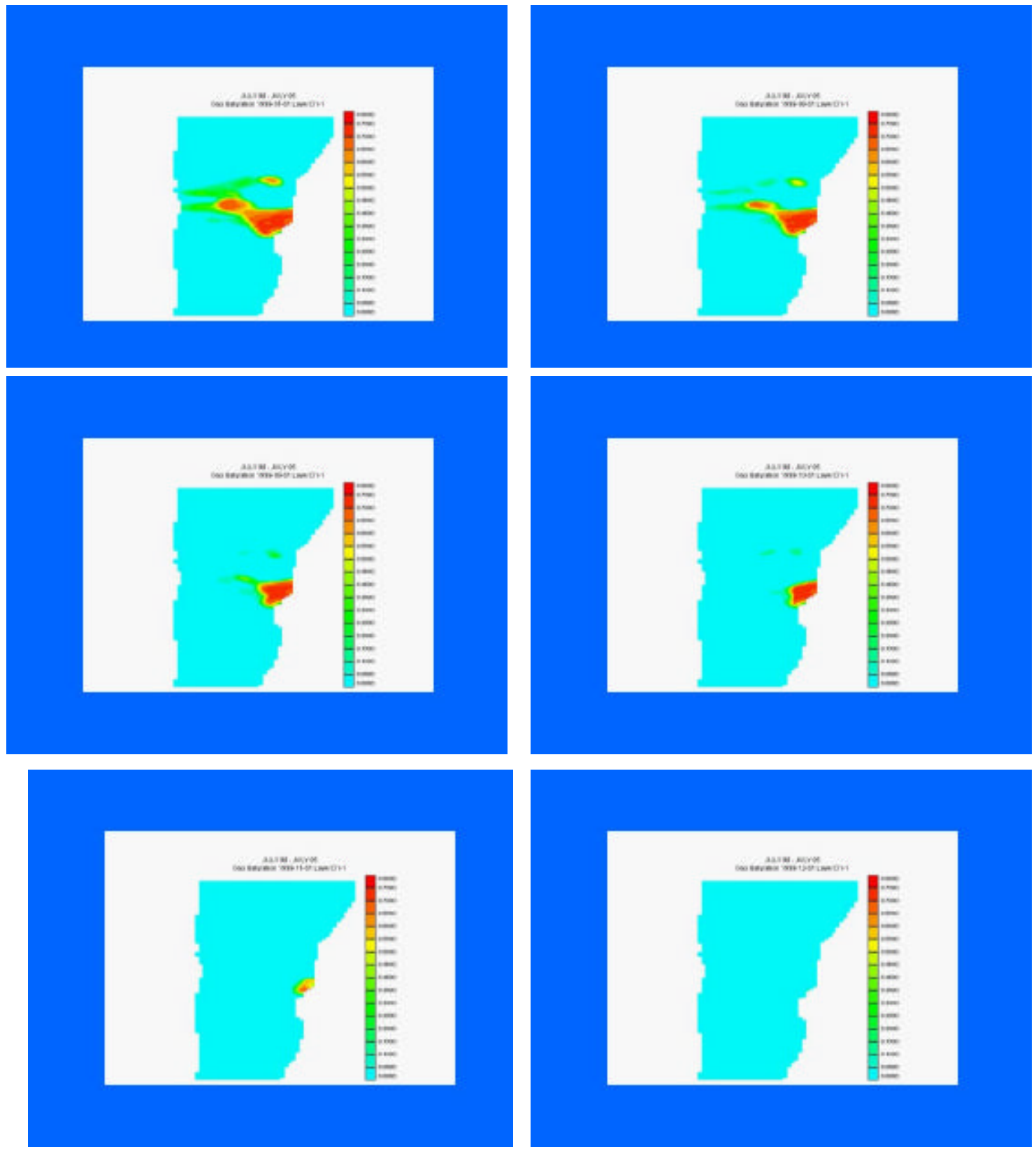

Figure 3.1.12-13 through 3.1.12-18: Visualizations of the steam-chest collapsing.

\subsubsection{Conclusions}

1. Based on the geomechanical mechanisms, simple compaction/rebound formulations were developed. With the proposed approach, the formation compaction/rebound can be simulated dynamically and locally in the model according to the local pressure field. 
2. With the model developed, the production history for primary depletion and waterflooding was successfully matched resulting in the determination of formation compaction and rebound parameters.

3. Based on the history match results of the primary depletion and waterflooding stages, the pilot steamflooding was successfully predicted.

4. Using the deterministic approach, simulation was successful in all aspects except a few individual wells. This emphasizes the need for stochastic modeling of reservoir properties.

5. Availability of a history-matched simulator was a major asset in the life Tar Zone of FB II-A of the Wilmington Field during an unpredictable juncture necessitating a conversion from steam injection to water injection.

6. The simulator predicted the fill up time under various scenarios, computed reservoir pressure and temperature for the optimum rates and location of optimum injectors and the necessary volumes in sufficient levels to prevent subsidence while continuing the recovery process.

7. Monitoring of the actual field data after the implementation of this simulation based reservoir management plan, validated the successful conclusion predicted by the model and indeed during the entire conversion process, no evidence of subsidence were observed.

\subsection{Stochastic 3-D Reservoir Modeling}

No activity reported this period. 


\section{ACTIVITY 4 - RESERVOIR MANAGEMENT}

\subsection{Horizontal Wells and Surface Locations}

No activity reported this period.

\subsection{Horizontal Well Cyclic Steam Stimulation Pilot (4 Wells-2 Prod. \& 2 Injection)}

No activity reported this period.

\subsection{Horizontal Well Steam Drive}

See Section 4.7

\subsection{Hot Water Alternating Steam (WAS) Drive Pilot}

See Section 4.7

\subsection{Geochemistry of Rock / Fluid / Interactions}

See Section 5.1 and 5.5

\subsection{Steam Drive Mechanisms}

See Section 3.1.4 and 4.7

\subsection{Reservoir Surveillance}

\section{Introduction}

A post-steamflood operating plan was developed during the third quarter 1998 and implemented in the fourth quarter 1998 to mitigate problems associated with the January 1999 shutdown of steam injection and the probability of thermal-related surface subsidence from cooling and subsequent collapse of the steam chests in the "T" and "D" sands. Eleven water injection wells are in service on the northern and southern flanks of the steamflood area. The wells include two existing injectors (wells FW-101 and FW-103), seven wells that were added in the fourth quarter 1998 (wells FW-88, 901-UP, 935-UP, 937-UP, 943-UP, 951-UP, and 2AT-56), one well added in the second quarter 1999 (953-UP) and one well (2AT-20) added in the fourth quarter 1999. Their purpose is to increase and subsequently maintain reservoir pressures in the "T" and "D" sands at a high enough level to eliminate and prevent the reoccurrence of any steam chest. Increasing reservoir pressure causes the steam vapor phase to go back into solution before it can collapse through overburden heat loss and cause possible formation compaction. The flank water injection fills up the steam chests that exist without introducing cold water into the interior of the mature steamflood area. 
The new 3-D deterministic thermal reservoir simulation model is being used to provide sensitivity cases to optimize production, steam injection, flank cold water injection and reservoir temperature and pressure. According to the model, reservoir fill up of the steam chest would occur in October 1999 at a constant injection rate of 28,000 BPD and gross fluid production rate of 7,700 BPD (injection to production (I/P) ratio of 3.6 , net injection of 20,300 BPD). Further modeling runs found that varying individual well injection rates was better for addressing localized sub-zone pressure problems caused by added production and could reduce steam chest fill-up by up to one month. Based on this information, Tidelands increased water injection in July and August to an average of 36,000 BPD while only increasing gross fluid production to 9,500 BPD (I/P ratio of 3.8, net injection of 26,500 BPD). This operational change accelerated the reservoir steam chest fill-up in the "T" and "D" sands, with fill-up occurring in the "D" sands in August 1999. Steam chest fill-up was accompanied by steeply rising reservoir pressures, as would be expected in a fully liquid, relatively incompressible fluid situation. In September, water injection was reduced substantially in the "D" sands from 24,200 BPD to 14,500 BPD (net injection from 18,000 BPD to 6700 BPD) and increased slightly in the "T" sands from 10,700 BPD to 12,700 BPD (net injection from 7100 BPD to 9000 BPD). The "T" sands reached fill-up in October 1999.

It was believed that once steam chest fill-up occurred, the reservoir would act more like a waterflood and production and cold water injection could be operated at lower I/P ratios and net injection rates. Decreasing net injection rates significantly from 18,000 BPD to 6700 BPD in mid-September in the "D" sands caused reservoir pressures to plummet about 100 psi within six weeks. Starting in late-October, net injection was increased to 9600 BPD in the "D" sands and reservoir pressures have slowly increased back to steam chest fill-up pressures as of the end of March 2000. When the "T" sands reached fill-up, net injection was lowered only slightly to 7500 BPD and reservoir pressures stabilized.

\subsubsection{Reservoir Pressures}

Reservoir pressures in the mature Phase 1 area increased during 1999. The average "T" sand pressure rose from 818 psi in June 1997, to 889 psi in March 1999, to 979 psi in September 1999 and to 1006 psi in December 1999. Reservoir pressures were maintained at an average of about 1000 psi or $90-95 \%$ hydrostatic pressure in the "T" sands. The average "D" sand pressure went from 594 psi in May 1996, to 748 psi in August 1998, to 874 psi in March 1999, to 1033 psi in September 1999 and to 946 psi in December 1999. The objective was to increase the "D" sand pressures back to an average of about 1030 psi or 90-95\% hydrostatic pressure during the first quarter 2000 . At first, it was postulated that reservoir pressures only needed to reach an estimated 800 - 1000 psi to fill the steam chests based on the saturated steam pressure temperature relationship. Field experience shows that higher reservoir pressures above $1000 \mathrm{psi}$ are needed to actually achieve reservoir steam chest fill-up throughout the reservoir, which means that certain areas in the steamflood had maximum reservoir temperatures of about $545^{\circ} \mathrm{F}$. 
As reservoir pressures increased in the "T" and "D" sands, gross fluid production correspondingly increased due to higher differential pressures in the wellbore from 6145 barrels of gross fluid per day (BGFPD) and 725 barrels of oil per day (BOPD) in March 1999 to 9700 BGFPD and 828 BOPD in August 1999. Water injection rates in July and August averaged 36,000 BPD compared to the June rate of 29,400 BPD to compensate for the increased production levels and to accelerate steam chest fill-up. After achieving steam chest fill-up in the "D" sands in August, water injection was reduced into the "D" sands and increased into the "T" sands. Overall total water injection declined from 36,000 BPD in July and August to 26,800 BPD in October. Following steam chest fill-up of the "T" sands in October 1999, gross fluid production was increased from 10,500 BPD in September to 14,600 BPD in November by activating seven production wells, of which six were dual "T" and "D" completions and one was a "D" completion to replace an offset "D" well that sanded up. When the "D" sand reservoir pressures declined, total injection was increased to 30,900 BPD in November and 31,800 BPD in December with most of the increase going to the "D" sands. Five high water cut wells were idled in November and December and two of the best oil producing wells were idled in November to accommodate the surface owner for a possible 12 - 18 months. Six production wells were activated in December, including four "T" only completions and two "T" and "D" completions. The two dual completion wells were idled from January to March to ensure "D" sand pressure increases. The "D" sand pressures stabilized on average and increased slowly in several wells. With the higher net injection rates, the steam chest refilled by March 2000.

\subsubsection{Reservoir Pressure Monitoring}

Reservoir pressure data is retrieved approximately once a month from each idle well using sonic fluid levels and Amerada bombs. This is different from the previous manner of reading the instantaneous shut-in gauge pressure of the steam injection wells and therefore the initial fluid level pressures are occasionally different from the steam gauge pressure readings. The Amerada pressure bomb readings taken from wireline provide more accurate pressure readings than the sonic fluid levels and are being run within a few days of the sonic fluid level shots in the same wells. The Amerada bombs were specially calibrated to correct pressure readings for different wellbore temperatures as higher temperatures will expand the bomb and show higher pressures than actual. At first, the Amerada pressure bombs had a temperature probe attached that measured the highest temperature in the wellbore. The program has now been adapted to provide Amerada temperature bomb readings at the same stops as the pressure bombs. Most of the time, the higher temperatures are limited to depths below 2000 feet vertical subsea (VSS) depth and the depths above have temperatures of about $120^{\circ} \mathrm{F}$. Occasionally, wells will show temperature profiles above $2000 \mathrm{ft}$ VSS that are significantly higher than $120^{\circ} \mathrm{F}$, as if the fluids were rolling in the wellbore due to the disturbance caused by the wireline tools or by refluxing.

To calibrate the sonic fluid levels, the Amerada bomb data was correlated with the sonic fluid level data taken within a few days of each other, where the Amerada bomb was assumed correct. The correlations show that the fluids below $2000 \mathrm{ft}$ VSS 
have an average fluid pressure gradient of 0.38 pounds per vertical foot of head (psi/ft) and the fluids above $2000 \mathrm{ft}$ VSS have a fluid pressure gradient of $0.406 \mathrm{psi} / \mathrm{ft}$. This makes sense when considering that the deeper fluids are at a higher temperature than the shallower fluids. The water temperature that corresponds to a fluid pressure gradient of $0.38 \mathrm{psi} / \mathrm{ft}$ is $375^{\circ} \mathrm{F}$, which is very possible for the interior Tar II-A steamflood wells which range from $250-525^{\circ} \mathrm{F}$ based on Amerada temperature bomb readings. A fluid pressure gradient of $0.406 \mathrm{psi} / \mathrm{ft}$ corresponds to water at $250^{\circ} \mathrm{F}$ or a $19.5^{\circ} \mathrm{API}$ gravity crude oil at $60^{\circ} \mathrm{F}$. The water temperature of the wellbore fluids above $2000 \mathrm{ft}$ VSS average about $120^{\circ} \mathrm{F}$ based on Amerada temperature bomb readings, which would have a higher fluid pressure gradient of $0.429 \mathrm{psi} / \mathrm{ft}$. The typical Tar II-A crude of $14^{\circ}$ $\mathrm{API}$ at $60^{\circ} \mathrm{F}$ has a fluid pressure gradient of $0.421 \mathrm{psi} / \mathrm{ft}$, still too high but it could be lower when temperature effects are considered. The gas gradient varied but averaged $0.038 \mathrm{psi} / \mathrm{ft}$ when the casing pressure exceeded $600 \mathrm{psi}$ and averaged $0.003 \mathrm{psi} / \mathrm{ft}$ when the casing pressure was less than 300 psi. We did not have enough sampling at casing pressures between $300-600$ psi to determine a correlation. The higher gas gradient at higher casing pressures is because the gas is denser. In this case, the gas is about 12.6 times denser which corresponds to 186 psi of pressure differential. What can complicate this correlation is the fact that the gas can contain steam, methane, carbon dioxide, mercaptanes, and hydrogen sulfide.

Many wells have had high casing pressures and low fluid levels, especially the updip half of the wells. This was mostly attributable to the steam chest. As the reservoir pressures rose above $900 \mathrm{psi}$, many of the wells with high casing pressures experienced a conversion to high fluid levels with low casing pressures. Three "D" sand wells, 2AT-21, 2AT-31, and 2AT-41, initially had high casing pressures which converted to higher fluid levels upon reaching steam chest fill-up pressures and then started to experience higher casing pressures again when the " $\mathrm{D}$ " sand reservoir pressures declined. This appears to be a good indicator that the steam chest was condensing and going back into solution as pressure increased and then reoccurring as pressure decreased. The other wells with continued high casing pressures are believed to have non-condensable gases in the wellbore such as methane, mercaptanes, carbon dioxide and hydrogen sulfide that are being created in the reservoir because of heat-induced geochemical diagenesis. Taking a gas sample at the wellhead will probably not indicate what gases are present because each gas has a distinct density and only the lightest gases will be at the top of the wellbore. This phenomenon will continue to be observed in future quarters. 


\section{ACTIVITY 5 - OPERATIONAL MANAGEMENT}

\subsection{Alkaline Water/ Steam Injection Sand Control}

This study discusses a competitively-priced and superior well completion technique for controlling unconsolidated sand formations by injecting high temperature and pressure steam to geochemically bond the sand grains in the perforation tunnels. Wells applying this method are cased and cemented through the desired producing interval and completed with only a few small diameter perforations. This well completion technique has been applied in 12 horizontal wells and 22 vertical wells with over $90 \%$ of the wells capable of production or injection after two years.

The use of the hot alkaline / steam sand consolidation technique to complete wells is based on the geochemical bonding of unconsolidated formation sand grains with a lattice of primarily high temperature complex synthetic silicate cements and possibly other lower temperature precipitates such as silica cements and carbonate scales. The complex silicate cements and other mineral precipitates are created by the high temperature and high alkaline $\mathrm{pH}$ steam condensate that preferentially dissolves sand grains with high specific surface area. The injected fluids rapidly lose heat to the formation and various cements precipitate with changes in temperature, alkalinity, and contact time. The lattice of cement bonds are created by the relatively high volume and high velocity steam vapor phase which dissipates through the near-wellbore region quickly and carries away excess cements and other precipitates where they do not adversely affect formation porosity and permeability.

The wells completed with this technique have equivalent or higher productivity and injectivity than wells completed with opened-hole, gravel-packed slotted-liner completions. In addition, this technology can significantly lower drilling and completion costs, improves fluid entry or injection profile control, provides a low cost means to eliminate unwanted completion intervals, and provides flexibility to use the wells interchangeably as producers or injectors.

\section{Introduction}

Thermal recovery operations in the Wilmington Field have met with operational difficulties peculiar to its geology. Thermal operations have been subject to premature well and downhole equipment failure as a result of early steam breakthrough and sanding. These problems are commonplace in other Slope and Basin Clastic reservoirs with heterogeneous and unconsolidated sands. Additionally, the high reservoir pressures and associated high steam temperatures in the Wilmington Field aggravate the wellbore completion and equipment problems associated with early steam breakthrough.

The unconsolidated nature of the turbidite sands in the Wilmington Field result in well producibility problems. Thus, a means of limiting sand production has been of paramount importance with regard to operations in the field. The conventional well 
completion method applied in the field involves using an opened-hole, gravel-packed and slotted liner completion. To reduce capital costs and to improve vertical injection profile control, two new vertical steam injection wells in the Fault Block II-A, Tar Zone (Tar II-A) were selected in 1990 to test a new well completion technique applying limited-entry perforating ${ }^{\mathrm{D} 1}$ with the wells cased and cemented to total depth. Three subsequent new vertical steam injection wells were given conventional perforated completions in wells cased and cemented to total depth. Engineering observed that the five steam injection wells had only minor to no sand inflow problems and suspected that a form of sand consolidation was occurring in the perforation tunnels, most likely bonding with silica cements. The alkaline hot water/steam sand consolidation technique for completing wells (henceforth called "the Sand Consolidation Technique or Treatment") was first intentionally tested in producer well UP-779. Well UP-779 was an existing producer that was recompleted into the Tar II-A, placed on steam injection in December 1991, and performed equivalent to offset steam drive producers. The new sand consolidation technique was further tested in eight new vertical wells and two vertical well recompletions in the Tar II-A and two new horizontal wells in the Tar I using various numbers of perforations, perforation sizes, steam volumes and steam rates from 1992 - 1994. An empirical well completion process was developing, but an understanding of the actual detailed geochemistry of the sand consolidation process occurred with its application in the four DOE project horizontal wells (UP-955, UP-956, 2AT-61 and 2AT-63) in the Tar II-A in 1996. Consolidated sand samples were found encrusted to the steam injection tubing tail following a cyclic steam stimulation job in well UP-955 in October 1996. The samples showed bonding of the sand grains with high temperature cements not found in the native formation rocks, but geochemically created through the dissolution of formation minerals from the hot alkaline in the condensate phase of the steam. The success of the sand consolidation technique led to its subsequent application in six new horizontal wells and four vertical well recompletions.

The Sand Consolidation Technique has been applied for purposes other than new well completions and has proven to have other beneficial qualities. In October 1994, well UP-932 successfully underwent the technique to repair enlarged slots in its slotted liner. Well UP-932 production was restored to its previous production rates without sand production. A second well, UP-924, was successfully given a sand consolidation treatment to repair a damaged slotted liner in November 1997. Several wells with sand consolidation completions have been given hydrochloric acid jobs to successfully remove scale damage without affecting the consolidated sands. Gross fluid production rates following the $\mathrm{HCl}$ acid jobs typically are restored to pre-scale damaged rates.

Wells with sand consolidation completions have very high productivity for the relatively small number and size of perforations used and production and injection well rates have been equivalent to greater than wells with opened-hole gravel-packed slotted-liner completions. The sand consolidation completions can fail if produced under high differential pressures. However, these types of well failures have generally 
been repaired successfully by applying another alkaline hot water/steam sand consolidation treatment.

Tables 5-1, 5-2 and 5-3 list the wells that have been given Sand Consolidation Treatments and pertinent well data including the number and size of perforations, the volume of steam used, the length of the completion interval, and the maximum stabilized injection and production rates. Table 5-1 lists the new vertical wells, Table 52 lists the new horizontal wells, and Table 5-3 lists the wells that were recompleted or had liner repairs.

\subsubsection{Geology}

The Tar II-A consists of four major producing intervals exhibiting typical California-type alternation of sands and shales. The Tar Zone reservoir sands are unconsolidated, friable, fine to medium-grained with varying amounts of silt, and comprised dominantly of subangular grains of quartz and plagioclase feldspar as shown in Figure 5.1.1-1. No cemented sands have been found in any of the cores taken from pre- and post-steamflood wells in the field.

The thickness of the sand layers varies from a few inches to several tens of feet. Shales and siltstones are generally massive, with abundant foraminifera, mica, and some carbonaceous material. The shales are generally soft and poorly indurated, although there are thin beds of fairly firm to hard shale. The oil is of low gravity, ranging from $12-15^{\circ}$ API with a viscosity of $360 \mathrm{cp}$ and an initial formation volume factor of $1.057 \mathrm{RB} / \mathrm{STB}$. Based on available information, the Tar zone sands have an average porosity ranging from $28-33 \%$ and permeabilities ranging from 500-8,000 millidarcies with a weighted average of 1,000 millidarcies. Approximate zone thickness ranges from 250-300 ft. The top of the structure appears at a depth of 2,330 ft below sea level in Fault Block II.

\begin{tabular}{|c|c|}
\hline \multicolumn{2}{|l|}{$\begin{array}{c}\text { Mineral Composition of } \\
\text { Sandstones }\end{array}$} \\
\hline $\begin{array}{l}\left.\text { Quartz }-\mathrm{SiO}_{2} \quad\right\} \\
\left.\text { Calcedony }-\mathrm{SiO}_{2}\right\}\end{array}$ & $48-50 \%$ \\
\hline - Feldspars & \\
\hline $\begin{array}{l}\text { Orthoclase - } \mathrm{KAISi}_{3} \mathrm{O}_{8} \\
\text { Anorthite }-\mathrm{CaAl}_{2} \mathrm{Si}_{2} \mathrm{O}_{8}\end{array}$ & $11-12 \%$ \\
\hline $\begin{array}{l}\left.\text { Albite - NaAISi } \mathrm{O}_{8} \quad\right\} \\
\text { Igneous Rock Fragments\} }\end{array}$ & $32-35 \%$ \\
\hline - Mica (Biotite) $-\mathrm{K}_{2}(\mathrm{Mg}, \mathrm{Fe})_{2}(\mathrm{OH})_{2}\left(\mathrm{AlSi}_{3} \mathrm{O}_{10}\right)$ & $4-6 \%$ \\
\hline - Clays - Smectites, Illites, Chlorites & $1-2 \%$ \\
\hline
\end{tabular}


Table 5-1

\section{WILMINGTON FIELD}

\section{SAND CONSOLIDATION JOBS}

\section{NEW VERTICAL WELLS}

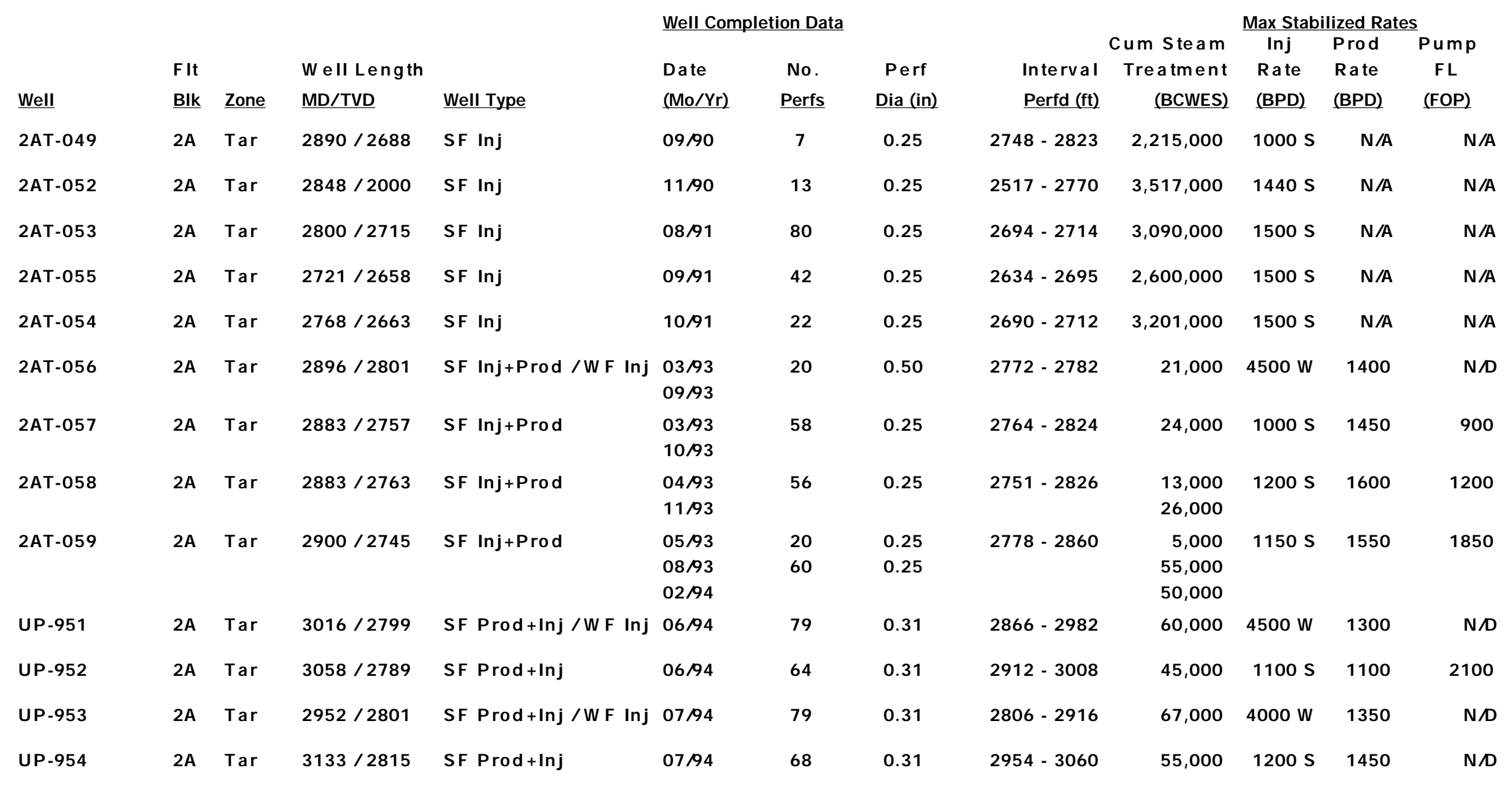


Table 5-2

\section{WILMINGTON FIELD \\ SAND CONSOLIDATION JOBS NEW HORIZONTAL WELLS}

\begin{tabular}{|c|c|c|c|c|c|c|c|c|c|c|c|c|}
\hline & & & & & Well Com & ion Dat & & & & Max Stab & lized Rat & \\
\hline & & & & & & & & & Cum S team & $\operatorname{lnj}$ & Prod & Pump \\
\hline & Flt & & Well Length & & Date & No. & Perf & Interval & Treatment & $R$ ate & Rate & $\mathbf{F L}$ \\
\hline Well & Blk & Zone & MD/TVD & Well Type & $(\mathrm{Mo} / \mathrm{Yr})$ & Perfs & Dia (in) & Perfd (ft) & (BCWES) & (BPD) & (BPD) & (FOP) \\
\hline $1 T-001$ & 1 & Tar & 3520 / 2487 & Cyclic & 07/93 & 140 & 0.50 & $2890-3500$ & 72,000 & $2300 \mathrm{~S}$ & 2500 & 750 \\
\hline S F-001 & 1 & Tar & $3510 / 2555$ & Cyclic & $02 / 94$ & 160 & 0.50 & $2890-3500$ & 160,000 & $1600 \mathrm{~S}$ & 3100 & $\mathrm{~N} / \mathrm{D}$ \\
\hline 2AT-061 & $2 \mathrm{~A}$ & Tar & 4357 / 2438 & Cyclic / SF Inj & $12 / 95$ & 11 & 0.25 & $3972-4302$ & 146,000 & $1770 \mathrm{~S}$ & 1800 & N/D \\
\hline 2AT-063 & $2 A$ & Tar & $4726 / 2418$ & Cyclic / SF Inj & $12 / 95$ & 11 & 0.25 & $4240-4705$ & 186,000 & $1400 \mathrm{~S}$ & 1450 & 1300 \\
\hline FJ -202 & 5 & Tar & 4475 / 2114 & Cyclic / SF Inj & 04/96 & 14 & 0.29 & $3730-4470$ & 97,000 & $2100 \mathrm{~S}$ & 1550 & 40 \\
\hline FJ -204 & 5 & Tar & 4141 / 2126 & Cyclic / SF Inj & 05/96 & 14 & 0.29 & $3600-4050$ & 119,000 & $1800 \mathrm{~S}$ & 900 & 450 \\
\hline UP-955 & $2 A$ & Tar & 4466 / 2432 & SF Prod & 06/96 & 48 & 0.30 & $3915-4430$ & 114,000 & $1800 \mathrm{~S}$ & 2450 & 1250 \\
\hline UP-956 & $2 A$ & Tar & 4805 / 2374 & SF Prod & 06/96 & 36 & 0.22 & $4230-4710$ & 183,000 & $1800 \mathrm{~S}$ & 2000 & 1600 \\
\hline$J-205$ & 5 & Tar & 4145 / 2130 & SF Prod & 08/96 & 45 & 0.29 & $3388-4094$ & 167,000 & $1900 \mathrm{~S}$ & 1100 & 150 \\
\hline J -203 & 5 & Tar & 4648 / 2127 & SF Prod & 11/96 & 44 & 0.29 & $3745-4640$ & 122,000 & $1300 \mathrm{~S}$ & 1600 & 1450 \\
\hline J -201 & 5 & Tar & $4800 / 2111$ & SF Prod & 01/97 & 46 & 0.29 & $3742-4125$ & 169,000 & $1300 \mathrm{~S}$ & 1250 & 400 \\
\hline J -017RD & 5B & UT & $4110 / 2849$ & Cyclic & $05 / 97$ & 40 & 0.29 & $3285-3900$ & 91,000 & $820 \mathrm{~S}$ & 900 & 1200 \\
\hline
\end{tabular}


Table 5-3

WILMINGTON FIELD

SAND CONSOLIDATION JOBS

\section{VERTICAL WELL RECOMPLETES / LINER REPAIRS}

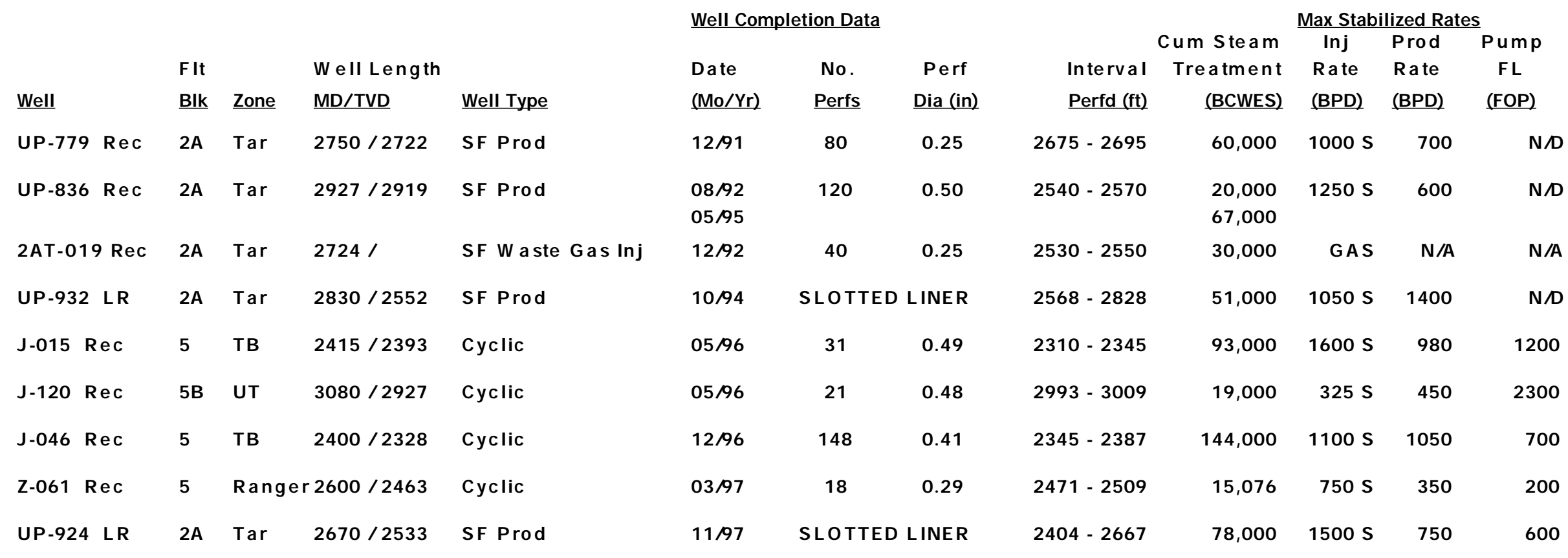




\subsubsection{Alkaline Hot Water/Steam Sand Consolidation Procedure - A Brief Description}

A well with cemented casing is first selectively perforated with 1/4in. to 1/ 1 . perforations, preferably $1 / 4 \mathrm{in}$., with the number of perforatio ns needed based on attaining limited-entry conditions ${ }^{\mathrm{D} 1}$ for the steam rates and pressures available. To minimize heat loss, thermally insulated tubing, an expansion joint and a thermal packer are run into the well. Steam quality should range from $60-80 \%$, which provides a highly alkaline $(\mathrm{pH}=10-12)$ liquid phase and the steam temperatures should be high enough $\left(>300^{\circ} \mathrm{C}\right.$ ) to geochemically create the cements for bonding the sand grains. The steam rate should be high enough to achieve the critical velocities required by the limited-entry perforating theory to ensure distribution of the steam into all of the perforations. The empirically based minimum steam volume necessary to achieve sand consolidation is 750 barrels of cold water equivalent steam per $1 / 4 \mathrm{n}$. perforation.

The hot alkaline liquid phase in the $80 \%$ quality steam causes sandstone dissolution ${ }^{\mathrm{D} 6}, \mathrm{D7}, \mathrm{D} 8, \mathrm{D} 9$, preferentially acting on the sand grains with high specific surface area such as clays, rock fragments, and micas. As the injected fluids exit the perforations and cool, various precipitates drop out at different temperatures. The high temperature precipitates or cements bond the sand grains around the perforation tunnels and control sand movement into the wellbore. The lower temperature precipitates are driven away from the wellbore by the injected fluids, especially the steam vapor phase, where they are dispersed over enough rock volume to not cause any appreciable negative effect on formation porosity and permeability. Limited-entry perforating ${ }^{\mathrm{D} 1}$ assures that each perforation is treated with steam, that the steam is moving at maximum fluid velocities to drive off unwanted precipitates, and that the operator will have future steam injection profile control. Gross fluid rates from production wells completed with sand consolidated perforations appear

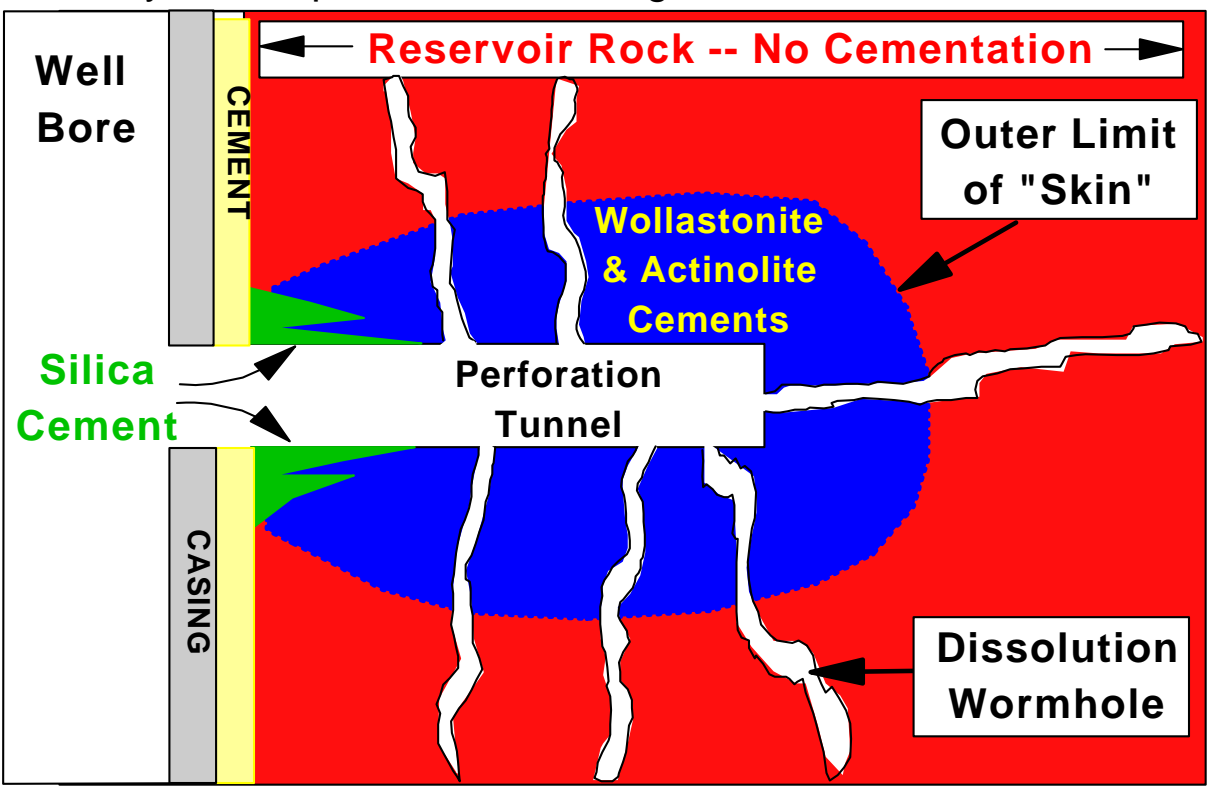

Figure 5.1.2-1 Schematic representation of an ideal perforation showing distribution of synthetic cements and dissolution wormholes. 
better than wells completed with a gravel-packed liners over a similar interval. This indicates that the sand consolidation treatment is creating secondary porosity, or wormholes, through the selective dissolution of formation fines and thus increasing permeability. Many wells given a Sand Consolidation Treatment also experience higher oil cuts than offset wells. This could be attributable to the wormholes having less formation fines and therefore higher oil relative permeability. A schematic of the sand consolidation process is shown is Figure 5.1.4-1.

\subsubsection{Application of Sand Consolidation Technique on UP-955}

UP-955 is a horizontal steamflood well that was completed and cyclically steamed from June - October 1996. The horizontal section of the well was drilled into the "D1" Sand, within the Tar II-A, and completed using the sand consolidation technique.

The well was completed with 48 perforations from 3915' to 4430', which were 0.3 " in diameter. A casing scraper was then run and the casing was circulated clean with clean water. Sand consolidation began in June 1996, with the injection of $80 \%$ quality steam through insulated tubing, an expansion joint and a thermal packer set at 2398' with a tubing tail to 3907'. See Figure 5.1.3-1 for a wellbore diagram schematic.

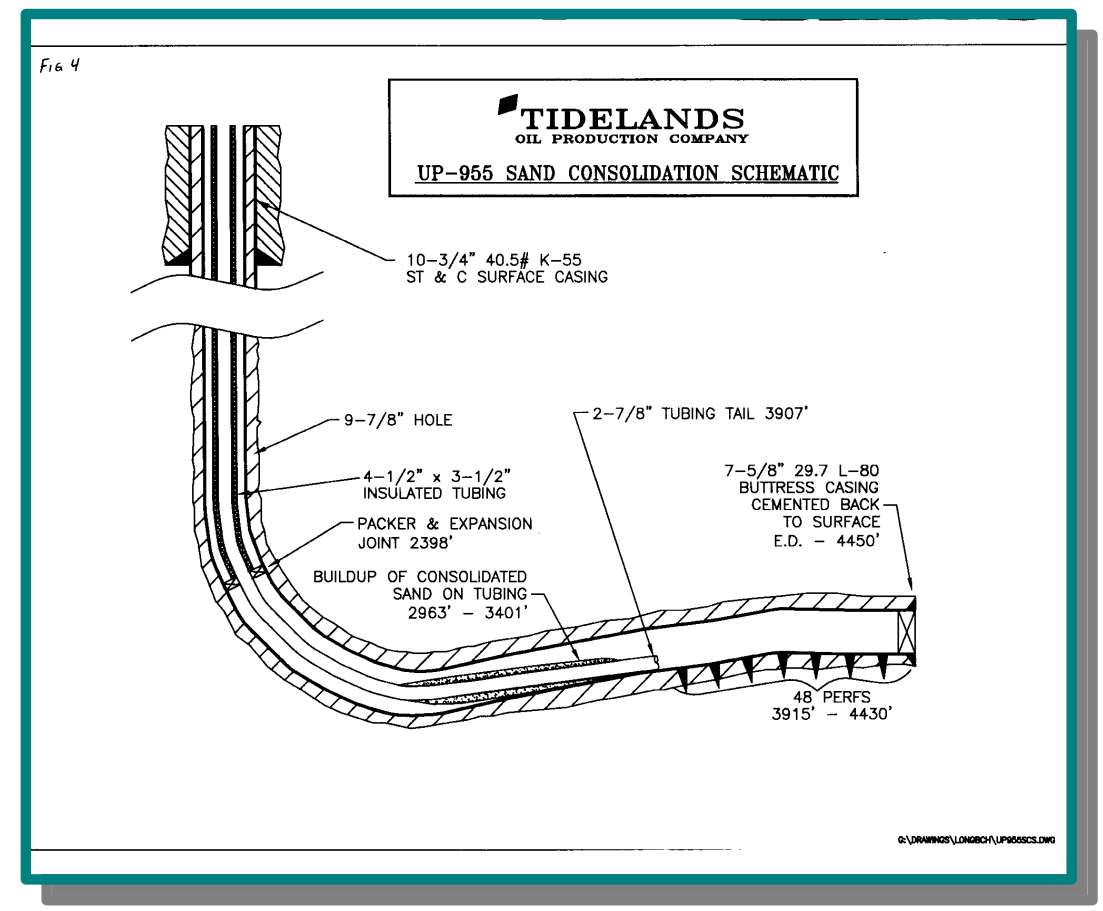

Figure 5.1.3-1: Wellbore Schematic for UP-955 showing sand inflow encrusted onto tubing tail.

The Sand Consolidation Treatment required 36,000 CWE Barrels of steam and an additional 78,000 CWE Barrels of steam were injected for the Huff "N" Puff cycle. The well was then shut-in for a 5 week steam soak. In October 1996, the insulated 
tubing was pulled and a coating of formation sand was found cemented to the tubing tail from 2963' to 3401'. Samples of the sand were analyzed using thin sections, x-ray diffraction and a scanning electron microscope (SEM).

The sand cemented onto the tubing tail is believed to be the result of unconsolidated sands entering the wellbore early in the cyclic steam job when the steam source underwent a shutdown on July 13 and 14 . This occurred after cumulative injection was 11,500 CWE bbls of steam, approximately $30 \%$ of the volume needed to perform a successful sand consolidation on the 48 perforations. The remainder of the cyclic steam injection job proceeded without problems.

The well was placed on production in November 1996 at an initial rate of 29 BOPD and 1037 BWPD, and by March 1997, had peaked at 80 BOPD and 1450 BPD gross, with a $1700-\mathrm{ft}$ fluid level over the pump. A vertical well completed over a $280-\mathrm{ft}$ interval with an opened-hole, gravel-packed and slotted liner completion typically produces 1000 BPD gross. In effect, $48-0.3$ " holes were too many by a factor of two and the high fluid level hurt net oil production.

\subsubsection{Analyses of Sand Consolidation on UP-955 tubing Tail}

The thin section, $x$-ray diffraction and SEM work revealed that the grain composition and grain size of the artificially cemented sands were the same as the formation sands and entered into the wellbore by means of the open perforations ${ }^{A 19}$. The sand grains flowed down the casing annulus between the casing and tubing tail, completely surrounding the tubing tail, as shown in Figure 5.1.3-1. The cemented sand samples indicated the presence of three concentrically arranged layers as described below and shown in Figure 5.1.4-1:

Layer 1 was the closest to the tubing wall and consisted of sand grains bonded with silica cement $\left(\mathrm{SiO}_{2}\right)$. The 1 to $3 \mathrm{~mm}$ thick layer had a low porosity of $<1 \%$, as determined from thin section analysis, and was considered to be essentially impermeable. Silica cement is a low temperature cement which precipitates at about $150^{\circ} \mathrm{C}$. Layer 1 is believed to have been initially bonded with high temperature Layer 2 cements and subsequently covered with Layer 1 cements when cyclic steam injection ceased and the tubing filled with cool kill fluids. The silica cement occurs as grain coating chalcedony and as quartz overgrowths.

Layer 2 formed within and above Layer 1 and is 1 to $3 \mathrm{~mm}$ thick. This layer consisted of artificially cemented sand grains, primarily by a complex calcium silicate $\left(\mathrm{CaSiO}_{3}\right)$ mineral. The crystals formed a plate structure, which extended from one grain to the next. This layer had high porosity $>25 \%$ as determined by thin section analysis, however, a reduced permeability resulted from cemented pore throats. This layer is loosely referred to as the Wollastonite layer, as Wollastonite is the closest known mineral to this artificially-made cement. Wollastonite is a high temperature cement which precipitates at about $300^{\circ} \mathrm{C}$. 


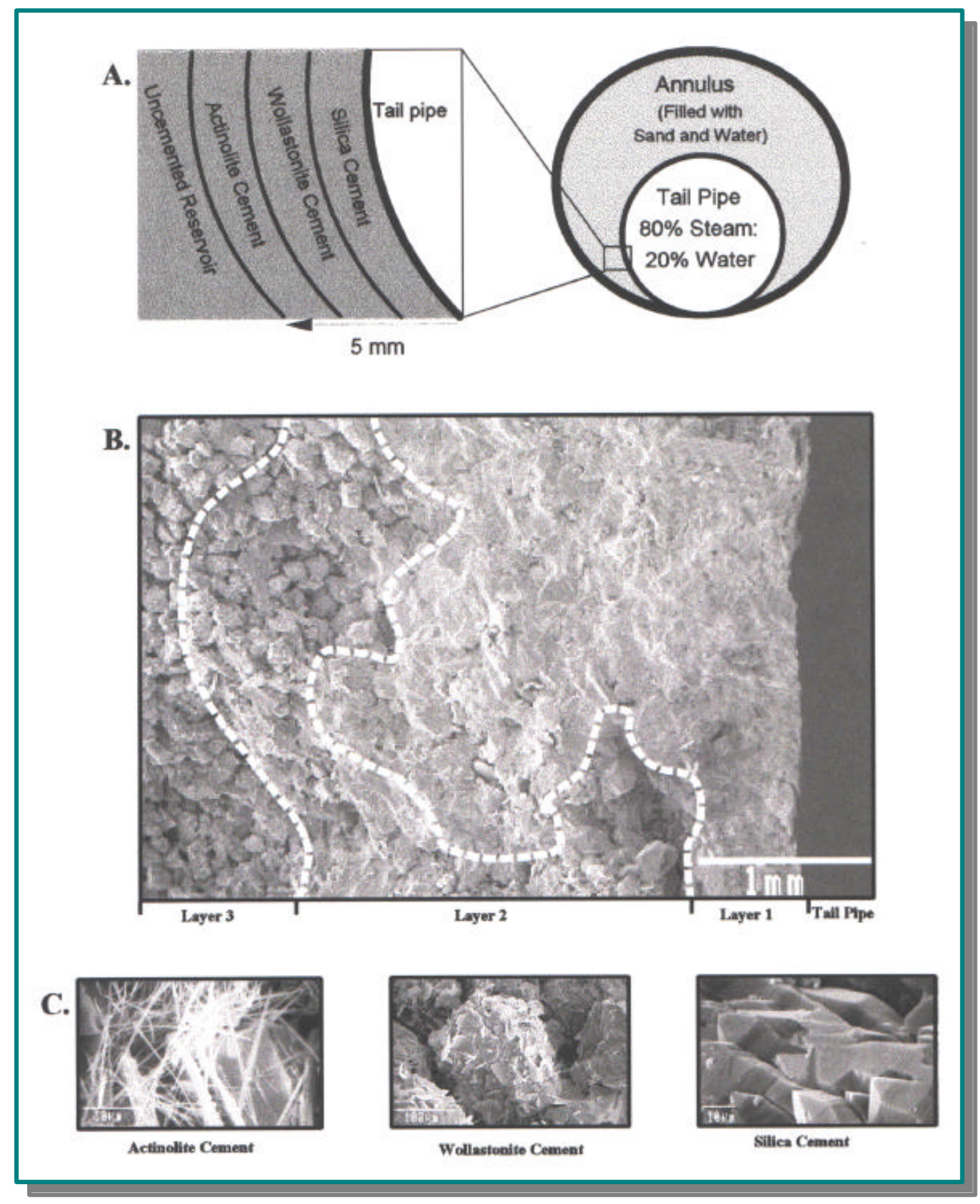

Figure 5.1.4-1: UP-955 tubing tail sample showing the three cement layers and the pictures of the three cement types bonding the sand grains. 
Layer 3 was the outermost layer and was 1 to $3 \mathrm{~mm}$ thick. Synthetic accicular (needle-like) crystals of another complex calcium silicate loosely cemented the sand grains. This layer has a high porosity $>25 \%$ as determined by thin section analysis. Permeability is higher than Layer 2 (by visual analysis), but like Layer 2 , cannot be accurately determined reliably as the layers are too thin. This layer is loosely referred to as the Actinolite layer, as Actinolite is the closest known mineral phase of this artificially-made cement. Actinolite is also a high temperature cement which precipitates at about $250^{\circ} \mathrm{C}$.

\subsubsection{Geochemistry of the Process}

The use of the hot alkaline / steam sand consolidation technique to complete wells is based on the geochemical bonding of unconsolidated formation sand grains with a lattice of primarily high temperature complex synthetic silicate cements. In the case of well UP-955, the high temperature $\left(>250^{\circ} \mathrm{C}\right)$ synthetic silicates created contained calcium, magnesium, and iron ${ }^{A 19}$. Many relatively lower temperature precipitates are also created including other calcium and magnesium-based silicates, silica cements and sulfate, carbonate, and oxide scales ${ }^{A 6}$. The complex silicate cements and other mineral precipitates are created by the high temperature and high alkaline $\mathrm{pH}$ steam condensate which preferentially dissolves sand grains with high specific surface area ${ }^{\mathrm{D} 6, \mathrm{D} 7, \mathrm{D} 8, \mathrm{D9}}$ and that the framework sand grains, such as quartz, are less affected. The injected fluids rapidly lose heat to the formation and various cements precipitate with changes in temperature, alkalinity, and contact time. The lattice of cement bonds are created by the relatively high volume and high velocity steam vapor phase which dissipates through the near-wellbore region quickly and carries away excess cements and other precipitates where they do not adversely affect formation porosity and permeability.

Research by Reed ${ }^{D 6}$ of Chevron USA and Watkins, et a $I^{D 7}$ of Union Oil of California describe how high temperature and high $\mathrm{pH}$ fluids above 9.5 can cause significant silica dissolution of the gravel pack and formation sands. They discussed how typical oil field steam generators created $80 \%$ quality steam, of which the $80 \%$ vapor phase was slightly acidic $(\mathrm{pH}$ of $5-7)$ and the $20 \%$ liquid condensate phase was highly alkaline $(\mathrm{pH}$ of $10-12)$ based on the bicarbonate $\left(\mathrm{HCO}_{3}\right)$ content of the steam feedwater. The bicarbonate ions decompose into $\mathrm{CO}_{2}$ and $\mathrm{H}^{+}$ions which partition to the vapor phase and make it acidic and $\mathrm{OH}^{-}$ions which partition to the liquid phase and make it alkaline.

Research by McCorriston, et al of Gulf Canada, Sydansk of Marathon Oil, and Caballero of Advanced Technology Laboratories ${ }^{\mathrm{D} 8, \mathrm{D} 9}$, D10 touch on the geochemical reactants created by injecting steam into the formation and the resultant precipitates which can fill the pore spaces between the formation sand grains and gravel pack. The geochemical reactants include the sand grain minerals dissolved by the high temperature highly alkaline steam condensate and the minerals and salts in the steam feedwater and the formation oil, gas, and water. Figure 5.1.5-1 shows the typical water 
analyses for the steam feedwater and the pre- and post-steamflood formation waters for the Tar II-A project.

In summary, the complexity of analyzing the dissolved geochemical reactants created from sandstone dissolution was recognized in previous research, but generally for adverse effects. That research was concerned about silica dissolution of gravel packs, the related well failures, and formation damage from plugging the pore spaces with precipitates, primarily silica cements and acid insoluble silicates and scales. All of the tests were performed in the laboratory, usually at temperatures and pressures below $250^{\circ} \mathrm{C}$ and 700 psia. Some researchers mentioned the possible benefits of sandstone dissolution, such as increased porosity and permeability from dissolving sand grains and creating water-soluble silicates for enhanced oil recovery, but did not elaborate in their papers.

\begin{tabular}{|c|c|c|c|}
\hline \multicolumn{4}{|c|}{$\begin{array}{c}\text { Analyses of Produced Water } \\
\text { and Steam Feedwater }\end{array}$} \\
\hline $\begin{array}{l}\text { Selected } \\
\text { Radicals } \\
\end{array}$ & Steam & $\begin{array}{l}\text { Pre-Steam } \\
\text { Wells }\end{array}$ & $\begin{array}{l}\text { Post-Steam } \\
\text { Wells }\end{array}$ \\
\hline Calcium & 0.2 & 500 & $0-200$ \\
\hline Magnesium & 0.1 & 500 & $5-50$ \\
\hline Iron & 0 & $0.7-3.0$ & 0.3 \\
\hline Silica & 0 & $50-100$ & $100-200$ \\
\hline Sodium & 200 & 9500 & $1000-3000$ \\
\hline Chloride & 260 & 17,000 & $2000-4000$ \\
\hline TDS & 600 & 29,500 & 4000 - 9000 \\
\hline
\end{tabular}

Figure 5.1.5-1: Typical Water Analyses of Steam Feedwater and Formation Waters

The precipitation of synthetic cements reduces the permeability of the formation sands because the cements occur in the pore throats. However, the effective formation permeability in the near-wellbore region is probably greater following a sand consolidation treatment because of sandstone dissolution that creates secondary porosity and permeability. As mentioned previously, the dissolution reactions show selectivity towards grains with inherent planes of weakness and high specific surface areas. In this case, feldspathic grains appear to be extensively leached as shown in Figure 5.1.5-2. Due to the high abundance of feldspathic grains in the Tar II-A, extensive dissolution is apparent in the cemented sand samples, especially where several feldspathic grains occur in series. This group dissolution forms wormholes that have significantly larger pore throat channels than the natural intergranular pores. This 
phenomenon increases absolute permeability and explains the high productivity and injectivity indexes for the sand consolidated wells. This phenomenon could also be increasing relative oil permeability as evidenced in the production performance of certain wells. These dissolution wormholes appear to form only in areas of high heat transfer - immediately adjacent to the wellbore in steam injection wells. No evidence of wormholes or precipitates from the dissolution process has been observed in poststeamflood cores.

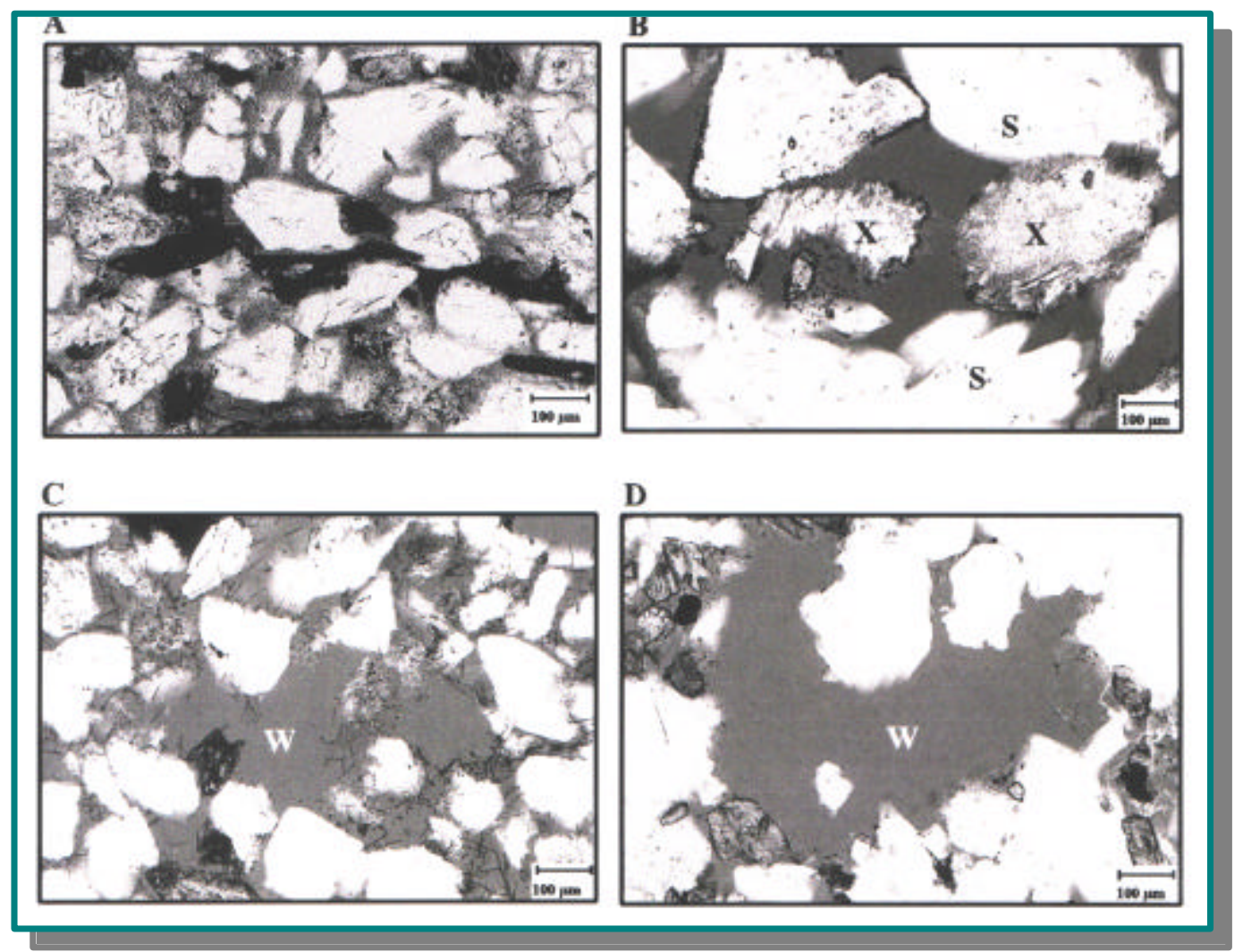

Figure 5.1.5.2: Thin section photomicrographs of pore structure. Sand grains are white and black; pores are gray areas between sand grains.

A Actual pore structure of Tar Zone Sands (pre-steam core).

B. Partial dissolution of unstable grains.

Note: irregular grain outlines. Surrounding sand grains are relatively large due to precipitation of silica cement.

C\&D Dissolution wormholes (W) produced through leaching of pre-exiting silicate grains.

A closer analysis of the Wollastonite and Actinolite crystals reveals the presence of loose cement bonds between the sand layers. This is due to the habit (shape) of the said crystal layers. The loosely bonded nature of the Wollastonite and Actinolite layers implies that the rock framework is stabilized but not rigid. Thus, the skin around the perforation is correspondingly loosely cemented and can fail in the presence of high differential pressures across the formation face that has occurred in several wells. 
These types of well failures have generally been repaired successfully by applying another alkaline hot water/steam sand consolidation treatment.

\subsubsection{Results and Conclusions}

1. The Sand Consolidation Technique has seen successful applications on 13 vertical wells, 12 horizontal wells, 7 recompletes, and two repaired liners in three heavy oil zones in Fault Blocks I, II-A and V in the Wilmington Field. After 2 years of production and injection well service, over $90 \%$ of the wells experienced minor or no sand inflow problems. The application in horizontal wells has significantly reduced the risk of wellbore completion failures.

2. The Sand Consolidation Technique can provide substantial cost savings in well drilling and completion operations by eliminating the need for "conventional" opened-hole gravel-packed slotted-liner completions and replacing it with a simple cased-through and cemented completion with a limited number of selected small perforations. The wells completed with this technique have equivalent to higher production or injection rates than wells with the "conventional" completions due to increased permeability from sandstone dissolution.

3. The limited-entry perforating used in the Sand Consolidation Technique provides superior production and injection profile control in the treated wells. The treated wells can easily be reworked to eliminate unwanted perforations and to recomplete and treat new perforations.

4. The synthetic cements bonds tend to resist hydrochloric acid and therefore the wells with Sand Consolidation Treatments can be acidized to remove scales and other formation damage.

5. The Sand Consolidation Technique allows both production and injection wells to be completed the same way, thereby making it possible to convert wells easily to either service.

6. The Sand Consolidation Technique appears to work best in "dirty" sandstone reservoirs, those with chemically complex and unstable sand grains that are typically sensitive to foreign fluids or easily move in the reservoir, both causing formation damage. The sand consolidation process preferentially dissolves the sand grains with high specific surface area and, where several affected grains are connected, leaves "wormholes" in the near-wellbore region that enhance well performance.

\subsection{Horizontal Well Completion Techniques}

See Chapter 5.1. 


\subsection{Profile Control in Horizontal Injectors}

To ensure good profile control in the two horizontal injectors in the Tar II-A steamflood and the two horizontal injectors in the Tar V steamflood pilot, all four wells were completed with limited-entry perforations as described by Small ${ }^{\mathrm{D} 1}$. In general, each of the wells was completed with about 10-12 quarter-inch perforations. See Section 5.1 for more details.

\subsection{Minimize Carbonate Scale Problems}

No activity this reported this period.

\subsection{Determine Temperature Limits to Minimize Operating Problems}

\section{Introduction}

While steam injection can improve the recovery of heavy oil from a reservoir, it can also potentially affect the composition and physical properties of the reservoir rock and surrounding shales. Of particular interest in this regard is the effect of steam injection on the compactional properties of shales occurring within and surrounding the Tar II-A reservoir. Changes in shale volume in response to steaming could impact surface subsidence.

Shale compaction due to steamflooding became a concern in 1994 as an isolated surface area within the structurally updip portion of the steamflood project began to subside. Several activities, both surface and sub-surface, were occurring in the area that could have caused or contributed to the subsidence. The activities included the steamflood project, the laying of 100 million tons of compacted fill by the Ports of Long Beach and Los Angeles onto the adjacent lands, shallow gas production, waterflood production from deeper sands, and ground water changes. This study pertains to the operational and laboratory tests performed to study the possible effects of the steamflood on surface subsidence.

\subsubsection{Cased-hole Log Tests}

In October 1998, the project team ran a cased-hole log through the Tar II-A zone in well UP-800 and determined that 2-3 feet of compaction occurred within the 12 feet of shale directly above the "D1" sands. No apparent compaction was identified anywhere else in the steamflood interval. This compaction is consistent with the post steamflood core evaluation by David K. Davies (DKD) and with the density-neutron log from one of the post-steamflood cored wells that shows a possible $3 \%$ reduction in porosity $(3 \%$ of bulk volume) for about the first seven feet of "shale" above the steam injection "D1" sands (which would total 2.5 inches of compaction).

In February 1999, a second cased-hole log was run in well $1 \mathrm{~F}-10$ to confirm the findings in well UP-800 and to see if compaction occurred elsewhere, such as the top of 
the "T" sands. This log showed about 2.5 feet of compaction in the shales between the "T" and AD@zones and nowhere else. This work confirmed the initial work performed on post-steamflood cores by DKD that changes in color and dehydration of smectites could be observed in the shales, especially above the "D" sands, but no noticeable changes could be seen in the sands.

\subsubsection{Analysis of High Temperature Laboratory Tests on Shales and Post- Steamflood Cores}

David K. Davies and Associates, Inc analyzed both the pre-steam cores from well OB2-3 and the pre- and post-steam cores from wells OB2-5 and UP-908. They concluded that the most serious shale compaction is occurring in a six-foot interval above the D1 sand as was conjectured. They also concluded that lesser forms of shale compaction are occurring above and throughout the T2 sand, the thickest T sand, and in the interbedded shales within the upper D1 sands above the apparent steam / oil interface as delineated by the density -neutron log crossover.

The study suggests that the shale compaction process occurs in two stages, an early compaction stage and a late compaction stage. The early compaction stage is a result of a relatively gradual expulsion of fluids from the shales through the matrix pore system into the surrounding sand laminations. The late compaction stage is a result of fluid expansion causing pore pressures to build up high enough to cause hydraulic microfracturing throughout the shale matrix. The shales exposed to high temperatures are going through a general sequence of events that includes the following:

\section{Early Compaction Stage}

1) Clay dehydration resulting in the expulsion of interlayer clay water from the clays to the adjacent shale pores. This is believed to start at $60^{\circ} \mathrm{C}$ or $135^{\circ} \mathrm{F}$. Earlier studies indicated that the virgin shales can have high porosities above $35 \%$ of the bulk volume and that dehydrated shales from clay dewatering can have porosities as low as $15 \%$. Dehydrated clays can rehydrate back to original conditions upon cooling if water is present, even if heated to $288^{\circ} \mathrm{C}$ or $550^{\circ} \mathrm{F}$ during steamflooding;

2) Kerogens within the shales are partially converting to liquid hydrocarbons, pressuring up and exuding into adjacent pores. The kerogens in the shales are organic rich and can yield gas and oil when heated. Well OB2-5 had minimal kerogen thermal effects $11 \mathrm{ft}$. above the D1 sand and the shales bordering the sands had the most "live" oil in them. Apparently, an expert can deduce the temperature range a kerogen has experienced by looking at their "reflectance" or shininess factor and estimated that the kerogens above the $\mathrm{D} 1$ sands underwent $439^{\circ} \mathrm{C}$ or $822^{\circ} \mathrm{F}$ in the lab, which is too high. The lab procedure consistently raises temperatures rapidly compared to actual reservoir conditions, therefore higher temperatures are needed to crack or refine the crude oil than is probably needed in the reservoir. It is possible that the hydrocarbon distillates which form in the steam chest from the D1 sand oil could be affecting this evaluation or 
maybe some of the geochemical reactions that occur at higher temperatures are exothermic and increasing local temperatures above reservoir temperatures;

3) Thermal expansion of all shale pore fluids, including the original connate water, the new oil generated from the kerogens and the interlayer clay water, increases the pore pressure within the shale;

4) Gradual and continuous escape of some of the pore fluids through the matrix pore system without significant textural changes in the rock. Lab work indicates that the clays in the Tar II-A shales can be dewatered at temperatures below $275^{\circ} \mathrm{F}$ without microfracturing the shale matrix or causing textural changes in the rock. The actual temperature necessary to dewater the shales is dependent on the proximity of sand layers, the pore pressure and horizontal and vertical permeability of the shale matrix. Color changes in the shales are subjective and qualitative, but are definitely different for virgin and heated shales. The virgin shales have a dominant green color with patches of very light brown. Shales that undergo some heat are light brown without the green hue. The highly heated shales are dark brown to black. The first color change is attributed to generating oil from the kerogens and the second color change is attributed to coking the oil. Some color changes could be due to mineral transformations;

\section{Late Compaction Stage}

5) Coking of the liquid hydrocarbons which darkens the shale color and possibly reduces the shale matrix permeability. According to tests performed from 1990-92 by Alberta Sulphur Research LTD. of the University of Calgary for Union Pacific Resources Corp, Tar II-A crude oil begins cracking at $250^{\circ} \mathrm{C}$ or $482^{\circ} \mathrm{F}$ and coking reactions require temperatures exceeding $285^{\circ} \mathrm{C}$ or $545^{\circ} \mathrm{F}$;

6) As temperature and pressure increase, mineral transformations occur due to the geochemistry between the shale pore fluids and the surrounding rocks. Specific diagenetic minerals can precipitate or dissolve at certain temperatures, making them possible paleothermometers for defining the temperature ranges experienced by the formation rocks. A few diagenetic transformations include the creation of chlorites, epidote, the zeolite, Analcime, and pyrites; and

7) Micro-fracturing of the shales occurs when the pore pressure exceeds the lithostatic pressure which results in the rapid release of pore fluids and shale compaction. It appears that the micas immediately above the D1 sands in the presteam cores are more randomly packed and oriented whereas in the post-steam cores the micas are oriented more parallel with the bedding plane, indicating late stage shale compaction. Virgin and early stage compacted shales generally have less than $35 \%$ of the micas oriented within $0-10^{\circ}$ of horizontal bedding whereas compacted shales The compaction also causes mica grains to fold or break. These microfractures cannot generally be seen in thin sections unless specifically looking for them since they are hidden where the kerogens and smaller than 2 micron size grains are located and because they do not break individual grains of quartz and feldspar. 
Using these indicators, late stage shale compaction occurred in well OB2-5 from 2412.5 - $2440.15 \mathrm{ft}$ (above and throughout T2 sand), from 2531.5 - $2534.8 \mathrm{ft}$ (above D1 sand) and in the interbedded shales within the D1 sands down to $2542 \mathrm{ft}$ which is above the steam / oil contact. The most impacted samples were above the D1 sands. According to the density-neutron log, the steam chest (log separation) in the T2 sand extended throughout the sand from 2417-2446 $\mathrm{ft}$ and the D1 sand steam chest also extended throughout the sand from $2535-2587 \mathrm{ft}$ with a major log separation from 2535$2550 \mathrm{ft}$. In UP-908, the shales exhibited late stage compaction from 2558.25 - 2561.75 $\mathrm{ft}$ (above D1 sand). The ReSpec core sample that was heated to $550^{\circ} \mathrm{F}$ also experienced late stage shale compaction. Early stage compaction was observed in most of the shales that experienced reservoir heating and in the ReSpec core sample that was heated to $275^{\circ} \mathrm{F}$. Recent Thermal-Decay-Time logs run in wells UP-800 and $1 \mathrm{~F}-10$ only show noticeable compaction in the twelve foot interval above the D1 sands and none in the "T" sands or interbedded shales in the "D" sands, even when comparing total gross sub-zone thicknesses with the original logs.

The temperature ranges for the early and late compaction stages have not been clearly defined, but evidence uncovered to date can place some temperature limits on the processes. For early stage compaction, clay dewatering is known to start at $60^{\circ} \mathrm{C}$ or $140^{\circ} \mathrm{F}$. The ReSpec core sample that was heated to $135^{\circ} \mathrm{C}$ or $275^{\circ} \mathrm{F}$ experienced clay dewatering but not late stage compaction symptoms. Based on paleo-thermometry, a sample of post-steamflooded core in well OB2-5 experienced mineral transformations (chlorites and vitrinite reflectance values) indicative of late stage compaction. The core underwent minimum temperatures of $192-202^{\circ} \mathrm{C}\left(398-416^{\circ} \mathrm{F}\right)$ to create chlorites and could not have experienced temperatures above $280^{\circ} \mathrm{C}$ or $536^{\circ} \mathrm{F}$ as the chlorites dissolve. Vitrinite is a kerogen-based hydrocarbon that provides reflectance values of the highest temperatures it encounters. The vitrinite reflectance values further reduced the upper range to $250^{\circ} \mathrm{C}$ or $482^{\circ} \mathrm{F}$. Yet as mentioned above, the crude oil tends to coke at approximately $285^{\circ} \mathrm{C}$ or $545^{\circ} \mathrm{F}$ and epidotes commonly form at $260-270^{\circ} \mathrm{C}$ or $500-518^{\circ} \mathrm{F}$ so discrepancies still exist. Therefore, it is safe to conclude that early stage compaction starts at $60^{\circ} \mathrm{C}$ or $140^{\circ} \mathrm{F}$ and late stage compaction starts between 135$192^{\circ} \mathrm{C}$ or $275-398^{\circ} \mathrm{F}$. The upper temperature limits cannot be determined, other than to conclude it is below the steam injection temperature of $316^{\circ} \mathrm{C}$ or $600^{\circ} \mathrm{F}$ or to use the maximum thermal reservoir simulation model temperature of $273^{\circ} \mathrm{C}$ or $523^{\circ} \mathrm{F}$ in the shales at the end of steamflood injection. These findings indicate that more ReSpectype "open" shale compaction tests should be performed, perhaps at $177^{\circ} \mathrm{C}$ and $218^{\circ} \mathrm{C}$ $\left(350^{\circ} \mathrm{F}\right.$ and $425^{\circ} \mathrm{F}$, respectively), to determine the critical microfracture temperature and measure the physical expansion and contraction of the samples.

With respect to the ReSpec "open-system" high temperature compaction tests on sands and shales where fluids were allowed to bleed off to maintain constant pressures, the tests on the shales were probably closer to a "semi-closed" system because of the lack of vertical permeability in the samples. During the shale tests at $275^{\circ} \mathrm{F}$ and $550^{\circ} \mathrm{F}$, both samples were allowed to bleed fluids out of the system to maintain constant pressure in the test vessel. However, the rate of fluid expulsion was not recorded and 
therefore it cannot be determined when, if at all, the pore pressures exceeded critical lithostatic pressures and a resultant sudden release of pore fluids occurred. The sample heated to $550^{\circ} \mathrm{F}$ appears to have microfractures whereas the sample heated to $275^{\circ} \mathrm{F}$ did not. The test procedure also ramped up temperatures within an hour, which may not have allowed the "whole core-size" shale samples to heat up uniformly and to "gradually" bleed off pressure to adjacent interbedded sands as would happen in the field. In the ReSpec shale test at $275^{\circ} \mathrm{F}$, compaction was based on early stage compaction symptoms or mostly through dehydration of the clays. The ReSpec shale test at $550^{\circ} \mathrm{F}$ underwent late stage compaction symptoms such as microfracturing, color changes, and mica realignment. Further shale tests at ReSpec should measure the rate of fluid expulsion from the core samples and ramp up temperatures more gradually to allow the large shale samples to heat up more uniformly. 


\section{ACTIVITY 6 - EXPANSION PROGRAM}

The Thermal project will expand the S sand steamflood in the Fault Block V Tar Zone in Budget Period 2 of this project. The current Tar V steamflood pilot is based on the knowledge gained from the horizontal well drilling and completion technology and reservoir characterization, pilot testing, and reservoir management techniques learned from the Tar II-A steamflood project performed in Budget Period 1. The plan is to add four horizontal producers, four horizontal injectors, and three observation wells to the existing pilot project. The original Budget Period 2 plan to expand the Tar II-A steamflood project has been withdrawn because of the loss of the Tar II-A steam source from the Harbor Cogeneration Plant.

The expansion project has a drainage area of approximately 88 acres and a net oil sand thickness of $50 \mathrm{ft}$. The remaining oil saturation after waterflooding is estimated to be $50 \%$. The remaining oil in place is estimated to be $4,850,000$ barrels of oil. Projected recovery from the expansion project is estimated to be $1,940,000$ barrels of oil.

The overall project is expected to take eleven years to complete. The expansion project is scheduled to start in the second half of 2001 and proceed through 2012. 


\section{ACTIVITY 7 - TECHNOLOGY TRANSFER}

\section{Introduction}

State of the art work as performed in this project is of particular interest to the industry, as the Wilmington Field operations and producing reservoirs are among the most researched, with respect to academic and applied field applications, than any other oil and gas field in the world. The turbidite sand or SBC geology is prevalent in many of the frontier reservoirs being explored in the North Sea, West Africa and the deep Gulf of Mexico offshore areas, among others.

The project team was extremely active this reporting period in publishing and presenting the new technologies detailed in the preceding pages to the petroleum engineering community. Twenty-three original technical papers and eight articles related to original project technical work were published for industry professional societies and prestigious industry magazines and journals. At USC, one student did her doctoral thesis on the project, a multi-media CD-Rom of the project was developed, and the project web page was updated. The project team was heavily involved in the 1997 Western Regional Meeting of the Society of Petroleum Engineers in Long Beach and in the activities of the West Coast Petroleum Technology Transfer Council. In addition to presenting papers, the project team members gave 24 technical oral presentations at professional society and industry meetings given throughout California, in Texas, and even internationally in China, Spain and Finland.

\subsection{DOE Reports}

The project team is current on quarterly and annual reports from project inception on March 30, 1995 through this reporting period, which total 20 quarterly reports and 3 annual reports. This "annual report" covers a three-year period from April 1, 1997 to March 31, 2000.

\subsection{Publications}

Project team publications written during the reporting period have been categorized by professional society, DOE, or other organizations for which original technical work has been prepared.

\subsubsection{Professional Societies}

\section{Western Regional Meeting of the Society of Petroleum Engineers (SPE)}

In 1997, the Western Regional Meeting (WRM) of the Society of Petroleum Engineers was held in the City of Long Beach from the 23rd to the 27th of June. Project team member, Scott Hara was the General Chairman of the WRM while Dr. Iraj Ershaghi and Dr. David K. Davies were instructors on "PTTC Intermediate Internet Training" and "Identification and Prevention of Formation Damage through detailed 
Rock Analysis", respectively. Project team members prepared and presented six papers and three oral presentations (see Section 7.3.2) at the convention. Significant time was expended to promote the technical transfer of DOE Class III projects and other DOE activities at this convention including 14 Class III-related presentations or field trips (11 by Tidelands, the City of Long Beach, USC, and David K. Davies and Associates); distribution of a CD-ROM on the two City of Long Beach DOE projects at the DOE exhibit booth; the "National Petroleum Technology Resource Center", an exhibit booth sponsored by DOE providing information on low cost resources available to operators; and an "Alternative Dispute Resolution" class sponsored by DOE.

The PTTC conducted an "Intermediate Internet Training" workshop at the Petroleum Technology Transfer Council West Coast Office, located at the University of Southern California. The workshop provided attendees a selection of Internet sites by which petroleum industry information could be accessed, as well as familiarizing attendees with the necessary hardware and software needed to access these on-line databases.

Dr. David Davies conducted a workshop on "Identification and Prevention of Formation Damage through detailed Rock Analysis" that provided an overview of formation damage identification, prevention and correction to petroleum engineers and geologists. In relation to the Class III DOE project, the workshop emphasized the importance of rock and fluid characterization in successful field operations. This workshop is being reprised at the 2000 Pacific Section AAPG / Western Regional SPE Meeting to be held June 17-22 in Long Beach.

Project team members Donald Clarke and Chris Phillips, and George Ottot of THUMS Long Beach Company jointly conducted a field trip entitled "A Visit to the Giants of the Los Angeles Basin". This field trip focused on the production histories as well as the specific difficulties encountered with production from the Wilmington, Huntington Beach and Long Beach Oil Fields. In addition, a field trip guidebook of the same title was generated with excerpts from papers detailing the history, operational difficulties and problem mitigation of the oil fields. The field trip and accompanying guidebook was revised for the 1997 Western Regional Meeting from the trip entitled "Old Oil Fields and New Life: A Visit to the Giants of the Los Angeles Basin" conducted at the 1996 AAPG Annual Meeting. The field trip has been reprised each year for industry professionals and public school teachers, including this year for teachers at the 2000 Pacific Section AAPG / Western Regional SPE Meeting to be held June 17-22 in Long Beach.

Yucel I. Akkutlu of USC presented SPE Paper No. 38309 entitled "Conceptual Model of Fault Block II-A, Wilmington Field, from Field Performance Data" at the 1997 Western Regional Meeting in Long Beach, CA, 23-27 June. His co-authors were Dr. Iraj Ershaghi and Dr. Lyman L. Handy of the University of Southern California and Julius J. Mondragon III of Tidelands Oil Production.

Pouya Amili of USC presented SPE Paper No. 38297 entitled "Correlations for Prediction of Steamflood Oil Recovery in Steam-Assisted Gravity Drainage (SAGD) 
Process Using Horizontal Injectors and Producers" at the 1997 Western Regional Meeting in Long Beach, CA, 23-27 June. Her co-author was Dr. Iraj Ershaghi of USC.

Walt Whitaker II of Tidelands Oil Production presented SPE Paper No. 38277 entitled "7-ppm No. 50 MM BTU/hr Oilfield Steam Generator Operating on Low-Btu Produced Gas" at the 1997 Western Regional Meeting in Long Beach, CA, 23-27 June.

Scott Walker of Tidelands Oil Production presented SPE Paper No. 38283 entitled "Locating and Producing Bypassed Oil: A DOE Project Update" at the 1997 Western Regional Meeting in Long Beach, CA, 23-27 June. This paper described a new application of the well completion technology using steam to consolidate sand developed in the DOE waterflood project for Wilmington.

Richard Cassinis of Tidelands Oil Production presented SPE Paper No. 38273 entitled "Improved $\mathrm{H}_{2} \mathrm{~S}$ Caustic Scrubber" at the 1997 Western Regional Meeting in Long Beach, CA, 23-27 June. His co-author was William A. Farone of Applied Power Concepts, Inc.

David K. Davies presented SPE Paper No. 38262 entitled "Improved Prediction of Permeability and Reservoir Quality through Integrated Analysis of Pore Geometry and Open-hole Logs: Tar Zone, Wilmington Field, California" at the 1997 Western Regional Meeting in Long Beach, CA, 23-27 June. His co-author was Richard K. Vessel of David K. Davies and Associates.

\section{Other SPE Papers}

Rick Cassinis of Tidelands Oil Production presented SPE Paper No. 37530 entitled "2100-foot, 14-inch Steam Line Under a Ship Channel" at the 1997 SPE International Thermal Operations and Heavy Oil Symposium in Bakersfield, CA from February 10-12.

Dr. David K. Davies presented SPE Paper No. 38914 entitled "Improved Prediction of Reservoir Behavior through Integration of Quantitative Geological and Petrophysical Data", 1997 Society of Petroleum Engineers Annual Technical Conference and Exhibition in San Antonio, TX, 6-8 October. His co-authors were John Aumon and Richard K. Vessel of David K. Davies and Associates.

Scott Hara presented SPE Paper 38793 entitled "A Novel, Low Cost, Well Completion Technique Using Steam for Formations with Unconsolidated Sands, Wilmington Field, California" at the 1997 SPE Annual Technical Conference in San Antonio from October 6-8. The primary author was Dr. David K. Davies and the coauthors were Julius Mondragon and Scott Hara.

Zhengming Yang of USC presented SPE Paper \#49314 entitled "Method for Handling the Complexities Associated with History Matching the Performance of a 
Highly Stress-Sensitive Formation" at the 1998 SPE Annual Technical Conference in New Orleans, LA on Sept. 27-30.

Zhengming Yang of USC presented a paper entitled "A Simulation Study of Steamflooding in a Highly Stress-Sensitive Heavy Oil Formation" at the 1998 UNITAR International Conference on Heavy Crude and Tar Sands in Beijing, China from October 27-31.

Julius Mondragon of Tidelands presented a paper entitled "Reservoir Characterization in a Steamflood Using Produced Water Chemistry Data", SPE Paper \#54118, at the 1999 SPE International Thermal Operations and Heavy Oil Symposium in Bakersfield, CA from March 17-19, 1999. The co-authors were Iraj Ershaghi of USC, Jon Bronson of Mobil, and Scott Hara of Tidelands.

David Davies of DKD presented two papers at the 1999 SPE Annual Technical Conference and Exhibition (ATCE) held in Houston, TX from October 3-6. SPE Paper \#56813 was entitled "Stress-Dependent Permeability: Characterization and Modeling" and his co-author was J. P. Davies of Chevron. The other presentation was SPE Paper \#56819 entitled "Geometry, Internal Heterogeneity and Permeability Distribution in Turbidite Reservoirs, Pliocene California".

Mahnaz Hassibi of USC presented SPE Paper \#56818 entitled "Reservoir Heterogeneity Mapping Using an Artificial Intelligence Approach" at the 1999 SPE Annual Technical Conference and Exhibition (ATCE) held in Houston, TX from October 3-6.

Julius Mondragon, Zhengming Yang, and Iraj Ershaghi of USC, et al will publish SPE Paper \#62571 entitled "Post Steamflood Reservoir Management Using a FullScale Three-Dimensional Deterministic Thermal Reservoir Simulation Model, Wilmington Field, California" to be given at the 2000 AAPG/SPE Western Regional Meeting in Long Beach, CA on June 19-22.

\section{Other Papers and Publications}

Changan Du and Iraj Ershaghi of USC completed a research report entitled "Reservoir Characterization and Stochastic Modeling of Fault Block IIA Turbidite Sand Formation of Wilmington Oil Field, Long Beach, California" in December 1998. The report was edited and revised by Julius Mondragon III of the City in May 2001.

Mahnaz Hassibi of USC completed her Doctoral Thesis entitled "A Method For Automating Delineation of Reservoir Compartments and Lateral Connectivity From Subsurface Geophysical Logs" in May 1999 in partial fulfillment of her requirements for the degree of Doctor of Philosophy, Petroleum Engineering.

\subsubsection{Industry Trade Journals and Newspapers}




\section{Society of Petroleum Engineers (SPE)}

SPE Paper 38793 entitled "A Novel, Low Cost, Well Completion Technique Using Steam for Formations with Unconsolidated Sands, Wilmington Field, California" by David K. Davies, Julius Mondragon and Scott Hara was published in the September 1998 issue of SPE Journal of Petroleum Technology in an abridged form.

David Davies, Richard Vessel, and John Aumon of DKD had their SPE Paper \#38914 entitled "Improved Prediction of Reservoir Behavior Through Integration of Quantitative Geological and Petrophysical Data" peer-reviewed and published in the prestigious SPE Reservoir Evaluation and Engineering Magazine in April 1999. The peer-reviewed paper was assigned SPE Paper \#55881.

\section{American Association of Petroleum Geologists (AAPG) Papers}

The American Association of Petroleum Geologists, in collaboration with Tidelands and City of Long Beach, published a two part article for The AAPG Bulletin on the Wilmington Field DOE projects entitled "Increasing Reserves in a Mature Giant: Wilmington Field, Los Angeles Basin". Part I was published in March 1998 and was subtitled "Reservoir Characterization to Identify Bypassed Oil". Part II was published in April 1998 and is subtitled "Improving Heavy Oil Production through Advanced Reservoir Characterization and Innovative Thermal Technologies".

\section{Canadian Institute of Mines - Petroleum Society Papers}

Don Clarke and Chris Phillips worked with Dynamic Graphics Inc. on an article entitled "3-D Modeling / Visualization Guides Horizontal Well Program in Wilmington Field" that was published in the October 1998 issue of the Canadian Petroleum Society's Journal of Canadian Petroleum Technology.

\section{Other Industry Trade Journals and Newspapers}

SPE Paper \#56813 entitled "Stress-Dependent Permeability: Characterization and Modeling" by David Davies of DKD and J. P. Davies of Chevron was published as an abridged article in the February 2000 edition, pages 82-84, of Offshore Magazine.

Richard Cassinis and Sean Massey of Tidelands and Stuart M. Heisler of TJ Cross Engineers Inc. wrote an article/advertisement for March 1997 edition, back cover, of the Oil, Gas and Petrochem Equipment Magazine entitled "The Story Behind Lo CoST SM",. This advertisement by the Sulfatreat Company was about a product developed through the DOE project work related to SPE Paper 38273 entitled "Improved $\mathrm{H}_{2} \mathrm{~S}$ Caustic Scrubber". Also refer to, http://www.ingersoll-rand.com/compair

Iraj Ershaghi of USC, Herb Tiederman of DOE, and Gail Dutton of Compressed Air Magazine wrote an article entitled "Coaxing Crude from the Ground" for the March 1997 edition of Compressed Air Magazine, pages 22-26. 


\subsubsection{DOE Symposium Proceedings}

Dr. I. Ershaghi and M. Al-Qahtani gave a presentation entitled "Characterization and Estimation of Permeability Correlation Structure from Performance Data" at the 4th International Reservoir Characterization Technical Conference sponsored by the DOE, BDM and AAPG in Houston, TX from March 2-4, 1997.

Scott Hara presented a paper entitled "A Well Completion Technique for Controlling Unconsolidated Sand Formations by Using Steam" at the 1999 DOE Oil and Gas Conference in Dallas, TX from June 28-30. His co-authors were Julius Mondragon III of Tidelands and David K. Davies of DKD.

\subsubsection{Professional Society Newsletters / Mailing List}

Jeff Schwalm of Dynamic Graphics Inc. and Chris C. Phillips of Tidelands wrote an article entitled "Earth Vision Software Solutions for Structurally Consistent 3-D Geologic Modeling, 3-D Well Placement Planning" as an advertisement mailer that was sent to the 1997 American Association of Petroleum Geologists (AAPG) Annual Meeting attendees, conducted 7-9 April 1997. The mailer contained a copy of the paper entitled "3-D Modeling, Horizontal Drilling... Gives New Life to Aging Fields" A8. The Wilmington DOE projects were featured in Dynamic Graphics' exhibit booth at the convention and in their Internet homepages: info@dgi.com and http://www.dgi.com/topko.html.

The City of Long Beach and Tidelands wrote an article for the summer 1997 edition of the U. S. DOE's The Class Act entitled "Horizontal Drilling for Thermal Recovery in the Wilmington Field, California."

Don Clarke of the City and Chris Phillips of Tidelands worked with Dynamic Graphics Inc. on an article entitled "Successful Horizontal Well Program In Wilmington Field" that was published in the First Quarter 1999 issue of the DGInsider, the EarthVision Newsletter.

\subsubsection{Database Files}

No activity this period.

\subsection{Presentations}

Presentations on project-related technical work given during the current reporting period are categorized by PTTC, professional society, DOE, or other organizations.

\subsubsection{Professional Societies}

\section{SPE-organized Oral Presentations}


Julius J. Mondragon III gave an oral presentation entitled "Novel Sand Consolidation Completion Technique Using Alkaline-Steam Injection in the Tar Zone, Wilmington Field" at the 1997 Western Regional Meeting in Long Beach, CA 23-27 June. His co-authors were Dr. David Davies and Scott Hara.

Chris C. Phillips gave an oral presentation "Three-Dimensional Geological Modeling as a Cost-Effective Tool for Horizontal Drilling" at the 1997 Western Regional Meeting in Long Beach, CA 23-27 June. His co-author was Scott Hara.

Mark Kapelke of Tidelands Oil Production gave two oral presentations entitled "How to Work With the DOE" and "Multimedia and Technical Transfer" in the National Petroleum Technology Resource Center booth sponsored by the DOE at the 1997 Western Regional Meeting in Long Beach, CA 23-27 June.

Scott Hara of Tidelands reprised the sand consolidation well completion presentation at the SPE Los Angeles Basin Section's New Technology and Environmental Forum meeting on November 19, 1997 at the Long Beach Petroleum Club.

\section{AAPG-organized Oral and Poster Presentations}

The AAPG Annual meeting was held in Dallas, TX on the 7-9th April 1997. Donald Clarke, Chris Phillips and Linji An gave a poster session presentation entitled "Horizontal Wells in a clastic oil field with Intraformational Compaction". Linji An, Iraj Ershaghi, Donald Clarke and Chris Phillips gave a poster session entitled "Sealing Behavior of Normal Faults in Fault Block II, Wilmington Field, CA."

An exhibition booth was set up and run by Dynamics Graphics and Chris Phillips on "EarthVision Software Solutions for Structurally Consistent 3-D Geologic Modeling and 3-D Well Placement Planning". An advertisement mailer was sent to 1997 AAPG Annual Meeting attendees which offered copies of a September 1996 article from The American Oil and Gas Reporter entitled "3-D Modeling, Horizontal Drilling...Give New Life to Aging Fields" by Clarke, Phillips, An. The Wilmington DOE projects were featured in the Dynamic Graphics' exhibit booth at the convention and in their Internet homepages (info@dgi.com and www.dgi.com/topko.html).

Don Clark of the City of Long Beach gave an oral and poster presentation on "Subsidence and Old Data Present Unique Challenges in Aging Turbidite Oil Fields. Examples of Successful Technologies Solutions from the Wilmington Oil Field, California, USA" at the 1998 3rd AAPG/EAGE Joint Research Conference on Developing and Managing Turbidite Reservoirs: Case Histories and Experiences in Almeria, Spain from October 4-9.

Don Clarke of the City of Long Beach gave two oral presentations entitled "Subsidence and Old Data Present Unique Challenges in Aging Turbidite Oil Fields. 
Examples of Successful Technological Solutions from the Wilmington Oil Field, California, USA" and "At 68, Wilmington Still Has Life: New Technology Revitalizes the Old Field" at the 1999 AAPG/SPWLA Hedberg Research Symposium in The Woodlands, TX from October 10-13.

Don Clarke will reprise his presentation entitled "At 68, Wilmington Still Has Life: New Technology Revitalizes the Old Field" at the 2000 Pacific Section AAPG/SPE Western Regional Meeting in Long Beach, CA from June 19-22.

\subsubsection{Industry Organizations}

\section{PTTC-Related Presentations}

A problem identification workshop was conducted on the 20th, 25th and 26th of November 1996 in Bakersfield, Long Beach and Ventura respectively. Dr. Iraj Ershaghi served as coordinator of the workshop and Mark Kapelke gave an oral presentation entitled "Multimedia and Technical Transfer", based on the CD Rom being prepared for this project.

The West Coast PTTC Office located at the University of Southern California in Los Angeles was officially inaugurated on the 6th of December 1996. The opening ceremony speaker was Dr. Iraj Ershaghi and in addition, the following brief presentations were made: "Tar Zone Reservoir Stimulation on Primary Production" by Zhengming Yang; "Tar Zone Reservoir Material Balance Studies" by Yucel Akkutlu and Dr. Lyman Handy; "Geologic 3-Dimensional Modeling" by Linji An; "Stochastic Reservoir modeling" by Changan Du and an update on the CD-ROM project by Mark Kapelke.

A PTTC workshop entitled "CA Geology: With or Without Computer Graphics" was conducted on the 15th of January 1997, with Dr. Iraj Ershaghi and Donald Clarke as coordinators. Dr. Iraj Ershaghi gave an oral presentation entitled "Geological Control on Reservoir Productivity". Don Clarke gave an oral presentation on "New Ways To Do Geology". Chris Phillips gave an oral presentation on "Case Histories - DOE Supported Projects, Thermal Flood, Tar Zone, Wilmington Oil Field. His co-authors were Don Clarke and Dr. Linji An.

A half day workshop entitled "3-D geologic Modeling: Theory and Application" was conducted at the PTTC West Coast office on 2 May 1997 by Jeff Schwalm and John Perry of Dynamic graphics. This workshop featured the EarthVision ${ }^{\mathrm{TM}}$ software that was heavily used for reservoir characterization work performed on our project. The presentation used the 3-D deterministic geologic model from this project to explain fundamentals of 3-D geologic modeling.

Dr. Changan Du of USC, through the West Coast PTTC, organized a short course entitled "GOCAD++ Training" held on November 14, 1997 at USC and made a presentation during the course. 
Dr. Iraj Ershaghi of USC and Don Clarke of the City of Long Beach, through the West Coast PTTC, organized a geologic short course and field trip on "Turbidite Reservoirs in California" on November 24, 1997 in Ventura, CA.

Scott Hara reprised his DOE presentation entitled "A Well Completion Technique for Controlling Unconsolidated Sand Formations by Using Steam" at two West Coast Petroleum Technology Transfer Council (PTTC) workshops on "Sand Control for California Oilfield Operations" given in Long Beach, CA on November 18, 1999 and in Bakersfield, CA on November 19, 1999.

Scott Hara made an oral presentation summarizing this DOE project's achievements related to reservoir and operational management and technical transfer of steamflood experience to the Wilmington Fault Block V Tar zone. The presentation was given at the West Coast PTTC Annual Forum held on the USC campus on December 10, 1999.

\section{DOE and US Federal Agency-organized Presentations}

Tidelands and USC project team members gave a presentation of the two Wilmington Class III projects to Guido DeHoratiis and Gary Walker of the DOE on December 4, 1997 in Tidelands' office.

Scott Hara gave an oral presentation entitled "Steamflooding Recovery of a Class 3 Reservoir - DOE's Cooperative Efforts with Independent Producers to Enhance Production While Maintaining Safe and Environmentally Compatible Operations" at the Technology Assessment \& Research Program's Technology Seminar held on May 19, 1999 at the office of the U. S. Minerals Management Service in Camarillo, CA.

Scott Hara will reprise his DOE presentation entitled "A Well Completion Technique for Controlling Unconsolidated Sand Formations by Using Steam" at the 2000 IPAA (Independent Petroleum Association of America) Mid-year Meeting in San Francisco, CA from May 18-20.

\section{Other Presentations}

Tidelands hosted an all day technology transfer meeting with Dave Rushford and Jean-Pierre Fossey of PanCanadian Petroleum Limited of Canada on May 14, 1998. The meeting agenda included all aspects of thermal recovery covered by the DOE project and PanCanadian presented several case histories of their thermal recovery operations and drilling techniques employed in Canada.

\subsubsection{Non-oil Industry Organizations}

The City of Long Beach and Tidelands Oil Production Company sponsor several presentations about the Wilmington Field operations and oil and gas industry every 
month for schools, foreign dignitaries, government agencies and the general public. These presentations are given at no expense to interested groups.

\subsection{Technology Awards}

Hart's Oil and Gas World Magazine honored Tidelands with the Best Field Improvement Project award in their Best of the Pacific contest in April 1999. This award was for the design and implementation of a lower-cost $\mathrm{H}_{2} \mathrm{~S}$ scrubber as part of the DOE thermal project. Our project partners were T. J. Cross Engineers and the Sulfa Treat Company. Rick Cassinis accepted the Hart's Oil and Gas World Magazine's "Best Field Improvement Project" award in their 1999 Best of the Pacific contest for Tidelands at the 1999 Pacific Coast Oil Show on November 9 in Bakersfield.

The U. S. Secretary of Energy Bill Richardson officially recognized Tidelands with a letter of commendation dated July 2, 1999 for their technical achievements that led to their receiving Hart's Oil and Gas World Magazine's "Best Field Improvement Project" award in their 1999 Best of the Pacific contest.

\subsection{Web Site and CD-ROM Projects}

A home page on the USC service provider has been set up in conjunction with the existing account for the Petroleum Engineering Program at USC. The ongoing DOE projects on the West Coast are comprehensively summarized and can be accessed at:

http://www.usc.edu/dept/peteng/topko.html

The web site is also linked to a significant number of petroleum related sites both in industry and in academia, which includes the national PTTC site.

A CD-ROM of the project has been completed and was presented at the DOE and PTTC exhibit booths at the 1997 SPE Western Regional Meeting. The CD-ROM is available on IBM PC format and is distributed free to interested operators and organizations by contacting Scott Hara by phone at 562-436-9918 or through email at scott.hara@tidelandsoil.com. The CD-ROM project is essentially a collection of interviews and presentations saved as brief movie clips detailing the scope of operations at Tidelands Oil production related to the Class III DOE project.

A new CD-Rom will be created this year that will include the library of papers, articles and publications developed through this project.

\subsection{Field Tours}

The City of Long Beach and Tidelands Oil Production Company sponsor several field tours of the Wilmington Field operations every month for industry groups, foreign dignitaries, government agencies and the general public. The field tours are given at no expense to interested groups. 


\section{ACTIVITY 8 - PROJECT MANAGEMENT}

\section{Executive Committee and Steering Committee}

The Executive and Steering Committees are active in supporting the operation of the Tar II-A and Tar V thermal projects and committing to the technology transfer aspects of this DOE project. In fact, as of the end of the reporting period, the Project Team partners have published more papers that are original and given more presentations to industry and non-industry groups than any other DOE Class Project. 


\section{REFERENCES}

References in "A", "B", and "E" below provide all of the papers and publications of original technical work completed throughout the project or in progress. References in "C" below are poster and oral presentations that were given throughout the current reporting period only. References in "D" below were cited in this report, but were not specifically part of this project.

A. Papers, Articles, Reports, CD-ROMs, Web Sites, and Other Original Technical Work Generated by DOE Project Team

A1 Sameer Joshi, L.M. Castanier and W.E. Brigham (Stanford University), Mike C. Wood (Union Pacific Resources Co.), "Steamflooding a Waterflooded Reservoir Performance Evaluation Prediction", SPE Paper 29669 presented at the 1995 Western Regional Meeting of the Society of Petroleum Engineers in Bakersfield, CA, 8-10 March 1995.

A2 Mike C. Wood, Bruce Laughlin, Doug Fuller and Robert Fickes (Tidelands Oil Production), "The Use of Downhole Submersible Pumps in a High Temperature Steamflood", SPE paper 29507, presented at the 1995 Society of Petroleum Engineers Production Operations Symposium in Tulsa, OK, April 1995.

David Crane, William R. Barry II (Digital Petrophysics Inc.), "Database preparation for Wilmington Field, Fault Block II-A - Tar Zone" dated 15 June 1995.

A4 Herman E. Schaller, "Study of Water Injection Surveys, Tar Zone, Fault Block II, Wilmington Field" dated 8 November 1995.

David Crane (Digital Petrophysics Inc.), report dated 12 March 1996 detailing list of well data that had undergone checking and processing.

David K. Davies, Richard K. Vessel (David K. Davies and Associates), "Nature, Origin, Treatment and Control of Well-Bore Scales in an Active Steamflood, Wilmington Field, California", SPE Paper No. 35418, 1996 Society of Petroleum Engineers/Department of Energy Tenth Symposium on Improved Oil Recovery in Tulsa, OK, 21-14 April.

Donald Clarke (City of Long Beach), Chris Phillips (Tidelands Oil production), "Old Oil Fields and New Life: A Visit to the Giants of the Los Angeles Basin", field trip and guidebook of 14 papers, given at the 1996 Annual Meeting of the American Association of Petroleum Geologists (AAPG) in San Diego, California, May 1996. The guidebook was revised for a tour given at the 1997 Western Regional Meeting of the Society of Petroleum Engineers and subsequently reprised each year for industry professionals and public school teachers. 
Donald D. Clarke (City of Long Beach), Chris C. Phillips (Tidelands Oil Production), and Linji An (University of Southern California), "3-D Modeling, Horizontal Drilling... Give New Life to Aging Fields", American Oil \& Gas Reporter, September 1996 issue, pages 106-115.

A9 Iraj Ershaghi, M. Hassibi (University of Southern California), "A Neural Network Approach for Correlation Studies in a Complex Turbidite Sequence", SPE Paper No. 36720, 1996 Society of Petroleum Engineers Annual Technical Conference and Exhibition in Denver, CO, 6-9th October.

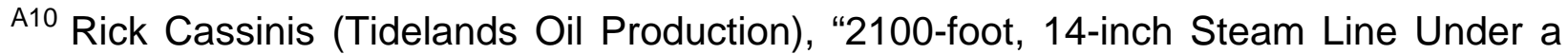
Ship Channel", SPE Paper No. 37530, 1997 SPE International Thermal Operations and Heavy Oil Symposium in Bakersfield, CA, 10-12 February 1997.

A11 Al-Qahtani, M., Ershaghi, I., University of Southern California: "Characterization and Estimation of Permeability Correlation Structure from Performance Data", Paper presented at Fourth International Reservoir Characterization Technical Conference sponsored by DOE, BDM, and AAPG, 2-4 March 1997.

A12 Iraj Ershaghi, Lyman L. Handy, Yucel I. Akkutlu (University of Southern California), Julius J. Mondragon III (Tidelands Oil Production), "Conceptual Model of Fault Block II-A, Wilmington Field, from Field Performance Data", SPE Paper No. 38309, 1997 Western Regional Meeting in Long Beach, CA, 23-27 June.

A13 Iraj Ershaghi, Pouya Amili (University of Southern California), "Correlations for Prediction of Steamflood Oil Recovery in Steam-Assisted Gravity Drainage (SAGD) Process Using Horizontal Injectors and Producers", SPE Paper No. 38297, 1997 Western Regional Meeting in Long Beach, CA, 23-27 June.

A14 Walt Whitaker II (Tidelands Oil Production), "7-ppm No. 50 MM BTU/hr Oilfield Steam Generator Operating on Low-Btu Produced Gas", SPE Paper No. 38277, 1997 Western Regional Meeting in Long Beach, CA, 23-27 June.

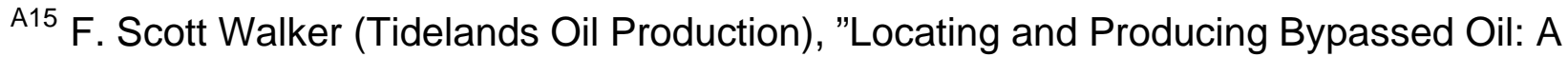
DOE Project Update", SPE Paper No. 38283, 1997 Western Regional Meeting in Long Beach, CA, 23-27 June. This DOE waterflood project for Wilmington describes new application of well completion technology using steam to consolidate sand developed in this project.

${ }^{\text {A16 }}$ Richard Cassinis (Tidelands Oil Production), William A. Farone (Applied Power Concepts, Inc.), "Improved $\mathrm{H}_{2} \mathrm{~S}$ Caustic Scrubber", SPE Paper No. 38273, 1997 Western Regional Meeting in Long Beach, CA, 23-27 June.

A17 David K. Davies, Richard K. Vessel (David K. Davies and Associates), "Improved Prediction of Permeability and Reservoir Quality through Integrated Analysis of Pore 
Geometry and Open-hole Logs: Tar Zone, Wilmington Field, California", SPE Paper No. 38262, 1997 Western Regional Meeting in Long Beach, CA, 23-27 June.

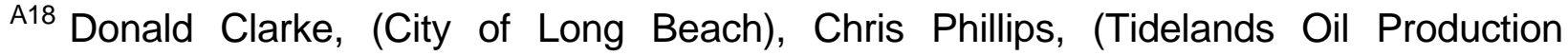
Company), "Horizontal Drilling for Thermal Recovery in the Wilmington Field, California", Article for Summer 1997 edition of U. S. DOE The Class Act.

${ }^{A 19}$ David K. Davies (David K. Davies and Associates), Julius J. Mondragon III, P. Scott Hara (Tidelands Oil Production), "A Novel Low-Cost Well Completion Technique Using Steam for Formations with Unconsolidated Sands, Wilmington Field, California", SPE Paper No. 38793, 1997 Society of Petroleum Engineers Annual Technical Conference and Exhibition in San Antonio, TX, 6-8 October.

A20 David K. Davies, John Aumon, Richard K. Vessel (David K. Davies and Associates), "Improved Prediction of Reservoir Behavior through Integration of Quantitative Geological and Petrophysical Data", SPE Paper No. 38914, 1997 Society of Petroleum Engineers Annual Technical Conference and Exhibition in San Antonio, TX, 6-8 October.

A21 Iraj Ershaghi, Chang-An Du, Linji An (University of Southern California), "A Three Stage Conditioning Process for Scrutinizing Stochastic Representation of a Turbidite Sequence in a Densely Drilled Formation", SPE Paper No. 38681, not done in 1997 as planned.

A22 Zhengming Yang, Linji An (University of Southern California): Developed COMPACT software program was incorporated as module into Computer Modeling Group's STARS 97.2 thermal simulator program. COMPACT is an algorithm that can mimic local and dynamic features of rock compaction and rebound as a function of reservoir pressure.

${ }^{\text {A23 }}$ Montgomery, Scott (Consultant Technical Writer), "Increasing Reserves in a Mature Giant: Wilmington Field, Los Angeles Basin, Part I: Reservoir Characterization to Identify By-passed Oil", AAPG Bulletin, March 1998, pages 367-385.

A24 Montgomery, Scott (Consultant Technical Writer), "Increasing Reserves in a Mature Giant: Wilmington Field, Los Angeles Basin, Part II: Improving Heavy Oil Production Through Advanced Reservoir Characterization and Innovative Thermal Technologies", AAPG Bulletin, April 1998, pages 531-544.

${ }^{\text {A25 }}$ Yang, Zhengming and Ershaghi, Iraj, (University of Southern California), Mondragon, Julius III and Hara, Scott, (Tidelands Oil Production Co.), "Method for Handling the Complexities Associated with History Matching the Performance of a Highly StressSensitive Formation", SPE Paper \#49314, 1998 SPE Annual Technical Conference, New Orleans, LA, Sept. 27-30. 
${ }^{\text {A26 }}$ Phillips, Christopher C., Tidelands Oil Production Co, Clarke, Donald D., City of Long Beach, "3-D Modelling / Visualization Guides Horizontal Well Program in Wilmington Field", CIM Journal of Canadian Petroleum Technology, October 1998, pages 7-15.

A27 Yang, Zhengming and Ershaghi, Iraj, (USC), Mondragon, Julius J. III, (Tidelands), "A Simulation Study of Steamflooding in a Highly Stress-Sensitive Heavy Oil Formation", 1998 UNITAR International Conference on Heavy Crude and Tar Sands, Beijing, China, Oct. 27-31.

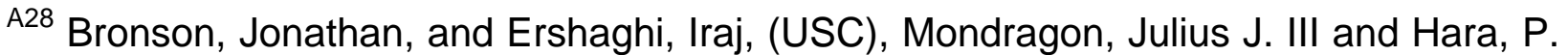
Scott, (Tidelands), "Reservoir Characterization in a Steamflood Using Produced Water Chemistry Data", SPE Paper \#54118, 1999 SPE International Thermal Operations and Heavy Oil Symposium, Bakersfield, CA, March 17-19.

A29 Hassibi, Mahnaz, (USC), "A Method For Automating Delineation of Reservoir Compartments and Lateral Connectivity From Subsurface Geophysical Logs", Doctoral Thesis, USC Department of Chemical Engineering - Petroleum Engineering Program, May 1999.

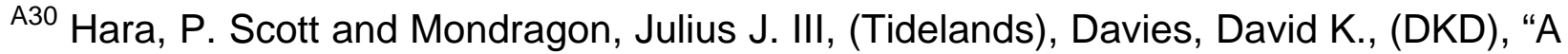
Well Completion Technique for Controlling Unconsolidated Sand Formations by Using Steam", 1999 DOE Oil and Gas Conference, Dallas, TX, June 28-30.

A31 Davies, David K., (DKD), Davies, John P., (Chevron), "Stress-Dependent Permeability: Characterization and Modeling", SPE Paper \#56813, 1999 SPE Annual Technical Conference and Exhibition (ATCE), Houston, TX, October 3-6.

A32 Davies, David K., (DKD), Hara, P. Scott and Mondragon, Julius J. III, (Tidelands), "Geometry, Internal Heterogeneity and Permeability Distribution in Turbidite Reservoirs, Pliocene California”, SPE Paper \#56819, 1999 SPE Annual Technical Conference and Exhibition (ATCE), Houston, TX, October 3-6.

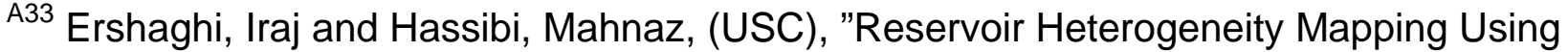
an Artificial Intelligence Approach", SPE Paper \#56818, 1999 SPE Annual Technical Conference and Exhibition (ATCE), Houston, TX, October 3-6.

${ }^{\text {A34 }}$ Mondragon, Julius J. III, Yang, Zhengming, Ershaghi, Iraj, U. of Southern California, Hara, P. Scott, Tidelands Oil Production Co., Bailey, Scott, Koerner, Roy, City of Long Beach, "Post Steamflood Reservoir Management Using a Full-Scale ThreeDimensional Deterministic Thermal Reservoir Simulation Model, Wilmington Field, California", SPE Paper \#62571, to be given at 2000 AAPG/SPE Western Regional Meeting, Long Beach, CA, June 19-22;

A35 Changan Du, Iraj Ershaghi, (USC), "Reservoir Characterization and Stochastic Modeling of Fault Block II-A Turbidite Sand Formation of Wilmington Oil Field, Long Beach, California", technical report, USC Department of Chemical Engineering - 
Petroleum Engineering Program, December 1998. Revised by Julius Mondragon III, (City of Long Beach), May 2001.

\section{B. Publications Related to Original DOE Project Technical Work and Articles of Interest}

B1 Steve Bell, "Extraction Technologies May Increase Recoverable Reserves by Billions", Hart's Petroleum Engineer, Tech Trends, page 9, March 1995.

Donald D. Clarke, Xen Colazas (City of Long Beach), Janet Wiscombe (Los Angeles Times), "Drilling in Disguise", Los Angeles Times, Metro Section, page B2, 15 November 1996.

Chris C. Phillips (Tidelands Oil Production), Pat Prince Rose (Los Angeles Times), "In Geological Time, He's Ancient", Los Angeles Times, Business Section, Trends, page D5, 9 December 1996.

Iraj Ershaghi (University of Southern California), Frank Clifford (Los Angeles Times), "A New Oil Boom", Los Angeles Times, Metro Section, Next L.A., page B2, 24 December 1996.

B5 Richard Cassinis, Sean Massey (Tidelands Oil Production), Stuart M. Heisler (TJ Cross Engineers Inc.), for the Sulfatreat Company "The Story Behind Lo CoST SM", Oil, Gas and Petrochem Equipment Magazine, back cover page, March 1997. Advertisement by the Sulfatreat Company on product developed through the DOE project work related to "Improved $\mathrm{H}_{2} \mathrm{~S}$ Caustic Scrubber" technology. Also refer to, http://www.ingersoll-rand.com/compair

Iraj Ershaghi (University of Southern California), Herb Tiderman (DOE), Gail Dutton (Compressed Air Magazine), "Coaxing Crude From The Ground", Compressed Air Magazine, pages 22-26, March 1997.

Jeff Schwalm (Dynamic Graphics Inc.), Chris C. Phillips (Tidelands Oil Production), "Earth Vision Software Solutions for Structurally Consistent 3-D Geologic Modeling, 3-D Well Placement Planning", Advertisement Mailer sent to the 1997 American Association of Petroleum Geologists (AAPG) Annual Meeting attendees, conducted 7-9 April 1997. Mailer contains copy of "3-D Modeling, Horizontal Drilling... Gives New Life to Aging Fields", Wilmington DOE projects featured in Dynamic Graphics' exhibit booth at convention and in Internet homepages: (info@dgi.com and http://www.dgi.com/topko.html)

University of Southern California, West Coast DOE projects comprehensively summarized and can be accessed at: http://www.usc.edu/dept/peteng/doe.html. Summarized content of the previous year's annual report is located at: http://www.usc.edu/dept/peteng/topko.html 
B9 University of Southern California, A collection of interviews and presentations saved as brief movie clips detailing the scope of operations at Tidelands Oil production related to the Class III DOE project on CD-ROM.

B10 Davies, David K., David K. Davies and Assoc. Inc., Mondragon, Julius J. III and Hara, P. Scott, Tidelands Oil Production Co., SPE Paper \#38793 "Well-Completion Technique Using Steam For Formations With Unconsolidated Sands", SPE Journal of Petroleum Technology, September 1998, pages 46-52, an abridged version of the paper.

B11 Clark, Donald D., City of Long Beach, Phillips, Christopher C., Tidelands Oil Production Company, "Successful Horizontal Well Program In Wilmington Field", DGInsider, the EarthVision Newsletter, First Quarter 1999.

${ }^{B 12}$ Davies, David K., Vessel, Richard K., Aumon, John P., DKD, Almproved Prediction of Reservoir Behavior Through Integration of Quantitative Geological and Petrophysical Data@, SPE Paper \#38914 peer-reviewed and assigned SPE Paper \#55881, SPE Reservoir Evaluation and Engineering Magazine, April 1999.

${ }^{B 13}$ Davies, David K., DKD, Davies, John P., Chevron wrote an article entitled "Stressdependent Permeability in Unconsolidated Sand Reservoirs", Offshore Magazine, February 2000, pp 82-84, a summary of SPE Paper 56813, "Stress-Dependent Permeability: Characterization and Modeling" in ref. A31 above.

C. Presentations, Poster Sessions, Tours, and Other Activities from which No New Reference Materials were Generated

C1 Donald D. Clarke (City of Long Beach), Chris C. Phillips (Tidelands Oil Production), Linji An (University of Southern California), "Horizontal Wells in a Clastic Oil Field with Intraformational Compaction", poster session presentation at the 1997 American Association of Petroleum Geologists (AAPG) Annual Meeting in Dallas, TX, 7-9 April.

C2 Iraj Ershaghi, Linji An (University of Southern California), Donald D. Clarke (City of Long Beach), Chris Phillips (Tidelands Oil Production), "Sealing Behavior of Normal Faults in Fault Block II, Wilmington Oil Field, California", poster session presentation at the 1997 American Association of Petroleum Geologists (AAPG) Annual Meeting in Dallas, TX, 7-9 April.

C3 Jeff Schwalm, John Perry (Dynamic Graphics Inc.), :"3-D Geologic Modeling: Theory and Application", a half day workshop sponsored by the PTTC at USC Campus, Los Angeles, CA on 2 May 1997. Presentation utilizes 3-D Deterministic Geologic Model from this project to explain fundamentals of 3-D Geologic Modeling.

C4 Donald D. Clarke (City of Long Beach), Chris C. Phillips (Tidelands Oil Production), Linji An (University of Southern California), "Tertiary Development of Heavy Oil 
Sands through Thermal Recovery in the Wilmington Oil Field, California: An Update and Some New Challenges", Oral presentation at the 1997 American Association of Petroleum Geologists (AAPG) Pacific Section Convention in Bakersfield, CA, on 1416 May.

C5 Donald D. Clarke (City of Long Beach), Chris C. Phillips (Tidelands Oil Production), Linji An (University of Southern California), "Reservoir Characterization Using Advanced 3-D Computer Modeling Technology: A Case Study of the Fault Block II in Wilmington Field, California", Electronic poster session at the 1997 American Association of Petroleum Geologists (AAPG) Pacific Section Convention in Bakersfield, CA, 14-16 May.

M. Hassibi, Iraj Ershaghi (University of Southern California), "Characterization of Lithological Log Responses in Turbidite Series using Neural Networks", oral presentation at the 1997 American Association of Petroleum Geologists (AAPG) Pacific Section Convention in Bakersfield, CA, 14-16 May 1997.

David K. Davies, Richard K. Vessel (David K. Davies and Associates), "Geological Controls on Permeability Distribution and Sand Distribution: Tar Zone, Fault Block IIA, Wilmington Field", oral presentation at the 1997 American Association of Petroleum Geologists (AAPG) Pacific Section Convention in Bakersfield, CA, 14-16 May.

Donald D. Clarke (City of Long Beach): Project status presentation for DOE/BDM conference regarding status of all DOE contracted projects, Houston, TX, 16-20 June 1997.

C9 Julius Mondragon III, Scott Hara (Tidelands Oil Production), "Novel Sand Consolidation Completion Technique Using Alkaline-Steam Injection in the Tar Zone, Wilmington Field", SPE GEM Presentation WR GEM 29, 1997 Western Regional Meeting in Long Beach, CA 23-27 June.

${ }^{\mathrm{C} 10}$ Chris Phillips, Scott Hara (Tidelands Oil Production), "Three-Dimensional Geological Modeling as a Cost-Effective Tool for Horizontal Drilling", SPE GEM Presentation WR GEM 6, 1997 Western Regional Meeting in Long Beach, CA 23-27 June.

${ }^{C 11}$ Mark Kapelke (Tidelands Oil Production), "How to Work With the DOE" and "Multimedia and Technical Transfer", National Petroleum Technology Resource Center sponsored by the DOE, 1997 Western Regional Meeting in Long Beach, CA 23-27 June.

${ }^{C 12}$ Du, C., University of Southern California, West Coast PTTC staff, organized short course entitled "GOCAD" Training" and made a presentation during the course, November 14, 1997 at USC campus. 
${ }^{\mathrm{C} 13}$ Hara, S., Tidelands Oil Production Company, reprised sand consolidation well completion presentation - SPE paper 38793, SPE Los Angeles Basin Section New Technology and Environmental Forum meeting, November 19, 1997, Long Beach Petroleum Club.

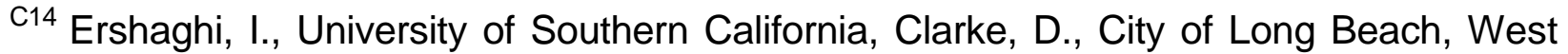
Coast PTTC staff: Organized geologic short course and field trip on "Turbidite Reservoirs in California", November 24, 1997, Ventura, CA.

${ }^{C 15}$ Tidelands Oil Production Company gave a short presentation of the two Wilmington Class III projects to Guido DeHoratiis of the DOE on December 4, 1997 in Tidelands' office.

${ }^{C 16}$ Clark, D., City of Long Beach, Phillips, C., Tidelands Oil Production Company, "Subsidence and Old Data Present Unique Challenges in Aging Turbidite Oil Fields. Examples of Successful Technologies Solutions from the Wilmington Oil Field, California, USA", 3rd AAPG / EAGE Joint Research Conference on Developing and Managing Turbidite Reservoirs: Case Histories and Experiences, Almeria, Spain, 4-9 October 1998.

C17 Scott Hara gave an oral presentation entitled "Steamflooding Recovery of a Class 3 Reservoir - DOE's Cooperative Efforts with Independent Producers to Enhance Production While Maintaining Safe and Environmentally Compatible Operations" at the Technology Assessment \& Research Program's Technology Seminar held on May 19, 1999 at the office of the U. S. Minerals Management Service in Camarillo, CA.

C18 Same as (C18), but given at 1999 EAGE Conference and Technical Exhibition, Helsinki, Finland, June 7-11.

C19 Same as (C18), but given at 1999 AAPG/SPWLA Hedberg Research Symposium, The Woodlands, TX, October 10-13.

C20 Clarke, Donald D., City of Long Beach, "At 68, Wilmington Still Has Life: New Technology Revitalizes the Old Field", 1999 AAPG/SPWLA Hedberg Research Symposium, The Woodlands, TX, October 10-13.

C21 Scott Hara reprised his presentation entitled "A Well Completion Technique for Controlling Unconsolidated Sand Formations by Using Steam" at two West Coast Petroleum Technology Transfer Council (PTTC) workshops on "Sand Control for California Oilfield Operations" given in Long Beach, CA on November 18, 1999 and in Bakersfield, CA on November 19, 1999.

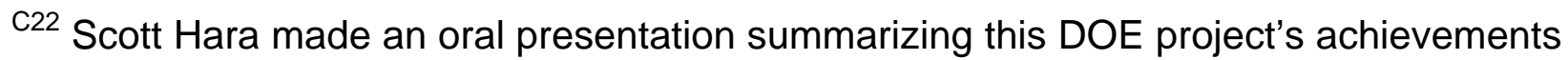
related to reservoir and operational management and technical transfer of steamflood experience to the Wilmington Fault Block V Tar zone. The presentation 
was given at the West Coast PTTC Annual Forum held on the USC campus on December 10, 1999.

${ }^{C 23}$ Scott Hara will reprise his DOE presentation entitled "A Well Completion Technique for Controlling Unconsolidated Sand Formations by Using Steam" at the 2000 IPAA Mid-year Meeting, San Francisco, CA, May 18-20.

C24 Don Clarke will reprise his presentation entitled "At 68, Wilmington Still Has Life: New Technology Revitalizes the Old Field" at the 2000 Pacific Section AAPG/SPE Western Regional Meeting, Long Beach, CA, June 19-22.

\section{Outside References Cited in Report}

D1 Small, G.P., Shell California Production Inc. "Steam-Injection Profile Control Using Limited-Entry Perforations", SPE Paper 13607, presented at the 1985 California Regional Meeting in Bakersfield, CA, March 27-29 1985.

R.M. Butler, "Gravity Drainage to Horizontal Wells", Journal of Canadian Petroleum Technology, Volume 31, No. 4, pages 31-37, April 1992.

D3 F.H. Lim, W.B. Saner and W.H. Stillwell (Union Pacific Resources Co.) and J.T. Patton (New Mexico State University), "Steamflood Pilot Test in Waterflooded, 2500 ft. Tar Zone Reservoir, Fault Block II Unit, Wilmington Field, California", presented at the 1993 Society of Petroleum Engineers Annual Technical Conference and Exhibition in Houston, TX, 3-6 October 1993.

D4 R.M. Butler, "Horizontal Wells for the Recovery of Oil, Gas and Bitumen; Monograph 2", Petroleum Society of CIM, Calgary 1994.

D5 M. Polikar, D.A. Redford, "Evolution of Steam-Based Technology for the Recovery of Canadian Heavy Oil Reservoirs", Journal of Petroleum Technology, Volume 34, No. 5, pages 33-40, May 1995.

D6 Ershaghi, I., Omoregie, O., University of Southern California, "A Method for Extrapolation of Cut Vs. Recovery Curves," Journal of Petroleum Technology, pages 203-04, February 1978.

D7 Ershaghi, I., Abdassah, D., University of Southern California, "A Prediction Technique for Immiscible Processes Using Field Performance Data," Journal of Petroleum Technology, pages 664-70, April 1984.

\section{E. Required Reports Generated for the Department of Energy}

E1 P. Scott Hara (Tidelands Oil Production), Quarterly Technical Progress Report Class III Mid-Term Project, "Increasing Heavy Oil Reserves in the Wilmington Oil 
Field Through Advanced Reservoir Characterization and Thermal Production Technologies", DE-FC22-95BC14939, (30 March 1995 - 30 June 1995).

P. Scott Hara (Tidelands Oil Production), Quarterly Technical Progress Report Class III Mid-Term Project, "Increasing Heavy Oil Reserves in the Wilmington Oil Field Through Advanced Reservoir Characterization and Thermal Production Technologies", DE-FC22-95BC14939, (1 July 1995 - 30 September 1995).

P. Scott Hara (Tidelands Oil Production), Quarterly Technical Progress Report Class III Mid-Term Project, "Increasing Heavy Oil Reserves in the Wilmington Oil Field Through Advanced Reservoir Characterization and Thermal Production Technologies", DE-FC22-95BC14939, (1 October 1995 - 31 December 1995).

P. Scott Hara (Tidelands Oil Production), Quarterly Technical Progress Report Class III Mid-Term Project, "Increasing Heavy Oil Reserves in the Wilmington Oil Field Through Advanced Reservoir Characterization and Thermal Production Technologies", DE-FC22-95BC14939, (1 January 1996 - 31 March 1996).

P. Scott Hara (Tidelands Oil Production), Quarterly Technical Progress Report Class III Mid-Term Project, "Increasing Heavy Oil Reserves in the Wilmington Oil Field Through Advanced Reservoir Characterization and Thermal Production Technologies", DE-FC22-95BC14939, (1 April 1996 - 30 June 1996).

P. Scott Hara (Tidelands Oil Production), Quarterly Technical Progress Report Class III Mid-Term Project, "Increasing Heavy Oil Reserves in the Wilmington Oil Field Through Advanced Reservoir Characterization and Thermal Production Technologies", DE-FC22-95BC14939, (1 July 1996 - 30 September 1996).

E7 P. Scott Hara (Tidelands Oil Production), Quarterly Technical Progress Report Class III Mid-Term Project, "Increasing Heavy Oil Reserves in the Wilmington Oil Field Through Advanced Reservoir Characterization and Thermal Production Technologies", DE-FC22-95BC14939, (1 October 1996 - 31 December 1996).

E8 P. Scott Hara (Tidelands Oil Production), Quarterly Technical Progress Report Class III Mid-Term Project, "Increasing Heavy Oil Reserves in the Wilmington Oil Field Through Advanced Reservoir Characterization and Thermal Production Technologies", DE-FC22-95BC14939, (1 January 1997 - 31 March 1997).

E9 P. Scott Hara (Tidelands Oil Production), Quarterly Technical Progress Report Class III Mid-Term Project, "Increasing Heavy Oil Reserves in the Wilmington Oil Field Through Advanced Reservoir Characterization and Thermal Production Technologies", DE-FC22-95BC14939, (1 April 1997 - 30 June 1997).

${ }^{E 10}$ P. Scott Hara (Tidelands Oil Production), Quarterly Technical Progress Report Class III Mid-Term Project, "Increasing Heavy Oil Reserves in the Wilmington Oil 
Field Through Advanced Reservoir Characterization and Thermal Production Technologies", DE-FC22-95BC14939, (1 July 1997 - 30 September 1997).

E11 P. Scott Hara (Tidelands Oil Production), Quarterly Technical Progress Report Class III Mid-Term Project, "Increasing Heavy Oil Reserves in the Wilmington Oil Field Through Advanced Reservoir Characterization and Thermal Production Technologies", DE-FC22-95BC14939, (1 October 1997 - 31 December 1997).

E12 P. Scott Hara (Tidelands Oil Production), Quarterly Technical Progress Report Class III Mid-Term Project, "Increasing Heavy Oil Reserves in the Wilmington Oil Field Through Advanced Reservoir Characterization and Thermal Production Technologies", DE-FC22-95BC14939, (1 January 1998 - 31 March 1998).

${ }^{E 13}$ P. Scott Hara (Tidelands Oil Production), Quarterly Technical Progress Report Class III Mid-Term Project, "Increasing Heavy Oil Reserves in the Wilmington Oil Field Through Advanced Reservoir Characterization and Thermal Production Technologies", DE-FC22-95BC14939, (1 April 1998 - 30 June 1998).

${ }^{E 14}$ P. Scott Hara (Tidelands Oil Production), Quarterly Technical Progress Report Class III Mid-Term Project, "Increasing Heavy Oil Reserves in the Wilmington Oil Field Through Advanced Reservoir Characterization and Thermal Production Technologies", DE-FC22-95BC14939, (1 July 1998 - 30 September 1998).

${ }^{E 15}$ P. Scott Hara (Tidelands Oil Production), Quarterly Technical Progress Report Class III Mid-Term Project, "Increasing Heavy Oil Reserves in the Wilmington Oil Field Through Advanced Reservoir Characterization and Thermal Production Technologies", DE-FC22-95BC14939, (1 October 1998 - 31 December 1998).

${ }^{E 16}$ P. Scott Hara (Tidelands Oil Production), Quarterly Technical Progress Report Class III Mid-Term Project, "Increasing Heavy Oil Reserves in the Wilmington Oil Field Through Advanced Reservoir Characterization and Thermal Production Technologies", DE-FC22-95BC14939, (1 January 1999 - 31 March 1999).

${ }^{E 17}$ P. Scott Hara (Tidelands Oil Production), Quarterly Technical Progress Report Class III Mid-Term Project, "Increasing Heavy Oil Reserves in the Wilmington Oil Field Through Advanced Reservoir Characterization and Thermal Production Technologies", DE-FC22-95BC14939, (1 April 1999 - 30 June 1999).

${ }^{E} 18$ P. Scott Hara (Tidelands Oil Production), Quarterly Technical Progress Report Class III Mid-Term Project, "Increasing Heavy Oil Reserves in the Wilmington Oil Field Through Advanced Reservoir Characterization and Thermal Production Technologies", DE-FC22-95BC14939, (1 July 1999 - 30 September 1999).

${ }^{E 19}$ P. Scott Hara (Tidelands Oil Production), Quarterly Technical Progress Report Class III Mid-Term Project, "Increasing Heavy Oil Reserves in the Wilmington Oil 
Field Through Advanced Reservoir Characterization and Thermal Production Technologies", DE-FC22-95BC14939, (1 October 1999 - 31 December 1999).

${ }^{E 20}$ P. Scott Hara (Tidelands Oil Production), Quarterly Technical Progress Report Class III Mid-Term Project, "Increasing Heavy Oil Reserves in the Wilmington Oil Field Through Advanced Reservoir Characterization and Thermal Production Technologies", DE-FC22-95BC14939, (1 January 2000 - 31 March 2000).

E21 Project Team, Annual Report entitled "Increasing Heavy Oil Reserves in the Wilmington Oil Field through Advanced Reservoir Characterization and Thermal Production Technologies", DE-FC22-95BC14939, (30 March 1995 - 31 March 1996).

E22 Project Team, Annual Report entitled "Increasing Heavy Oil Reserves in the Wilmington Oil Field through Advanced Reservoir Characterization and Thermal Production Technologies", DE-FC22-95BC14939, (1 April 1996 - 31 March 1997).

${ }^{\text {E23 }}$ Project Team, Annual Report entitled "Increasing Heavy Oil Reserves in the Wilmington Oil Field through Advanced Reservoir Characterization and Thermal Production Technologies", DE-FC22-95BC14939, (1 April 1997 - 31 March 2000).

\section{F. $\quad$ References for Section 2.2.2}

F1 Norton, T.F., Otott, G.E.: "The Stratigraphy of the Wilmington Oil Field, Thums Long Beach Company".

F2 Ershaghi, I. and Omoregie, O.: "A Method for Extrapolation of Cut vs. Recovery Plots," JPT (Feb. 1978) 203-04.

F3 Ershaghi, I., and Abdassah, D.: "A Prediction Technique for Immiscible Processes Using Field Performance Data," JPT (April 1984) 664-70.

F4 Ershaghi, I., Handy, L.L., and Hamdi, M.: "Application of the X-Plot Technique to the Study of Water Influx in the Sidi El_Itayem Reservoir, Tunisia," JPT (Sept. 1987) 1127-36.

\section{G. $\quad$ References for Section 2.3.2.1 and 2.4.1}

G1 .Walker, R.G., 'Deep-Water Sandstone Facies and Ancient Submarine Fans: Models for Exploration for Stratigraphic Traps", AAPG Bulletin (1978), V.62, 932 966.

G2 Zeito, G. A., "Interbedding of Shale Breaks and Reservoir Heterogeneities", JPT, Oct. 1965. $1223-1228$.

G3 Weber, K. J., "Influence of Common Sedimentary Structures on Fluid Flow in Reservoir Models", JPT, March 1982, 665 - 672. 
G4 Haldorsen, H. H and L. W. Lake, "A New Approach to Shale Management in FieldScale Models”, SPEJ, Aug. 1984, 447 - 457.

G5

Begg, S. H., D. M. Chang and H. H. Haldorsen, "A Simple Statistical Method for Calculating the Effective Vertical Permeability of a Reservoir Containing Discontinuous Shales", SPE 14271, 1985.

G6

Begg, S. H. and P. R. King, "Modeling the Effects of Shales on Reservoir Performance: Calculation of Effective Vertical Permeability", SPE 13529, 1985.

G7 Haldorsen, H. H., "On the Modeling of Vertical Permeability Barriers in Single-Well Simulation Models", SPEFE, Sept. 1989, 349 - 358.

G3

Deutsch, C., "Calculating Effective Absolute Permeability in Sandstone/Shale Sequences", SPEFE, Sept. 1989, 343 - 348.

G9 Richardson, J. G., D. G. Harris, R. H. Rossen and G. Van Hee, "The Effect of Small, Discontinuous Shales on Oil Recovery", JPT, Nov. 1978, 1531 - 1537.

${ }^{610} \mathrm{Hsu}, \mathrm{K}$, J., "Studies of Ventura Field, California, I: Facies Geometry and Genesis of Lower Pliocene Turbidite”, AAPG (1977), V.61, 137 - 146.

${ }^{11}$ Hsu, K.J., "Studies of Ventura Field, California, II: Lithology, Compaction, and Permeability of Sands," AAPG Bulletin (1977), V.61, 169 - 191.

G12 Ostermeier, R. M., "Deepwater Gulf of Mexico Turbidites: Compaction Effect on Porosity and Permeability," SPE26468, 1993.

G13 Ostermeier, R. M., "Stressed Oil Permeability of Deepwater Gulf of Mexico Turbidite Sands: Measurements and Theory", SPE 30606, 1995.

G14 Slatt, R. M., S. Phillips, J. M. Boak and M. B. Lagoe, "Scales of Geologic Heterogeneity of a Deep-Water Sand Giant Oil Field, Long Beach Unit, Wilmington Field, California", in E. G. Rhodes and T. F. Moslow (eds.), Frontiers in Sedimentary Geology: Marine Clastic Reservoirs: Example and Analogues, Springer-Verlag, 1993.

G15 Slatt, R.M. and G.L. Hopkins, "Scales of Geological Reservoir Description for Engineering Applications: North Sea Oil Field Example", Paper SPE 18136, Presented at the 1988 Soc. Pet. Eng. Ann. Meeting, Houston, Texas, Oct. 2-5, 1988.

${ }^{G 16}$ Damsleth, E., C. B. Tj Isen, H. More, and H. H. Haldorsen, "A Two-Stage Stochastic Model Applied to a North Sea Reservoir", JPT, April 1992, 402 - 486.

G17 Jordan, D. L. and D. J. Goggin, "An Application of Categorical Indicator Geostatistics for Facies Modeling in Sand-Rich Turbidite Systems”, SPE 30603, 1995. 
${ }^{G 18}$ Alabert, F. G., G. J. Massonat, "Heterogeneity in a Complex Turbiditic Reservoir: Stochastic Modeling of Facies and Petrophysical Variability", SPE 20604, 1990.

${ }^{G 19}$ Dehghani, K., W. M. Basham and L. J. Durlofsky, " Modeling and Scaleup of Steamflooding in a Heterogeneous Reservoir”, SPEFE, Nov. 1995, 237 - 245.

G20 Johann, P., F. Fournier, O. Souza Jr., R. Eschard, and H. Beucher, "3-D Stochastic Reservoir Modeling Constrained by Well and Seismic Data on a Turbidite Field", SPE 36501, 1996.

G21 Conrey, B.L., "'Sedimentary History of the Early Pliocene in the Los Angeles Basin, California", Unpublished Ph.D. Dissertation, University of Southern California, 1959.

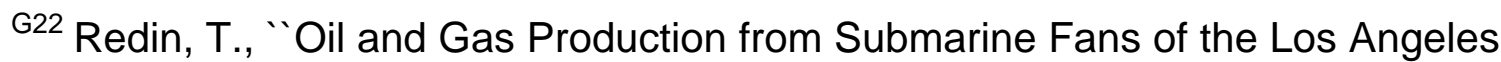
Basin", in Biddle, K. T. (ed.), Active Margin Basins, AAPG, Memoir 52 (1991), 239 259.

${ }^{\text {G23 }}$ Yerkes, R. F., T. H. McCulloch, J. E. Schoellhamer, and J. G. Vedder, "'Geology of the Los Angeles Basin, California - An Introduction", U.S. Geol. Survey Prof. Paper 420-A.

${ }^{2} 24$ Clarke, D. D. and C. P. Henderson (eds.), "'Geological Field Guide to The Long Beach Area", Pacific Section AAPG (1987), No. GB58.

G25 Smith, L., "Stratigraphic Equivalents of the Wilmington Field "Tar Zone" in the Subsurface Los Angeles Basin, California", Report, Petroleum Engineering Program, University of Southern California, 1996.

${ }^{\text {G26 }}$ Davies, D. K., Core photo description work for Tidelands Oil Production Company, 1995.

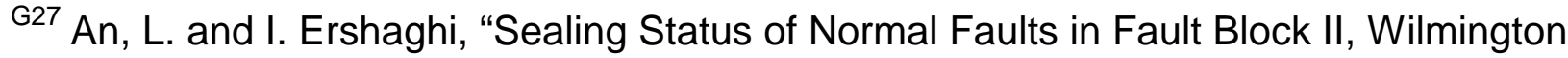
Oil Field, California", submitted to AAPG Bulletin, Oct. 1997.

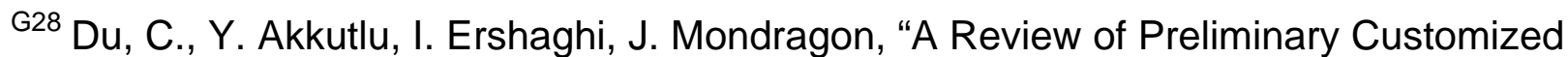
Core Analysis and Recommendations for Future Tests", Report to Petroleum Engineering Program USC and Tidelands Oil Production Company, July 1998.

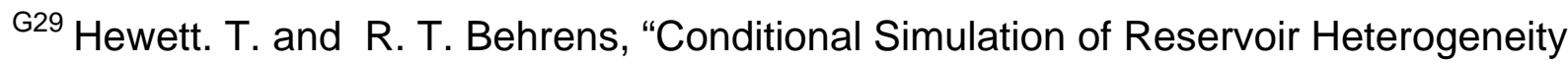
with Fractals", SPEFE, Sept. 1990, 217 - 225.

G30 Journel, A. G. and F. G. Alabert, "New Method for Reservoir Mapping", JPT, Feb. $1990,212-218$. 
G31 Haldorsen, H. H. and E. Damsleth, "Stochastic Modeling", JPT, April 1990, 404 412.

G32 Tran, T., Class Note for geostatistics, Petroleum Engineering, USC, Spring, 1997.

G33 Phillips, C. C. and L. An, supporting all faults and surfaces files for USC, 1997Cheng, A., GOCAD Manual, GOCAD Consortium, Nancy Geological School, August, 1997.

${ }^{\text {G34 }}$ Du and Nadim, Shale mapping of D1 interval, FBIIA, Petroleum Engineering Program, Dec. 1998.

${ }^{G} 35$ McGrill, C., P. King and J. Williams, "Estimating Effective Permeability: A Comparison of Techniques", Poster, Third International Reservoir Characterization Technical Conference, 1991, Tulsa, OK.

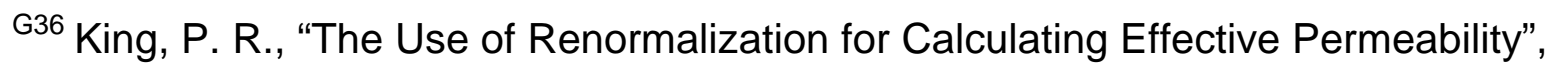
Transport in Porous Media, Feb. 1989, 37 - 58.

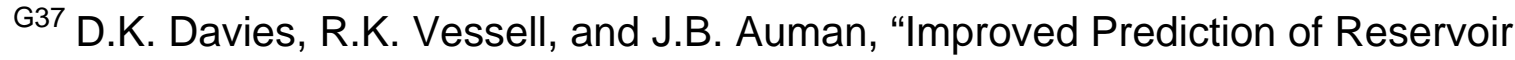
Behavior Through Integration of Quantitative Geological and Petrophysical Data" SPE Reservoir Evaluation \& Engineering. April 1999, P. 149-160.

${ }^{G} 38$ Davies, David K., (DKD), Hara, P. Scott and Mondragon, Julius J. III, (Tidelands), "Geometry, Internal Heterogeneity and Permeability Distribution in Turbidite Reservoirs, Pliocene California", SPE Paper \#56819, 1999 SPE Annual Technical Conference and Exhibition (ATCE), Houston, TX, October 3-6.

\section{H. $\quad$ References for Section 3.1}

H1 Espinoza, C.E., "A New Formulation for Numerical Simulation of Compaction, Sensitivity Studies", paper SPE 12246 (1983).

H2 Settari, A., and Mourits, F.M., "A Coupled Reservoir and Geomechanical Simulation System", paper SPE 29112 (1994).

H3 Geertsma, J.: "The Effect of Fluid Pressure Decline on Volumetric Changes of Porous Rocks", Trans. AIME, Vol. 210 (1957) 331-340.

H4 de Waal, J.A., and Smits, R.M.M., "Prediction of Reservoir Compaction and Surface Subsidence: Field Application of a New Model", paper SPE 14214 (1985).

H5 Geertsma, J., "Land Subsidence Above Compacting Oil and Gas Reservoirs", JPT (June 1973) 734-744. 
H6 Ostermeier, R.M.: "Deepwater Gulf of Mexico Turbidites: Compaction Effects on Porosity and Permeability", paper SPE 26468 (1993).

H7 Barenblatt, G.I., Entov, V.M., and Ryzhik, V.M., Theory of Fluid Flows through Natural Rocks, Kluwer Academic Publisher (1990).

H8 Palmer, I., and Mansoori, J., "How Permeability Depends on Stress and Pore Pressure in Coalbeds: A New Model", paper SPE 36737 (1996). 